\title{
THE IMPLEMENTATION OF TASK-BASED LANGUAGE TEACHING IN EFL PRIMARY SCHOOL CLASSROOMS: A CASE STUDY IN VIETNAM
}

By

BUI LE DIEM TRANG

\begin{abstract}
A thesis
submitted to Victoria University of Wellington

in fulfilment of the requirements for the degree of

Doctor of Philosophy in Applied Linguistics
\end{abstract}

Victoria University of Wellington, New Zealand 


\begin{abstract}
Research into the introduction of task-based language teaching (TBLT) in Asian primary school classrooms is rare, despite curriculum initiatives in many Asian countries promoting communicative and task-based teaching and learning. This study addresses this gap by investigating the implementation of TBLT in EFL classrooms in primary schools in Vietnam, a context hitherto under-research from a TBLT perspective. The research was conducted in two phases.

Phase 1 was a multiple case study which used classroom observations, stimulated recall and in-depth interviews to investigate how seven Vietnamese EFL primary school teachers implemented speaking lessons and how they viewed the lessons. The results showed that all teachers followed the presentation-practice-production (PPP) sequence specified in the textbooks, but that they independently incorporated communicative activities into the lessons. The teachers' view of the PPP lessons varied but they shared a concern about the mechanical nature of the PPP lessons.

Phase 2 investigated the implementation of two task-based lessons redesigned from PPP speaking lessons in a textbook by three teachers who participated in Phase 1 of the study. The data were collected from classroom observations, stimulated recall and in-depth interviews with the teachers, interviews with pupils, and recordings of task performances by nine pairs of learners. The results showed that all three teachers successfully carried out the two task-based lessons and reported a higher level of learner engagement and communication in their classes. Analysis of pupil interview data reveals evidence to support the teachers' views. All pupils expressed interest in the task-based lessons with stronger pupils affirming the scaffolding role of the pre-tasks and communicative value of the main tasks. Weaker pupils reported challenges of completing the main tasks due to lack of pre-teaching of the target structural patterns. Analysis of task interaction data showed that all dyads worked consistently towards completing the main tasks in the task-based lessons, although the achieved outcomes varied slightly. They were able to assist each other to co-construct their utterances, correct their own errors and help correct each other's errors, negotiate for meaning to overcome comprehension difficulties and use L1 to foster task completion. All of these strategies were found to facilitate task completion and provided a fruitful context for language development. In sum, the results point to the viability of TBLT in the Vietnamese EFL primary school context. They contribute to an understanding of the implementation of TBLT in authentic classrooms and the nature of task interaction among EFL primary school pupils.
\end{abstract}




\section{DEDICATION}

Dedicated to the memory of my mother, Le Thi Bay, who selflessly devoted her life to the personal and academic growth of her children

(1956-2010) 


\section{ACKNOWLEDGEMENTS}

First of all, I would like to express my deepest gratitude to my primary supervisor, Associate Professor Jonathan Newton, for his strategic guidance, constructive criticism, and patience throughout the $\mathrm{PhD}$ process. His confidence in me and my research kept me motivated. I would also like to thank my secondary supervisor Dr. Jean Parkinson for her enthusiasm, kindness and moral support throughout the project.

I am especially indebted to the New Zealand Scholarships for granting me a doctoral scholarship to pursue this study. Without this support this thesis would not have been possible. I am also grateful for the financial support provided by the Faculty of Humanities and Social Sciences which allowed me to carry out data collection in Vietnam and present this research abroad.

I am grateful to the Vietnamese teacher participants for their time and support. I would also like to thank the pupils for participating in my research and the parents for allowing them to participate. My sincere thanks also go to my colleagues and former students at An Giang University for their invaluable help during my data collection.

I am grateful to the staff at the School of Linguistics and Applied Language Studies (LALS) of Victoria University of Wellington (VUW) for creating a supportive and friendly academic environment. Special thanks go to Bernie Hambleton, Janet Attrill, and Matthew Vink for their administrative assistance.

I would like to thank VUW student advisors, particularly Dr. Deborah Laurs, and Language Learning Centre (LLC) staff member, Dr. Diego Navarro, for their useful advice on my writing. I am thankful to my officemates and all of my Vietnamese friends for their friendship and kindness.

Finally, I cannot express sufficient gratitude to my entire family, who are always standing beside me to provide their support. I deeply want to thank my father, my parents-inlaw, my sisters and brothers for encouraging and supporting me to pursue this PhD study. My heartfelt thanks go to my dear friends, Le Nguyen and Hue Tran, for their encouragement and wholehearted support, to my beloved husband, Khoa Nguyen, for taking care of my father during my absence and for always being there for me, and to our beloved son, Khoi Nguyen, for his company and care during my $\mathrm{PhD}$ journey. I cannot thank you enough, my dearest friends, husband and son! 


\section{TABLE OF CONTENTS}

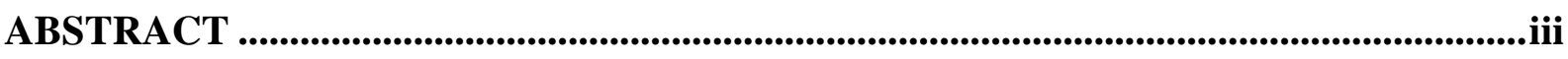

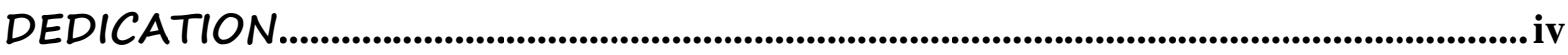

ACKNOWLEDGEMENTS ................................................................................................

TABLE OF CONTENTS .......................................................................................................... vii

LIST OF TABLES................................................................................................................

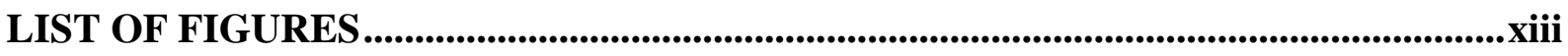

ABBREVIATION USED IN THE THESIS.........................................................................xiv

TRANSCRIPTION SYMBOLS USED IN THE THESIS ............................................

CHAPTER 1 INTRODUCTION

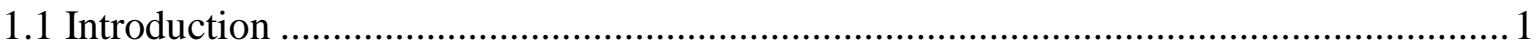

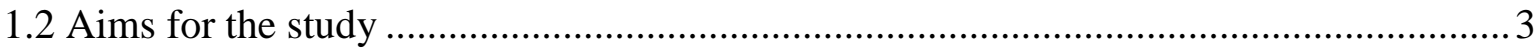

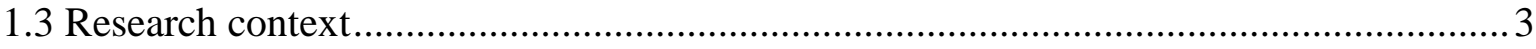

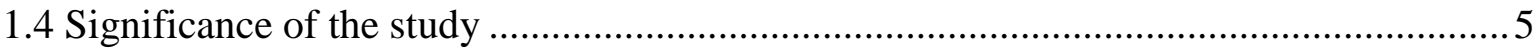

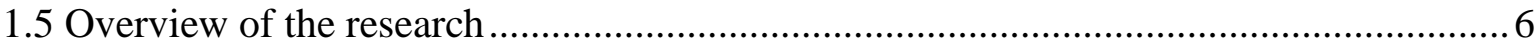

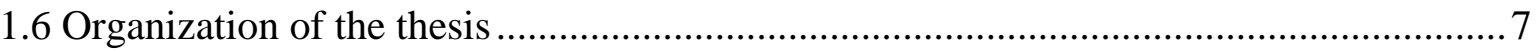

CHAPTER 2 LITERATURE REVIEW: TASKS, THEORETICAL BASIS FOR TASK-BASED LANGUAGE TEACHING, TASK-BASED METHODOLOGY AND CLASSROOM TASK IMPLEMENTATION ..................................................................................9

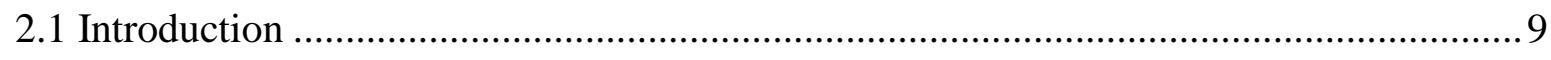

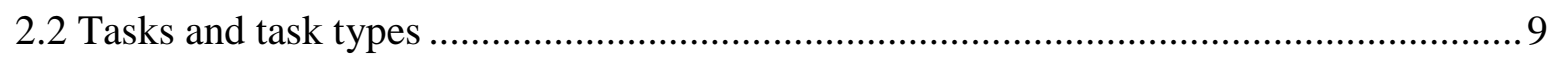

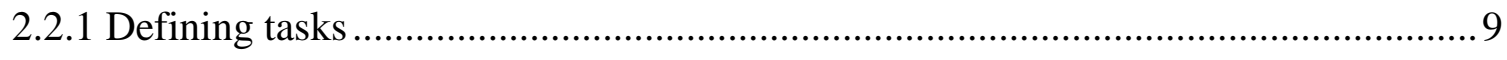

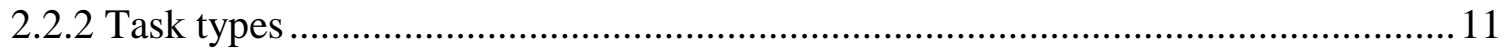

2.3 Theoretical perspectives on task-based learning ................................................... 13

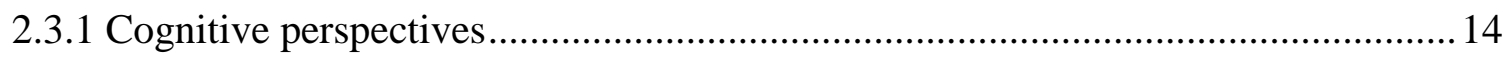

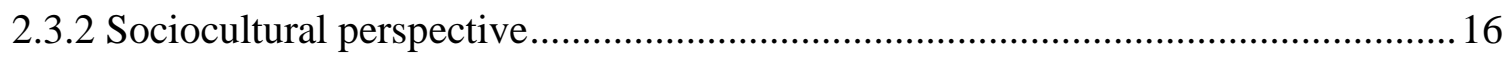

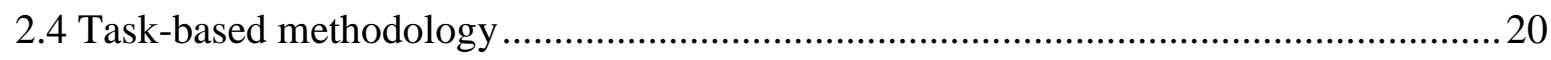

2.4.1 Frameworks for lesson design and focus on form in a task sequence ....................2 20

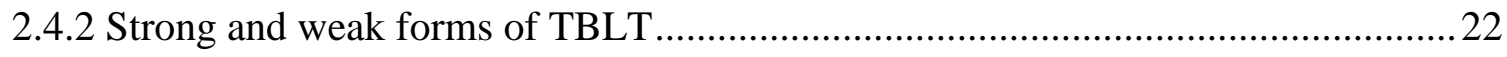

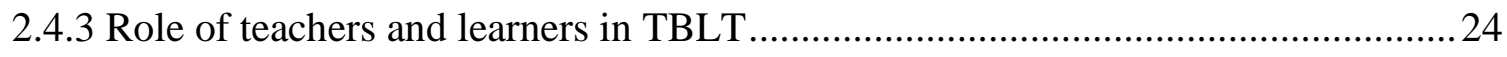

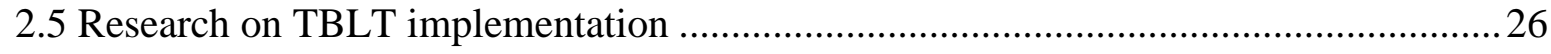

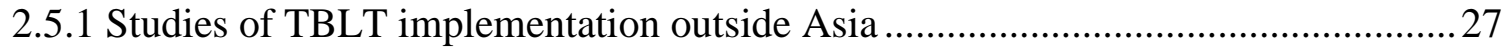

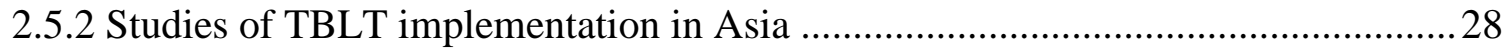

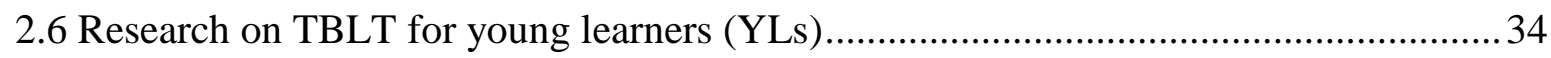




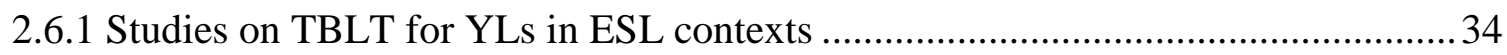

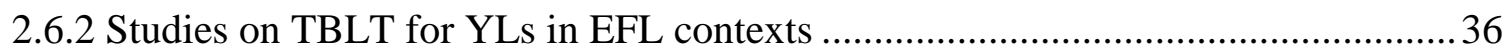

2.7 Implementation of task-based teaching in primary classrooms ..................................39

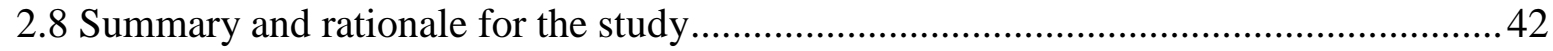

CHAPTER 3 METHODOLOGY ….............................................................................. 45

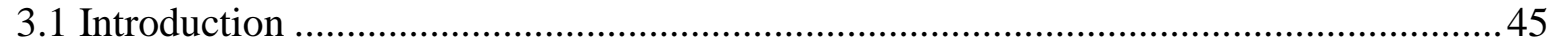

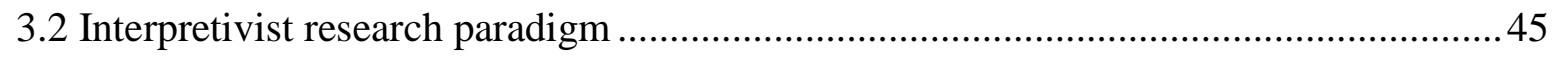

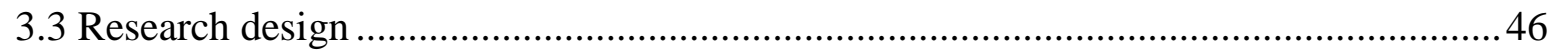

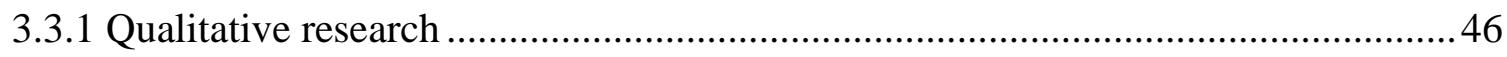

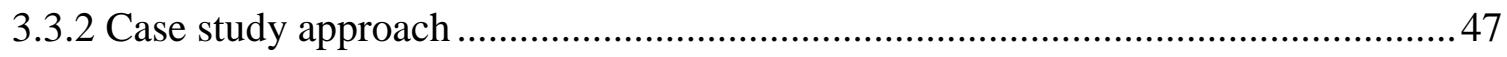

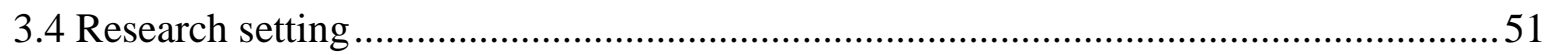

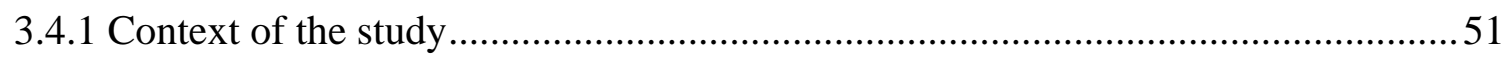

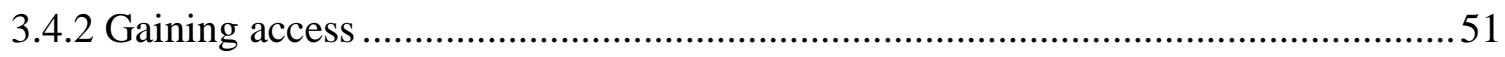

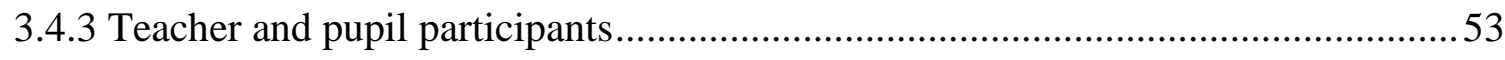

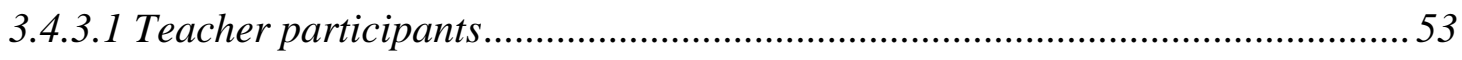

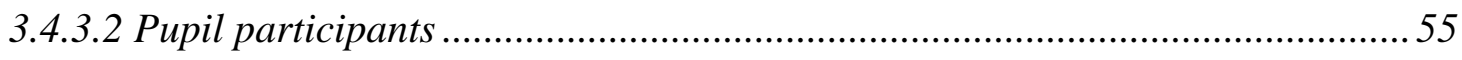

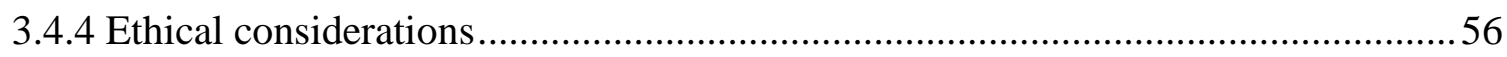

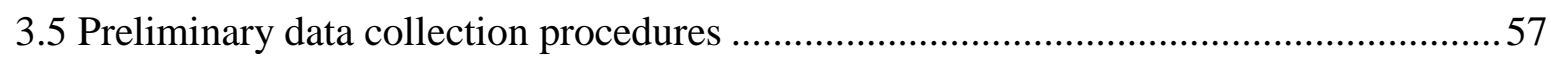

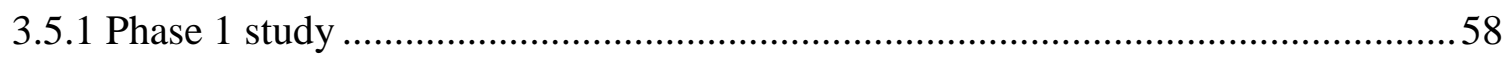

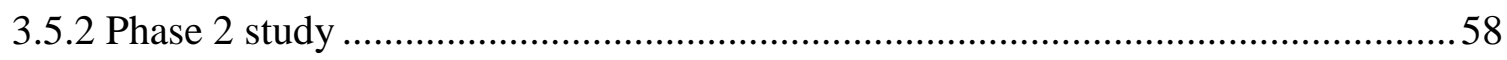

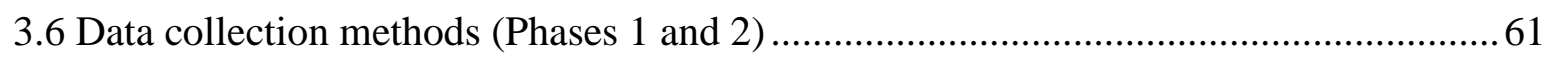

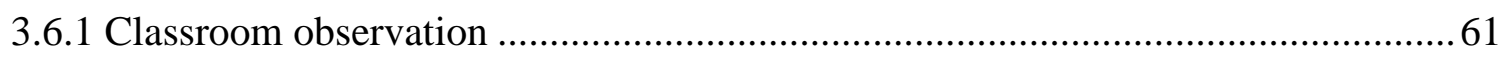

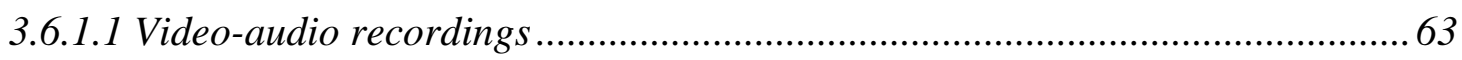

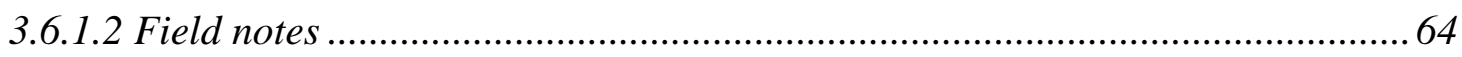

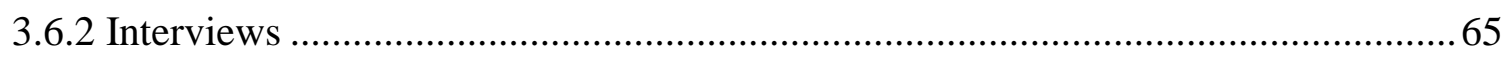

3.6.2.1 Stimulated recall and in-depth interviews with teachers................................. 65

3.6.2.2 Group interviews with pupils in Phase 2.....................................................6 67

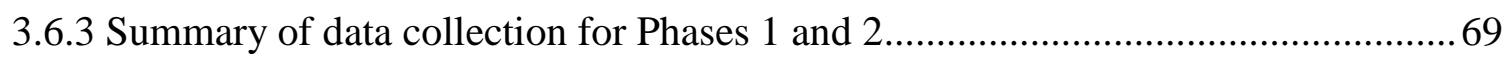

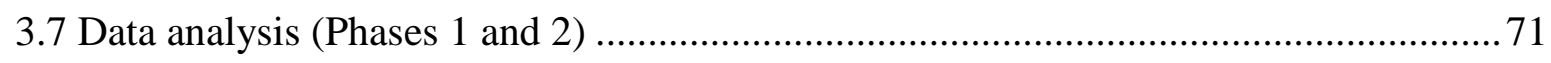

3.7.1 Teachers' implementation of the PPP speaking textbook lessons (Phase 1)...........71

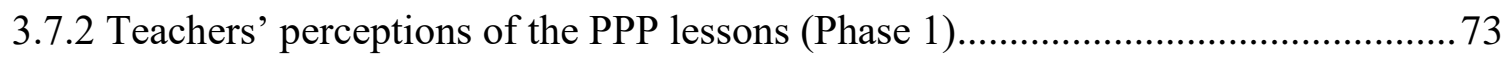

3.7.3 Teachers' implementation of the task-based lessons and their evaluation of the

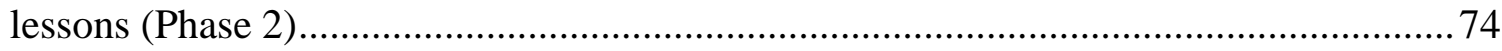

3.7.4 Pupils' perceptions of their experience with the task-based lessons (Phase 2) ....... 75

3.7.5 Pupils' task-based interaction data (Phase 2) ...................................................... 76 


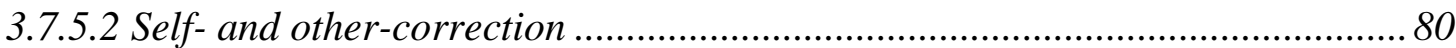

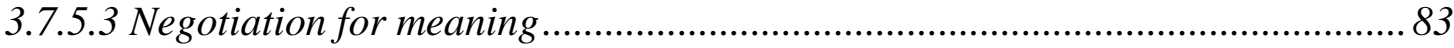

3.7.5.4 L1 use as a scaffold and functions of L1 use .................................................. 85

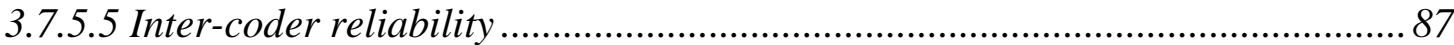

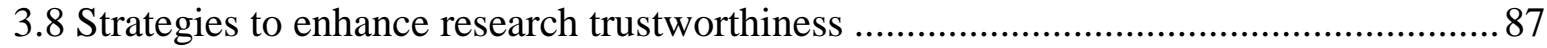

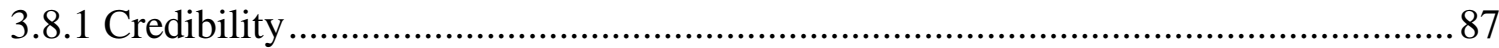

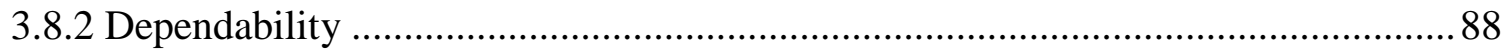

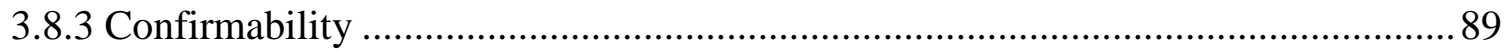

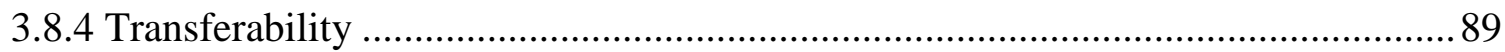

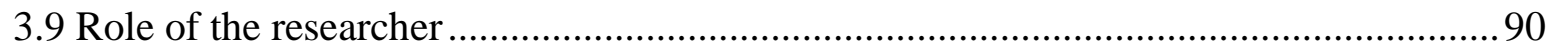

\section{CHAPTER 4 PHASE 1: THE IMPLEMENTATION OF TEXTBOOK SPEAKING} LESSONS .............................................................................................................93

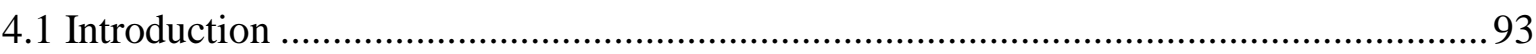

4.2 Overview of the textbook series and a specific textbook unit .......................................93

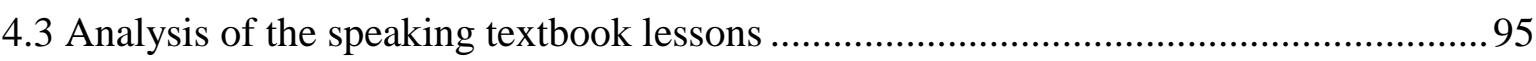

4.4 Teachers' implementation of the speaking textbook lessons ........................................ 100

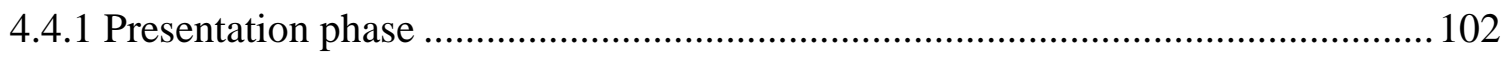

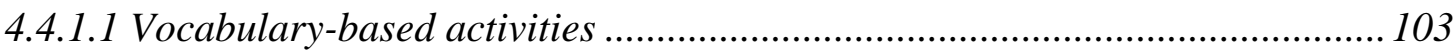

4.4.1.2 Teacher-led dialogue practice and explicit target structure explanations..... 106

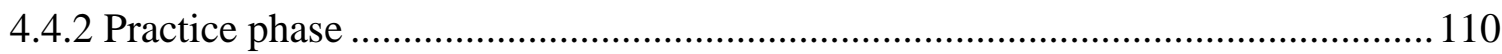

4.4.2.1 Teacher-led drill practice …........................................................................ 110

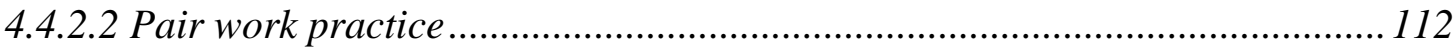

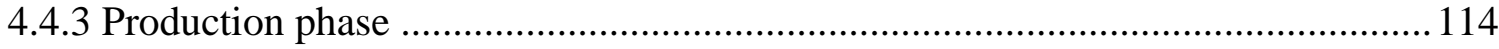

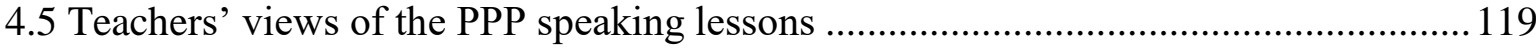

4.6 Discussion of teachers' implementation of the speaking lessons ................................ 124

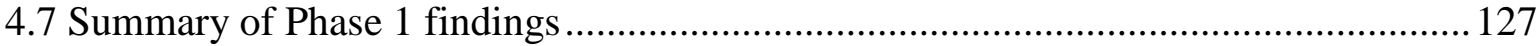

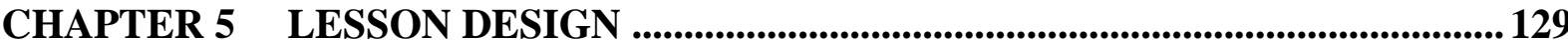

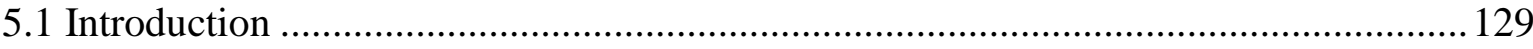

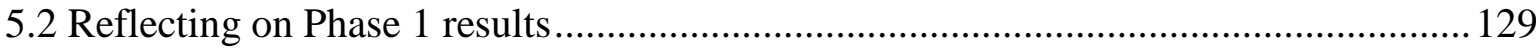

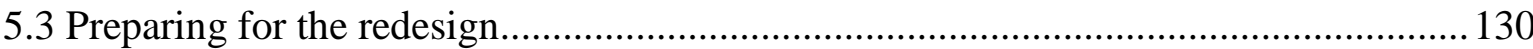

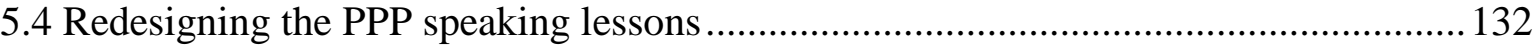

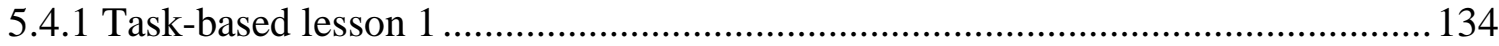

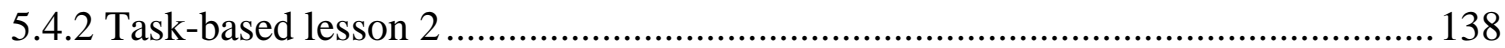

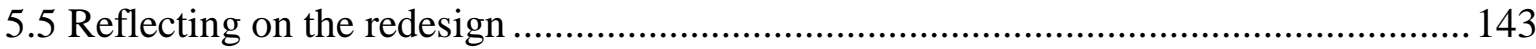




\section{CHAPTER 6 PHASE 2: THE IMPLEMENTATION OF TWO TASK-BASED}

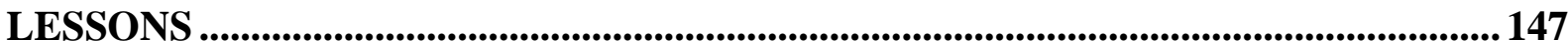

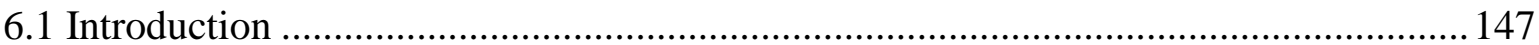

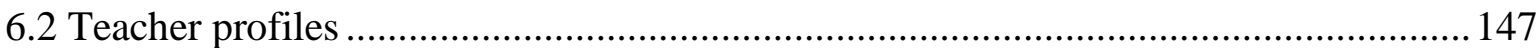

6.3 Teachers' implementation of the task-based lessons................................................ 150

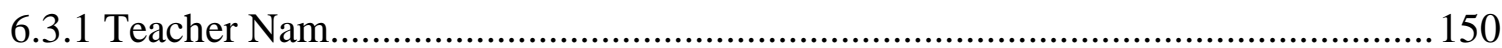

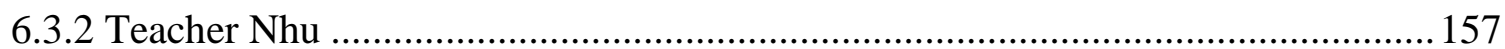

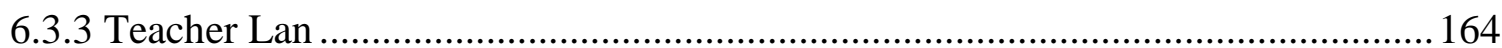

6.3.4 Discussion of the implementation of the task-based lessons............................... 170

6.3.4.1 Implementation of the task-based lessons ................................................... 170

6.3.4.2 Teachers' evaluation of their implementation of the task-based lessons ....... 172

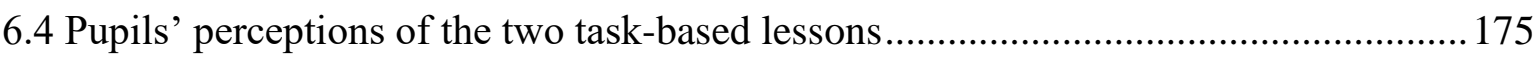

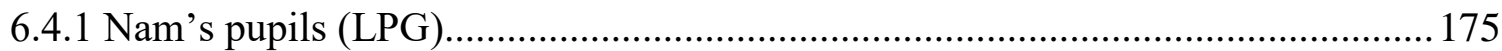

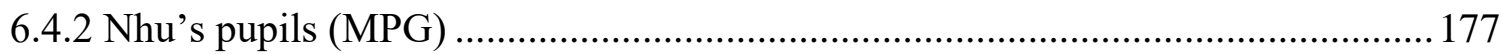

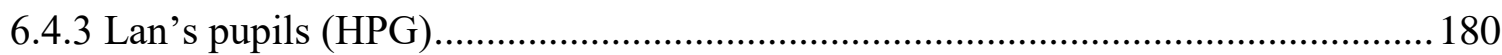

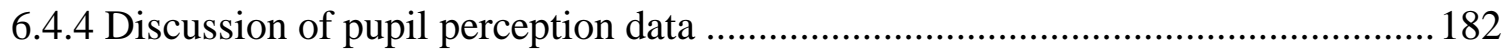

6.5 Pupils' performance of the main tasks in the task-based lessons ................................ 184

6.5.1 Amount and characteristics of pupils' main-task interaction .............................. 184

6.5.2 Verbal interactional strategies the pupils used to complete the main tasks .......... 185

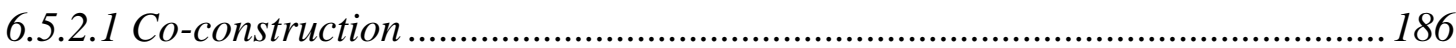

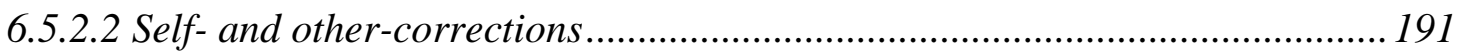

6.5.2.3 Negotiation for meaning (NfM) ............................................................... 198

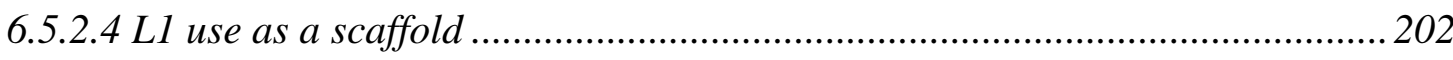

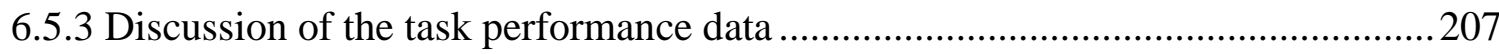

6.5.3.1 Characteristics of the task-interaction ............................................................207

6.5.3.2 Verbal interactional strategies in the task performances...............................208

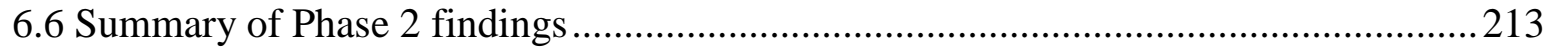

CHAPTER 7 CONCLUSION: SUMMARY OF FINDINGS AND IMPLICATIONS, LIMITATIONS, AND FUTURE RESEARCH DIRECTIONS ....................................... 215

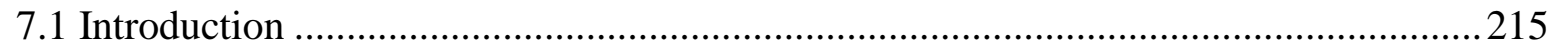

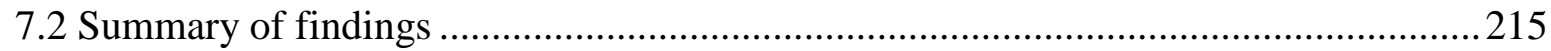

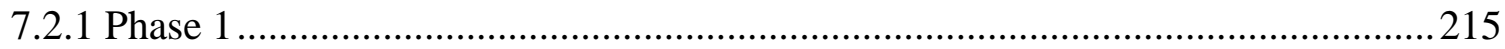

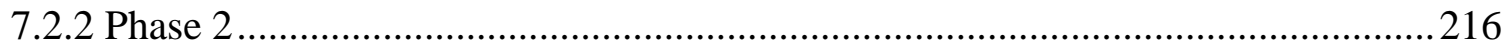

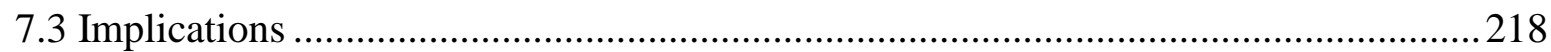

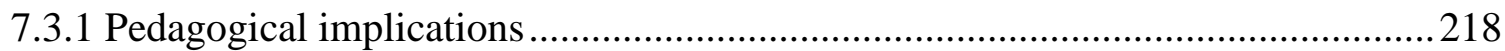

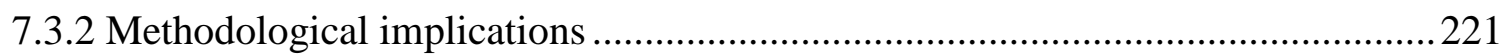


7.3.3 Theoretical implications

7.4 Limitations and future research directions 222

7.5 Concluding remarks. 224

REFERENCES .227

APPENDICES. .243 


\section{LIST OF TABLES}

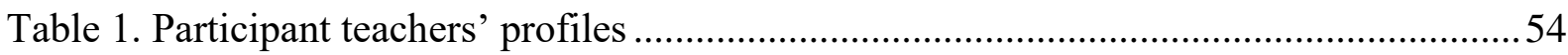

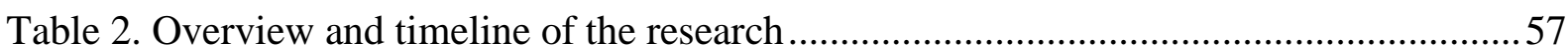

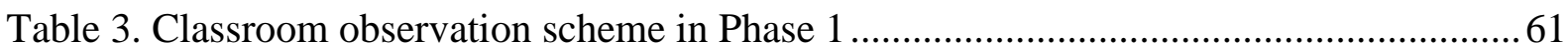

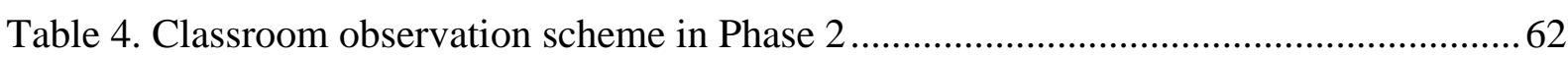

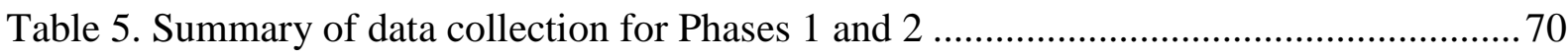

Table 6. An example of coding of classroom observation and stimulated recall interview data

Table 7. Coding of self-and other-correction strategies and their associated features .............81

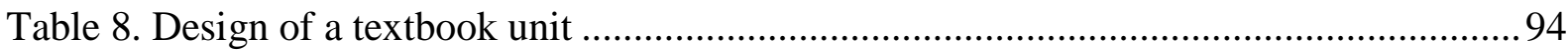

Table 9. The procedures of implementing the PPP speaking lessons .................................... 101

Table 10. The two task-based versions of the PPP speaking lessons ................................... 133

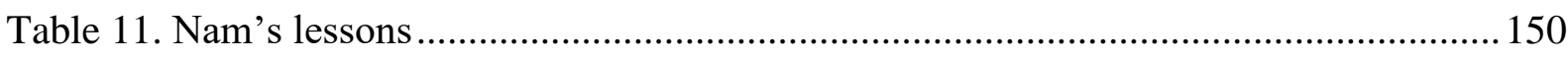

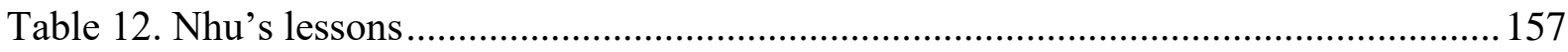

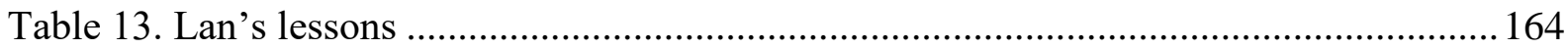

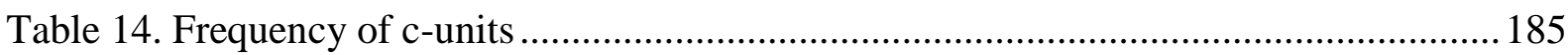

Table 15. Occurrence of co-construction provided by peers and teachers ............................ 187

Table 16. Occurrence of self- and other-corrections in response to non-target-like utterances

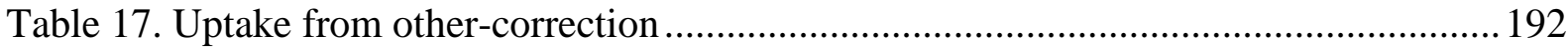

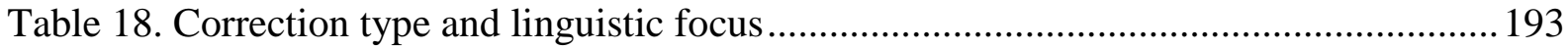

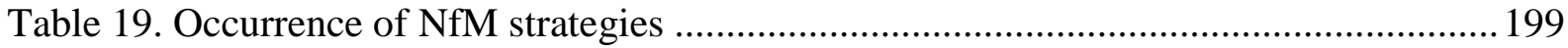

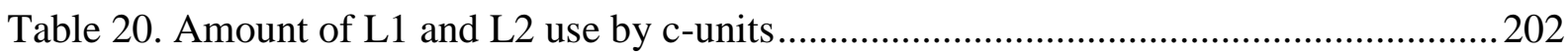

Table 21. Functions that the first language L1 served.....................................................204 


\section{LIST OF FIGURES}

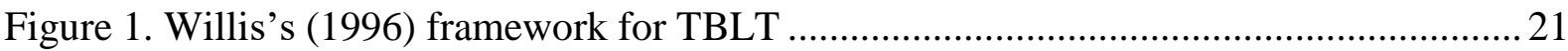

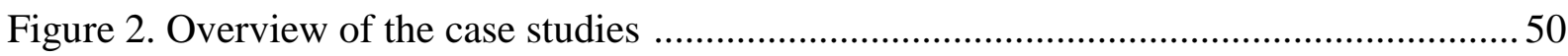

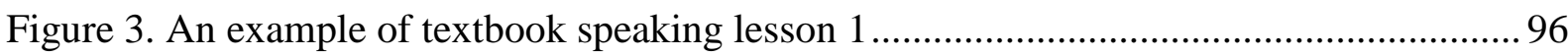

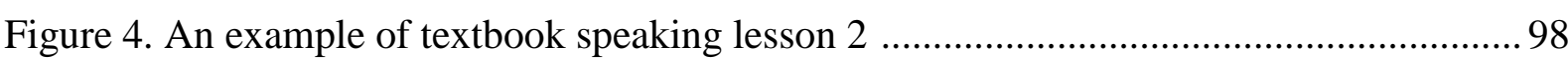

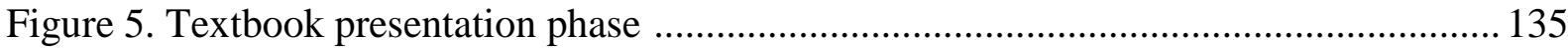

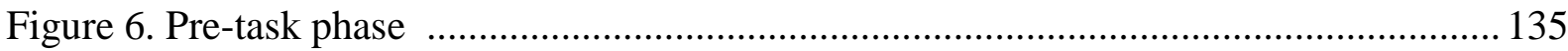

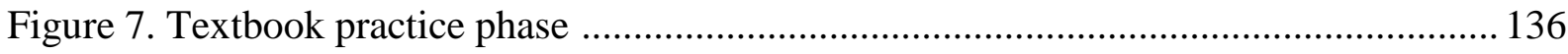

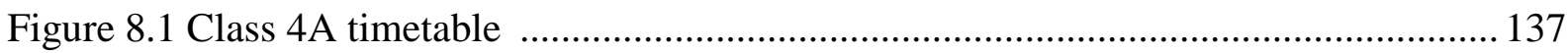

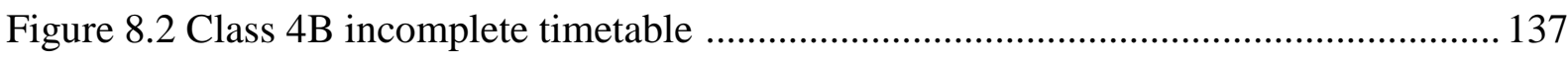

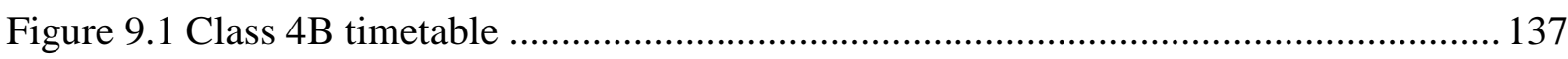

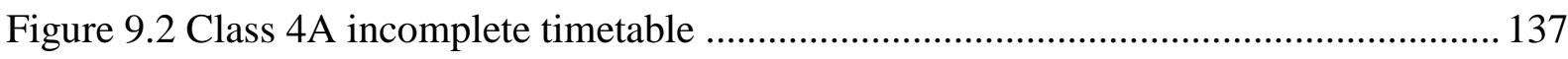

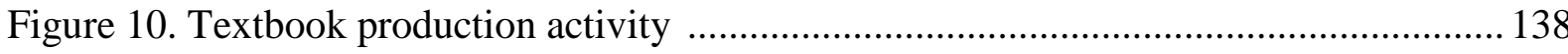

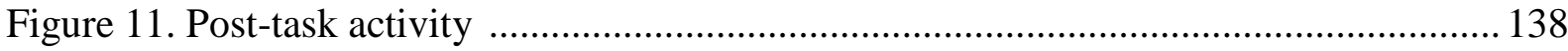

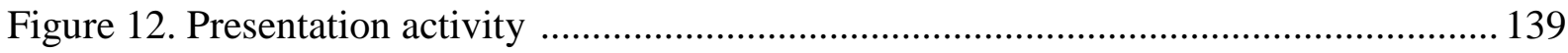

Figure 13. Input-based listening task for the pre-task phase .............................................. 139

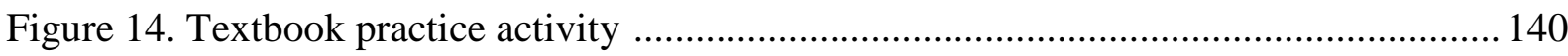

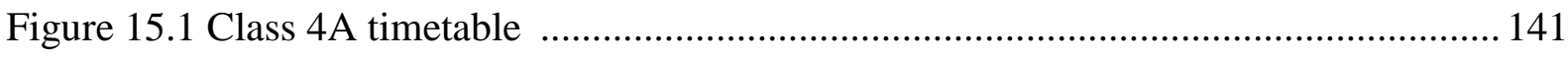

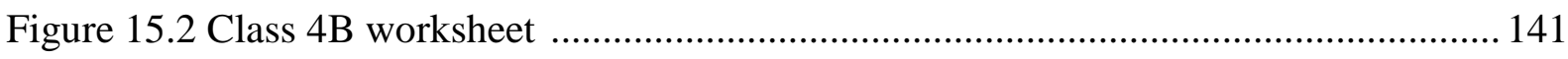

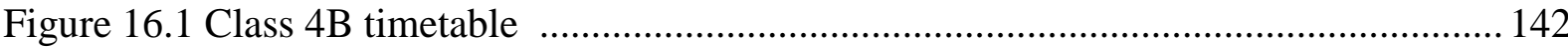

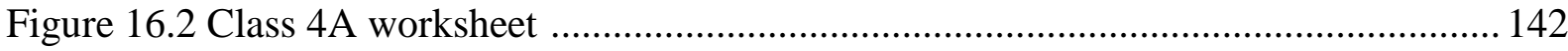

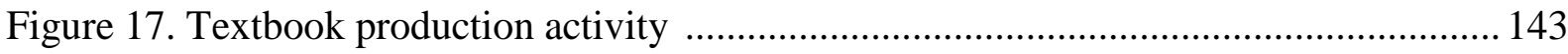

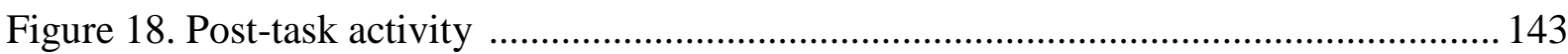

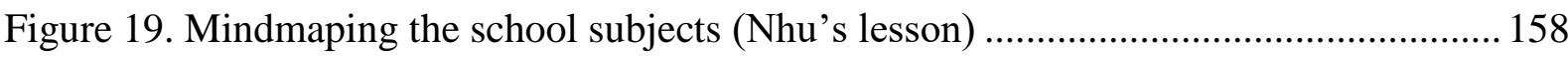

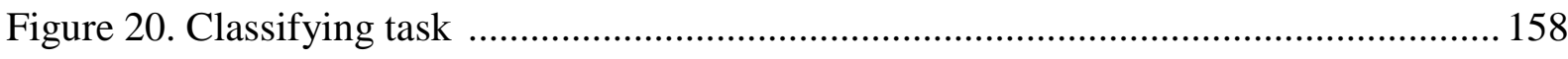

Figure 21. Mindmaping the school subjects (Lan's lesson) ............................................. 165

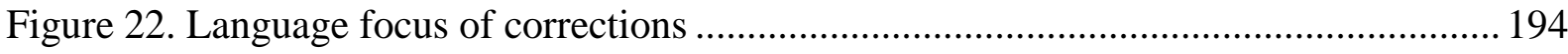




\section{ABBREVIATION USED IN THE THESIS}

$\begin{array}{ll}\text { CEFR } & \text { Common European Framework of References for Languages } \\ \text { CLIL } & \text { Content and Language-Integrated Learning } \\ \text { CLT } & \text { Communicative Language Teaching } \\ \text { EFL } & \text { English as a Foreign Language } \\ \text { ELT } & \text { English Language Teaching } \\ \text { ESL } & \text { English as a Second Language } \\ \text { L1 } & \text { First Language (Mother Tongue) } \\ \text { L2 } & \text { Target Language (second, third or foreign) } \\ \text { NNS } & \text { Non-Native speakers } \\ \text { LRE } & \text { Language-Related Episode } \\ \text { PPP } & \text { Presentation-Practice-Production } \\ \text { TBLT } & \text { Task-based Language Teaching } \\ \text { TSLT } & \text { Task-supported Language Teaching } \\ \text { ZPD } & \text { Zone of Proximal Development } \\ \text { NfM } & \text { Negotiation for Meaning } \\ \text { CF } & \text { Corrective Feedback } \\ \text { NF } & \text { Negative Feedback } \\ \text { SCT } & \text { Socio-Cultural Theory } \\ \text { YLs } & \text { Young learners }\end{array}$




\section{TRANSCRIPTION SYMBOLS USED IN THE THESIS}

\begin{tabular}{ll}
\hline Symbol & Meaning \\
\hline ( ) & English translation of Vietnamese L1 utterances \\
{$[$ ] } & Researcher's explanations/comments \\
$\ldots$ & Unfilled pause (one second or longer) \\
Uhm & Filled pause \\
{$[\ldots]$} & Deleted text \\
xxx & Unintelligible speech \\
a-b-c-d-e-f & The speaker is spelling out the word \\
$?$ & The speaking is asking a question or raising the intonation \\
$\cdot$ & Falling intonation \\
, & Continuing intonation \\
Upper case & Word emphasis \\
(e.g., SCIENCE) & \\
$!$ & Emotional emphasis at the end a phrase/sentence \\
/'s $\Lambda$ b.dzekt / & Phonetic transcription (International phonetic alphabet (IPA)) \\
T & Teacher \\
P1 & Pupil 1 \\
P2 & Pupil 2 \\
Ps & Many pupils \\
R & Researcher \\
\hline
\end{tabular}


This page is intentionally left blank 


\section{CHAPTER 1 INTRODUCTION}

\subsection{Introduction}

\section{Vignette: My experience of primary English education in Vietnam}

I work at a Vietnamese university in the Mekong delta province. One of the key goals of the university is to train teachers to work in local schools in the province and in some neighbouring provinces. Over the years in my job, I have taught a range of courses to both English and non-English major students. In early 2012, I had my first experience training primary school pre-service teachers. I was tasked with delivering a course in primary English education called "English teaching methodology". The course was divided into two phases. The first phase was theoretical where I introduced and evaluated methods and techniques in English language teaching. The second phase was practical where students worked on lesson planning and teaching practices to prepare for their teaching practicum in local schools. To better prepare my students and myself for their practicum, in the trimester before the second phase started, I travelled to local schools with my colleagues to observe their student teachers doing their practicum, which took place earlier than mine. These field trips were important to me as I was able to put together a better picture of the current teaching practices being used in different primary schools across my province.

But more than this, I enjoyed these field trips to the local primary schools. The English lessons I observed at the schools were very different from the ones when I first started my education in English. Classes were well equipped with all sorts of resources such as television sets, CD cassette players, computers and even interactive whiteboards. The classroom atmosphere was also very exciting with games, songs and chants, and with pupils engaging in English through different play activities. Being better informed about the existing practices, I was encouraged and excited to start the second phase of the course. In light of what I had observed, I devoted a lot of time to designing and practicing play activities similar to the ones I had observed in action.

By the end of the course in late 2012, my student teachers started their own practicum. I visited some of them to see how they were performing and how their supervisors ${ }^{1}$ were assessing their practice. I was so happy to observe my student teachers successfully carrying out the activities they designed. I was even happier to hear their supervisors praise them for

\footnotetext{
${ }^{1}$ Supervisors for student teachers are chosen among experienced teachers at local primary schools.
} 
their use of enjoyable and creative games, for their ability to use the games to motivate children, for their skilful classroom management, and most of all for the fact that the play activities my students designed and implemented engaged children in using the target structures from the textbooks. As a result, many of my students received excellent grades for their teaching performances.

The course ended with success and everyone seemed satisfied and pleased and for good reason: we had worked very hard and the evaluations of our work were positive. However, I began to feel a little uneasy about it all. I could not help wondering about the extent to which learning had actually occurred in these lessons. I kept thinking about the local supervisors' assessment of my teacher students' teaching. For example, although my teacher students' supervisors emphasized the need to provide a variety of play activities to keep children interested and to enhance classroom interaction, most of these activities we planned and I observed were the type of play activities where children practiced, in quite a controlled context, using pre-specified forms. I realised that the supervisors and, to a large extent, the teacher students, and even myself interpreted children's enjoyment of activities as proof that learning was taking place. Also, we all seemed to believe that communicative language learning takes place as soon as children do pair-work activities and that repetitive practice of target vocabulary and structures through these activities will lead to communicative competence.

My uneasy feelings were confirmed in subsequent school visits in later years, which urged me to further explore communicative language learning and ways of ensuring that learning is happening. My reading of the literature told me that the practices I had observed focus learners' attention on language forms while a better way to promote communicative competence is to focus learners' attention on meaning (i.e., using language to express their meaning rather than just reproducing the target language). I also learned that there are other ways to design play activities which may provide more effective communicative opportunities. Thus, motivated by an interest in primary English education, guided by an enthusiasm to ensure that the teaching and learning are both interesting and effective, and driven by a desire to be the best teacher trainer I can be, I decided to embark on my research journey which would help me bridge sound theory with innovative practice.

Below I outlined the research aims for this research. 


\subsection{Aims for the study}

The primary aim of the current study is to investigate the viability of adopting TBLT in EFL primary school classrooms in the Vietnamese context. Specifically, the study first aims to investigate the implementation of the existing textbook speaking lessons before examining the viability of implementing the task-based version of the lessons. The current study delves into an area of previously limited exploration: EFL primary school pupils' performance and perceptions of tasks. This study is especially timely as the Vietnamese government is committed to making communicative outcomes a key goal for primary English education. Broadly, it responds to a recent call for shifting the focus of TBLT research from investigating the constraints to TBLT implementation to examining "the range of teachinglearning procedures available, the outcomes and the relative efficiency of the approach" (Bygate, 2016, p. 397).

\subsection{Research context}

The introduction of English teaching at primary school levels has gained considerable attention in East Asian countries, particularly in Vietnam. In these countries, English has traditionally not been used as a main means of communication although it has been taught as a foreign language in formal schooling (at the secondary level and beyond) for years (Butler, 2015). To serve the country's economic development goals, many Asian governments have introduced English at the primary school level with the expectation that an early introduction of English will better develop learners' English ability (Butler, 2015). As English curricula have been introduced or updated, many Asian countries (e.g., Hong Kong and China) have adopted communicative and task-based language teaching as a leading means to promote language learning in schools (Butler, 2015; Lai, 2015). The adoption of TBLT was based on increasing theoretical and empirical evidence that TBLT improves communicative confidence and skills of language learners. It does this by providing opportunities for needsdriven attention to and noticing of language forms in the context of meaningful language use (Ellis, 2003;Willis \& Willis, 2007).

Vietnam, along with many other Asian countries such as China, has made a strong commitment to boosting the teaching and learning of English in primary schools to meet the high demand for proficient users of English in the context of globalization and economic integration. Driven by this commitment, over the last two decades, primary English education in Vietnam has gone through significant reforms. Starting in 1997, because of the high 
demand for English in big cities such as Ha Noi and Ho Chi Minh, English was first piloted as an elective subject in primary schools from Grade 3 (when children are aged eight or nine) with two 40-minute periods a week (Nguyen, 2011; Nguyen \& Nguyen, 2007). In 2003, due to a growing demand, English was officially approved as an optional subject from Grade 3 in primary schools nationwide where there were adequate teaching resources and interest from parents (Nguyen \& Nguyen, 2007). Following this approval, a formal syllabus was produced and, in the 2005-2006 school year, the first domestically produced textbook series Let's learn English 1,2,3 (Nguyen et al., 2010) was developed and taught in primary English classrooms for two 40-minute periods per week (Le \& Do, 2012).

In 2008, English was introduced as a compulsory subject in primary schools. At the same time, Vietnam's government issued Decision No. 1400/QD-TTg, approving a 20082020 national foreign languages project (NFLP) called "Teaching and learning foreign languages in the national formal education system from 2008 to 2020" (Vietnamese Prime Minister, 2008). The project aims to (1) to renovate the foreign language teaching and learning at all school levels; (2) enhance the Vietnamese young generation to communicate confidently and effectively in a foreign language (mainly English) so that they can study and work in multi-lingual and multi-cultural environments; (3) meet the needs of the country's industrialization and modernization (Vietnamese Prime Minister, 2008). In December 2017, the government approved amendments and supplements to the 2008-2020 NFLP. As part of these approved amendments, the project has been extended to a new period from 2017 to 2025 to facilitate the achievement of the established goals (DanTri, 2017).

In an effort to work toward these established goals, in August 2010, a pilot primary school English curriculum was issued. The curriculum stipulates that the English language is to be a compulsory subject for the first time in primary schools starting from Grade 3 , and is to be taught for four periods (35-40 minutes each) per week. The curriculum adopts a communicative language teaching approach and requires teachers to assess learning in terms of learners' abilities to communicate in English with a particular focus on the listening and speaking skills. This assessment initiative reflects the government's emphasis on promoting young learners' abilities to communicate in English across a range of contexts.

Accompanying the new curriculum is a new textbook series Tieng Anh 3-4-5 (Hoang et al., 2015c) for Grades 3, 4 and 5, produced in collaboration with Macmillan Publishers and introduced in 2013. In a recent evaluation of the new textbooks, Dang and Seals (2018) reported that "the textbook design succeeds quite well in adopting a communicative language teaching approach" (p.108). The new curriculum and accompanying textbooks are intended to 
be adopted at schools with adequate facilities and teacher resourcing. To teach the curriculum, teachers are required to attend English enhancement programs to achieve Level B2 or above of the Common European Framework of References for Languages (CEFR) (Council of Europe, 2001) in terms of their English proficiency (Vietnamese Prime Minister, 2008). They are also required to attend training workshops which target a range of areas such as principles of teaching English to young leaners, techniques of developing learners' communicative skills, language assessment, and integrating technology in language teaching. The 2008-2020 NFLP seeks, through this curriculum, to enhance the English proficiency of primary school pupils so that they can obtain a foundation Level A1 of the CEFR at the end of their primary English education.

Seven years after the introduction of the new primary English curriculum, research into its implementation remains scant, with only two studies to date looking specifically at the actual implementation of these curricular innovations (Le \& Do, 2012; Nguyen, 2011). These studies, however, were able to identify important issues with the implementation process. For example, they reported that teachers followed the PPP approach for the teaching of English in primary schools, which, 'to some extent, limits the students' interaction and communication as they have little chance to be exposed to more authentic situations" (Nguyen, 2011, p. 239). However, both studies investigated the implementation of the curriculum when teachers were still using the old textbooks series Let's learn English 1-2-3 (Nguyen et al., 2010). These books were reported to "focus more on grammar and vocabulary than on communication" (Le \& Do, 2012, p. 108) and they were not sufficiently "grounded in an understanding of children's learning and language learning” (Moon, 2005, p. 53). Given the recent language proficiency enhancement for teachers and their experiences with using the new textbooks, research into the implementation of the new textbooks and how the communicativeness of the textbook lessons can be enhanced is critical to the successful implementation of the new curriculum.

\subsection{Significance of the study}

The current research is of significance in several ways. First, given the current importance of primary English education in Vietnam to meet its recent national goals for English language proficiency, the findings from this research provide grounds for potential enhancement of primary English teaching and learning in Vietnam. Reporting on how 
teachers are implementing the new curriculum and accompanying textbooks carries implications for the on-going implementation of the new curriculum.

Second, this research adds to the steadily growing research on the implementation of TBLT in authentic English classrooms. It is hoped that this research will contribute to the professional knowledge of how TBLT can be implemented in Asian EFL primary school contexts as well as providing insights for policy-making and improving the quality of primary-school level English language teaching in general.

Third, this research considers the experience and perceptions of the key decision makers, the teachers, while they are implementing PPP speaking lessons and task-based versions of the lessons. It will, therefore, add to the literature on teacher and learner cognition in the under-researched context of primary schools in Vietnam. An understanding of the beliefs and contextual factors that shape the teachers' instructional decisions can inform the development of the pre-service and in-service teacher training, which can support more effective curriculum implementation.

Finally, this research contributes to an under-researched area, namely young learners' perspectives of tasks (Carless, 2012; Pinter, 2014, 2015). It provides a new understanding of what aspects of tasks they enjoy and why, how they collaborate to complete tasks and what they think they can learn from them.

\subsection{Overview of the research}

The current study investigates the implementation of TBLT in primary EFL classrooms. The study consists of two phases. Phase 1 is a multiple case study investigating the implementation of PPP textbook speaking lessons and teachers' perceptions of the PPP lessons. Motivated by Phase 1 results, Phase 2 explores how teachers implemented task-based versions of the PPP speaking lessons in their classrooms, how learners perceived their experiences of working with tasks, and ultimately what came out of task performance. The study aims to address the following research questions (RQs):

\section{Phase 1: Teacher implementation of the textbook speaking lessons}

RQ1. (a) How did the teachers implement the textbook speaking lessons?

(b) How did they explain their implementation decisions?

RQ2. How did the teachers view the textbook PPP speaking lessons? 


\section{Phase 2: Teacher implementation of the task-based versions of the textbook speaking lessons.}

RQ1. (a) How did the teachers implement the task-based lessons?

(b) How did they evaluate their implementation of the task-based lessons?

RQ2. How did the pupils perceive their experience of carrying out the two task-based lessons?

RQ3. (a) How did the pupils perform the main tasks in the task-based lessons?

(b) What verbal interactional strategies did they adopt to perform the tasks?

\subsection{Organization of the thesis}

The thesis consists of seven chapters. This first chapter has introduced the thesis. Chapter 2 deals with the relevant literature review. Chapter 3 presents the methodology for both phases of the study, followed by Chapter 4 which reports on the results of teachers' implementation of the PPP textbook speaking lessons and their perceptions of their implementation decisions in particular and of the PPP lessons, in general. Chapter 5 acts as a bridge detailing the rationale and the design of the task-based version of the PPP speaking lessons. Chapter 6 discusses the results of the implementation of the task-based lessons. It reports on teachers' implementation and perceptions of the lessons and pupils' perceptions of the task-based lessons as well as their actual performance of the main tasks in the lessons. Chapter 7 is the conclusion which summarises the main findings of the thesis, and discusses pedagogical, methodological and theoretical implications. It also discusses important limitations and proposes future research directions. The chapter ends with a concluding statement. 
This page is intentionally left blank 


\section{CHAPTER 2 LITERATURE REVIEW: TASKS, THEORETICAL BASIS FOR TASK-BASED LANGUAGE TEACHING, TASK-BASED METHODOLOGY AND CLASSROOM TASK IMPLEMENTATION}

\subsection{Introduction}

This study investigates the feasibility of implementing TBLT in primary schools in Vietnam. Therefore, the purpose of this chapter is to critically evaluate the case for adopting TBLT in this context. This chapter will start by reviewing different definitions of tasks in an effort to decide on a working definition of tasks for this specific study. This will be followed by a review of theoretical perspectives and research findings that have lent support to the use of tasks for language learning. The next section will discuss task-based methodology with respect to a framework for lesson design, approaches to teaching with tasks and the roles of teachers in implementing TBLT. Next, research on implementing TBLT in real classrooms is discussed. Since the current study involved young learners, the final section reviews research on tasks for young learners in both ESL and EFL contexts. This includes a review of research into implementing TBLT in primary classrooms, which then leads to the rationale for the current study.

\subsection{Tasks and task types}

\subsubsection{Defining tasks}

One of the main aims of this study is to evaluate activities in textbook speaking lessons and in teachers' implementation of these lessons. It is, therefore, necessary to specify what a task is and how it is different from traditional language teaching activities. In addition, a clear understanding of this distinction is essential for the design and implementation of taskbased versions of the textbook speaking lessons for EFL in the Vietnamese primary school classroom, which is another objective of the current study.

In the 1980s, as TBLT emerged out of communicative language teaching (CLT), the term "task" was increasingly used in place of communicative activities (Skehan, 2003). CLT is defined as "a broad approach to teaching that resulted from a focus on communication as the organizing principle for teaching rather than a focus on mastery of the grammatical system of the language" (Richards, 2001, p. 36). In other words, CLT is based on communicative 
language use with meaning being of primary importance. Therefore, TBLT is regarded as sharing many characteristics of CLT such as the importance of meaning, genuine communication and learner-centreness.

A task is the central component of TBLT and the primary unit for planning individual lessons or designing a language program (Ellis, 2003, 2009). However, a language task has been defined in various ways in the literature. For example, Bygate, Skehan, and Swain (2001) define a task as "an activity which requires learners to use language, with an emphasis on meaning, to attain an objective" (p.11). These authors consider this definition as a basic, all-purpose definition which can be modified according to the purposes for which tasks are used.

Ellis (2003), however, argued for a need to have an inclusive definition which reflects "essential commonalities in tasks" regardless of their actual use (p. 9). Drawing on various definitions of tasks in the literature, Ellis (2003, 2009) proposes a definition which includes four criteria. The four criteria remain unchanged in Ellis and Shintani's (2014) more recent discussion of TBLT as follows:

1. The primary focus should be on 'meaning' (i.e., learners should be mainly concerned with encoding and decoding messages not with focusing on linguistic form).

2. There should be some kind of 'gap' (i.e., a need to convey information, to express an opinion or to infer meaning).

3. Learners should largely rely on their own resources (linguistic and non-linguistic) in order to complete the activity. That is, learners are not 'taught' the language they will need to perform the task, although they may be able to 'borrow' from the input the task provides to help them perform it.

4. There is a clearly defined outcome other than the use of language (i.e., the language serves as a means for achieving the outcome, not as an end in its own right). Thus, when performing a task, learners are not primarily concerned with using language correctly, but rather with achieving the goal stipulated by the task (pp.135-136).

According to Ellis and Shintani (2014), on the basis of these criteria, activities can be classified as tasks or task-like activities depending on the extent to which they satisfy the criteria. Ellis (2003) further argues that a task can be distinguished from a kind of situational grammar exercise used in the production phase of the PPP sequence, despite some obvious 
common ground. In performing a task, learners focus primarily on expressing their meaning rather than relying on pre-specified grammatical structures. By contrast, in doing a situational grammar exercise, learners tend to focus on using the grammatical features pre-taught to them. This distinction refers to two versions of TBLT in the literature which will be discussed in Section 2.4.2 below. Overall, the critical feature that distinguishes tasks from more traditional language learning exercises is that tasks require learners to function primarily as "language users" who treat language as a tool for achieving communicative goals; whereas, exercises require learners to act as "language learners" who treat language as an object to be studied (Ellis, 2003; Ellis \& Shintani, 2014).

Ellis's definition provides clear criteria for the evaluation of task design and task utilization which suit the main purpose of the current study. The primary purpose is to evaluate the design and implementation of speaking textbook lessons in Phase 1 and the design and implementation of the task-based versions of the speaking lessons in Phase 2 of the current study. These criteria were also discussed with the participant teachers at a briefing session prior to their implementation of the task-based versions of the speaking lessons in Phase 2 of the study.

\subsubsection{Task types}

Beyond trying to define a task, research on TBLT has also distinguished and proposed various types of tasks. For example, Willis and Willis (2007) classified seven different types of tasks including (1) Listing, (2) Ordering and sorting, (3) Matching, (4) Comparing and contrasting, (5) Problem-solving tasks and puzzles, (6) Projects and creative tasks, (7) Sharing personal experiences, story and anecdote telling. According to Willis and Willis (2007), this classification was based on the different cognitive processes involved in completing tasks.

Similarly, based on the kind of cognitive activity involved in task completion, Prabhu (1987) classified activities in the classroom into three types: (1) information-gap activity involving a transfer of information from one person to another or one place to another; (2) reasoning-gap activity involving deriving new information from given information; and, (3) opinion-gap activity involving sharing a personal preference, feeling, or attitude. In choosing task types for the pre-task phase in one of the task-based lessons implemented in Phase 2 of this study, listing tasks with brainstorming, being a particular kind of task, were used. Brainstorming can result in a list of words or phrases and hence, tasks involving listing or brainstorming are described as "the simplest types of task" (Willis \& Willis, 2007, p. 66). 
Less cognitively demanding tasks such as listing tasks were deemed as best suited for the EFL primary school pupils in this study because they can serve as effective facilitating tasks.

Tasks are also categorized as closed or open and one-way or two-way according to types of goals and directions of communication, respectively (Pica, Kanagy, \& Falodun, 1993). Two-way tasks provide learners with more opportunities to improve their language skills because both learners need to pool together their ideas and exchange the information they hold in order to achieve an outcome. Tasks with a closed outcome might also benefit L2 learners more than open tasks because learners are forced to reach one possible solution (Pica et al., 1993). Information gap tasks have been used widely in L2 interaction studies and have been shown to provide favourable language learning opportunities (Newton, 2013; Pica, Kang, \& Sauro, 2006). Thus, the main tasks for both lessons in the current study were designed as two-way information gap tasks with closed outcomes. Moreover, this task type lends itself to pair work practice, thus conforming to the regular classroom activity in the classroom setting for the current study.

Another distinction used in this study is between "focused" and "unfocused" tasks (Ellis, 2003). Unfocused tasks afford learners opportunities to use the language in general for a communicative purpose. Focused tasks, however, aim to provide opportunities to target particular language features. In other words, the target features are embedded in a focused task to create an opportunity for incidental learning through meaningful communication. Ellis suggests that the focused tasks must satisfy the four criteria stated above. Moreover, focused tasks better suit school aged learners as they are tightly structured, and so they are able to adequately scaffold task-based performance (Carless, 2008). For this reason, the current study adopts focused tasks for the design of the main tasks in both task-based lessons. The focused tasks suit the primary purpose of promoting learning by getting learners to use the language communicatively. They also ensure a focus on the target grammatical structures specified in the syllabus.

Tasks have also been classified as input-based and output-based. While output-based tasks or production tasks are central to TBLT, input-based tasks can be used at the start of teaching with tasks (Ellis, 2003), that is, when teachers and learners are still unfamiliar with tasks. Input-based tasks take the form of reading and listening activities which do not require learners to engage in free language production (Ellis, 2003). However, when learners perform input-based tasks, they nevertheless can still engage in second language (L2) production through private or social speech (Shintani, 2016). Also, input-based tasks tend to suit learners who are new to TBLT or have a limited proficiency (Ellis, 2003; Shintani, 2016). The current 
study used a combination of both input and output tasks. Input-based tasks were employed as facilitating tasks (Willis \& Willis, 2007) in the pre-task phase to prepare pupils linguistically for their performance of the main tasks in both task-based lessons. Output-based tasks were chosen as the main tasks as a way to develop pupils' communicative competence given that the pupils in my study possessed a basic knowledge of English.

In summary, this section has established a definition of task and outlined the basis for the decision for particular task types for the study by outlining definitions of task and task types available for task designers and practitioners. Following is a review of the theoretical foundations that support the use of tasks in language teaching and learning.

\subsection{Theoretical perspectives on task-based learning}

Research on tasks has been informed by various theoretical perspectives. In an early overview of task-based instruction, Skehan (2003) distinguishes four approaches to researching tasks. He first contrasts a psycholinguistic approach which informs negotiation for meaning (NfM) and corrective feedback $(\mathrm{CF})$ research with a socio-cultural approach which explores how learners co-construct meaning while engaging in interaction. He then discusses cognitive perspectives with particular emphasis on the Limited Attentional Capacity model (Skehan, 1998), task conditions, and task repetition. Finally, he devotes a small section to discussing structure-focused tasks.

In a more recent review, Bygate (2016) incorporates the psycholinguistic perspective of tasks into a cognitive approach. Within this approach, he discusses two types of cognitively-oriented studies: studies which have explored NfM and those which have investigated tasks, task conditions and language processing. He then contrasts cognitive studies with socio-cognitive studies. Within a socio-cognitive approach, he discusses research that has been informed by sociocultural theory (SCT). Similar to Skehan (2003), Bygate (2016) highlights studies that have investigated the way learners work together to accomplish a task and how this process might contribute to language acquisition.

The current study, seeing strengths in both approaches, analyses task interaction data from both a cognitive and sociocultural perspective. Thus, the following sections discuss NfM from a cognitive perspective and the role of scaffolding, the role of language production, and the role of L1 use from a sociocultural perspective. 


\subsubsection{Cognitive perspectives}

Research on the use of tasks within the cognitive perspective has been influenced by Long's $(1983,1996)$ proposal about the role of interaction and specifically of NfM in SLA. This proposal is based on an expansion of Krashen's Input Hypothesis which claims that input alone is sufficient for language learning. Long suggested that comprehensible input is important, but such input is especially beneficial when it arises from interaction where learners have attempted to repair breakdown in communication. In other words, interaction serves to induce learners to attend to language form in the context of meaningful language use and in so doing encourages the "noticing" that has been claimed to be crucial for acquisition to occur (Schmidt, 1990).

NfM occurs as learners work interactively to resolve communication problems triggered by communication difficulties. This motivates learners to use interactional adjustments such as clarification requests, confirmation checks and comprehension checks to address the difficulties they encounter as they communicate. In his revised version of the Interaction Hypothesis, (Long, 1996) noted three ways that these conversational efforts could facilitate L2 learning. First, they enable learners to notice the linguistic forms in the input. Second, they push learners to produce comprehensible output and modify their own erroneous production utterances to reflect the target language form. Third, they provide learners with opportunities to receive feedback on their non-target-like utterances, thus pushing them to modify their output towards a more target-like form.

As mentioned above, Long's (1996) updated version of his Interaction Hypothesis highlighted the role of feedback negotiated in conversational interaction. This interpretation of interaction reflected a marked shift in research focus, moving from meaning negotiation to feedback moves such as recasts (Skehan, 2003). This was also motivated by the growing critical evaluation of Krashen's Input Hypothesis (Long, 1991; Swain, 1985). As with NfM, tasks provide a fruitful context for feedback and particularly for recasting to occur (Skehan, 2003). According to Long (1991) and Swain (1985), the feedback learners receive on nontarget like forms draws their attention to mismatches between their current knowledge of the forms of the target language and the standard or target forms, thus fostering a learner-led focus on form. Feedback takes many forms such as clarification requests, which are requests during interaction for more information to clarify an interlocutor's previous utterance, and recasts, which are target-like reformulations of interlocutors' previous incorrect utterances (Pica, 1994). According to Long (1996), this process promotes learning through feedback learners receive and modified output produced through their efforts at self-correction. 
Cognitive perspectives have also motivated research into task-based interaction.

Research has investigated the effects of task characteristics on the occurrence of NfM and the relationship between NfM and acquisition/learning (see Ellis, 2000, 2003; Mackey, 2012 for reviews). For example, Pica et al. (1993) found that two-way tasks and tasks with a specific goal were found to provoke greater amounts of NfM than one-way tasks. Newton (2013) found that adult ESL learners engaged in more NfM in information-gap tasks than opiniongap tasks when they negotiated unfamiliar vocabulary. However, while students negotiated more word forms (e.g., spelling and pronunciation) in the information-gap tasks, they paid more attention to word meaning in the opinion-gap tasks. His findings also showed an improved recall of word meaning that had not been negotiated. Regarding this finding, Newton argued that NfM should not be considered as the only factor that drives vocabulary learning through interaction. According to Bygate (2016), studies like these which look at the effect of NfM on learning are still rare and a question remains concerning how language can be acquired through NfM.

Another issue concerns the amount of NfM in authentic classrooms. Studies conducted in the classroom settings reported a lower frequency of NfM than those carried out in laboratory settings. Foster (1998) and Foster and Ohta (2005) reported that ESL adult learners rarely negotiated for meaning while carrying out tasks in pairs and groups. Instead, they employed many other strategies to achieve task completion including co-construction, otherand -self corrections, and continuers. They also tended to self-correct more than correcting others. This shows that through the process of producing an utterance in the L2, learners noticed errors in their own utterances and attempted to repair them (Philp, Adams, \& Iwashita, 2014). Similar findings have been reported by other researchers such as McDonough (2004) and Shehadeh (2001), suggesting that, in addition to NfM, the interactional strategies such as self-and other-corrections are conducive to L2 development. However, Gass, Mackey, and Ross-Feldman (2011) challenged the claim that there is a lower frequency of NfM in classrooms than in laboratory settings. Their research findings provided evidence for equal amount of NfM identified in classroom settings and laboratory settings.

A related cognitive approach to investigating tasks can be seen in much of Merrill Swain's research. Swain (1985) argued for the role of language production as a primary catalyst in process of in language acquisition; a role that has also been incorporated into Long's (1996) revised Interaction Hypothesis. In her Output Hypothesis, Swain (1985, 1995, 2005) argued for the insufficiency of comprehensible input for language learning. She made this claim based on the results of her research into the language development of Canadian 
pupils in immersion programs. In her studies, she found that the pupils still maintained apparent grammatical errors despite extensive exposure to comprehensible input. For the development of their grammatical competence, she suggested that learners need to be pushed into making their language production more accurate, coherent and appropriate. According to Swain (1995), this "pushed output" drives language development in three main ways (1) it provides opportunities for learners to notice a gap between what they want to say and what they can say (2) it affords an opportunity for the learners to test hypotheses about the language, and (3) it encourages the learner to reflect on language forms and thus to "control and internalise linguistic knowledge" (p. 126). Swain's early research on modified output has primarily focused on the cognitive dimension of learning. However, her recent research has drawn on sociocultural perspectives of L2 learning, which will be discussed further in the section follows.

In sum, the cognitive view of research with respect to NfM and CF has helped develop a better understanding of the potential of TBLT based on both theoretical and empirical investigations. However, as Bygate (2016) argues, research within the cognitive approach has paid a greater attention to the cognitive processes of language learners working with tasks than on what actually happens in the complex pedagogic context of language classrooms. Therefore, Bygate calls for more exploration within classroom contexts and specifically more research on both how teachers and learners engage with tasks and the effect of this engagement on L2 development. This classroom orientation aligns with an alternative approach to task-based research which draws on SCT. This will be elaborated in the following section.

\subsubsection{Sociocultural perspective}

Socio-cultural theory argues that interaction is an opportunity to learn as well as serving as the actual site where learning occurs. During interaction leaners have the opportunity to co-construct knowledge and develop their cognitive and linguistic skills (e.g., Aljaafreh \& Lantolf, 1994; Ohta, 1995; Swain, 2000). Within a sociocultural perspective, learning is seen as a mediated process in a social context and language plays a crucial role in mediating this process. The mediational functions of language include the roles of scaffolding, the role of language production in L2 learning, and the role of L1 use, which are increasingly influencing task-based research.

The first mediational function of language concerns the role of scaffolding (Wood, Bruner, \& Ross, 1976). The concept of scaffolding is drawn from the work of Vygostky who 
argued that learning occurs when a novice learner (e.g., a student) is assisted by an expert interlocutor (e.g., a teacher). This expert assistance enables the novice learner to achieve what he/she cannot achieve without support. Vygotsky conceptualised this as a process of coconstructing a Zone of Proximal Development (ZPD). Relating this concept of ZPD to second language learning, Ohta (1995) defined it as “the difference between the L2 learner's developmental level as determined by independent language use, and the higher level of potential development as determined by how language is used in collaboration with a more capable interlocutor" (p. 53).

The expert-novice interaction has been extended to include learner-learner interaction. SCT researchers such as Lantolf (2000) and Lantolf and Thorne (2006) have suggested that the collaborative efforts in interaction mediate language learning because such efforts facilitate the process of internalising knowledge. Donato (1994) referred to this process as "collective scaffolding" which is defined as "the support given to language learners to enable them to perform tasks and construct communications which are at the time beyond their capacity" (Carter \& Nunan, 2001, p.226). In his study of college learners of French, Donato showed that the learners were able to assist each other regardless of their language abilities. Collective scaffolding enabled learners to construct the correct form of the verb which was entirely new for them. In another study, De Guerrero and Villamil (2000) found that when the ZPD was activated, the two learners in their study assisted each other through advising, eliciting, requesting clarifications and using L1. These scaffolding studies show that when learners interacted in pairs or groups, they provided mutual scaffolding which enabled them to solve language problems that were beyond their individual abilities.

The second mediational function of language is related to the role of language production. Various concepts have been employed to capture this role. One concept concerns "collaborative dialogue", a term used by Swain (2000) to refer to the important role played by language production in which language is used as a cognitive tool to mediate thinking in social talk. Subsequently, Swain (2006) introduced the term "languaging" to refer to the process of using language to learn a language. According to Swain (2006), the process of coconstructing knowledge encourages learners to put thoughts into words (i.e., verbalization) to explain, reflect and describe language problems. This process can occur in social talk as well as in private speech as a way to solve language problems, and is important for language development (Swain, 2006, 2010).

A series of socioculturally informed studies conducted by Swain and her colleagues have used tasks to explore the nature of collaborative dialogue during task-based interaction 
(e.g., Brooks, Swain, \& Polio, 2009; Swain \& Lapkin, 2002; Watanabe \& Swain, 2007). These studies showed how L2 learners sought and provided assistance with language-related problems when they engaged in collaborative dialogues. This process involved what Swain and her colleagues referred to as "language related episodes" (LREs) which they defined as "any parts of a dialogue in which learners talk about the language they are producing, question their language use or correct themselves or others" (Swain \& Lapkin, 1998, p. 326). Findings from this research revealed evidence to support the claim that LREs are occasions for language learning.

Following Swain, task research has investigated various moderating factors such as tasks, interlocutor proficiency and planning time, which may affect the quantity and quality of interaction in collaborative dialogues (e.g., Dao \& McDonough, 2017; Iwashita, 2001; Philp, Oliver, \& Mackey, 2006; Storch, 2002). For example, focusing on written activities performed by adult ESL learners and using LREs as a unit of analysis, Storch (2002) identified various patterns of peer interaction: collaborative, dominant-dominant, dominantpassive and expert-novice. Among these patterns, either collaborative or expert-novice patterns resulted in positive effects on language learning. Further research on this area by Storch and her colleagues (e.g. Storch, 2007; Storch \& Aldosari, 2013; Storch \& Wigglesworth, 2007) provided further evidence to show how the pairing of learners affected the quality of learning opportunity.

Additionally, as with the concept of language production, research on CF has increasingly drawn on sociocultural perspectives of L2 acquisition. SCT claims that CF mediates learning in two ways: (1) CF provides learners with comprehensible input that can be internalised; (2) CF affords learners opportunity to engage with collaboratively produced, new linguistic forms (Ellis, 2012). CF was first contextualized within cognitive perspective. However, according to Lantolf and Thorne (2006), CF has recently been contextualised within a collaborative process. Within this process, the feedback that learners receive is considered "other-regulation". As soon as assistance is provided within the ZPD, learners are able to move to "self-regulation". Aljaafreh and Lantolf (1994) examined the nature of assistance provided by a tutor to learners to help them identify and self-correct their written errors in an oral conference. Results show that the degree of scaffolding diminished over time, which, as the authors argued, demonstrated that learning was taking place. Therefore, $\mathrm{CF}$, as conceptualised in SCT, affords opportunities for development when learners are able to selfcorrect successfully and when the support required for self-correction to occur reduces gradually (Ellis, 2012). 
The third meditational function concerns the role of L1 use. L1 use from a sociocultural perspective of L2 is instrumental in mediating development. Research has shown L1 use functions as a scaffolding mechanism that facilitates interaction (Antón \& DiCamilla, 1998; Swain \& Lapkin, 2000) and that learners use their L1 as a tool to build knowledge. For example, Swain and Lapkin (2000) explored the ways in which pairs of Grade 8 French immersion students used L1 as a stepping stone to complete narrative writing reconstruction tasks in the target language. Additionally, several researchers (e.g., Azkarai \& García Mayo, 2015; Storch \& Aldosari, 2010; Storch \& Wigglesworth, 2003) have identified the use of L1 as an essential resource for adult learners to deal effectively with task demand and facilitate task management, thus contributing to successful task completion.

Recent studies with EFL young learners (e.g., Azkarai \& García Mayo, 2017; Tognini $\&$ Oliver, 2012) have also reported similar results. For example, Azkarai and García Mayo (2017) found that although Spanish EFL young learners employed L1 more frequently than EFL adult learners within task-based interaction, they did not use L1 excessively. Similar to adults, these young learners used L1 (Spanish) mostly to ask for words they did not know in English and/or use L1 as borrowings. They also used L1 for metacognitive talks and phatics. All of these functions of L1 use were found to move the task along and avoid communication breakdowns.

According to Bygate (2016, p.395), socio-cultural research "offers a promising bridge to the classroom use of tasks and to further classroom-based exploration of TBLT". However, he also notes that this type of research, as with the cognitive approach, has prioritised research on "the task per se rather than the ways in which it is or can be used in classrooms by teachers and learners" (Bygate, 2016, p. 396). It is therefore important, when adopting a socio-cultural perspective, to examine how tasks can be incorporated in the cycle of learning and teaching in real classrooms.

In sum, this section has outlined theoretical support for TBLT and discussed research studies that have sought to substantiate these claims empirically. In many of the studies reviewed above, task implementation conditions are typically controlled to serve the research purposes. In authentic classrooms, however, tasks are transacted and controlled by teachers and students. Given that the purpose of the current study is to investigate the implementation of TBLT in real classrooms, it is important to review the methodology of task-based teaching with respect to the framework for lesson design, approaches to teaching with tasks and the roles of teachers in implementing TBLT. 


\subsection{Task-based methodology}

The discussion above has shown that tasks have found support from different theoretical frameworks and perspectives. The value of tasks has thus been established in the field of second language teaching and learning. It is now essential to examine in what ways teachers can design and carry out task-based teaching in their classrooms. Below is a review of frameworks for designing task-based lessons and approaches to task-based teaching before identifying a framework and an approach that best suit the current study.

\subsubsection{Frameworks for lesson design and focus on form in a task sequence}

As outlined in Section 2.2, a task-based lesson is built around one or more tasks. Various frameworks for constructing a task-based lesson has been proposed (e.g., Estaire \& Zanon, 1994; Lee, 2000; Nunan, 2004; Prabhu, 1987; Skehan, 1996; Willis, 1996). As Ellis (2003) notes, various frameworks share a common three-phase pedagogical sequence consisting of a pre-task phase, (during) task phase and post-task phase. More specifically, the three main phases of task-based teaching begin with a preparation and priming phase in the pre-task phase during which the teacher introduces the topic or students are engaged in activities that help them recall topic-related vocabulary items or learn key words essential to the main task. The (during) task phase is where students perform the main task in pairs or groups. Finally, in the post-task phase, learners have an opportunity to reflect or practice the language forms that arise out of the performance of the tasks. The main task phase is obligatory while the pre-and post-task phases can be optional (Ellis, 2003). However, Ellis also notes that the pre-task and post-task phases "serve a crucial role in ensuring that the task performance is maximally effective for language development” (p. 243). In Willis's (1996) model, the main task phase is called a task cycle which includes the performance of the main task followed by the planning and report activities. After performing the task, leaners prepare a report in which they report how they did the task and what the outcome was. During the planning phase, the teacher advises learners on language and gives incidental correction and feedback if required. Finally, the learners present their findings to the class in written or spoken forms. The post-task phase, with its explicit focus on form, might also include more varied approaches to grammar instruction, including inductive and consciousness-raising tasks.

Willis (1996) also suggested that a standard framework as shown in Figure 1 can be adapted to suit young learners or beginners. 


\section{Figure 1. Willis's (1996) framework for TBLT}

\begin{tabular}{|c|}
\hline PRE-TASK \\
Introduction to topic and task \\
TASK CYCLE \\
Task -> Planning -> Report \\
FOCUS ON FORM \\
Analysis and practice \\
\hline
\end{tabular}

According to Willis, the adapted framework for young learners should centrally provide more language exposure compared to the standard framework. This can be done by (1) lengthening the pre-task phase to provide more exposure to the language input; (2) including a set of short tasks rather than one long task in the task cycle; (3) shortening or skipping the planning and report stages to minimise demands on public use of the language; (4) putting a greater focus on words and phrases for expressing meaning first and followed by a gradual increase in grammar. This framework has been adapted in the current study to suit learners who were unfamiliar with TBLT, but had some background English knowledge and skills after at least a year studying English in the mainstream classrooms. Chapter 5 provides a detailed account of how this framework is adapted in accordance with the speaking textbook lessons.

Tasks require a focus on form which refers to the learners' occasional shift of attention from meaning to a linguistic form while their overriding focus remains on meaningful communication (Long, 1991). In performing tasks, while focusing on constructing and comprehending messages, learners also need to pay attention to form for learning to take place (Ellis \& Shintani, 2014). Central to the task-based framework is the question of where focus on form should occur in the task sequence. Willis and Willis (2007) argue for the delayed focus on form, maintaining that the post-task phase is the appropriate phase to focus on target structures explicitly. According to these authors, the language analysis and practice activities in this phase ensure that learners can more easily make the connection between the meanings they have been communicated and the forms required to express those meanings. In contrast, in his TBLT framework, Nunan (2004) argues for controlled practice which involves learners in using the target language vocabulary, structures and functions communicatively before performing pedagogical tasks. In this way, the prior practice of the target language builds lexical and grammatical scaffoldings (or focus on form) before doing tasks. Alternatively, Ellis (2003) proposes various options for promoting focus on form at all 
stages of a task-based lesson. For example, teachers can pre-teach language in the pre-task phase, provide contextual support in the main task phase and/or carry out "language work" in the post-task phase.

The current study adopts Willis's adapted framework which suggests how a task-based lesson can be designed and implemented with young learners. It also considers Ellis's (2003) argument that focus on form can be promoted implicitly throughout all phases of a task-based lesson. However, what is meant by focus on form varies across versions of TBLT. The following section discusses various approaches to focus on form within TBLT before justifying the version the current study adopts.

\subsubsection{Strong and weak forms of TBLT}

Both strong and weak forms of task-based learning have been proposed when TBLT was taken into classroom practice (Skehan, 1996). Weak forms were referred to by Ellis (2003) as "task-supported language teaching" (TSLT) and strong forms as "task-based language teaching" (TBLT). TSLT is considered to be a weak form of CLT (Ellis, 2003). In this weak form, tasks provide opportunities to practice pre-selected language items and thus tasks are used as the means of implementing the free production stage in the PPP sequence. Ellis considers TSLT in many ways to be comparable to the PPP model. In Skehan's (1996) weak form of TBLT, tasks are roughly comparable to the production stage of the PPP sequence. In other words, weak forms of TBLT are often assimilated into PPP.

PPP has been a long-standing approach to English language teaching from the 1960s onwards (Harmer, 2001). This approach views language learning as a series of products acquired through sequentially staged practice of rule-based structures (Ellis, 2003). More specifically, in a PPP lesson, individual language items are first explicitly introduced and then intensively practiced in isolated sentences in a controlled activity. It is in the final stage that tasks are used to provide opportunities for practicing the target language items. PPP has been used widely in both pre-and in-service teacher education programs worldwide (Anderson, 2017). Teachers favour this approach because it allows them a greater control of the content and progress of the lesson (Skehan, 1998; Thornbury, 1999). Widdowson (2003) stated that PPP "has endured because teachers genuinely believed in it, and found some basis of their belief in their classroom experience" (p. 131). Swan (2005) in fact defends PPP as a useful routine for presenting and practicing structural elements under semi-controlled conditions, which suits learners who lack exposure to the English speaking environment. 
However, PPP has been critiqued in a number of ways. Researchers such as Ellis (2003), Long (1985, 2015), and Willis (1996) have argued that the PPP approach to language teaching is not compatible with theories of SLA. Long (1985) has identified three problems associated with the approach. Firstly, the PPP approach exposes learners to inauthentic language input which prevents them from knowing how the target language is used outside the classroom. Secondly, learners are expected to produce errorless utterances through repetitive practice while second language acquisition involves the process of making errors and learning from errors. Thirdly, practicing a rule in isolated sentences does not result in learners' ability to converse spontaneously in the target language. Learners instead need to learn how to make communicative efforts of mobilising the correct language items, pronouncing an utterance appropriately or monitoring the conversation effectively to be able to engage in authentic, real-life conversations. Willis (1996) also points out three problems with the PPP approach: (1) leaners at the final P (production) phase may not use the language items presented; (2) learners cannot produce the target language freely if they are required to use the pre-selected language items; (3) mechanical artificial use of language can result from overuse of language items presented in advance. Willis claims that these problems prevent learners from being able to communicate effectively in real life situations despite years of learning the target language.

TBLT, on the other hand, is considered a strong form of the CLT approach (Ellis, 2003). It is regarded as an improvement of the communicative approach due to its focus on balancing accuracy and fluency. Tasks are thus used to design a whole course or a language syllabus. Therefore, the teaching of a language is not based on pre-selected language items, but communicative tasks which focus learners' primary attention on meaning to develop their communicative competence (Ellis, 2003; Long, 2015). TBLT invites students to act as language users rather than learners, with the explicit analysis of language structures and forms emerging from difficulties experienced during the completion of tasks (Willis, 1996; Willis \& Willis, 2007). The underlying principle is that "people learn a language not only in order to use the target language for functional purposes, but also by doing so" (Van den Branden, 2012, p. 133, original italics). Therefore, a fundamental rationale for TBLT is that language form is best acquired when the focus is on meaning (Prabhu, 1987). TBLT enables learners to learn a language through communication and engaging in language use (Prabhu, 1987; Ellis, 2003). For these reasons, advocates of TBLT argue that the task-based approach does adequately draw on research into L2 acquisition (e.g., Ellis, 2003; Long, 2015; Samuda \& Bygate, 2008; Skehan, 1998). 
That said, strong forms of TBLT have also been critiqued on both theoretical and pedagogical grounds. Critics such as Seedhouse (1999) argue that tasks result in the production of minimal language use which fails to promote acquisition. Swan (2005) claims that TBLT neglects the teaching of grammar, limits the role of the teachers, and that TBLT is unsuitable for beginner learners because unless learners have a basic grammatical knowledge they will not be able to communicate. Swan (2005) and Sheen (2003) maintain that TBLT is not workable for foreign language contexts where learners have limited opportunity to communicate in the target language outside the classroom. Littlewood (2007) doubts the feasibility of introducing TBLT in Asian classroom contexts where both teachers and learners have been used to viewing language as an object to be studied rather than a tool for communicating.

Therefore, there exists controversy over the use of tasks in language teaching and over the robustness of the research evidence in support of TBLT. There are also contrasting views on whether to adapt or adopt TBLT. Researchers such as Carless and Littlewood have called for adaptation of TBLT to Asian contexts where PPP has endured. Carless (2009), for example, argues that in some contexts it might be more desirable to enhance the effectiveness of PPP rather than introducing TBLT, particularly when the latter is not supported with adequate resources. However, in the context of foreign language education in New Zealand, East (2012) criticizes the "softly, softly approach", arguing that it sets the bar too low. Other scholars such as Long (2015) also reject any role for explicit instruction in TBLT.

While acknowledging that TBLT is somewhat complex and that the strong version of TBLT may be more theoretically desirable, Ellis (2015) argues that TBLT should not be viewed as an alternative to traditional approaches such as PPP. Instead, Ellis (2015) argues for a gradual switch to TBLT by "introducing TBLT in some lessons while continuing with familiar traditional approaches in others” (p. 383). The current study adopted Ellis's (2015) suggestion of adopting TBLT alongside PPP. It attempted to introduce a point of departure to approach TBLT from a more traditional PPP approach to language teaching by redesigning the PPP lessons to reflect principles of TBLT. By doing so, it was believed that TBLT would be more likely be accepted by the teachers and learners who are used to PPP and are under the pressures of completing the textbook materials.

\subsubsection{Role of teachers and learners in TBLT}

Teacher and learner roles have been highlighted in the pedagogically oriented literature of TBLT (e.g., Ellis, 2003; Van den Branden, 2016; Willis \& Willis, 2007). 
Empirical studies on TBLT implementation have also indicated that teachers play a crucial role in the successful implementation of TBLT in language programs and formal classrooms (e.g., McAllister, Narcy-Combes, \& Starkey-Perret, 2012). Shehadeh and Coombe (2012) suggest that teacher and student factors come first in the list of factors that decide the successful adoption of TBLT. Researchers have suggested a variety of roles teachers should take in TBLT. For example, the role of the teacher is implied in Ellis's (2003) principles of task-based language teaching as follows:

1. Ensure an appropriate level of task difficulty

2. Establish clear goals for each task-based lesson

3. Develop an appropriate orientation to performing the task in the students

4. Ensure that students adopt an active role in a task-based lesson

5. Encourage students to take risks

6. Ensure that students are primarily focused on meaning when they perform a task

7. Provide opportunities for language-focused learning

8. Require learners to evaluate their performance and progress (p. 276-278).

These principles highlight the crucial roles the teachers need to play in task design and throughout the implementation of a task-based lesson. More specifically, Willis $(1996,2009)$ suggests that teachers should adopt the roles of a "monitor", "language adviser", and "chairperson" to carry out the pre-task, task-cycle, and post-task, respectively. Recently, by drawing on the pedagogical literature on TBLT implementation (e.g., Ellis, 2003; Samuda, 2015; Willis \& Willis, 2007), Van den Branden (2016) identified a number of actions and decisions teachers should take before, during and after a task performance. For the pre-task, the teacher should select appropriate content and decide the focus of the classroom activity. The teacher should consider other issues such as the timeline of each classroom activity, the extent of focus on meaning and a focus on form, and the particular forms to be highlighted and covered. In the during-task phase, apart from operating as an organizer who can organise and control classroom activities, the teacher should remain a crucial interactional partner who can "raise the quantity and quality of interaction that occurs" (p. 70). This can be done by facilitating NfM and enhancing form-meaning mapping process. Providing feedback, sufficient input and task modelling will be necessary. Additionally, motivational support measures such as creating a relaxed classroom atmosphere, keeping students motivated, and encouraging them to persist are all conducive to successful implementation. 
Finally, in the post-task phase, the teacher can provide an opportunity for languagefocused learning by reviewing students' performance (Willis \& Willis, 2007). Teachers can implement various actions and decisions such as highlighting the form or discussing the strategies students use. Assessing task performance and language development are other tasks for the teacher to do. Additional to students' self-assessment (Ellis, 2003), Van den Branden (2016) expects the teacher to conduct assessment by using available types of tests or selfdesigned tests. Assessments in TBLT are instrumental in providing feedback to the learners and in tailoring the tasks to their needs (Long, 2015; Norris, 2009).

TBLT promotes a learner-centred approach which requires learners to take an active role during a task-based lesson. Learners should have the confidence to task risks in order to succeed with the language that is inherent in the task. For learning to occur, the interactional support of another person is crucial. That person is preferably the teacher, but in many cases, support from a peer or a more competent peer is equally useful (Philp et al., 2014). Furthermore, learners need to perform as both a learner and a communicator, which is required "when they work collaboratively, assist each other with linguistic problems when they arise, but orienting primarily to achieving the task outcome" (Ellis \& Shintani, 2014, p. 143).

With these considerations in mind, the pedagogically oriented TBLT literature reviewed in this section provided valuable guidance for the design and implementation of the task-based versions of the PPP speaking lessons in the current study.

\subsection{Research on TBLT implementation}

The review above shows that TBLT has been supported by theoretical perspectives from SLA and SCT and, that there is much theoretical and pedagogical discussion concerning how tasks should be designed and implemented. It is now important to examine how tasks are realised in classrooms. Studies have shown some interesting contrasts between, for example, the implementation of TBLT inside versus outside Asia; ESL versus EFL contexts; young learners versus adult learners. The review in this section is first centred on studies on TBLT implementation in different adult language learning contexts outside Asia and studies on TBLT implementation at the secondary school level and beyond inside Asia. Then research on TBLT for young learners in both ESL and EFL contexts and research on TBLT implementation in primary school classrooms is addressed in separate sections. 
This section begins with an examination of studies on TBLT implementation both inside and outside Asia. The review of studies in these contexts reveals an interesting contrast on the uptake of TBLT. While studies on TBLT implementation outside Asia generally reported effective uptake of TBLT, studies on TBLT implementation inside Asia (except for a few studies conducted by small-scale projects) reported more challenges than successes.

\subsubsection{Studies of TBLT implementation outside Asia}

Several studies have reported positive learning outcomes from the implementation of TBLT in foreign language classrooms outside Asia (e.g., Andon \& Eckerth, 2009; Bao \& Du, 2015; Gonzalez-Lloret \& Nielson, 2015). For example, Bao and Du (2015) investigated the effects of TBLT on beginner adult learners of Chinese as a foreign language in Denmark in a language program. Results from classroom observations and interviews with learners showed that TBLT increased learner participation, created more opportunity for speaking, eased learners' anxiety, and enhanced enjoyment. However, the learners also reported challenges regarding lack of Chinese pronunciation, lack of sufficient instructional support time and difficulty in balancing learners' different preferences for learning strategies. More positive results were shown in a recent study by Gonzalez-Lloret and Nielson (2015). This study reported on an evaluation of a task-based Spanish course for a government agency in the USA. Results from three empirical studies conducted to investigate the effects of the course suggested that it was successful. Students' oral proficiency in terms of accuracy, fluency and complexity was better at the end of the course than that of students in an equivalent grammarbased course. Their overall Spanish proficiency was improved as a result of the course. The learners also perceived the course to be useful and relevant to their on-the-job needs.

Apart from research in small-scale language programs, research has also investigated TBLT in national curriculum renewal in both foreign language and second language contexts outside Asia. In the foreign language context of New Zealand, East (2012) investigated the perspectives of teachers who sought to incorporate the use of tasks into the modern foreign language curriculum in high school contexts. Results from semi-structured interviews with 19 experienced teachers revealed that a quarter of the participants had minimal understanding of TBLT while the rest had relatively high understanding of TBLT. Teachers who had experimented with tasks in their classrooms over a longer period of time reported that they were satisfied with students' performance of the tasks. In particular, they noted that the tasks enhanced their students' fluency and motivation. 
TBLT has been promoted in schools for the teaching of Dutch in Flanders, a Dutchspeaking region in Belgium since the early 1990s. In this context, task-based syllabi and extensive teacher education programmes were developed. A series of empirical studies (Van den Branden, 2006, 2009c; Van den Branden, Van Gorp, \& Verhelst, 2007) documented how teachers and learners took up tasks in authentic classrooms at the levels of primary school, secondary school, and adult education. For adult education, in particular, Van den Branden (2009b) summarised four studies of teachers' and students' use of tasks at various class levels. Data were collected by means of recordings of classroom interaction and interviews with teachers and students. In his discussion of two examples of tasks, the author noted that the tasks stimulated a high level of enthusiasm in students, leading the author to conclude that "the performance of these tasks seems to have sparked the kind of interactional work that has been claimed by SLA researchers to stimulate language development" (Van den Branden, $2009 \mathrm{~b}$, p. 278). The teachers in these studies showed their willingness to experiment with the tasks given to them. One teacher reported that the tasks promoted a high level of spontaneous interactional involvement and a focus on meaning negotiation even though the learners had relatively limited proficiency in the target language. A higher level of success was reported in the non-Asian studies conducted at the primary school level in the teaching of Dutch in Flanders, which will be discussed in Section 2.7 below.

Taken together, the studies generally reported positive results regarding TBLT implementation in foreign language programs and in school-based contexts. However, the studies also reported teachers' concerns regarding the time required for setting up and completing tasks and classroom management issues. Moreover, the studies also reported that teachers tended to make "context-specific adaptations" to tasks (East, 2012, p. 10). They attempted to modify tasks to suit their own teaching styles and classroom situations in order to overcome issues related to noisy classrooms and time constraints. While studies on TBLT implementation outside Asia have reported more successes than challenges, studies conducted in Asia generally reported the reverse.

\subsubsection{Studies of TBLT implementation in Asia}

In Asia, TBLT has been widely promoted across a range of language learning and curriculum development contexts (Adams \& Newton, 2009; Butler, 2011; Carless, 2012; Nunan, 2003). Like studies conducted outside Asia, many studies conducted in foreign language programs in Asia have reported positive results. There have been several success stories reported from small-scale projects at the tertiary level (e.g., Hood, Elwood, \& Falout, 
2009; McDonough \& Chaikitmongkol, 2007). McDonough and Chaikimongkol (2007) reported on an innovative task-based course for EFL students in a Thai university. The course replaced a traditional focus-on-forms course and was developed by the teachers involved in the program. Results showed that both teachers and learners generally had a positive reaction to the course. They reported that the course addressed the real world academic needs of the learners and encouraged them to be more independent. One important element that contributed to the success of the course was the amount of support, in terms of materials and training workshops, the teachers received in their transition from traditional teaching methods to the task-based approach. Similar positive results were also reported in Hood, Elwood and Falout's (2009) study into students' perceptions of TBLT in a Japanese context. These studies suggest that there is fruitful ground for TBLT to develop within an Asian context.

Another line of research in TBLT implementation in Asia has sought to investigate the implementation of TBLT as an EFL curriculum innovation. This line of research involves a range of studies conducted across different Asian contexts. In Korea, for example, Jeon and Hahn (2006) explored teachers' perceptions of TBLT in a secondary school context. Data were collected by means of a questionnaire survey of 228 teachers at 38 different middle and high schools. Results showed that almost two-thirds of the teachers had a relatively clear understanding of TBLT concepts and supported the TBLT approach. Despite this, many teachers were reluctant to adopt TBLT in their classroom practice because they lacked the pedagogical knowledge of task-based instruction and the confidence to use the target language. However, for the teachers who chose to implement TBLT in the classrooms, they valued the motivational features of TBLT and its appropriateness for small group work. Similar findings were reported in a study by Xiongyong and Samuel (2011) conducted in China.

Evaluation studies conducted by Carless $(2007,2009)$ in a Hong Kong secondary school context were, in contrast, purely qualitative interview studies. These two studies sought to explore teachers' perceptions of the suitability of TBLT in secondary schools. Carless (2007) interviewed 11 school teachers and 10 teacher educators for their views on the suitability of TBLT in secondary schools. The findings showed that the participants expressed a desire for a "situated version of TBLT" which can accommodate a balance between TBLT and public examination, between receptive and productive skills in TBLT, and the need for grammar instruction. The study suggests that a weak version of TBLT may be more appropriate in this secondary school context. 
In a similar interview study in Hong Kong, Carless (2009) explored the relative advantages of TBLT and PPP and the rationales behind preferences for TBLT or PPP from the perspectives of the teachers and teacher educators. The majority of teachers reported that they preferred and mainly used PPP in their teaching practices. The teachers who were positive about PPP reported that PPP facilitates direct grammar instructions while those in favour of TBLT reported greater student engagement. In contrast, the majority of teacher educators revealed greater support for TBLT than PPP. They showed knowledge of TBLT and SLA theory in support of TBLT, but they also acknowledged that TBLT was complex and often difficult to implement in the school classrooms. These findings were, however, based on the teachers' self-reported practice and lacked triangulation with other data sources such as classroom observation in order to provide additional insights into the implementation of task-based teaching.

More recently, in Taiwan, Lin and Wu (2012) investigated high school teachers' perceptions and understandings of TBLT and their views on the feasibility of TBLT. Data were collected from a survey of 136 teachers from 30 high schools and supplemented by interviews with four teachers. Like the teachers in the Korean study, these Taiwanese high school teachers just possessed basic understandings of TBLT concepts. In particular, they considered TBLT as similar to CLT and thus, their practices reflected pedagogical principles and practices of CLT rather than TBLT. However, although many teachers did not totally believe in the feasibility of TBLT, they held positive attitudes towards TBLT. They agreed that TBLT enhanced student motivation and encouraged communicative language use. In brief, these two evaluation studies shared some similar findings regarding the issue of teacher understanding of TBLT. An overarching finding is that although many teachers had comparatively basic understanding of TBLT and held positive attitudes towards TBLT, they failed or chose not to implement TBLT. Because these findings were derived from large-scale surveys, and sometimes supplemented by interview data, they unfortunately do not provide evidence of actual classroom practice.

That said, there have been more recent studies which have attempted to incorporate a variety of collection methods in an attempt to triangulate data. For example, in China, $\mathrm{Hu}$ (2013) investigated teachers' responses to TBLT through multiple data collection methods such as interviews, field observations and document analysis. Thirty teachers across school levels in Beijing were recruited. Results suggest that Chinese teachers of English responded differently to TBLT. Half of the teachers (50\%) held a positive attitude toward TBLT and actively implemented TBLT in their classrooms. They agreed that TBLT created an 
“interesting, meaningful and practical" learning environment (p. 12). However, the other teachers did not believe that TBLT would adequately prepare their students for examinations. These teachers focused on covering the textbook content and adhered to the traditional teacher-centered approach. Their primary goal was to help students achieve high scores on examinations.

In a case study in China, Zheng and Borg (2014) explored understanding of TBLT and its implementation by exploring the beliefs and practices of three secondary school teachers of English. Observation and interview data were pulled together to construct a narrative account for each teacher. Results suggest that the two more experienced teachers were more strongly oriented to grammar teaching. They had limited understanding of TBLT and interpreted it as involving oral communicative activities and pair/group work. They regarded examinations and large class sizes as obstacles to the implementation of TBLT. The other younger teacher was more positive toward TBLT, believing that TBLT prepared learners for real-life problems and allowed for co-operative learning. According to the authors, the differences persisted due to the fact that the more experienced teachers possessed "deep-rooted beliefs about grammar" (p. 218) while the younger teacher had a desire to challenge herself with TBLT. The narrative accounts which enabled comparison of what the teachers did with their explanations provided a broader and more in-depth understanding of teachers' implementation of TBLT in the secondary English curriculum in China.

In Vietnam, research on the 2006 task-based curriculum ${ }^{2}$ with respect to teachers' cognition and classroom practices has been carried out in public high school classrooms. Studies conducted in non-elite schools have found a considerable distance between teachers' beliefs and TBLT principles (Le \& Barnard, 2009; Nguyen, 2014; V. G. Nguyen, Le, \& Barnard, 2015). For example, V. G. Nguyen et al., (2015) conducted two qualitative case studies on the implementation of TBLT in high schools in rural areas in Northern Vietnam. The first case study sought to investigate teachers' understanding and implementation of tasks. Eleven teachers from two high schools in Central Vietnam participated in the study. Multiple data collection procedures were employed, including narrative frames, lesson planning sessions, lesson observations and stimulated recall interviews. The second case study investigated the beliefs and practices of eight teachers working in a high school in the North of Vietnam. The teachers were interviewed and their lessons were observed in order to examine their understanding and practice regarding grammar instruction within the mandated

\footnotetext{
2 The 2006 task-based curriculum was issued by the Vietnam Ministry of Education and Training, and was prescribed nation-wide from Grades 6-12 (Le \& Barnard, 2009)
} 
task-based textbooks. Results from the two studies suggest that teachers from the three different high schools had limited understanding of TBLT. They prioritized form rather than meaning, believing that learners needed explicit grammar instruction before they could communicate in the target language. Therefore, they changed the prescribed textbook tasks into form-focused teaching activities. Their classroom practices were predominantly teacherled and textbook-reliant. Pressure to cover the textbook tasks, teacher proficiency, insufficient resources, and non-task-based examinations were among the teachers' explanation for their classroom teaching. Overall, findings from the two case studies suggest that beliefs and practices of the participating teachers were divergent from TBLT principles and remained irresponsive to the innovation.

Contrary to V. G. Nguyen et al., (2015), B. T. Nguyen, Newton, and Crabbe (2015) found congruence between TBLT and the practices of teachers through classroom observations and an analysis of the accounts of nine experienced teachers in an elite high school for gifted students in central Vietnam. The findings showed that the teachers adapted and replaced the textbook tasks to make them more communicative and relevant to their students' real-life experience. These positive findings were attributed to the strong English language skills of both teachers and students in an elite school, a context which distinguishes the current study from other studies. The contradictory findings between the two studies, as B. T. Nguyen et al. (2015) suggest, highlight the need for research to take account of the influence of specific settings and contextual factors on the dispositions of teachers towards communicative and task-based teaching approaches and on their capacity to adopt these approaches.

Recent studies in the Vietnamese context have turned to the tertiary setting, investigating teachers' experiences of TBLT compared to PPP. Three studies (Nguyen \& Nguyen, 2017; Nguyen, Jaspaert \& Van den Branden, 2018; Phuong, 2016) conducted in the same university in Vietnam share some similar results. Nguyen and Nguyen (2017), for example, investigated how three in-service teachers reacted to TBLT training in their actual teaching practice. Findings from observation of classroom teaching show that despite being trained, the teachers were not fully able to implement TBLT in their classrooms. However, they highly valued the effectiveness of TBLT in promoting communicative language use. They strongly believed that TBLT can be successfully implemented if changes are made to accommodate TBLT. The authors concluded by stressing the key role teachers play in a TBLT innovation and the indispensable role of TBLT training, asserting that "if this task cannot be done properly, any changes in language teaching will not be possible" (p. 61). 
An important theme that runs through most evaluation studies on TBLT implementation in Asia is that the feasibility of TBLT for schooling in Asia has not yet been convincingly demonstrated. Teachers have failed to successfully implement the task-based curriculum at the classroom level due to various constraints such as examinations, teachers' limited language proficiency and TBLT know-how as well as teachers' beliefs about language teaching. However, there is some evidence to indicate that contextual factors, including factors associated with the teachers play an important role in success or failure of TBLT. For example, TBLT has been successfully implemented in the study by B. T. Nguyen et al., (2015) with teachers and students from a gifted high school while contrasting results were reported by V. G. Nguyen et al., (2015) conducted in a rural school. Furthermore, despite facing numerous difficulties in implementing TBLT, many teachers such as those in $\mathrm{Hu}$ (2013) and Nguyen and Nguyen's (2017) research reported positive attitudes towards TBLT. These teachers reported that TBLT could result in increasing students' interest and language ability. They believed that TBLT could be successfully implemented if sufficient training is provided. These factors were all carefully considered in the current study.

Central to the abovementioned studies is a focus on the relationship between teacher cognition and task-based teaching. This research direction has provided valuable information of how teachers perceived and implemented TBLT in different settings and various factors that hinder the implementation of TBLT. Moreover, studies into teacher cognition highlight issues concerning the compatibility between the intended/resourced curriculum and teachers' implementation of this curriculum. Teacher cognition, commonly defined as, what teachers "know, believe, and think" (Borg, 2003, p. 81), has been shown to shape teachers' enactment of TBLT. According to Borg, teachers are "active, thinking decision-makers who make instructional choices by drawing on complex, practically-oriented, personalised, and contextsensitive networks of knowledge, thoughts and beliefs" (Borg, 2003, p.81). Research into language teachers' cognition is regarded as essential because their thinking and pedagogical practices inevitably play a decisive role in shaping classroom events (Borg, 2006). According to Lai (2015), researching teacher cognition is valuable for an on-going dissemination of an innovation. However, Lai suggests moving the current research direction a step further by "experimenting with effective implementation models [of TBLT] in different contexts" (p.24). The current study utilised teacher cognition to explore teachers' perceptions of textbook speaking lessons and the task-based versions of the lessons. Data on students' perceptions of the task-based lessons was also collected in Phase 2. 
In sum, the above review has evaluated research into how TBLT has been implemented with adult learners in both controlled conditions and authentic classrooms. An important, remaining question for the current study is how TBLT has been implemented with young or primary school age learners. The next sections aim to address this question.

\subsection{Research on TBLT for young learners ${ }^{3}$ (YLs)}

Research on TBLT originally focused on young adult learners and mostly took place in adult ESL contexts. However, in recent years, there has been increasing interest in extending the range of contexts in which TBLT takes place. One of those contexts which is typically prominent in language teaching is task-based language teaching for YLs (Pinter, 2007, 2015; Shintani, 2016). This context emerged in accordance with a trend towards the introduction of English to primary-age learners (Butler, 2015; Cameron, 2003; Pinter \& Zandian, 2014).

Reflecting this trend, governments around the world, particularly those in Asia, have introduced new curricula that emphasize the development of oral communicative skills in English (Butler, 2015). As a result, current communicative approaches such as CLT and TBLT (Richards \& Rodgers, 2001) have been promoted at the elementary school level (Butler, 2015) in these contexts. Because of this, research into the effects of particular approaches to teaching English to YLs has developed.

Like adult research, research on TBLT for YLs started in ESL contexts and more recently moved to EFL contexts. This research has focused on how tasks can be used with YLs, on actual implementation of task-based teaching in primary schools and the impact of tasks on learning. This section reviews research on TBLT for YLs in both ESL and EFL contexts and research into the implementation of TBLT in primary schools.

\subsubsection{Studies on TBLT for YLs in ESL contexts}

Studies on child task-based interaction in ESL contexts have been extended from adult studies (Pinter, 2015). One early line of research has examined whether YLs were able to negotiate meaning with their peers or adult interlocutors during the performance of a language task and the relationship between NfM and child language development. One such early study

\footnotetext{
${ }^{3}$ Young learners in this review are defined as children up to and including the primary school level (typically, children up to age 12) (Butler, 2015)
} 
was that undertaken by Ellis and Heimbach (1997) conducted with ESL kindergarten children aged five to six. This study used input-based tasks to investigate the links between the children's participation in negotiation for meaning, their comprehension of directions and their acquisition of new vocabulary. The results showed that negotiation facilitated comprehension. However, there was no significant relationship between active meaning negotiation and vocabulary acquisition. This led the authors to conclude that "meaning negotiation may play a less prominent role in acquisition for children than it does for adults" (p. 247).

Although a causal relationship between NfM and language development for kindergarten children was not established in Ellis and Heimbach (1997), other studies with older ESL learners have shown a positive impact of NfM on learning. Studies by Oliver $(1998,2000,2002)$ shed light on the process of NfM among children in an ESL setting in Australia. In her 1998 study, for example, 192 children were grouped into age- and gendermatched dyads in order to complete a picture description task and an object-placement task. The results of that study suggested that children negotiated for meaning and the strategies they used were similar to those used by adults, but the proportion was smaller. Children used far fewer comprehension checks but more self- and other-repetitions. Oliver claimed that although children were less developed cognitively, socially and linguistically they were "aware of their conversational responsibility and attempt to work towards mutual understanding” (p.379). In her 2002 study, Oliver also showed evidence of NfM and of variables that influenced it. The results suggested that the nativeness and proficiency of pairing affected the amount of NfM. However, unlike the results in adult studies, age and gender comparison showed no significant differences.

Other studies have described children's provision and incorporation of negative feedback (NF) (e.g., Mackey, Oliver, \& Leeman, 2003) and provided clear evidence of the positive effects of feedback on children's language learning (Mackey \& Oliver, 2002; Mackey \& Silver, 2005). Mackey, Oliver and Leeman (2003) found that 24 dyads of young ESL learners (NNS-NNS pairs) in Australia used more NF and produced significantly more modified output than a comparison group of 23 adult (NNS-NNS pairs). During the negotiation process, the YLs not only strived to resolve the communication difficulties, but also corrected each other. The authors claimed that the YLs were able to make use of corrective feedback from their peers and, as a result, improved their language production. Mackey and Oliver (2002) investigated the paired task-based interaction between 22 ESL children and adult nonnative English speakers. The participants were divided into two groups. 
The experimental group received corrective feedback in response to non-target like question forms through interactional modifications, and the control group did not receive any corrective feedback during the interaction. The results of immediate and delayed posttests showed that significantly more children in the experimental group improved their formation of English questions than did children in the control group. The researchers concluded that interactional feedback had facilitated second language development for the child learners and that this development had occurred more rapidly for children than previous research had shown for adult learners.

Like adult-focused studies, most studies with children were informed by the cognitive interactionist approach. Studies which explicitly draw on SCT have been rare. One notable exception is a study by Gagné and Parks (2013). Building on the work of Foster and Ohta (2005) who invested ESL adults in classroom settings, Gagné and Parks investigated classroom interaction of 29 Grade 6 pupils (10-11 years of age) in an intact class in an intensive ESL program in Canada. Results show that the Grade 6 children in this study rarely used the strategies associated with NfM. However, they were able to use a variety of scaffolding strategies, notably assistance and other-correction to complete the task. The study concluded that young ESL learners were able to provide varied scaffolding to peers as they worked with cooperative tasks such as jigsaw tasks.

Overall, the above-mentioned studies have revealed findings suggesting that ESL children are able to negotiate for meaning and benefit in this process as adults do, although the exact benefits are different. From a cognitive perspective, YLs are able to negotiate for meaning and provide NF and incorporate this feedback into their language production. From a sociocultural perspective, YLs are able to support each other during their performance of tasks. The support they receive from each other facilitates the completion of tasks and enables them to achieve task outcomes. The question now is whether these findings have also been found in studies with EFL children.

\subsubsection{Studies on TBLT for YLs in EFL contexts}

Research on task-based interaction has recently turned to the EFL contexts in order to explore whether task-based interaction benefits EFL young learners as it does with ESL adults and children. Similar to ESL studies, the majority of studies have been conducted in controlled conditions in a range of EFL contexts.

Pinter $(2005,2007)$ investigated the benefits of task-based interaction for YLs in a primary state school in Hungary. In the 2007 study, Pinter explored the interaction of the two 
10-year-old beginner learners when they were repeating versions of the spot-the-difference task designed. Although the children were exposed to traditional teaching methods before they undertook the tasks and their level of competence was very low, they were able to assist each other with peer correction. In addition, they were able to pay attention to each other's utterances over repetitions and express their views about their experience of performing the task. Results of this study encouraged the introduction of fluency task to primary school children at low-level of proficiency in order to provide them with opportunities for more "real" communication rather than drilling and pattern practice (Pinter 2007, p. 202). However, data from this study were collected from the performance of only two children outside their everyday classroom. While acknowledging the limitation of her study, Pinter suggested that "research with different tasks, more learners in different contexts and of different age groups would be essential to begin to build up a picture about the processes that occur in children's peer interaction in language tasks" (Pinter, 2007, p.203).

Shintani (2016) compared the PPP approach with the TBLT approach in the Japanese context. The study was conducted at a private language school with young beginner learners (6 years old). A group of fifteen children engaged in repeating three input-based tasks over five weeks while the other two groups engaged in the PPP instructions and a mixture of PPP and TBLT, respectively. Results showed that the children were able to engage successfully in input-based tasks. The qualitative analysis of the data show that the children were able to elaborate on their ideas and used less L1 when they repeated the tasks. The quantitative analysis shows the TBLT approach used in the research helped learners improve their vocabulary and grammar more effectively than the PPP approach. The findings lend support to the work of other studies with EFL young learners (Pinter, 2005, 2007), suggesting that children were able to work successfully with tasks. This study also provides evidence to support the claim that TBLT promotes a natural language learning environment for YLs and develops their L2 as a consequence.

A series of recent studies in Spain have shown that young EFL learners are able to negotiate for meaning in task-based interaction and benefit from this negotiation process as do in adult learners and ESL children (e.g., Azkarai \& Imaz Agirre, 2016; García Mayo \& Lázaro-Ibarrola, 2015). By examining L2 task-based interaction in two instructional settings, CLIL (content and language-integrated learning) and EFL, García Mayo and Lázaro-Ibarrola (2015) found that two EFL groups of 7-8 year olds and 10-11 year olds used NfM while completing a picture-placement task. This finding was confirmed in a follow-up study conducted by Azkarai and Imaz Agirre (2016) which examined the interaction of the same 
two groups of learners a year later. The results from these two studies lend support to Oliver's (1998, 2000, 2002) studies on NfM among young ESL learners, confirming that young EFL learners were also able to negotiate for meaning and employ various negotiation strategies during their task-performance. The negotiation strategies the learners used helped them move the task along and achieve task completion.

Researchers in Spain have recently extended their focus from investigating whether children are able to negotiate for meaning and provide NF to documenting the impact of task repetition on children's use of NF, NfM, interaction patterns and L1 (e.g., Azkarai \& García Mayo, 2017; Azkarai \& Imaz Agirre, 2016; García Mayo \& Imaz Agirre, 2016, 2019). Azkarai and Oliver (2016) found that both ESL and EFL learners provided and used NF including recasts and NfM, but they used more NF when they repeated the task. The ESL learners were able to provide more feedback on their errors than EFL learners. However, the EFL learners used more NfM strategies such as clarification requests and lexical searches. These strategies seemed to facilitate their understanding of the tasks and the unfamiliar vocabulary items. Despite quality differences in the task performance due to the English proficiency levels between ESL and EFL children, these findings provide further support to Oliver's (1998) claim that children can and successfully negotiate in task-based interaction. Regarding interaction patterns and L1 use, García Mayo and Imaz Agirre (2016) found that children collaborated more effectively when they repeated the task. Azkarai and García Mayo (2017) found that children used less L1 when they repeated the task. When the L1 was used, it was mainly to scaffold language production and to manage and expedite the completion of the task. Overall, results from these studies lend support to the benefits of task repetition, suggesting that not only ESL adult and YLs but also EFL young learners learn the target language effectively under task repetition conditions.

Guk and Kellogg (2007) and Butler and Zeng (2014, 2015) examined EFL classroom interaction from a socio-cognitive perspective. Guk and Kellogg's (2007) study involved fifth grade primary school pupils in Korea (10-11 years old). The researchers reported that the way a teacher provided scaffolding during one-on-one interaction with a pupil differed from how pupils provided scaffolding to each other in group work and that scaffolding was more evident in group work than in whole class teacher-student interaction. The researchers concluded that peer-peer interaction was reflective of symmetrical collaborative dialogue where the emphasis was on participation and discourse co-construction rather than the appropriation of accurate forms. In China, Butler and Zeng $(2014,2015)$ investigated patterns of interaction, interactional characteristics and self-assessment of $4^{\text {th }}$ and $6^{\text {th }}$ graders in task- 
based interaction. The authors found that the $6^{\text {th }}$ graders (11-12 years old) engaged in more collaborative interactional patterns, more elaborate topic sequences, more dynamic turntaking patterns, and more diverse communicative functions than the $4^{\text {th }}$ graders $(9-10$ years old) did. Proficiency level and age factor were found to be partly responsible for fixed turntaking patterns and little mutual engagement on topic development among the $4^{\text {th }}$ graders.

The studies presented thus far provide evidence to support the benefits of task-based interaction for both ESL and EFL young learners. Nevertheless, the positive results from many of these studies were primarily accomplished in controlled settings or in classroom settings where data were collected to serve the research purposes from the implementation of tasks added on to the regular classroom agenda (Pica, 2012). To address this gap in the literature, research into TBLT has recently shifted to investigating the pedagogic application of tasks within live classroom contexts.

\subsection{Implementation of task-based teaching in primary classrooms}

This section follows up on Section 2.5 above which has reviewed research on the implementation of TBLT in actual classrooms in adult learning contexts. The review here centres on research studies that have investigated the actual implementation of task-based teaching in primary school classrooms. For the purpose of the study, I will look at major studies in two notable teaching classrooms: the teaching of Dutch in primary schools in Flanders, the Dutch-speaking region of Belgium and the teaching of English as a foreign language in Asian primary school settings where TBLT has been promoted as a curriculum innovation.

As mentioned in Section 2.5 above, research studies have reported that the implementation of TBLT in small-scale, regional settings as in the teaching of Dutch as L2 in Flanders has been a success, particularly in the primary school context (Berben, Van Den Branden, \& Van Gorp, 2007; Van den Branden, 2009c). For example, Berben, Van den Branden and Van Gorp (2007) investigated how three primary school teachers carried out the same single task, a radio news bulletin, designed by professional experts. In this study, Dutch was used as a medium of instruction for teaching all school subjects to multilingual students. Results from classroom observations showed that each of the three teachers interpreted and adapted the tasks in their own ways to suit the students' purposes and their beliefs. They allowed pupils to redefine task objectives so as to add more fun and creativity to their task performance. Of note is that the uptake of TBLT in this study was attributed to the support 
from the syllabus designers who designed the task, the teachers' professional skills and their understanding of tasks.

However, these successful examples of task-based teaching of Dutch as a second language in primary schools in Flanders are in contrast to research into curriculum-mandated implementation of TBLT in primary schools in Asia, particularly in Hong Kong (Carless, 2002, 2003, 2004; Chan, 2012) and China (Deng \& Carless, 2009; Nunan, 2003; Zhang, 2007, 2015; Zhang \& Hu, 2010). Framed within a qualitative research framework, these studies examined several implementation issues such as how TBLT is understood and actually implemented in authentic classrooms and whether it suits existing classroom practices and teacher beliefs. The following reviews studies that focused on those key questions.

Carless $(2003,2004)$ depicted an early picture of how TBLT was understood and implemented in primary classrooms in East Asia. Carless (2003) explored three elementary school teachers' understanding of TBLT and factors affecting their implementation. Data were collected from attitude scale surveys, focused interviews and classroom observations. Carless identified six factors that influence teachers' uptake of TBLT in the classroom. These include teacher beliefs, teacher understanding, time availability, textbooks and topics, resource availability, and students' language proficiency. Findings showed that the teacher (Priscilla, pseudonym) who held a more positive attitude toward TBL and who had a clearer understanding of TBLT evidenced much greater implementation of tasks than the other two teachers (Susan and Gloria, pseudonym). In addition, other factors such as time and resource availability did not affect her implementation due to her advanced planning and collaboration with colleagues. Carless suggested that both time and resource availability should be considered for TBLT to be successfully implemented in the classroom. In a 2004 study of the same three teachers, Carless analysed an extensive database of 51 classroom episodes in order to identify implementation issues in the three classrooms. Carless found three factors constraining the implementation of tasks in the classroom, namely pupils' use of the mother tongue, classroom management problems and the quality of pupils' language production. Carless claimed that the implementation of TBLT in this context was congruent with tasksupported language teaching rather than task-based language teaching.

In a more recent study in Hong Kong, Chan (2012) investigated how TBLT was implemented in primary school classrooms. The study focused on the way the teachers managed linguistic, cognitive and interactional demands of tasks. Multiple data sources were collected including 20 lessons taught by four teachers, interviews with the teachers, teaching materials, and students' completed task work. The author found that the teachers differed in 
implementing TBLT, particularly in the way they managed the linguistic, cognitive and interactional demands of tasks. Chan suggested that timely and appropriate scaffolding strategies given when the needs arise is more important for task-based learning than the task per se. Overall, like Carless's studies, Chan's study suggested that the version of TBLT implemented in primary schools was less strong than what was envisaged by the official government documentation and guidelines

Studies in mainland China, however, described how teachers struggled to implement the current TBLT innovation in primary schools (Deng \& Carless, 2009; Zhang, 2015; Zhang $\& \mathrm{Hu}, 2010)$. Deng and Carless (2009) examined how a Year Four primary school teacher implemented activities in her classroom. Data were collected from classroom observations and interviews. The analysis of classroom activities was based on Littlewood's (2004) continuum of communicativeness of activities in order to examine the extent to which the activities reflected principles of task-based learning. Results showed little evidence that teaching practices were compatible with principles of task-based teaching. The teacher's lack of uptake of TBLT was attributed to two major constraining factors: traditional examinations and the teacher's limited understanding of how to implement TBLT. According to the authors, teacher development activities were one way to enhance teacher understanding of how to carry out communicative activities in the classroom. Support from teacher educators who were familiar with the theory and practice of TBLT was instrumental.

Further insights into the extent to which TBLT has been implemented in primary school classrooms in China and factors that shape the implementation were provided by Zhang's 2015 study conducted in South China. Zhang (2015) investigated how three primary school teachers implemented the TBLT innovation in their classroom practices. Results show that two of the three teachers rarely used tasks in their teaching, while the third teacher adopted a medium-to-strong form of TBLT. Factors inhibiting the implementation of TBLT of the two teachers were explained in terms of limited opportunities for professional development, their experience in learning English and their perceptions of students. In contrast, these factors did not apply to the case of the third teacher (Helen, pseudonym) who was able to successfully carry out TBLT in her practices. Regarding the case of this positive teacher, Zhang concluded that TBLT was not necessarily inappropriate or incompatible in China's EFL cultural contexts. This study highlights the fact that successful implementation of TBLT depends on teachers' confidence and capacity to carry out tasks in the classroom. 
With regard to the Vietnamese context, while several studies have investigated TBLT implementation at high school and tertiary levels, no study has investigated TBLT in primary schools, the site of the current study.

\subsection{Summary and rationale for the study}

This chapter began by defining tasks, types of tasks and theoretical perspectives to task-based learning. It then discussed the methodology for task-based language teaching and research on TBLT classroom implementation. A review of research on tasks for YLs revealed a growing body of research conducted to evaluate the value of tasks for YLs. The results have provided empirical evidence showing that tasks benefit YLs in both ESL and EFL contexts. Studies that explored the implementation of TBLT in authentic classrooms in primary schools showed that most studies have investigated the suitability of TBLT in the Asian context and reported several factors that hindered the implementation of TBLT in real classrooms.

This review suggests that research into TBLT implementation has several limitations. First, the review shows that studies that reported successful implementation of tasks with YLs (e.g., Pinter, 2007; Shintani, 2016) mostly documented the implementation of individual tasks designed by experts, outside regular instructional routines. In such studies, the researchers designed tasks and implemented them in quasi-experimental conditions to answer questions of theoretical interest. Such tasks do not typically meet lesson objectives or textbook activities and fail to be integrated into the normal instructional practices of the classroom. Therefore, it is less likely that teachers will use the results from such research to inform their classroom practices, even though data are collected in the school context. This suggests that classroombased task research where tasks are anchored to the classroom routine is much needed (Bygate, 2016; McDonough, 2015; Pica, 2012). For this reason, the current study responds to the need for designing and implementing tasks that "meet the twin demands of being genuine learning activities as well as effective research tools within authentic classroom settings" (Pica, 2012, p. xvii).

Second, the review reveals limited research into how EFL primary school pupils perform tasks in authentic classrooms and how EFL teachers and learners perceive and reconstruct the classroom tasks that they are confronted with (Bygate, 2016; Van den Branden, 2016).

Finally, although the implementation of TBLT in this Asian context has been regarded as challenging, there have been success stories reported in several qualitative case studies 
(e.g., the case of Priscilla in Carless (2003) and of Helen in Zhang (2015)). Such success stories, though rare, revealed the potential for TBLT implementation in authentic primary classrooms. However, little research has sought to examine factors that led to the success in order to find ways to introduce TBLT in this context, particularly in the primary school context in Vietnam.

The current study is an attempt to fill these gaps in the literature by exploring the feasibility of implementing the task-based lessons redesigned from the PPP textbook speaking lessons in authentic primary school classrooms. The study was conducted through two phases and set out to answer the following research questions (RQ):

\section{Phase 1: Teacher implementation of the textbook speaking lessons} RQ1

(a) How did the teachers implement the textbook speaking lessons?

(b) How did they explain their implementation decisions? RQ2

How did the teachers view the textbook PPP speaking lessons?

\section{Phase 2: Teacher implementation of the task-based versions of the textbook speaking lessons}

RQ1

(a) How did the teachers implement the task-based lessons?

(b) How did they evaluate their implementation of the task-based lessons?

RQ2

How did the pupils perceive their experience of carrying out the taskbased lessons?

RQ3

(a) How did the pupils perform the main tasks in the task-based lessons?

(b) What verbal interactional strategies did they adopt to perform the tasks?

The next chapter describes the research design and the methods used to gather and analyse the data for the current study. 
This page is intentionally left blank 


\section{CHAPTER 3 METHODOLOGY}

\subsection{Introduction}

This chapter discusses the methodological approach and research design used to examine the research questions for both phases of the study. It starts with a discussion of the research paradigm that guided the current study. It is followed by an overview of the research design in which the qualitative research approach and case study approach designed to address the research questions are justified. Following an overview of the research setting, the subsequent sections include description of the specific process of data collection, followed by an overview of methods used for data analysis. The last sections clarify strategies used to enhance the quality of the research project and the role of the researcher. The chapter concludes with a brief summary of the preceding sections.

\subsection{Interpretivist research paradigm}

A worldview or paradigm is "a basic set of beliefs that guide action" (Guba, 1990, p. 17). A research paradigm comprises beliefs about ontology, epistemology and methodology (Hesse-Biber, 2017). Ontology refers to the nature of social reality, or "what can be known and how" (Hesse-Biber, 2017, p.6). Epistemology refers to the nature of knowledge or "what and how can we know about it?" (Hesse-Biber, 2017, p.7). Epistemology, in a research context, is concerned with the relationship between the researcher and research participants and how this relationship shapes the construction of knowledge (Denzin \& Lincoln, 2000; Hesse-Biber, 2017). The methodology of a study is determined by the research purpose and informed by researchers' ontological and epistemological assumptions (Hesse-Biber, 2017).

Researchers tend to hold different ontological and epistemological beliefs about research. The differences lead to two major distinctive research paradigms: positivism and interpretivism (Hesse-Biber, 2017; Richards, 2003). Positivist researchers claim that reality is out there and exists independently of individuals. They believe that there is a single reality which is "observable, stable, and measureable" (Merriam \& Tisdell, 2016, p. 9). Therefore, they embrace an objective stance and use standardised measurement instruments to understand a research issue (Hesse-Biber, 2017). They value quantitative methods and emphasise independence between the researcher and the participants. In contrast, interpretivist researchers believe that knowledge is socially constructed; therefore, they assume that there exist "multiple realities, or interpretations, of a single event" (Merriam \& Tisdell, 2016, p. 9). 
They see themselves and the participants as "co-creators in the knowledge-building process and emphasise [s] the perspectives of the participants" (Hesse-Biber, 2017, p.6). Therefore, they value qualitative methods and try to minimise the "distance" or "objective separateness" (Guba \& Lincoln, 1988, p. 94) between themselves and the participants. Data collection focuses on the experiences, understandings and perceptions of the participants (Willis, 2007).

The interpretivist approach fits the two main purposes of my study, namely to investigate multiple participants' perspectives and interpretation of the experience of teaching and learning in PPP and task-based lessons. Ultimately, these perspectives are hoped to reveal insights into the nature and viability of teaching with tasks compared to the traditional PPP approach in this context. In addition, I believe that a true understanding of classrooms, and what goes in them, involves multiple perspectives from the researcher and participants. Professionally, as a teacher and teacher trainer, I possess knowledge about the Vietnamese social and cultural context, educational policies and teaching practices. In particular, for Phase 2 of my study, I can bring my own knowledge, beliefs and experiences to the design of the task-based versions of the speaking textbook lessons while the participant teachers can bring their experiences and pedagogical skills to the implementation of the lessons. These converging perspectives, both etic and emic, offer enhanced synergistic insights into the affordances of TBLT in this context.

As explained, my philosophical assumptions align with an interpretivist view of the world.

\subsection{Research design}

This section shows how my ontological and epistemological perspectives as a researcher impacted the methodology employed for the current study. It discusses the qualitative approach to research that informs the design of the study and my decision to use case study as an approach to qualitative inquiry to address the research questions.

\subsubsection{Qualitative research}

My interpretivist paradigmatic stance drove me to adopt the qualitative research approach for the design of the current study. Qualitative research involves studying "things in their natural settings, attempting to make sense of, or to interpret, phenomena in terms of meaning people bring to them" (Denzin \& Lincoln, 2000, p.3). This research tradition enables a rich and in-depth understanding of the research issue in a context-specific setting from an 
insider view (Guba \& Lincoln, 1994). It allows researchers to "capture what people say and do as a product of how they interpret the complexity of their world, to understand events from the viewpoints of the participants" (Burns, 2000, p.11). Moreover, qualitative researchers are encouraged to use multiple methods of data collection in order to create a rich description of the research problem (Dörnyei, 2007).

The current study employed a qualitative research design for two main purposes. First, Merriam and Tisdell (2016) state that qualitative research is a means for understanding "how people make sense of the world and the experiences they have in the world" (p. 15). Since my research aims to explore the implementation of the PPP speaking lessons and the task-based versions of the lessons, a qualitative approach provides a means for exploring and understanding the process of implementation from the perspectives and experiences of the teachers and their pupils. According to Dörnyei (2007), it is only actual participants themselves who can reveal the meaning and interpretation of their experiences and actions.

Second, qualitative research allowed me to position myself in the research process (Creswell \& Poth, 2018). As Merriam and Tisdell (2016) stated, "the researcher is the primary instrument for data collection and analysis" (p.16, original italics). Accordingly, the researcher's "values, personal history, and 'position" " are integral to the research process (Haverkamp, 2005; cited in Dörnyei, 2007, p. 38). In the current study, I brought to my research both my professional and cultural experiences. These provided important reference points for reflecting on the PPP lessons and the task-based versions of the lessons, and on the participants' responses.

\subsubsection{Case study approach}

A case study is an approach to research that involves the investigation of "a contemporary phenomenon (the "case") in depth and within its real-world context, especially when the boundaries between phenomenon and context may not be clearly evident" (Yin, 2014, p.16). A case study approach, according to Yin (2014), should be considered when the focus of the study is to answer "how" and "why" questions and when it is important to understand a phenomenon in detail. Therefore, case study enables a holistic understanding of a research issue from addressing such questions and allows for "a highly complex and nuanced understanding of the subject of inquiry" (Hesse-Biber, 2017, p. 221). In this sense, this approach was most suited to the exploratory and descriptive purposes of the current study, allowing for the questions of how the teachers implemented the PPP speaking lessons and the task-based versions of the lessons, and why they were implemented the ways they were to be 
addressed. More specifically, case study research enabled me to probe deeply into the teachers' viewpoints and actions, thereby helping me understand the implementation process from their perspectives.

Stake (1995) emphasises the importance of defining the case boundaries and proposes three types of case study: intrinsic, instrumental and collective. According to Stake, an intrinsic case study is used to understand a specific case itself while an instrumental case study uses one bounded case as an instrument to understand a phenomenon. Thus, an instrumental case study aims to facilitate understanding of a particular phenomenon rather than the case itself. A collective or multiple case study is similar to an instrumental case study in this sense; however, it involves several cases and allows for comparison of different cases (Dörnyei, 2007). Multiple cases are studied jointly in order to provide insights into a wider issue while the actual case is of secondary interest.

The multiple, collective type of case study guided the design of the current study. The main foci under investigation in this study were the implementation of the speaking lessons in the new textbooks being used by the participants and the task-based version of the lessons. For both, a multiple case study approach was adopted to address what, how and why questions. In Phase 1, the study addressed the questions of how the teachers implemented the lessons, what they thought about the implementation decisions, and how they viewed the PPP textbook speaking lessons. Phase 2 addressed the questions of how the teachers implemented the task-based versions of the lessons and how they evaluated the implementation of the lessons. Furthermore, it addressed the questions of how the pupils perceived their experiences and what strategies they employed to perform the main tasks in the lessons. Overall, these questions cannot be fully explored without a "real life" context, the actual classroom settings within which the teachers were implementing the new speaking textbook lessons and the taskbased versions of the lessons.

A case in case study research is the unit of analysis for research. To qualify as a case study, such a unit of analysis "must be a bounded system" (Burns, 2000). Phase 1 of this study involved a cohort of seven primary EFL teachers (three Grade 3 and four Grade 4 teachers). The whole group was considered a bounded system (a case) because they all implemented the same textbook speaking lessons that were being investigated. Moreover, data were collected within the context of primary school classrooms in the same province and within the first half a school year. Phase 2 of the study involved a group of three teachers and their pupils who participated in the implementation of the task-based versions of the speaking lessons in their classrooms. Each individual teacher was considered a bounded system (a case) 
in which different aspects of their implementation were investigated. Each group of pupils was considered a bounded system (a case) in which their experiences of the task-based lessons was the main focus. Analysing these multiple bounded cases allowed for holistic and rich description and in-depth understanding of the implementation (Stake, 1994; Yin, 2014).

This multiple case design also allowed for coverage and exploration of teachers and pupils from different primary schools in the same province in Vietnam. Phase 1 of the study involved at least two cases representing each school context with two teachers from an urban school, two from two semi-rural schools and three from three rural schools. Similarly, the three Grade 4 teachers and their pupils representing three different contexts participated in Phase 2 of the study. The classification of the schools was based on both my knowledge of the area and criteria set out by the local division of education and training. Overall, although such sampling procedures can never reflect the entire spectrum of views in Vietnam, I believe that the seven carefully chosen teachers in Phase 1 and the three teachers in Phase 2 may be adequate in providing a wide range of informed opinions and rich perspectives on the implementation of the new textbook speaking lessons and the task-based versions of the lessons in the context of primary schools in Vietnam. An overview of the two case studies is provided in Figure 2 below. 
Figure 2. Overview of the case studies

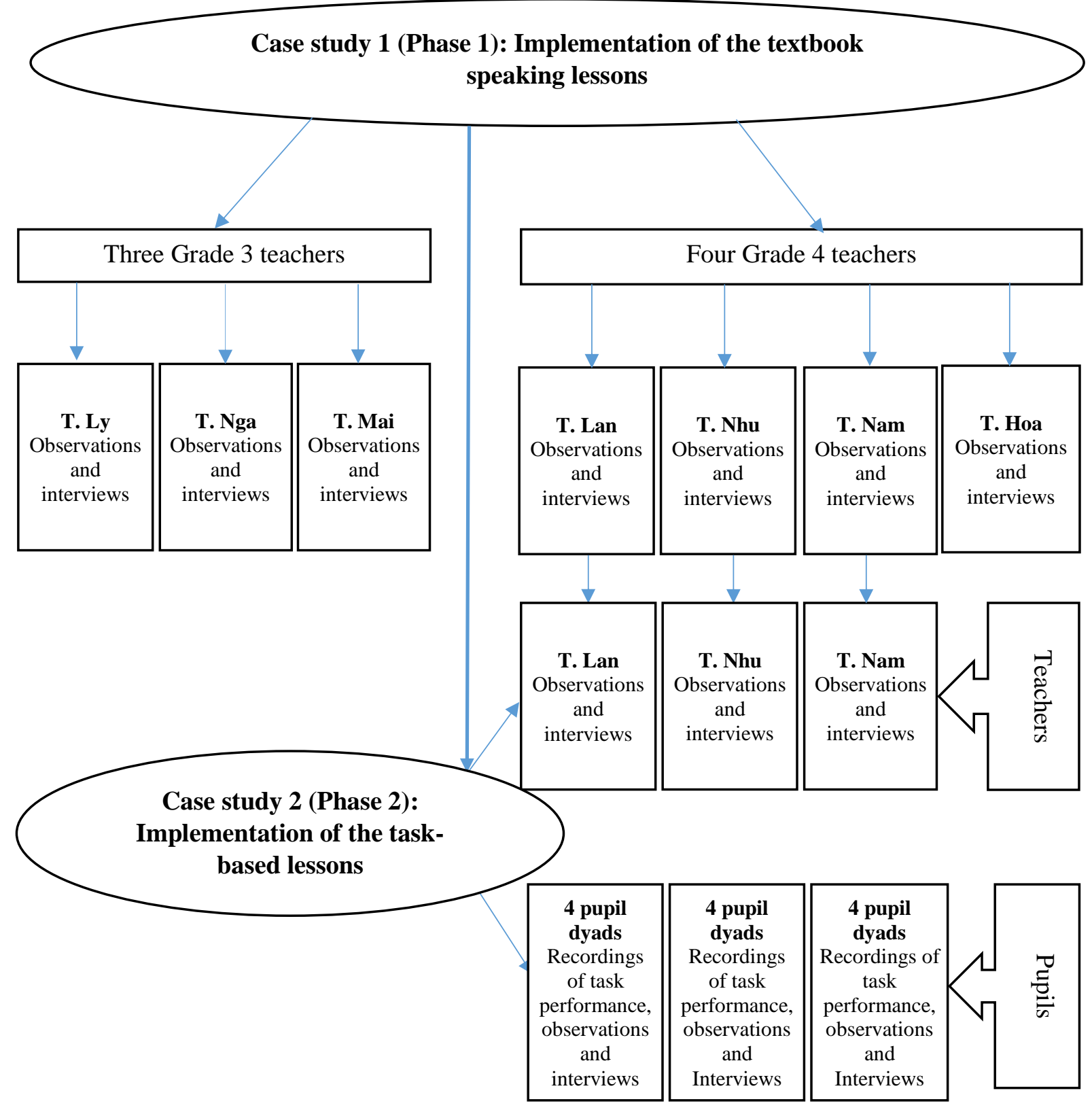




\subsection{Research setting}

This section provides information about the setting where the study was situated. It describes the context of the study, the procedures of approaching the research site, the teacher and pupil participants, and the ethical considerations for the study.

\subsubsection{Context of the study}

The study took place in An Giang province in the Mekong Delta in Vietnam. An Giang province, located approximately $200 \mathrm{~km}$ south of Ho Chi Minh city, is one of the largest and most populous provinces in the South of Vietnam. An Giang is also one of the provinces in the Mekong delta region that is committed to implementing the new curriculum and using the prescribed textbooks. Therefore, investigating the implementation of the new speaking textbook lessons and the task-based versions of the lessons provides insights into how to support the mandated 2008-2020 national foreign languages project and to enhance the quality of education in the region.

The study involved six public primary schools across An Giang province, of which all were selected to implement the new primary English curriculum between 2013-2014. The schools were chosen because they had sufficient facilities (i.e., classroom spaces) and enough teachers who had obtained a B2 or above CEFR certificate. Three of the schools were located in a rural area, two in a semi-rural area and one in the city. Although the schools varied in location, most schools were well-equipped with a special room for teaching English. Such a facility is provided to schools which implement the new curriculum. The room had either an interactive whiteboard or a television which was provided to facilitate the implementation of the new curriculum and accompanying textbooks. Although there was little variation in terms of school facilities and teacher resourcing across the schools, there was variation in terms of pupils' proficiency level. Generally speaking, pupils from the rural schools were less proficient than those in the semi-rural schools and pupils in the urban schools were more proficient again. The main reason for the differences was differences in access to English and private English classes. Despite this, studying these schools enabled a fuller understanding of the implementation of the textbook lessons and the task-based versions of the lessons.

\subsubsection{Gaining access}

After obtaining ethics approval from Human Ethics Committee, Victoria University of Wellington, I began recruiting participants for Phase 1 of the study. First, I approached the 
Head of the Primary English Program in the Department of Education and Training of An Giang province to ask for permission and information about the schools which were implementing the new curriculum across the province. I also asked for information from my colleagues and former students. Gaining support from these people was important because at the time of my study, the number of teachers who were qualified as implementers of the new curriculum and accompanying textbooks was small. Through recommendations from those contacts, I identified a list of teachers who met the recruitment criteria. After considering the grade levels and geographical diversity, I identified a sample of eight teachers ranging in contexts from urban to rural schools and grade levels from Grade 3 to Grade 4. At the time of data collection, the first semester of the academic year-2015, the textbooks for Grades 3 and 4 were being used after two years of piloting and revising. The textbooks for Grade 5 were being revised, so Grade 5 teachers and textbooks were not included in the study.

I started recruitment of participants by making an appointment with each teacher at their convenience. Of the eight teachers I met, seven agreed to participate in my research after being informed in detail about its purpose and procedures. The participants connected me with their managers (i.e. principal or vice-principal) so that I could inform them about my research and ask for their permission to conduct my observations and interviews with their staff regarding their implementation of the textbook lessons. Once permission had been given, all teacher participants and school leaders signed a consent form after being informed of their rights and assured of the measures that would be taken to ensure confidentiality of their personal information and of any information they provide (see Appendices 2.2 and 2.4 for consent forms for teachers and school leaders in Phase 1). The teachers helped me send the consent forms to the parents of pupils in their classes. Permission was given by parents of all pupils in all seven classes.

The three Grade 4 teachers helped me inform their managers about changes in Phase 2 of my study. The original consent form was modified and resent to the principal of each of the three schools for approval (see Appendix 4.4 for consent forms for school principals). Changes were made to Phase 2 of the research after I had discussed the possibility for a change with my supervisor and the three teachers who agreed to implement the redesigned versions of the speaking lessons. The change involved replacing an awareness-raising workshop with a session on implementing task-based versions of the speaking lessons. The teachers were also informed that data collection methods in Phase 2 were similar to Phase 1. They were aware that their implementation of the two task-based lessons was to be videoaudio recorded and that they would be invited to be interviewed after each implementation. In 
this sense, no changes were made to their regular schedules except that they used different lesson plans to deliver the normal lessons. All teachers signed the consent forms (see Appendix 4.2 for consent forms for teacher participants in Phase 2).

After the briefing session with each teacher (see Section 3.7.2) in Phase 2, the teachers helped brief their pupils about the purpose of my upcoming observations. The class was informed that the two speaking lessons in the next unit-Unit 8 would be taught in a slightly different way and that the researcher wanted to see how the adapted lessons would work in practice. The teachers then recruited pupil dyads to be recorded and informed their parents of the purpose of recording and interviewing them. Consent letters were sent to the parents of the selected pupils (see Appendix 4.5 for information and consent forms for parents in Phase 2). All parents consented to having their children involved in the study.

\subsubsection{Teacher and pupil participants}

\subsubsection{Teacher participants}

The participant teachers for Phase 1 were selected using a criterion sampling strategy which allows for the identification and selection of information-rich case participants who met the predetermined criteria (Dörnyei, 2007). The key criteria was that the participants had established ways of working with the new textbooks after at least two years of teaching and receiving textbook training. The selection was based on the assumption that the teachers were familiar with the new textbooks and the pedagogical approaches recommended for teaching the textbook lessons. This familiarity enabled them to reflect more easily on the existing textbook lessons and the approach used to teach the lessons, as well as on the task-based approach they would take in Phase 2. 
Table 1. Participant teachers' profiles

\begin{tabular}{cccccccc}
\hline Teachers & Age & $\begin{array}{c}\text { Years of } \\
\text { experience }\end{array}$ & Qualifications & Gender & $\begin{array}{c}\text { School } \\
\text { setting }\end{array}$ & $\begin{array}{c}\text { Grade } \\
\text { Class } \\
\text { size }\end{array}$ \\
\hline Lan & 24 & 3 & BA & F & Urban & 4 & 35 \\
Nga & 26 & 4 & BA & F & Urban & 3 & 38 \\
Nhu & 35 & 12 & BA & F & Semi-rural & 4 & 43 \\
Ly & 36 & 13 & BA & F & Semi-rural & 3 & 27 \\
Hoa & 26 & 5 & BA & F & Rural & 4 & 30 \\
Mai & 26 & 5 & BA & F & Rural & 3 & 26 \\
Nam & 26 & 5 & BA & M & Rural & 4 & 27 \\
\hline
\end{tabular}

Note. $\mathrm{F}=$ Female, $\mathrm{M}=$ Male, $\mathrm{BA}=$ Bachelor of Art

As seen from Table 1, the seven participants were four Grade 4 teachers and three

Grade 3 teachers from six different primary schools in the province. Six out of seven teachers were female. These teachers ranged in age from 24-36 with an average age of 33 years. They had between three and thirteen years of teaching experience. All were qualified and experienced teachers who were university and college graduates with qualifications in English language teaching. The majority of the participants had between three to five years of experience except two teachers who had more than ten years of experience. Importantly, schools were selected to reflect three distinct settings: rural, semi-rural and urban. The classification of the schools was based on my knowledge of the area and criteria ${ }^{4}$ set out by the local division of education and training.

Although the teachers had relatively different teaching situations (types of students, types of school), they had relatively homogenous backgrounds in terms of education, teacher training and previous learning/teaching experience. The selected teachers are representative of the Vietnamese primary EFL teachers who are qualified implementers of the 2008-2020 NFLP project. To be qualified as implementers of the project, they must obtain B2 or above in the CEFR certificate. This certificate can be more easily obtained by younger and more proficient teachers such as the participant teachers in this study. By the time of the study, the teachers had attended textbook training workshops held by textbook writers from the Ministry of Education and Training or the local Department of Training and Education.

\footnotetext{
${ }^{4}$ Schools are labelled as "A", "B" or "C" by the local education authority according to their location. "A" schools are located in the town center while "B" and "C" schools are located on the outskirt of a town or more rural areas, respectively. Generally speaking, pupils from "A" schools come from richer families and have better access to English and private English classes than those from "B" schools and "C" schools.
} 
One of the teachers (Ms Ly) was sent to Malaysia by the 2008-2020 NFLP for a three-month training course.

In Phase 2, all the Grade 4 teachers from Phase 1 (Lan, Nhu, Hoa and Nam) volunteered to implement the task-based lessons. However, given their concurrent teaching schedule and location, I could only arrange for three of these teachers to implement the two task-based lessons in their daily scheduled classes. These three Grade 4 teachers Nam, Nhu and Lan represented three different school contexts: rural, semi-rural and urban. A detailed profile of each of these three teachers is provided in Chapter 6 which documents the implementation of the task-based versions of the two PPP speaking lessons.

\subsubsection{Pupil participants}

Pupil participants were recruited in Phase 2 for the purpose of recording their pair task interaction and collecting their views of their experiences of the lessons. All pupils were nine years of age. There were two reasons for the choice of Grade 4 pupils. At the time of the study they had been learning English following the traditional PPP approach for at least one year starting from Grade 3 (Lan's pupils who were from the urban school had learned English for two years starting from Grade 2 and many had attended private English classes). Therefore, the pupils had limited but sufficient English language skills and knowledge to participate in the study. Furthermore, the nine-year-old pupils were sufficiently mature to reflect on their experiences of the implementation (Pinter, 2005).

Eight pupils in each of the three Grade 4 teachers' classes $(n=24)$ were selected to be recorded in pairs and interviewed in groups. The pupils were selected based on the teacher's rating of their overall proficiency to form four mixed proficiency dyads. The teachers were asked to rate the pupils as having higher or lower proficiency in relation to each other in terms of their overall ability. This pairing was also a way to manage the teachers' concern about their weak pupils' cognitive and proficiency ability to deal with tasks for the first time. In addition, there were differences in the overall proficiency level of pupils in the three settings. Pupils in Lan's class had a higher proficiency level than those in Nhu's and Nam's classes. Lan's pupils were based in the urban area, they had more access to private classes than the others. This difference aside, none of the pupils had experienced using English communicatively and spontaneously without preparation or rehearsal in the classroom prior to the implementation of the two task-based lessons. 


\subsubsection{Ethical considerations}

The study received ethical approval from the Victoria University of Wellington Human Research Ethics Committee (No. 22154) (see Appendix 1). I also sought the permission of the Head of the Primary English Program in the local Department of Education and Training before conducting the research at the schools. This research followed ethical guidelines set up by the university, ensuring that the research was conducted ethically and sensitively throughout the research process. These included the participants' informed consent, voluntary participation and withdrawal, and identity protection.

First, informed consent is necessary to ensure that the participants are voluntarily participating in the research and that they feel comfortable to participate (Johnson \& Christensen, 2014). In this study, the teachers, school leaders, and parents of the participant pupils received detailed information about the research (see Appendices 2.1, 2.3, 2.5 for information sheets for Phase 1 and Appendices 4.1, 4.3, 4.5 for Phase 2). The information includes the purpose of the study, methods, possible outcomes, and how the results might be used (Hesse-Biber, 2017). All teacher participants knew that their agreement to participate was completely voluntary and that they had a right to withdraw from the research at any stage. Additionally, all participants were informed about the degree of confidentiality afforded to them once they participated. In this study, the teachers were assured that their identities would not be revealed at any stage and in any reports of the research findings. In Phase 1, the parents who provided consent to allow their children to participate were informed that although the focus of the video recordings was on the teachers, their children were likely to be seen (see Appendix 2.5 for information and consent forms for parents in Phase 1). If they did not want their children's images to be captured, the images would be deleted. In Phase 2, the parents were also assured that the audio recordings of their children's interaction in the classroom and of their views expressed in the interviews were kept confidential (see Appendix 4.3 for information and consent forms for parents in Phase 2).

Finally, the study carefully considered protecting the identity of the schools, teachers and pupils. Identifiers such as names of the participants and their schools were protected from being identified through the use of pseudonyms in the reporting of the findings. The teachers clearly understood that any information relating to their views on the textbook lessons and the approach they used would be kept confidential between me and my supervisors. During the interviews, I encouraged the pupils to express their views freely after confirming with them that that their names would not be revealed. Ensuring the confidentiality of the data and the participants' identities reduced possible negative impacts on the participants (Dörnyei, 2007). 


\subsection{Preliminary data collection procedures}

This section first provides an overview and timeline of both Phases of the study. It then describes some preliminary data collection procedures for the two Phases.

Overview and timeline of the two phases of the study

The research commenced at the beginning of September, 2015. Table 2 details preliminary and main data collection procedures and timelines from the start to completion of the research. Phase 1 data were collected over a three-month period from September $9^{\text {th }}$ to November $15^{\text {th }}, 2015$. Phase 2 data were collected over a five-week period from late November, 2015 to early January, 2016. To prepare for the main data collection, some preliminary activities were conducted. Details regarding these preliminary activities are presented in the following sections.

Table 2. Overview and timeline of the research

\begin{tabular}{|c|c|}
\hline Activity & Timeline \\
\hline \multicolumn{2}{|l|}{ Phase 1} \\
\hline 1. Granted ethics approval to conduct research & July 29,2015 \\
\hline $\begin{array}{l}\text { 2. Prepared research instruments and selected teacher } \\
\text { participants. }\end{array}$ & August 2015 \\
\hline 3. Met with the participants and piloted the instruments & September 2015 \\
\hline 4. Collected the data & $\begin{array}{l}\text { September } 9 \text { - November } 15 \text {, } \\
2015\end{array}$ \\
\hline \multicolumn{2}{|l|}{ Phase 2} \\
\hline 5. Redesigned the two PPP speaking lessons & October 2015 \\
\hline 6. Piloted the lessons & November 2015 \\
\hline 7. Briefed the teachers and selected pupil participants & November 2015 \\
\hline 8. Collected the data & $\begin{array}{l}\text { Late November, } 2015 \text { - early } \\
\text { January, } 2016\end{array}$ \\
\hline
\end{tabular}




\subsubsection{Phase 1 study}

Phase 1 of the study investigated the implementation of the PPP textbook lessons. This involved observations and interviews with three Grade 3 teachers and four Grade 4 teachers. One preliminary activity conducted before collecting the data was to pilot the observation and interview instruments.

\section{Piloting the instruments}

As soon as I had obtained permission, I visited the schools to pilot the instruments I was planning to use for the data collection. With permission, I first observed one teaching period in one of the participant teacher's classes during her normal teaching schedule. A stimulated recall interview was piloted after this. This pilot interview helped me modify the interview questions and learn how to probe appropriately and effectively during the interviews (Patton, 2015). I also piloted observations in the other four teachers' classes within one to three days before my actual observation in their classes. This familiarised the teachers and pupils with the equipment and helped them become familiar with my non-participant presence in the classroom (Mackey \& Gass, 2005; McDonough \& McDonough, 1997). During each class period, a camera was placed in a corner to familiarise pupils with its presence without doing any recording. Two of the teachers did not want this pilot observation. The reason is, as these teachers explained, being observed was familiar to them and their pupils. They were used to having observers (mostly student teachers) in their classes.

\subsubsection{Phase 2 study}

Phase 2 of the study involved three preparatory steps: (1) redesigning the two PPP speaking lessons; (2) piloting the task-based version of the lessons; and (3) briefing the teachers. These preliminary steps are explained below.

\section{Redesigning the PPP speaking lessons}

As soon as the teachers agreed to implement the task-based lessons, I redesigned the two PPP speaking lessons in Unit 8 in the Grade 4 textbook (see Appendix 7 for the textbook lessons). The lessons were then implemented by the three Grade 4 teachers in their normally scheduled classrooms. Details of the redesign are provided in Chapter 5. In this chapter I explain how I reflected on the results of my Phase 1 study, how I adapted Willis' (1996) 
framework for redesigning the two PPP speaking lessons and how I addressed the task demands to suit the proficiency and cognitive levels of the pupils.

\section{Piloting the two task-based lessons}

This piloting was carried out with the hope that experiences learned from piloting the task-based lessons would help me, as the lesson designer, modify the lessons before having them used for data collection. Due to time and availability issues, the two task-based lessons were not piloted in real classrooms, but in an English class at a private English language centre. The piloting was carried out on two consecutive days with support of a teacher and 10 primary school pupils. Since the lessons could not be piloted in a "real" mainstream class, the purpose of this piloting was limited to examining how the instructions might work and how pupils of similar age and proficiency level might react to the redesigned lessons. The teacher of this class and I co-taught the lessons according to the lesson plans I designed. Both lessons worked well in practice.

Two main issues were identified in this piloting. First, it was important to make sure the instructions were clearly given (ideally in Vietnamese). Following this, the teachers needed to double check their pupils' understanding of task instructions prior to the start of each task performance. Second, the pilot also allowed me to measure the time needed for completing the tasks. I found that the normal 45-minute lesson may need to be extended because giving and checking task instructions took time. Finally, I piloted the interview questions with the teacher and five pupils in this class and then further refined the questions as a result of this process. During the piloting, I also discovered that it was important for teachers to explain to the pupils that when they share information with each other in the information gap task, they should do so by starting with the information in the left column and move progressively to the right. After the piloting, I wrote down the instructions for the teachers to try them out during the rehearsal.

\section{Briefing the teachers}

Prior to the implementation of the task-based lessons, I made an appointment with each individual teacher to further discuss the lesson plans (the lessons plans had received some initial comments from the teachers before the briefing). Each briefing session lasted roughly 90 minutes. At the briefing, I talked through the lesson plans with the teachers and invited them to identify the differences and similarities between the redesigned lessons and 
their original PPP versions. This helped the teachers better understand what TBLT is like and what differences exist between a PPP lesson and the task-based version of the lesson. For example, unlike the PPP versions, in TBLT the target structural patterns were not taught prior to the performance of the main tasks but delayed until after the main tasks. This aimed to encourage pupils to make use of their own language resources for the performance of the main task and to focus their attention on using English to communicate their meaning. Through this discussion and the identification of similarities and differences between the PPP and TBLT, the teachers were made aware of the fact that they were promoting meaningfocused language use through communicative tasks.

After the principles behind the design of the task-based lessons were made clear to the teachers, I talked them through the role of the teacher in a TBLT classroom. I also told them that activities in the pre- and post-task phases could be adjusted in a way that suited their pupils' ability and interests. The teachers were also invited to anticipate difficulties that might arise during the implementation. They expressed concerns over the ability of the weaker pupils to perform the main tasks, though they were positive about their pupils' overall ability. This was sorted out when I suggested that more capable and less capable peers be paired up. Each teacher then helped select eight pairs of pupils to be recorded on the basis of his or her rating. The teachers also helped brief the pupil participants about the purpose of recording and ways to ensure the quality of the recordings.

I learned from the piloting that giving clear instructions was critically important. Therefore, during this briefing session, I helped the teachers rehearse giving task instructions until they were confident. The rehearsal also aimed to familiarize the teachers with setting up the tasks. After the rehearsal, the teachers also realised that they needed to double check their pupils' understanding of task instructions and be prepared to extend a normal teaching period if necessary.

Finally, I discussed with the teachers some classroom issues related to the implementation such as discipline tensions, use of mother tongue and target language production that had been reported in the literature (e.g., Carless, 2002, 2003, 2004). The teachers were aware that these issues were reported as constraining factors in TBLT implementation. The teachers and I also discussed measures to ensure that the task-based lessons could function as normal lessons. We agreed that the teachers could interact with their pupils and assist them as they would in other lessons. However, to maintain a greater level of learner autonomy during their task performance, the teachers were asked to encourage pupils to draw on their own resources, rather than always provide target structures. 
All revised lesson plans and task materials (picture cards and handouts) were given to the teachers for their review and preparation before the lessons.

\subsection{Data collection methods (Phases 1 and 2)}

As discussed in Section 3.3, this study adopted a qualitative case study approach as the most appropriate methodology. Within this approach, data for both phases of the study were collected through multiple methods including classroom observations, interviews, and recording of pupil pair interaction. The following sections will describe in detail the methods used to collect data for both phases of the study.

\subsubsection{Classroom observation}

Observations are a primary way "to gather first hand, 'live' data in situ from naturally occurring social situations (Cohen, Manion, \& Morrison, 2017, p. 542, original italics). Observation in teacher cognition research is valuable because it "provides evidence of what happens in classrooms" (Borg, 2006, p. 247). The combined analysis of observation and interview data allows for "a holistic interpretation of the phenomenon being investigated" (Merriam \& Tisdell, 2016, p. 161), which for the current study, facilitated a deep understanding of the implementation process of the speaking lessons and the task-based versions of the lessons.

Table 3. Classroom observation scheme in Phase 1

\begin{tabular}{|c|c|c|c|c|}
\hline \multicolumn{2}{|c|}{ Teacher } & Textbook unit & Lesson & Teaching periods \\
\hline \multirow{3}{*}{ Grade 3} & Ly & Unit 2: What's your name? & Lessons 2,3 & 4 (1 speaking period) \\
\hline & Mai & Unit 4: How old are you? & Lessons 2,3 & 4 (1 speaking period) \\
\hline & Nga & Unit 5: Are they your friends? & Lessons 2,3 & 4 (1 speaking period) \\
\hline \multirow{4}{*}{ Grade 4} & Nhu & Unit 4: When's your birthday? & Lessons $1,2,3$ & 6 (2 speaking periods) \\
\hline & Hoa & Unit 5: Can you swim? & Lessons $1,2,3$ & 6 (2 speaking periods) \\
\hline & Lan & Unit 6: Where's your school? & Lessons $1,2,3$ & 6 (2 speaking periods) \\
\hline & Nam & Unit 7: What is he doing? & Lessons $1,2,3$ & 6 (2 speaking periods) \\
\hline Total & 7 & 7 & 18 & 36 (11 speaking periods) \\
\hline
\end{tabular}

Observations were conducted in both phases of the study. In Phase 1, the seven teachers (three Grade 3 teachers and four Grade 4 teachers) were asked to teach as they normally did. Table 3 above shows the observation scheme in Phase 1. Each of the four Grade 
4 teachers was observed across the three lessons that make up a whole textbook unit while each of the three Grade 3 teachers was observed across the last two lessons in a unit. This method permitted me to observe each classroom over an extended period and to observe lessons on different topics, which enabled me to develop a well-rounded impression of how the textbook lessons were implemented. Each textbook lesson was divided into two teaching periods (35 minutes for Grade 3 and 40 minutes for Grade 4). Depending on scheduling constraints, these periods were typically taught on separate days. However, for some classes, they were taught together as a single, two-period lesson. I observed a greater number of lessons taught by Grade 4 teachers to obtain a fuller picture of teachers carrying out the teaching of a whole unit and to learn more about the pupils who were participating in Phase 2 of the study.

The first period in Lessons 1 and 2 was designed to teach speaking skills while the second period in each of these lessons and the two periods in Lesson 3 were designed to teach integrated skills. In total, data were collected from 36 complete teaching periods within which there were 11 speaking periods (one from each of the three Grade 3 teachers and two from each of the four Grade 4 teachers) (see Table 3). Although the focus of the research was on the speaking periods, the integrated skill periods which followed each speaking period was also observed. This additional data was collected to understand the progression over a whole textbook unit. When the teachers planned their teaching, they thought of a teaching period as a lesson, even though the textbook is designed for one lesson to be taught across two periods. Following the teachers' practice of lesson planning, this study treats each teaching period as a lesson. Therefore, the two speaking periods are called the two speaking lessons. The taskbased versions of the two speaking lessons taught by each of the three Grade 4 teachers were observed, making a total of six lessons. The observation was conducted over a three-week period as seen in Table 4.

Table 4. Classroom observation scheme in Phase 2

\begin{tabular}{cccc}
\hline & Nam's class & Nhu's class & Lan's class \\
\hline Week 1 & Lesson 1 & & \\
\hline Week 2 & Lesson 2 & Lesson 1 & Lesson 1 \\
\hline Week 3 & & Lesson 2 & Lesson 2 \\
\hline
\end{tabular}


The observations for this study were unstructured and non-participant (Cohen et al., 2017). In all observations, I identified myself as an observer who did not participate in any class activities and remained solely in the role of the researcher (Hesse-Biber, 2017). Observation data were obtained by means of field notes and video-audio recordings taken during the normally scheduled lessons. These data sources acted as a basis for triangulation and for subsequent stimulated recall interviews (Borg, 2006).

\subsubsection{Video-audio recordings}

All speaking lessons and the task-based versions of the lessons were video-audio recorded because video data can provide "completeness of analysis and comprehensiveness of material" (Cohen et al., 2017, p.542). Video-audio recordings thus allowed me to repeatedly view the completely recorded lessons to document the moment-by-moment process of how each PPP speaking lesson and the task-based version of the lesson was implemented in the classrooms.

As detailed in Section 3.5.1, I piloted data collection prior to the main study to help pupils become accustomed to the presence of both the observer and the video camera (Mackey \& Gass, 2005). However, to further lessen the impact of these factors, on each observation day in both phases, I came to the class a little bit before the pupils. I placed the camera at the back or in a corner of the room and switched it on before the pupils arrived (Richards, 2003). I set the camera in close-up focus to catch the teachers' actions and to minimise the number of pupils being captured. In all observations, I was offered a seat in the back or off to the corner next to the video camera to be minimally intrusive. My presence and the camera attracted pupils' attention initially, but were quickly ignored when the teacher entered and the lesson proceeded. During each observation, the camera recorder with both video and audio recording functions was backed up with the audio recorder from a cell phone. Care was taken to ensure that recording was as unobtrusive as possible.

In Phase 2, apart from observing the classroom interaction as a whole, I also audiorecorded four pairs of pupils in each of the three classes while they were completing the main task in each of the two task-based lessons. Up to 14 minutes was allowed for the completion of each task, though most dyads completed the tasks within 9-12 minutes. Recording naturalistic classroom interaction requires strategies to minimise distractions (Richards, 2003). In each observation, care was taken to limit the distraction before and during the recording of pupils interacting in pairs. The participant dyads were spaced at the front of the room or down in a corner to minimise distraction across pairs and the possibility of the 
recorder picking talk from adjacent pairs. Each dyad was audio-recorded using individual high quality digital audio-recorders. The recorder was placed in the middle of the two pupils to pick up the voices of both as well as the interaction with the teacher if any. All recorded interactions were not affected by the noise of crowds or the passing traffic outside the classroom.

Due to time constraints, I was not able to familiarise the pupils with the recording of their interaction before the actual recording. In this situation, the possibility that the pupils might have performed better than usual seemed unavoidable. However, I noticed that there was little difference between the recorded pupils and the rest of the class. Most pupils were equally focused on completing the tasks. The recorded pupils seemed to ignore the recorder as soon as they were engaged in performing the tasks. Therefore, I believe that task engagement minimised both the Halo effect (Mackey \& Gass, 2005) and the intrusive effect of the recorder.

\subsubsection{Field notes}

Patton (2015) advises that field notes are significant for future recall of any particular details of the situation. He adds that descriptive notes not only allow the researcher an opportunity to look back at their classroom observation for the analysis and but also provide the reader an experience of how the activity took place during the observed lessons. Moreover, field notes allow the researcher to include reflective comments regarding their own feelings, reactions and initial interpretations (Merriam \& Tisdell, 2016; Patton, 2015). In reflecting on these comments, the researcher is "actually engaging in some preliminary data analysis" (Merriam \& Tisdell, 2016, p.152).

In both phases of the study, my field notes focused on recording and describing what occurred. In Phase 1, I took notes about the lesson sequence as well as instances when the teacher made changes to the lesson. For example, during a speaking lesson, I took notes about the steps the teacher carried out. I briefly described how the teacher started, carried on and finished a lesson. If the teacher added a new activity or changed an existing activity, I briefly described the activity, commented on it and wrote a question about it. In Phase 2, I noted any changes the teachers made to the lesson plans of the task-based lessons. The purpose of my observations was to understand the reasons why the teachers needed to make the changes and noted questions to ask the teachers in the interview. Furthermore, I took notes of the pupils' reactions and gave occasional comments. The notes enabled me to evaluate the task-based 
lessons through observing how they worked and if they served the purposes for which they had been implemented.

Due to ethical issues, the video-recording did not fully capture the interactions between the teacher and pupils and among the pupils themselves, and the learning performance the pupils displayed. Therefore, I was committed to taking detailed and careful notes on the classroom interaction during each observation. I also carefully noted pupils' feelings and reactions as well as my own feelings and reflections. After each observation, I wrote a brief summary capturing my reflections, tentative themes and questions to ask for clarification. While taking field notes and reflecting on them, I came up with insights, ideas and interpretations of what I observed and experienced (Patton, 2015). I used the notes and associated samples of video recordings to frame questions to ask the teachers about their pedagogical choices and to have them explain their rationale for any changes or adaptation they made to the textbook lessons and the task-based versions of the lessons.

\subsubsection{Interviews}

Interviews are useful because "if we want to understand what people do, we need to know what they think" (Nunan \& Baily, 2009, p.284). Combined with observations, interviews allow the researcher to "understand the meaning that everyday activity holds for people" (Marshall \& Rossman, 2006, p. 102). In this study, stimulated recall and follow-up, in-depth interviews were conducted with each individual teacher in Phases 1 and 2.

Group interviews were also conducted with pupils after the implementation of each taskbased lesson in Phase 2. The format of the interviews with teachers and pupils were semistructured in design, which allows me to "respond to the situation at hand, to the emerging worldview of the respondent, and to new ideas on the topic" (Merriam \& Tisdell, 2016, p. 111). Moreover, this format enabled similar interview questions to be used with each participant (McKay, 2006), which facilitated the quantification of the data. All interviews were audio recorded and conducted in Vietnamese.

\subsubsection{Stimulated recall and in-depth interviews with teachers}

Stimulated recall has been widely used in teacher cognition research. This technique enables the teacher to reflect on their beliefs and theories in relation to their practice (Borg, 2006). It also enables the researcher to obtain insights into immediate processes of learning and teaching from the perspectives of the lesson participants without interrupting the lessons in progress (Nunan \& Bailey, 2009). Moreover, data collected from stimulated recalls can 
provide "a valuable source of information for researchers interested in viewing a finely detailed picture of the classroom" (Mackey \& Gass, 2005, p. 203).

Shortly after each observed lesson in Phase 1, stimulated recall interviews were carried out following the guidelines suggested by Borg (2006) and Gass and Mackey (2000). The aim of using stimulated recall was to provide the teachers with the opportunity to elaborate on their actions and glean their rationales regarding particular aspects of their teaching. At each interview, I presented the teacher with recording samples of the videoed lessons. While viewing, I invited the teacher to describe what he/she was doing, what he/she was thinking, and why he/she was doing the way he/she did. I also relied on my field notes to prompt the teachers to elaborate on the actions they took and the decisions they made in the lessons.

All but two of the interviews were conducted immediately after each lesson (two interviews were conducted in the afternoon). This was done to help ease the teachers' recollection of their thought processes (Nunan \& Bailey, 2009) and enhance the reliability of the data (Ecrisson \& Simon, 1984). In Phase 1, each Grade 4 teacher participated in six stimulated recall interview sessions with two sessions after each of the two speaking lessons. Each Grade 3 teacher participated in four sessions with one session after the speaking Lesson 2. A total of 30 stimulated recall sessions were audio recorded, ranging from 20-30 minutes in length. Nine of these sessions (one with each Grade 3 teacher and two with each Grade 4 teacher) conducted on the PPP speaking lessons were used for the analysis.

In-depth interviews are issue-oriented (Hesser-Biber, 2017, p. 107, original italics), meaning that the researcher focuses on and tries to gain further information about particular topics of interest. In this study, follow-up in-depth interviews were carried out to further seek the teachers' elaboration and explanation on the issues identified in the earlier stimulated recall interviews. In Phase 1, the interviews centred around the issues of why the teachers used the approach and how they viewed this approach. Six of the seven interview sessions took place in the staff room or classrooms within one to three days after the simulated recall interviews. One interview was conducted over the telephone due to teacher availability. Each interview lasted between 40-50 minutes depending on the availability of each teacher. All the interviews were audio recorded, transcribed in full and coded.

In Phase 2, stimulated recall and follow-up, in-depth interviews were combined in one session with each individual teacher. A partial form of stimulated recall was utilized mainly to facilitate the discussion of specific changes the teachers made to the lesson plans and the rationales for the changes. I learned from Phase 1 data collection that if I took careful and 
comprehensive notes on the changes, I could use the notes to stimulate the teachers' recall of specific points in a lesson. Indeed, the notes worked as effectively as video-recordings. I presented the teachers with my field notes which described in detail how a particular change was made to the lesson plans. By comparing the notes with the lesson plans, the teachers were able to recall the changes they made easily. The teachers were then invited to comment on their thinking, decision-making and rationales at a specific point of change. The stimulated recalls were conducted briefly leaving sufficient time for the follow-up in-depth interviews. These interviews explored more in-depth information regarding the teachers' opinions of the learning processes in the task-based lessons compared with the PPP lessons and their concerns of implementing the task-based lessons. For the purpose of the study, the interviews are referred to as interview 1 (after Lesson 1) and interview 2 (after Lesson 2)

The stimulated recall interviews took place either on the same day or the following day after each task-based lesson had been implemented. One interview took place three days after the observation of the task-based lesson 2 due to teacher availability. Each interview session in this Phase 2 lasted 30-45 minutes and was conducted at the teacher's convenience in the staff rooms or in the classrooms. During the interviews, I tried to maintain a neutral rapport with the teachers (Merriam \& Tisdell, 2016; Patton, 2015). The teachers understood that their knowledge, experience, attitudes and feelings were important for my research and that I would not judge them for the content of what they said to me. Throughout the two interviews, the teachers reported consistent patterns of views of the learning processes in the task-based lessons. In this interview conducted after Lesson 2, the teachers were asked to express their concerns about implementing the task-based lessons. All interviews were taped, transcribed and returned for verification. I myself transcribed all interview data verbatim to deeply immerse myself in the data.

\subsubsection{Group interviews with pupils in Phase 2}

Interviewing young children, such as the nine-year old primary school EFL learners in this study, can be challenging. In order to address this challenge, group interviews were conducted because children are likely to feel more comfortable with their peers in a group rather than an individual interview (Cohen et al., 2017). The questions for the pupils' group interview centred on the three main issues: their general impressions of the lessons, comments on the activities they liked best, and any difficulties that they experienced when doing the tasks. The semi-structured pupil group interviews helped to obtain in-depth information regarding pupils' views of their experiences of learning English. The interviews were carried 
out in Vietnamese, the participants' mother tongue. The selected quotes were later translated into English. These quotes were then double-checked for the accuracy of transcriptions and translations by a Vietnamese EFL teacher before analysis.

A group of eight pupils in each class were interviewed after each task-based lesson. The length of the interviews varied from 15 to 18 minutes. All interviews were conducted in Vietnamese. The two interviews with Nhu's pupils were conducted right after the lessons in an additional staff room during the break time. The interviews with Lan's pupils were conducted in the afternoon in the staff room during the class time. These interviews were supported by the form teacher who allowed the pupils to be absent for a while for the interviews. Due to time constraints and a busy class schedule, Nam's pupils were interviewed once after Lesson 2 in a free classroom during the class time.

I took the role of a moderator or facilitator, there to invite and facilitate talk. I probed for opinions from all the pupils in the group. At each interview session, I showed the pupils the task materials to remind them of what happened during the lessons. At the same time, I invited them to identify the differences they found in the task-based lessons compared to the normal ones. After asking pupils about their general impression of the lessons, I went through the activities from the lessons and asked pupils to indicate the activities they liked best or the ones they did not like. For each response, I continued probing for the answers about the reasons. I avoided asking "Why" questions as advised by Patton (2015) because this question might pose difficulty for the respondents or push the respondents to respond with any random possibilities that came to their mind. Instead of asking "Why do you like this activity?" (Tai sao con thich hoạt động này?), I asked "What was it about the activity that interested you? "(Con thích hoạt động này ở điểm nào?). Sometimes, the pupils did not wait for me to probe them with this question, they automatically included the reasons in the answers. In this situation, I encouraged them to give the answer with prompts such as "You like this activity because..." (Con thích hoạt động này là vì...) or "You do not like this activity because..." (Con không thích hoạt động này là vì ...). For each question, I did not press for the answer or force pupils to give the answers. The pupils understood that they did not need to agree with their friends and that they were free to tell what they experienced and perceived. All interviews were audio-recorded and transcribed in-full. Each interview was supported by careful notes written immediately afterwards. The notes enabled me to identify the pupils when I transcribed the interviews and detect the frequency of the answers more easily. Transcription was also conducted early after each interview in order to ease the recall of the identities of the pupils. 
My presence in the classroom throughout Phases 1 and 2 helped the pupils feel relaxed and confident during the interviews in this Phase 2. It also helped me understand the participant pupils better, which in turn facilitated my analysis of their performance of the main tasks. Aware of the possibility that some higher proficiency pupils might dominate the interviews, I encouraged each individual pupil to respond. For example, I first encouraged each pupil to indicate their favourite activity after I went through all activities in each lesson and then encouraged him/her to explain the reason behind his/her choice. However, some of the lower proficiency pupils found it hard to explain why they preferred a certain activity although they were able to indicate the activities they liked. Therefore, they tended to rely on their stronger peers for the answers. In particular, the pupils from the rural school (Nam's pupils) were least able to express themselves clearly. Therefore, I tried to probe their answers and then wrote a summary based on my interpretation of the answers. Nonetheless, many stronger pupils, especially those in the semi-rural and urban groups (Nhu's and Lan's pupils) contributed several interesting insights about the task-based lessons and their English learning experiences in general.

\subsubsection{Summary of data collection for Phases 1 and 2}

The data collection methods for Phases 1 and 2 are summarised in Table 5 below. 
Table 5. Summary of data collection for Phases 1 and 2

\begin{tabular}{|c|c|c|c|c|}
\hline & Methods & Participants & Time & $\begin{array}{c}\text { Number of } \\
\text { sessions }\end{array}$ \\
\hline \multirow{6}{*}{ 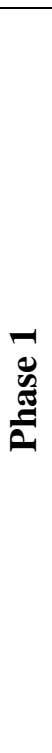 } & \multirow{2}{*}{$\begin{array}{l}\text { Classroom } \\
\text { observations }\end{array}$} & 3 teachers from Grade 3 & 35 minutes/lesson & $\begin{array}{c}12 \text { sessions, } 4 \text { per } \\
\text { teacher }\end{array}$ \\
\hline & & 4 teachers from Grade 4 & 40 minutes/lesson & $\begin{array}{c}24 \text { sessions, } 6 \text { per } \\
\text { teacher }\end{array}$ \\
\hline & \multirow{2}{*}{$\begin{array}{l}\text { Stimulated recall } \\
\text { interviews }\end{array}$} & 3 teachers from Grade 3 & \multirow{2}{*}{$\begin{array}{l}\text { 20-30 minutes/ } \\
\text { session }\end{array}$} & 10 sessions \\
\hline & & 4 teachers from Grade 4 & & 20 sessions \\
\hline & \multirow{2}{*}{$\begin{array}{l}\text { Follow-up } \\
\text { interviews }\end{array}$} & 3 teachers from Grade 3 & \multirow{2}{*}{$\begin{array}{c}40-50 \\
\text { minutes/session }\end{array}$} & $\begin{array}{c}3 \text { sessions , } 1 \text { per } \\
\text { teacher }\end{array}$ \\
\hline & & 4 teachers from Grade 4 & & $\begin{array}{c}4 \text { sessions, } 1 \text { per } \\
\text { teacher }\end{array}$ \\
\hline \multirow{4}{*}{ 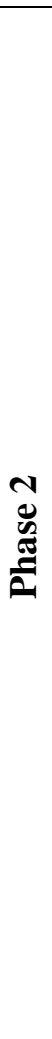 } & $\begin{array}{l}\text { Classroom } \\
\text { observations }\end{array}$ & 3 Grade 4 teachers & 40 minutes/lesson & $\begin{array}{c}6 \text { sessions, } 2 \text { per } \\
\text { teacher }\end{array}$ \\
\hline & $\begin{array}{l}\text { Audio-recordings } \\
\text { of pupil } \\
\text { interactions }\end{array}$ & 4 dyads per class & $\begin{array}{c}9 \text { to } 12 \\
\text { minutes/dyad }\end{array}$ & 24 audio-recordings \\
\hline & $\begin{array}{c}\text { Teacher } \\
\text { interviews } \\
\text { (stimulated recalls } \\
\text { and in-depth } \\
\text { interviews } \\
\text { combined) }\end{array}$ & 3 Grade 4 teachers & $30-45$ minutes & $\begin{array}{c}12 \text { sessions, } 2 \text { per } \\
\text { teacher }\end{array}$ \\
\hline & Pupil interviews & $\begin{array}{l}8 \text { pupils } \\
\text { per class }\end{array}$ & $15-18$ minutes & $\begin{array}{l}5 \text { sessions, ( } 2 \text { per } \\
\text { each semi-rural and } \\
\text { urban class, but } 1 \\
\text { session for pupils in } \\
\text { the rural class) }\end{array}$ \\
\hline
\end{tabular}




\subsection{Data analysis (Phases 1 and 2)}

Qualitative content analysis was employed in both phases of the study to establish patterns or themes in the observation and interview data. This involved an iterative, cyclical and inductive process (Dörnyei, 2007). Generally, for the analysis of most data sets I followed the six steps proposed by Merriam and Tisdell (2016, pp.207-208) as follows:

1) I reviewed the purpose of the study as well as the research questions and asked myself what I am trying to find out.

2) Guided by my interpretive paradigmatic stance, I looked through the lens of how different participants “construct knowledge or make meaning” (p.208).

3) I conducted open coding in which I captured any data with words or phrases that respond to or were associated with my research questions. I focused on patterns and insights related to my study's purpose and the research questions.

4) After I had obtained the initial codes, I stepped back from the data and asked myself: What were the main themes that emerged? What were the answers to my research questions?

5) Next, I went back to the initial codes to decide whether what I thought the themes were, was supported by the initial codes.

6) I developed patterns and themes using "the constant comparative method" and "combined the codes from open coding above, into fewer, more comprehensive categories" (p.208).

Following Merriam and Tisdell's advice, I went back and forth repeatedly between steps 4 and 5 and steps 5 and 6 . After the initial coding, I stepped away from the data to consider the extent to which my existing beliefs and experiences might affect my interpretation of the data. This enabled me to recognise and minimise both researcher and participant biases when I revisited the initial coding. Finally, in this study, I used quantification to detect and report patterns in the data sets. For example, I quantified some of the major qualitative themes generated from participants' in-depth interviews. Quantification of qualitative data adds greater accuracy to the findings (Bryman, 2016; Dörnyei, 2007; Mackey \& Gass, 2005).

\subsubsection{Teachers' implementation of the PPP speaking textbook lessons (Phase 1)}

In this phase, data analysis was done in conjunction with data collection since "data that have been analysed while being collected are both parsimonious and illuminating" (Merriam \& Tisdell, 2016, p. 197). I analysed the teachers' implementation of the PPP 
speaking lessons before I completed Phase 1 data collection. The analysis revealed a common pattern of sequencing the speaking lessons among the teachers' practices. Most teachers organised their speaking lessons in three phases: presentation, practice and production. They frequently added communicative and task-like activities to the presentation and production phases. These preliminary results provided ideas and insights for developing a coding system for a starting description of each lesson being implemented.

The main analysis involved "a period of intensive analysis in which tentative findings are substantiated, revised and reconfigured" (Merriam \& Tisdell, 2016, p.204). The data set for this analysis included observation and stimulated recall interview data, which provides the data to address the questions of how the teachers implemented the textbook speaking lessons and how they explained their decisions.

I conducted a three-step analysis of the data. First, I started with the observational data. I did not transcribe the audio-videoed lessons in full; however, I transcribed classroom episodes that typically illustrated ways of implementing the key stages in the lessons. I watched each recorded lesson several times until I had familiarised myself sufficiently with the data. When I watched each recorded lesson, I described exactly what the teacher did at each phase of the lesson. For each activity added or adapted, I briefly noted my comments in the margins. This process resulted in one-page classroom observation summaries pertaining to the research questions and other emerging issues for each of the 11 speaking lessons. Each complete summary was then compared with its field note summary to ensure accuracy of the description. Finally, I conducted initial coding on each complete summary according to what the teacher did in relation to the sequence of the PPP lessons. After working through each entire summary in this manner, I re-examined the codes and noted the frequency of certain practices to find patterns for each teacher, individually, and all the teachers, as a group.

Second, to address how the teachers explained their implementation decisions, I searched for statements of rationales in the stimulated recall interview transcripts. Before this, the interview data were transcribed in full and analysed following the steps proposed by Merriam and Tisdell (2016). I read over each interview transcript to familiarise myself with the data. After the initial coding on each interview transcript, I put together the codes to identify patterns and themes related to rationales in each transcript and all transcripts. This process helped me to identify similarities and differences across the teachers' explanations for their implementation decisions.

Finally, codes assigned to the interview transcripts and classroom observation summaries were pulled together to identify patterns and themes for each teacher and all 
teachers. This enabled me to tabulate a sequence of stages in a PPP speaking lesson, activities embedded in each stage, and the rationales behind each implementation decision. The tabulation was again conducted for each of the teachers. By comparing all tabulations of data across the teachers, I was able to identify the patterns and themes regarding the implementation of the speaking lessons and the rationale behind each implementing decision.

Table 6 below illustrates how I coded the data obtained from one of the observed lessons conducted by one of the teachers (Teacher Nhu).

Table 6. An example of coding of classroom observation and stimulated recall interview data

\begin{tabular}{|c|c|c|c|}
\hline Phase & Description of activity & Code & Rationale code \\
\hline \multirow{3}{*}{ Presentation } & $\begin{array}{l}\text { Teacher teaches new } \\
\text { vocabulary and then has } \\
\text { pupils practice to } \\
\text { memorise the vocabulary }\end{array}$ & $\begin{array}{l}\text { Vocabulary- } \\
\text { based activity }\end{array}$ & $\begin{array}{c}\text { Prepare pupils for the } \\
\text { practice and production } \\
\text { phase }\end{array}$ \\
\hline & $\begin{array}{l}\text { Teacher has pupils listen } \\
\text { to the dialogue three times } \\
\text { and repeat after the } \\
\text { recording or the teacher. }\end{array}$ & $\begin{array}{c}\text { Teacher-led } \\
\text { dialogue practice }\end{array}$ & $\begin{array}{c}\text { Prepare pupils for the } \\
\text { practice and production } \\
\text { phase }\end{array}$ \\
\hline & $\begin{array}{l}\text { Teacher explains the } \\
\text { form, meaning and use of } \\
\text { a grammar structure }\end{array}$ & $\begin{array}{l}\text { Explicit grammar } \\
\text { instructions }\end{array}$ & $\begin{array}{c}\text { Prepare pupils for the } \\
\text { practice and production } \\
\text { phase }\end{array}$ \\
\hline Practice & $\begin{array}{l}\text { Teacher has pupils repeat } \\
\text { the target structures and } \\
\text { vocabulary. Teacher asks, } \\
\text { pupils answer and vice } \\
\text { versa. Pupils ask each } \\
\text { other. }\end{array}$ & $\begin{array}{l}\text { Teacher-led drill } \\
\text { practice }\end{array}$ & $\begin{array}{l}\text { Prepare pupils for the } \\
\text { production phase }\end{array}$ \\
\hline Production & $\begin{array}{l}\text { Teacher engaged pupils in } \\
\text { an interview survey }\end{array}$ & $\begin{array}{c}\text { Communicative } \\
\text { task }\end{array}$ & $\begin{array}{l}\text { More meaningful } \\
\text { language use }\end{array}$ \\
\hline
\end{tabular}

\subsubsection{Teachers' perceptions of the PPP lessons (Phase 1)}

Data for this analysis included in-depth follow up interviews with seven teachers. Each interview lasted approximately 45 minutes. I transcribed all the interviews in their entirety. Care was taken to ensure the "accuracy and subtlety in translation" (Marshall \& 
Rossman, 2006, p.112). The data were then double-checked for the accuracy of transcriptions. After I had decided on what quotes to be included in the report of findings, I translated them into English. The translations were doubled checked by a Vietnamese EFL teacher.

The aim of the in-depth interview data analysis was to further explore the reasons why the teachers chose the PPP approach and how they perceived the effects of PPP lessons on the pupils' learning. Following Merriam and Tisdell (2016), I read over each interview transcript to familiarise myself with the data. As I did so, I circled repeated words/phrases which I felt were potentially relevant for addressing the research questions. I wrote down words, phrases, comments, and notes in the margins. This resulted in a number of initial codes which were then put together to identify patterns and themes. For example, the emerged patterns indicated that the teachers were divided into three different groups in terms of their general attitudes towards PPP: positive, negative or somewhere between.

I used quantification to detect and report patterns. I compared what one teacher said about the approach with another teacher's reported views. By so doing, I was also able to find frequency for a certain pattern of views the teachers held behind the approach. By collating all related codes, I developed themes within a particular pattern of views. For example, in each interview transcript and in all transcripts, I identified the repeated words such as "mechanical", "boring", "theoretical”, which were the participant's actual words and were an important indicator of meaning (Hesse-Biber, 2017). I grouped these vivo codes together to develop a theme regarding the perceptions of the PPP approach from the teachers who are negatively oriented towards PPP.

\subsubsection{Teachers' implementation of the task-based lessons and their evaluation of the lessons (Phase 2)}

Phase 2 involved three teachers each implementing the two task-based lessons. The findings were presented as three individual case teachers. For each case, I pulled together all data sources I had about each teacher, including audio-video recordings, field notes, and stimulated recall and in-depth interview data. Pooling all data for a case helped me identify evidence that may support or disconfirm a particular line of argument.

The analysis involved describing the moment-by-moment implementation of each of the two task-based lessons by each of the three case teachers. Rationales behind each implementation were included in the description followed by the teachers' reflection on the learning processes. Classroom episodes were chosen to illustrate certain ways of 
implementing the lessons or impacts of the implementation on pupil performance of the main tasks. After an individual case analysis, a cross-case analysis was done of issues or themes that arose across the data sets.

I followed the same approach I used for analysing the teachers' implementation of the PPP speaking lessons. I watched each videoed lesson repeatedly until I had a clear picture of each implementation. After that, I described exactly what each individual teacher did at each phase of a lesson. I compared each description with its field note summary to cross check and ensure the accuracy of the description. While describing the lessons, I made careful notes on decisions the teachers made during the lessons. To find the rationales behind the decisions, I searched for statements of rationales in the interview transcripts. Data from task interaction transcripts were included as extracts to illustrate the interaction processes during the lessons. The analysis also included the teacher's evaluation of the learning process and his/her perceptions of the task-based lessons compared with the PPP versions of the lessons. Finally, to better understand how and why the teachers implemented the lessons the way they did, I conducted cross-case analysis. I compared and contrasted the observation and interview data within each teacher and across the teachers. This enabled me to discuss the similarities and differences across the case teachers.

\subsubsection{Pupils' perceptions of their experience with the task-based lessons (Phase 2)}

Data collected from the semi-structured interviews with the pupils were analysed to examine how the pupils perceived their experiences with the task-based lessons. There were a total of five interviews (just one interview was conducted with Nam's pupils). The length of the interviews varied from 15 to 17 minutes. All interviews were transcribed in their entirety (excluding the session when I used the task materials to remind pupils of the activities they were involved in during the lesson). Analysing the pupil interview data followed the same approach for analysing the teacher interview data. I repeatedly compared the interview transcripts and summary field notes to understand the context of the interview and the pupils who responded or did not respond to my questions. I also used quantification to detect and report patterns. For example, I compared what one student said about the activity he or she liked best with another student' responses. By so doing, I was also able to find the frequency for pupils' likes or dislikes about certain activities. 


\subsubsection{Pupils' task-based interaction data (Phase 2)}

Data set

The three Grade 4 teachers and their pupils from three different schools (rural, semirural and urban) participated in Phase 1 of the study. For the purpose of the analysis, I labelled each school according to my understanding and perceptions of the general proficiency (see Section 3.4.1) of pupils in these school contexts. Hence, the four dyads recorded in the rural school were labelled as the lower proficiency group (LPG); the four dyads in the semi-rural school were labelled as the moderate proficiency group (MPG); the four dyads in the urban school were labelled as the higher proficiency group (HPG). I drew on two sources of evidence for these distinctions. First, I have extensive professional knowledge based on 10 years of teaching and three years of training teachers in this area. Second, my professional intuitions were confirmed during classroom observations in Phase 1 of the study. It became clear during these observations that the pupils in the rural school were generally less proficient than those in the semi-rural school and the pupils in the urban schools were more proficient again. Thus, this way of labelling enabled me to better understand how the pupils with different proficiencies perform the main tasks in the task-based lessons.

Additionally, as discussed in Section 3.4.3.2, the teachers paired the pupils for the task performance according to their perceptions of whether the pupils in each pair were of relatively higher or lower proficiency. This was done to address the teachers' concern about their lower proficiency pupils' ability to complete the main tasks in the task-based lessons. For the purpose of the analysis, in each dyad, the higher proficiency pupil is labelled as P1 and the lower proficiency pupil is labelled as P2.

Gender balance was not controlled since the teachers chose the dyads for recording. As a result, three of the nine dyads consisted of two female pupils. The other six dyads were mixed (a male and a female pupil in each). Having a male and a female in a dyad, however, helped me identify the speakers more easily.

A total of 24 audio-recordings of peer-peer interaction (4 dyads x 2 tasks x 3 schools) were collected from the three schools and so constituted three data sets (one from each school). The length of the recordings varied from 9 to 12 minutes. In each data set, data from one of the four dyads was incomplete and so was excluded from the analysis. This left data from three dyads from each school. Thus, the final data set comprised 18 recordings of peer-peer interaction from the three schools. 


\section{Transcriptions}

I adopted a denaturalised transcription method to transcribe the task interaction data, that is, I focussed on the content of the talk rather than the mechanics. Hence, I transcribed all selected audio recordings of peer interaction in simple English orthography without notating detailed discourse features such as overlaps and laughter. However, speech signals such as hesitations, fillers, and repetitions were included. This transcription style was appropriate because the study also featured interview and observation data (Richards, 2003). My familiarity with the pupils' accent ensured high quality transcripts (Révész, 2012). The transcripts were checked against the audio recordings several times to ensure accuracy. When a speaker produced a pronunciation error, his/her actual speech was transcribed according to the international phonetic alphabet (IPA) (see Appendix 9 for an example of an entire transcript of a task performance).

I also used this transcription method to transcribe selected whole classroom episodes which illustrated the ways the teachers implemented the speaking lessons in Phase 1 and the task-based versions of the lessons in Phase 2. Transcription conventions, mainly based on Gagné and Parks (2013), are provided on Page xiv earlier in this thesis.

\section{Coding of c-units}

The data were first analysed to examine the amount and characteristics of talk generated in the interactive discourse by each dyad in each group. To measure the amount of talk, c-units were adopted as the unit of measure. C-units are defined as utterances (i.e., words, phrases and sentences, grammatical and ungrammatical) which provide communication value (Rulon \& McCreary, 1986; cited in Iwashita, 2001). C-units put greater emphasis on the transmission of meaning than the completeness of utterances; therefore, they are more appropriate to study oral language (Foster, 1998). All 18 transcripts of pair interactions were coded for c-units as seen in Example 1 below.

\section{Example 1: (c-units)}

$1 \quad$ P1: What subject do you have Wednesday? (1 sentence) (1 c-unit)

2 P2: I have... I ...I have ... Science. (1 sentence) (1 c-unit)

3 P1: Science? (1word) (1 c-unit)

4 P2: Science. $\quad$ (1word) (1 c-unit)

(MPG, task 1, dyad 3) 


\section{Coding verbal interactional strategies}

An inductive analysis was carried out to identify the verbal interactional strategies pupils employed to perform the main tasks in the task-based lessons. Following this approach, I repeatedly read and examined the interactive data in order to search for salient categories that emerged from the data. This process was supported by my observations and field notes. The analysis started by determining the initial coding categories, followed by a more finegrained analysis of each category to identify its associated features. I read and reread each transcript to understand deeply what was going on. I kept regular contact with my fellow $\mathrm{PhD}$ candidates who were also doing similar research to discuss our analysis. This inductive, iterative and supportive process helped me identify and delineate reoccurring strategies the pupils across the three school contexts employed to perform the tasks as well as the features associated with each strategy.

Following discussion with my supervisor about the initial coding results, I devised my coding schemes for the strategies and their associated features based on constructs inherent in the task interaction research. The coding categories were operationalised following a number of earlier interaction studies such as Azkarai and Oliver (2016), Foster and Ohta (2005), Gagné and Parks (2013), García Mayo and Imaz Agirre (2016), and Sato (2016). As each feature emerged, I did the coding and then discussed the results with my supervisor.

Talk segments where pupils employed verbal interactional strategies and their associated features were qualitatively identified and analysed using a micro genetic approach (Brooks, Donato, \& McGlone, 1997; Vygotsky, 1978). This approach allowed me to analyse utterance by utterance so that "moment-to-moment changes in the pupils' behaviour were noted and examined" (De Guerrero \& Villamil, 2000, p. 54). Following this approach, I was able to "grasp the process in flight" (Vygotsky, 1978, p. 68) as dyads across groups were interacting to complete the main tasks in the task-based lessons.

Overall, the analysis was predominantly descriptive and qualitative, which allowed me to construct a nuanced picture of what strategies the pupils employed in their performance of the main task in each task-based lesson. However, as mentioned above, I also used quantification to detect and quantify patterns in the data. Combining the quantification with the qualitative analysis allowed for important triangulation of the data. The following sections provide definitions and examples taken from the transcripts for each strategy and its associated features. 


\subsubsection{Co-construction}

In the case of the present study, co-construction involves some type of assistance for task completion by both either/both the teachers and the stronger peers for the weaker pupils. As defined by Foster and Ohta (2005), co-construction allows learners "to participate in forming utterances that they cannot complete individually". Sato (2016) revised the idea of coconstruction in task completion as collaborative sentence completion (CSC). CSC can be identified "when a learner struggled to finish his or her utterance and another learner supplied the rest of the sentence" (p.14) This study adopted the definition used by Sato, but it was expanded to include any occasion when a prompt, either correct or incorrect, is provided by a teacher or a stronger peer to elicit a desired utterance. In this sense, a co-construction finished when a desired question or answer made good sense to the listener and enabled the listener to provide the answer. The example below shows a co-construction occasion in which a weaker student, P2, fails to make a question to ask a stronger peer, P1. P1 helps P2 complete the question by providing words in line 2 and then a prompt in line 4 . Though this prompt is incorrect, it elicits a desired word, English in line 5. This word completes a meaningful question and achieves an answer.

Example 2: (Pupil co-construction assistance)

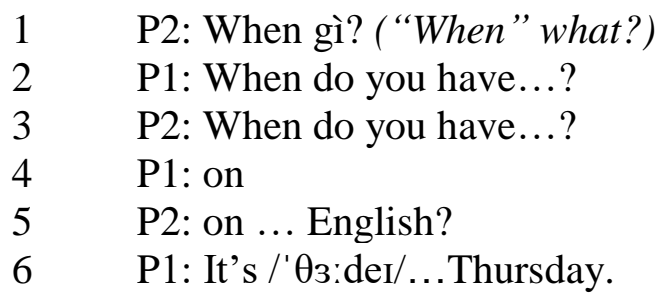

(MPG, task 2, dyad 2)

Example 3 below illustrates an occasion of teacher co-construction assistance in which a weaker pupil - P2 fails to formulate a complete sentence and provide sufficient information to answer P1's question. The teacher then prompts $\mathrm{P} 2$ with a subject and a verb and continues assisting this student until a desired answer is provided.

\section{Example 3: (Teacher co-construction assistance)}

$1 \quad$ P1: When do you have Vietnamese?

2 P2: Uhm Tuesday.

3 T: I have...

4 P2: Vietnamese

5 T: Vietnamese Tuesday. What?

6 P2: I have Vietnamese, Tuesday. 
$7 \quad \mathrm{~T}$ : and?

8 P2: Thursday

9 T: and?

10 P2: Friday

11 T: and Friday. Very good! Okay.

(HPG, task 2, dyad 1)

\subsubsection{Self- and other-correction}

The data was coded according to particular sources (i.e., whether the correction was made by self or peer). Based on Foster and Ohta (2005), self-correction is defined as "selfinitiated, self-repair, and occurs when a learner corrects his or her own utterances without being prompted to do so by another person” (Foster \& Ohta, 2005, p.420). Occasions of selfcorrection were further coded as successful or unsuccessful. "Successful" is used to indicate that the self-initiated correction attempts had a successful outcome (i.e., an error was corrected) (see Example 4 in Table 7 below). "Unsuccessful" attempts refer to those occasions where the self-initiated correction attempts were not correct (i.e., errors) (see Example 5 in Table 7 below).

Using the same process, the data were coded for occasions of other-correction. Based on Foster and Ohta's (2005) definition, other-correction involves a peer correcting his or her partner. Occasions of other-correction were further categorized as either recasts or explicit corrections. Lyster and Ranta (1997) defined a recast as consisting of target-like reformulation of the incorrect utterance maintaining the intended meaning. Recasts are distinguished from confirmation checks in that a recast does not involve a clarification request or NfM (Mackey et al., 2003). In this study, most recasts were given by stronger learners who recast the weaker learners' utterances with target-like versions. Following Lyster and Ranta (1997), explicit corrections are defined as consisting of provision of the correct form with a clear indication of what is being corrected. Examples of self- and other-corrections and their associated features are provided in Table 7 below.

A further analysis was carried out to trace the degree of uptake of negative feedback from recasts and explicit corrections. Three categories of uptake identified in prior research (e.g., Nguyen, 2013) including correct uptake, incorrect uptake or no uptake were coded by evaluating them against the level of correctness of the correction provided. In this study, accurate correction could lead to correct uptake or no uptake. Additionally, incorrect uptake could result from inaccurate or accurate correction. Based on this, "correct uptake" was coded as correct use of the language item that was correctly provided. "Incorrect uptake" was coded as incorrect use of the language items that were correctly or incorrectly provided (see 
Example 7 in Table 7). "No uptake" was coded as an occasion when a pupil ignored the correction or did not incorporate it in his or her subsequent utterances (see Examples 6 and 8 in Table 7).

Table 7. Coding of self-and other-correction strategies and their associated features

\begin{tabular}{cl}
\hline \multicolumn{1}{c}{ Code } & \multicolumn{1}{c}{ Example } \\
\hline Self-correction & \\
\hline \multirow{3}{*}{ a. Successful } & Example 4: (Self-correction, phonological focus) \\
& P1: When do you have Math? \\
& P2: Uhm /'tu: deI/...Tuesday, Thursday. (LPG, task 2, dyad 2) \\
\hline \multirow{2}{*}{ b. Unsuccessful } & Example 5: (Self-correction, syntactical focus) \\
& P1: Who...Who your teacher? ... Who is your English teacher name? \\
&
\end{tabular}

\section{Other correction}

Example 6: (Accurate correction - no uptake; phonological focus)

P1: What subject do you have today is...Friday?

P2: What subject do you have today chứ gì? (you mean?)

P1: $\mathrm{Xxx}$

P2: I have /vjet.nə mi:/, Science, Music.

P1: VIETNAMESE.

a. Recasts P2: /vjet.nə mi:/, Science, Music.

$$
\text { (HPG, task 1, dyad 2) }
$$

Example 7: (Inaccurate correction - incorrect uptake; syntactical focus)

P2: What subject and Wednesday?

P1: What subject do you have Wednesday?

P2: What subject do you have Wednesday?

( LPG, task 1, dyad 2)

Example 8: (Accurate correction - no uptake; syntactical focus)

P1: What subject do you have Wednesday?

b. Explicit correction

\section{P2: I have it Science.}

P1: I have Science không hà (just "I have science").

$\mathrm{P} 2: \ldots$.

P1: Ông hỏi đi (It's you turn).

(MPG, task 1, dyad 2) 


\section{Linguistic focus of correction}

A final further analysis was carried out to identify the linguistic focus of correction in order to investigate what linguistic areas attracted the most attention for correction. All occasions of self-and other-correction were further categorized according to three linguistic foci: lexical, syntactical or phonological, regardless of whether the corrections were successful or not. These correction foci are operationalised based on the discussion of the lexical, syntactical and phonological language-related episodes (LREs) in task interaction studies such as Philp, Walter, and Basturkmen (2010).

\section{Lexical focus}

In this study, there were several attempts of switching from one word to another while the pupils were searching the timetable for information regarding school subjects or days of the week. These attempts were not treated as a focus on errors, though they did reveal regular attempts at finding words or phases to express meaning. The data revealed only two occasions of lexical correction, one of which is illustrated in Example 9 below:

Example 9: (Self-correction - lexical focus)

$1 \quad$ P2: What subject do you have Monday?

2 P1: Science, Math and draw...Art.

(LPG, task 1, dyad 1)

\section{Syntactical focus}

In the case of self-correction, there were some instances where a pupil started with a non-target like utterance, but then reformulated his/her utterance to be more target like, even though the utterance could have made sense to his or her peer. However, given the fact that the participants were young EFL learners and that the learners treated the tasks as formpractice activities, those instances as in Example 10 below were coded as syntactical selfcorrection.

Example 10: (Self-correction - syntactical focus)

$1 \quad$ P1: Tui hỏi ông (Let me ask). What subject, what subject do you have on Friday?

2 P2: It's Vietnam...I have Vietnamese.

(MPG, task 1, dyad 3) 
Example 10 above shows that $\mathrm{P} 2$ is trying to correct the original sentence "It's Vietnam" because it does not reflect the target sentence structure "I have...". The correction shows an attempt to produce a target-like utterance, although the original attempt is not entirely wrong.

\section{Phonological focus}

Phonological focus refers to occasions when a peer offers the correct version of a pronunciation error or a learner self-corrects his or her own pronunciation errors (see Examples 4 and 6 in Table 7).

\subsubsection{Negotiation for meaning}

In order to measure incidences of NfM, the transcripts were coded for negotiation moves, namely confirmation checks, clarification request, and self-repetition. Descriptions of the coding categories in this study was based on those used in previous studies on child task interaction such as Azkarai and Imaz Agirre (2016), García Mayo and Imaz Agirre (2016) and Oliver $(1998,2002)$, which in turn were based on those developed previously by others (Long, 1983; Pica \& Doughty, 1985). Comprehension checks were not included because my initial coding showed that the pupils did not use comprehension checks to negotiate meaning.

\section{Confirmation checks}

Confirmation checks are made by "a learner to make sure that he or she has properly understood or heard what the partner has said" (Azkarai \& Imaz Agirre, 2016, p. 854). They might include a repetition (Oliver, 2002) accompanied by rising intonation. Example 11 below shows two occasions of confirmation checks. In line 2, P1 seems to be sceptical about the use of Mr or Ms placed before Nga. P1 asks for confirmation in line 2 and continue to confirm it in line 4.

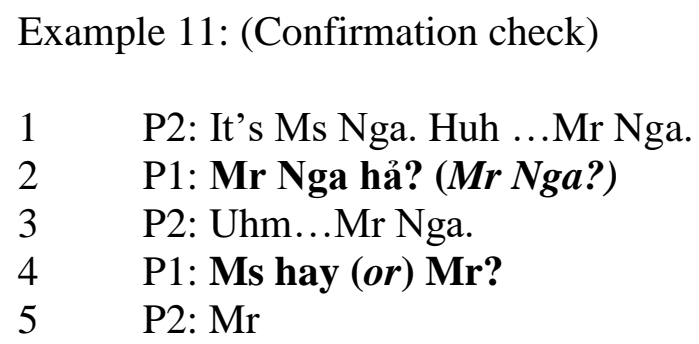

(MPG, task 2, dyad 3) 


\title{
Clarification requests
}

"Clarification requests are made by a listener to clarify what the speaker has said and include statements such as "I don't understand," wh-questions, yes/no questions, and tag questions" (Oliver, 2002, p. 103). In this study, most occasions of clarification requests included non-specified requests for clarification, such as huh? or what? to let the listener know that his or her utterance was either not understood or inappropriately formed. Clarification requests and confirmation checks in both Vietnamese and English were included.

\author{
Example 12: (Clarification request) \\ 1 P2: What, what /'sar.kən/ do you have /'tu:.deI/? \\ 2 P1: Cái gì? (What?) \\ $3 \quad \mathrm{P} 2$ : What /'sar.kən/... what /'sar.ən/ do you have today?
}

(MPG, task 2, dyad 2)

\section{Self-repetitions}

Self-repetitions are "the speakers' partial, exact, expanded repetition of lexical items from his or her own preceding utterances within the five speaking turns" (Oliver, 2002, p.103). In this study, there were some partial and exact repetition occasions when a learner repeated his or her utterance in order to help his or her partner catch the school subjects or days of the week he or she was listing in order to complete the timetable. Example 13 illustrates an example of self-repetition. P1 answers P2's question in line 5. To help P2 to record the answer, P1 repeats it in line 7.

\section{Example 13: (Self-repetition)}

1 P1: Bạn hỏi mình! (You ask me!) When do you have Vietnamese?

2 P2: When do you have Vietnamese?

3 P1: Bạn nghe ghi vô nè (You listen and write down).

$4 \quad$ P2: Đọc lớn lên! (Read loudly!)

5 P1: Tuesday, Thursday ... Thursday and Friday. Okay?

$6 \quad \mathrm{P} 2: \ldots$

$7 \quad$ P1: Thursday and Friday.

(HPG, task 2, dyad 2)

A few other-repetition occasions, defined as "partial, exact, and expanded repetitions of lexical items from an interlocutor' preceding utterances within five speaking turns" (Oliver, 
2002, p. 103), were found in this study. However, since the other-repetitions in this study were rare and did not serve to assist the learners in completing the tasks, they were not coded.

\subsubsection{L1 use as a scaffold and functions of L1 use}

\section{Coding L1 c-units}

All c-units were coded as L1 c-units, L2 c-units and mixed language c-units (Tognini \& Oliver, 2012). An L1 c-unit was an utterance (a word, phrase or sentence) where Vietnamese was entirely used. An L2 c-unit was an utterance where English was completely used. A mixed language c-unit was an utterance where both languages were used, even if one was used more than the other. However, c-units which contained English words followed by a single Vietnamese exclamation word such as "á" or "hả" were coded as L2 c-units because these additional exclamation words add little meaning to the c-units. Following this, the data were coded for functions of L1 use.

Example 14: (L1, L2 and mixed language c-units)

$1 \quad$ P2: Science á. [one L2 c-unit]

2 P1: Science? I have it on Monday, Wednesday and Friday. [Two L2 c-units)

3 P2: Đọc chậm (Slow down). I have gì? (I have what?). [one L1 c-unit and one mixed language c-unit]

$4 \quad$ P1: I have Monday, Wednesday and Friday. [one L2 c-unit]

5 P2: Gì (What?)... Rồi (done). [One L1 c-unit]

(MPG, task 2, dyad 2)

\section{Coding functions of L1 use}

Following Azkarai and García Mayo (2017), in coding functions of L1 use, any utterances that include L1 were coded as L1 c-units. All L1 c-units (including mixed language c-units) were coded for their functions. The initial coding of the functions of L1 was based on studies on L1 use in task interaction such as Azkarai and García Mayo (2017), Storch and Aldosari (2010), and Tognini and Oliver (2012). Several rounds of coding revealed that the learners in this study mainly used L1 for two functions, namely task management and seeking/giving assistance in order to achieve task completion. The examples below illustrate these functions: 


\section{Task management}

Task management includes occasions of metatalk when the pupils use L1 c-units to manage organisational aspects of the task (Tognini \& Oliver, 2012). This includes managing turn-taking and encouraging each other to speak or record the answer, and explain task procedures in order to complete the timetable. Example 15 below illustrates three examples of using L1 to manage the task performance. The example shows that P1 uses L1 in lines 1 and 4 to encourage P2 to talk. However, in line 6, P1 realises it is now her turn to ask, she uses L1 to let $\mathrm{P} 2$ know that she has to ask now.

Example 15: (L1 function - Task management)

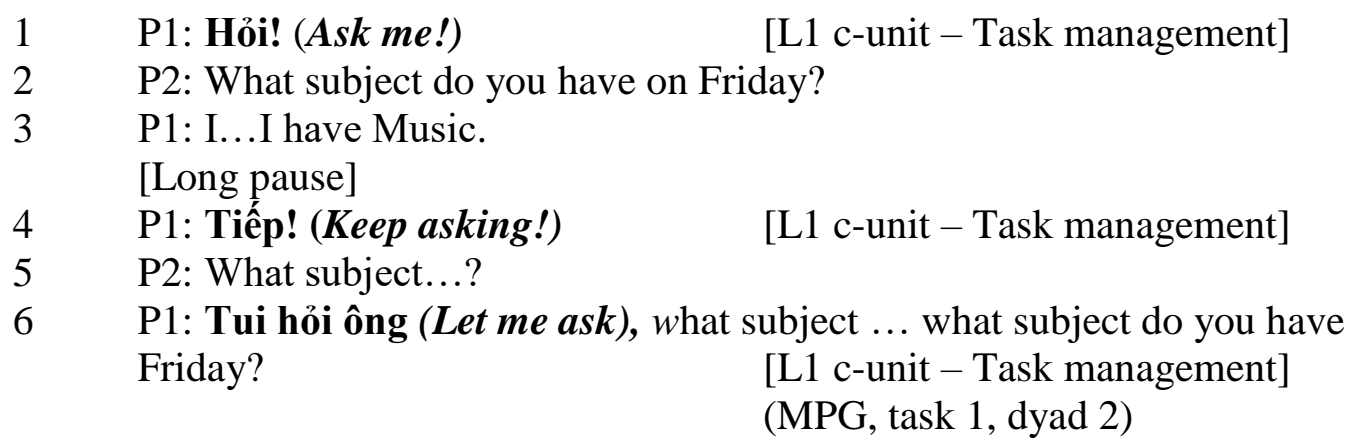

\section{Seeking/giving assistance}

Seeking/giving assistance includes occasions when the pupils use L1 or a mixture of L1 and L2 to give or seek assistance to/from each other regarding the meaning, spelling or pronunciation of a particular vocabulary item (Azkarai \& García Mayo, 2017). This also includes utterances starting with an English word followed by a translation of the word to assist understanding. Instances of self-talk for vocabulary search and spelling out in Vietnamese are also included. Requests for clarification or explanation on any aspect of the task completion are also included. Example 16 illustrates an example of using L1 to seek and give assistance. In line 2, P2 uses L1 to ask about how to say "Thú năm” (Thursday) in English. P1 gives assistance using a mixture of L1 and L2 in line 3.

Example 16: (L1 function - Seeking/giving assistance)

$1 \quad \mathrm{P} 1$ : Bạn học Vietnamese thứ mấy? (When do you have Vietnamese?)

2 P2: /vjet.nə mi:/ là (is) /'t fu:deı/, /'t fu:deı/. Huh, cái này là ...? (this is ...?). Thứ năm là gì bạn, thứ năm? (How do I say Thứ năm in English?)

3 P1: Thứ năm... thứ năm là (is) ... /' $\theta 3$ : deI/ ... /' $\theta 3$ : deI/. 
[L1 c-unit - Giving assistance]

(LPG, task 2, dyad 1)

\subsubsection{Inter-coder reliability}

The data set was composed of 18 task performances by nine pairs of pupils. Intercoder reliability was carried out for the coding of verbal interaction strategies and c-units. Two Vietnamese teachers were trained for coding a randomly selected subset of a sample of $33 \%$ of the data (6/18). The first Vietnamese teacher who was familiar with the pupils' accent coded c-units (including L1, L2 and mixed language c-units). This teacher then coded the total number of c-units into L1 c-units (including L1 and mixed language c-units) and functions of L1 use. The inter-coder agreement was $88 \%$ for the coding of c-units and $86 \%$ for the coding of L1 functions. The second teacher identified the verbal interactional strategies of co-construction, self- and other-correction, and NfM. The interrater reliability was $90 \%$ for the coding of co-construction, $87 \%$ for the coding of other- and self-correction, $89 \%$ for the coding of NfM strategies. Disagreements were resolved through follow-up discussion. Those items where the other coders and I could not reach an agreement were excluded from analysis. The final agreement rates were $90 \%$ for co-construction, $89 \%$ for other- and self-corrections and 90\% for NfM strategies. Regarding c-units and functions of L1 use, the agreement rate was $89 \%$ for c-units, and $87 \%$ for coding of $\mathrm{L} 1$ functions. These scores show satisfactory reliability (Miles \& Huberman, 19945). The difference in the intercoder reliability was mostly due to the fact that my coding system reflects the need to make highly sensitive coding decisions because of the nature of the data.

\subsection{Strategies to enhance research trustworthiness}

Validity and reliability in qualitative research are represented by the criteria of trustfulness including credibility, dependability, confirmability and transferability (Lincon \& Guba, 1985). These criteria were adhered to during the research process in order to ensure the trustworthiness of the study.

\subsubsection{Credibility}

Credibility is concerned with the validity or "true value" of the research findings (Lincoln \& Guba, 1985, p.296) and whether the data collected was carefully analysed and

\footnotetext{
${ }^{5}$ Coders should reach an agreement for a minimum of $80 \%$ of the time (Miles \& Huberman, 1994).
} 
presented in a "fair and unbiased manner" (McKay, 2006, p.13). Prolong engagement and persistence brings about credibility in a research study. Prolong engagement was one strong indicator of the credibility of the present study. In fact, during a period of five months, I worked closely with the teachers from different schools from rural to semi-rural and urban areas. This afforded me opportunities to observe a large number of lessons which helped me understand at a deep level the practices of the teachers in different grade levels and school contexts. In addition, when analysing the data, I maintained a persistent process of coding and developing the codes for each data source and across data sources. I repeatedly read and reread the data, analysed them, theorised about them and revised the coding categories accordingly. The categories were recoded and relabelled until the final categories provided the intended depth of insight. In writing up my thesis, I went through a persistent process of drafting and redrafting, which was also itself also a method of inquiry, discovery, and analysis (Richardson, 2000).

Another strong indicator of the credibility of the study was triangulation of data and triangulation of methods. In this study, I brought together multiples sources of data, research methods and perspectives for analytical purposes. Multiple data collection methods such as observations (video-audio recordings and field notes), interviews (stimulated recall and follow-up in-depth interviews) were employed in both phases of the study. Phase 2 also involved recording of student pair task interaction. The multiple data collection methods enabled multiple data sources to be collected and triangulated for the analysis and evaluation of the PPP speaking lessons and the task-based versions of the lessons. The sources for triangulation not only included the perspectives of the teachers and students, they were also supplemented with supportive evidence collected from student performances and my field notes and reflexive notes.

Finally, this research was ecologically valid (Loewen \& Philp, 2012) because it was conducted in intact classes in normally scheduled classroom hours. Principally, the study was contextualised in an on-going new Primary English Curriculum, hence addressing the "pressing" call for contextualised research on TBLT implementation in real classrooms (Bygate, 2016).

\subsubsection{Dependability}

Dependability refers to the consistency of the findings and data (consistency of collecting data, interpreting the findings and reporting the results) (Lincoln \& Guba, 1985). In this study, I shared with each of the teachers summaries of key findings and conclusions from 
classroom observation and interview data for their checking before I analysed them (Johnson \& Christensen, 2014). I also maintained regular contact with the participant teachers to ask for feedback on my interpretation of the data. To ensure consistency of data analysis, I followed the process of double-coding to identify and compare the results. Peer-debriefing was also employed to ensure the credibility of the emerging categories and interpretation. For example, in analysing task interaction data sources, I discussed the coding process, interpretation and conclusions with my Vietnamese $\mathrm{PhD}$ colleagues who have experience and knowledge of teaching and learning English in the Vietnamese primary school context. The discussions enabled problems such as misinterpretation, researcher bias, and unconvincing explanations to be identified and resolved.

\subsubsection{Confirmability}

Confirmability concerns aspects of neutrality. It refers to "the degree to which the findings are determined by the subjects (respondents) and conditions of the inquiry and not by the biases, motivations, interests or perspectives of the inquirer" (Lincoln \& Guba, 1985, p. 290). In this study, I acknowledge that my "beliefs, backgrounds and feelings are part of the process of knowledge construction" (Hesser-Bier, 2017, p. 134). In fact, I brought to my interpretation of the data my perspectives, experiences, and motivations as an insider - a teacher and teacher trainer in Vietnam. This might have influenced the way I interpreted the data and the researched issues. One way I remained mindful of this was to keep a reflective journal in which I kept a detailed record of my reflective thoughts, notes on the decisions made, and interpretations during the process of data collection and analysis. On-going selfreflections and self-awareness enabled me to recognize and understand how my positivity, beliefs, personal and professional experiences, and feelings might impact the process of collecting, analysing and interpreting the data. By actively and critically self-reflecting throughout the research process, I was able to monitor and mitigate the inevitable challenge of researcher bias (Johnson \& Christensen, 2014).

\subsubsection{Transferability}

Transferability refers to the degree to which the findings may be transferred to other contexts outside the study (Lincoln \& Guba, 1985). This study was qualitative and involved a small number of participants. Therefore, the purpose of the study was not to generalise, but to lend support to some broader theory (Yin, 2014). The study focuses on describing and 
understanding "the specifics in-depth", the implementation of the textbook lessons and the task-based versions of the lessons in the Vietnamese primary school contexts by the selected teachers. To allow readers to determine the degree of transferability of the study, I have provided a rich description of the research context and research participants, and data collection methods. This description was designed to help readers make sense of the findings, evaluate the study, and relate the insights of the study to similar educational contexts.

\subsection{Role of the researcher}

In this study, the researcher-participant relationship and the role that the researcher took during the data collection were important considerations. As a university lecturer and teacher trainer, I had the advantage of recruiting the teacher participants. Of the seven participants, one was my ex-student and the others were recommended to me by my colleagues. In this situation, the researcher-participant relationship existed to some extent. This required me to be sensitive to its effect so as to help reduce any potential threats related to a participant and researcher bias. In addition, I was mindful of my previous role as a teacher trainer, holding certain pre-conceptions of the PPP approach. Therefore, during the interviews, I refrained from expressing personal opinions or judging the teachers' practices as I had done in my previous role as a teacher trainer. Similarly, I was sensitive to the issues of socially desired responses from the teachers and pupils with regard to their perceptions of the task-based versions of the PPP lessons. All teachers clearly understood why I was conducting the interviews and that their authentic and honest responses were important for the integrity of my study.

In the current study, I acknowledge the possibility that the teachers and their pupils could have performed or behaved differently from what they normally would have done. However, I believe that this "Hawthorne" effect (Dörnyei, 2007; McDonough \& McDonough, 1997) was largely minimised because the teachers and their pupils clearly understood that I was not making observations for assessment or inspection. The pupils were familiarised with my presence through the piloting prior to Phase 1 data collection. By the time the Phase 2 data were collected, they considered me as a familiar member of the class. They were observed to be relaxed and behaved naturally during observation. Essentially, most teachers were experienced teachers who were familiar with being observed. Thus, my presence in their classrooms or discussions with them during the interviews were part of their regular teaching experiences. 
Finally, I believe that my previous experience as a teacher trainer did not create a power-distance relationship. Instead, it helped foster important rapport and trust with the participant teachers. My knowledge of the local situation provided me with an insider perspective and helped me build and maintain rapport with the local teachers. These qualities were strengthened when it came to Phase 2 of the study when the participant teachers were actively involved in the redesign and implementation of the task-based versions of the PPP speaking lessons. This process valued the teachers' experiences and their comments on the redesigned lessons and their pedagogical skills in implementing the lessons in their classrooms. Through their involvement, the teachers clearly understood that their experiences and comments were respected and valued and that their participation was important not only for my research but also for their professional development and their pupils' learning. It is important to note that two of the teachers (Lan and Nhu), who were positive towards the PPP approach, expressed their interest in seeing how the task-based lessons might work in practice and considered my research as an opportunity to challenge themselves and their pupils.

In this chapter, I have outlined the research design and described the research procedures used in detail. I have also discussed the strategies to ensure trustworthiness of my research. I will now report the findings for my Phase 1 study. 
This page is intentionally left blank 


\section{CHAPTER 4 PHASE 1: THE IMPLEMENTATION OF TEXTBOOK SPEAKING LESSONS}

\subsection{Introduction}

This chapter reports on and discusses the results of how teachers implemented the textbook speaking lessons and why they chose to implement the lessons in the manner they chose. It addresses two research questions (RQs):

RQ1. (a) How did the teachers implement the textbook speaking lessons?

(b) How did they explain their implementation decisions?

RQ2. How did the teachers view the textbook PPP speaking lessons?

To facilitate understanding of the implementation process, I first provide an overview of the textbook series, a specific textbook unit, and an analysis of the two speaking lessons in the described unit.

\subsection{Overview of the textbook series and a specific textbook unit}

A three-level textbook series for Vietnamese primary school pupils (Grades 3-5, 8-10 years old) accompanies the new Primary English Curriculum. The textbooks were written by Vietnamese scholars in collaboration with two international publishers-Macmillan Education and Pearson Education. They were first issued in 2011. The first two-levels of the textbooks for Grades 3 and 4 (8-9 years) were republished in 2014 and 2015 after a period of further piloting and revision. At the time of data collection for this project, the third level for Grade 5 (10 years) was being revised. It was republished in late 2016 and thus not included in this analysis. The textbook series for the Grades 3, 4 and 5 are each comprised of 20 units with each unit consisting of three lessons on a topic related to one of the four themes: me and my friends, me and my school, me and my family, and me and my community. These themes are repeated in each of the textbooks from Grades 3 to 5 but with different lesson topics at each level. As the teacher's book explains, the textbook series follows the curriculum approved by the Ministry of Education and Training. The series "covers a communicative, theme-based and learner-centered approach to the basic English language skills, with emphasis on listening and speaking for early levels" (Hoang et al., 2015a, p. 7). This shows that the textbook series 
were designed to support the ministry's commitment to the communicative approach for the English education at primary levels.

Table 8. Design of a textbook unit

\begin{tabular}{|c|c|c|c|c|c|c|}
\hline & \multicolumn{2}{|c|}{ Lesson 1} & \multicolumn{2}{|c|}{ Lesson 2} & \multicolumn{2}{|c|}{ Lesson 3} \\
\hline $\begin{array}{c}\text { Teaching } \\
\text { period (TP) }\end{array}$ & $\mathrm{TP} 1$ & $\mathrm{TP} 2$ & $\mathrm{TP} 1$ & $\mathrm{TP} 2$ & TP1 & $\mathrm{TP} 2$ \\
\hline Grade 3 & $\begin{array}{l}\text { Sections } \\
(1,2,3- \\
\text { Teaching } \\
\text { Speaking } \\
\text { skills }\end{array}$ & $\begin{array}{l}\text { Sections } \\
4,5,6) \\
\text { Teaching } \\
\text { integrated } \\
\text { skills }\end{array}$ & $\begin{array}{l}\text { Sections } \\
(1,2,3- \\
\text { Teaching } \\
\text { Speaking } \\
\text { skills }\end{array}$ & $\begin{array}{l}\text { Sections } \\
4,5,6) \\
\text { Teaching } \\
\text { integrated } \\
\text { skills }\end{array}$ & $\begin{array}{l}\text { Sections } \\
(1,2,3- \\
\text { Teaching } \\
\text { integrated } \\
\text { skills }\end{array}$ & $\begin{array}{l}\text { Sections } \\
4,5,6) \\
\text { Teaching } \\
\text { integrated } \\
\text { skills }\end{array}$ \\
\hline Grade 4 & $\begin{array}{l}\text { Sections } \\
(1,2- \\
\text { Teaching } \\
\text { Speaking } \\
\text { skills }\end{array}$ & $\begin{array}{l}\text { Sections } \\
3,4,5) \\
\text { Teaching } \\
\text { integrated } \\
\text { skills }\end{array}$ & $\begin{array}{l}\text { Sections } \\
(1,2,3- \\
\text { Teaching } \\
\text { Speaking } \\
\text { skills }\end{array}$ & $\begin{array}{l}\text { Sections } \\
4,5,6) \\
\text { Teaching } \\
\text { integrated } \\
\text { skills }\end{array}$ & $\begin{array}{l}\text { Sections } \\
(1,2,3- \\
\text { Teaching } \\
\text { integrated } \\
\text { skills }\end{array}$ & $\begin{array}{l}\text { Sections } \\
4,5,6) \\
\text { Teaching } \\
\text { integrated } \\
\text { skills }\end{array}$ \\
\hline
\end{tabular}

Note. $\mathrm{TP}=$ Teaching period

Table 8 shows how textbook units for Grades 3 and 4 are structured. Each textbook unit consists of three lessons. Each lesson consists of six sections except for Lesson 1 in the Grade 4 textbook. This lesson comprises five sections. Analysis of the syllabi and the lesson plans prepared by each of the seven teachers reveals that each lesson is divided into two teaching periods (35 minutes each for Grade 3 and 40 minutes each for Grade 4). Each period covers three sections except for the first period in Lesson 1 in the Grade 4 textbook. This period covers two sections with a pair/group work activity added to Section 2. This additional activity is designed as a production activity in many of the lesson plans analyzed. In total, there are six teaching periods allocated within the three textbook lessons with each lesson being covered in two teaching periods.

As shown in the lesson plans, the first three sections in Lesson 1 and the first three sections in Lesson 2 in a Grade 3 textbook unit are designed to teach speaking skills. Similarly, the first two sections in Lesson 1 and the first three sections in Lesson 2 in a Grade 4 textbook unit are designed to teach speaking skills. These sections in both textbooks are all followed by skill-focused activities, language games, songs or chants. Each lesson in a 
textbook unit is covered in two teaching periods. The teachers conceived of each of these periods as a distinct lesson with each lesson focusing on a particular language skill. The following section describes how the two speaking lessons in a textbook unit are designed and to what extent the design reflects principles of task-based language teaching.

\subsection{Analysis of the speaking textbook lessons}

The two speaking lessons in Unit 5 in the Grade 4 textbook were chosen to illustrate the design of the speaking lessons (see Figures 3 and 4 below). These two lessons were chosen for two reasons: (1) they possess features found across the other lessons and (2) they were lessons I observed being taught. These two speaking lessons belong to the theme "Me and My friends" and the topic "Can you swim?" Two main objectives for these lessons were: (1) ask and answer questions about what someone can/cannot do, using "What can you do?" and responding "I can..."; (2) ask and answer questions about whether someone can do something, using “Can you...?" and responding "Yes, I can/No, I can't” (Hoang et al., 2015b, p. 44). 
This image has been removed by the author of this thesis for copyright reasons.

As Figure 3 shows, this lesson starts with the first activity in Section 1 called "Look, listen and repeat". Four pictures are provided for this section and together they illustrate a conversation among three textbook characters Nam, Phong and Mai. The conversation is performed by three native English speaking children and is meant to expose pupils to a context in which the three textbook characters are asking and answering questions about what they can or cannot do. To do the activity, pupils are instructed to look over the pictures, listen to the dialogues, and practice the dialogues. This practice activity provides the context in which the target structural patterns are introduced while also presenting target vocabulary. The target structural patterns and vocabulary are then practiced in the next activity in Section 2, namely "Point and say", which is intended for "the controlled practice of the first language 
competence, key vocabulary and grammar points" (Hoang et al., 2015b, p. 8). This practice activity is facilitated by prompts containing the target structural patterns "What can you do? /I can..." in speech bubbles and by the four pictures of the girls skipping, skating, cooking and swimming. The teacher's book recommends using mechanical drills such as repetition, substitution and question-and-answer for this controlled practice activity. Additional to Section 2 is a pair work activity which "encourages pupils to reproduce the language they have just learnt in a real context using facts about themselves" (Hoang et al., 2015b, p. 8). As the activity says, pupils are instructed to talk in pairs about what they can do. Specifically, pupils practice asking and answering using "What can you do? I can ..." with facts about themselves. As such, this activity aims to provide an opportunity for more meaningful and freer production. Taken together, this final activity, together with the two preceding activities constitute a complete speaking lesson. This format, as described, explicitly follows the traditional PPP sequence to teaching speaking at the early phase of a unit. 


\section{Figure 4. An example of textbook speaking lesson 2}

This image has been removed by the author of this thesis for copyright reasons.

Speaking lesson 2 is designed with the same format and rationale as speaking lesson 1. As shown in Figure 4, Section 1 "Look, listen and repeat" includes three pictures a, b and c. These pictures together illustrate a conversation between Peter and Tom. Words in the conversation bubbles show that the conversation aims to expose pupils to the context where the target structural pattern is embedded. As the teacher's book states, the lesson aims to achieve the second learning objective for the unit which is asking and answering about ability, using "Can you...? Yes, I can/No, I can't". One important note is that the first two sections in this speaking lesson 2 (1. Look, listen and repeat and 2. Point and say) follow the same pattern as in Lesson 1. However, following these two sections is Section 3 called Let's talk. 
Like the additional activity that follows Section 2 in speaking lesson 1, this section is added to "invite [pupils] to practice the language they have learnt in Lessons 1 and 2 using facts about themselves" (Hoang et al., 2015b, p. 8). Thus, the two target structural patterns including "What can you do" and "Can you...?" are provided for the freer and more meaningful production practice. However, as seen in Section 3 in Figure 4, this production activity is rather bland. There is a simple work plan named Let's talk with the two target questions provided. From this analysis and description we can see that, like speaking lesson 1, the design of speaking lesson 2 follows the PPP sequence with three clearly separated sections and with communicative use treated as something of an afterthought.

Further analysis of this textbook unit reveals that the PPP approach informs not only the design of this speaking lesson but also that of the other lessons and the entire unit. In fact, reflecting this approach, the subsequent activities in this unit are designed for pupils to practice and consolidate language items that have already been presented. Following the activities in the speaking lessons 1 and 2 are the listening, reading and writing activities and the project task in the final section of Lesson 3. Based on Ellis's (2003) four criteria of tasks the initial tentative analysis of these activities reveals that many of them have features of tasks. For example, the activity following speaking lesson 1 involves pupils listening to three dialogues about someone's abilities and ticking the correct pictures. To do the activity, pupils are asked to make use of their available language resources to interpret the three pictures and then show their comprehension of the listening input by putting a tick in one of the three pictures. This activity possesses characteristics of tasks in that it has a gap and involves a nonlinguistic outcome. Similarly, the final activity in this unit is similar to an interview task. Pupils interview three friends about their abilities and fill in a chart with this information. Despite being task-like, this activity together with some other follow-up task-like activities is, as stated in the teacher's book, intended to help pupils to use structures and vocabulary items introduced in the preceding speaking lessons or earlier in the unit. In other words, the language forms needed for the performance of the tasks have already been determined. Any activities that follow the two speaking lessons are provided to primarily practice those target forms. This indicates that the design of the textbook speaking lessons reflects a task-supported approach to language teaching (Ellis, 2003) with tasks included for the practice of the prespecified target language items.

In conclusion, the above analysis shows that the design of the two speaking lessons in the textbook unit follows the PPP sequence, as also stated and guided in the teacher's book. A further analysis of the textbook unit as a whole shows that within the PPP approach, the 
burden of learning new language forms falls on the first two speaking lessons. The forms are then reinforced in the subsequent activities across these lessons with many of those activities being tasks and task-like activities. This suggests that not only the speaking lessons but also the whole textbook unit follows the PPP approach. The questions of how the teachers implemented the PPP speaking lessons in their practice and how they perceived the PPP approach are addressed in the following section.

\subsection{Teachers' implementation of the speaking textbook lessons}

This section addresses research question 1 for Phase 1 of this study: (a) How did the teachers implement the textbook speaking lessons and (b) how did they explain their implementation decisions? It presents the data from the participating teachers' actual classroom practices and what they said about their practices. Data for this section include audio-video records of 11 classroom observations, audio records of 11 stimulated recall interviews and evidence from classroom notes. The observations include speaking lessons 1 and 2 in a textbook unit conducted by each of the three Grade 4 participant teachers and the speaking lesson 2 conducted by each of the four Grade 3 teachers. 
Table 9. The procedures of implementing the PPP speaking lessons

\section{Grade 4 teachers}

$(n=4)$

PPP speaking lessons
Grade 3 teachers

$(\mathbf{n}=3)$

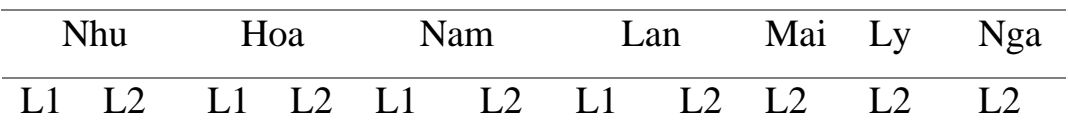

\section{Presentation}

a. Warm-up activities to review vocabulary

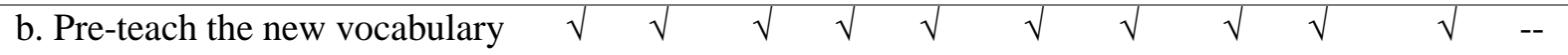

\begin{tabular}{lllllllllllllll}
\hline c. Vocabulary practice activities & $\sqrt{ }$ & $\sqrt{ }$ & -- & -- & $\sqrt{ }$ & $\sqrt{ }$ & -- & -- & $\sqrt{ }$ & & $\sqrt{ }$ & --
\end{tabular}

$\begin{array}{llllllllllllllll}\text { d. Listen to the recording of the } & \sqrt{ } & \sqrt{ } & \sqrt{ } & \sqrt{ } & \sqrt{ } & \sqrt{ } & \sqrt{ } & \sqrt{ } & \sqrt{ } & \sqrt{ } & \sqrt{ }\end{array}$ dialogues.

$\begin{array}{lllllllllllllll}\text { e. Dialogue practice } & \sqrt{ } & \sqrt{ } & \sqrt{ } & \sqrt{ } & \sqrt{ } & \sqrt{ } & \sqrt{ } & \sqrt{ } & \sqrt{ } & \sqrt{ } & \sqrt{ }\end{array}$

$\begin{array}{llllllllllllllllll}\text { f. Explicit explanations of target } & \sqrt{ } & \sqrt{ } & \sqrt{ } & \sqrt{ } & \sqrt{ } & \sqrt{ } & \sqrt{ } & \sqrt{ } & \sqrt{ } & \sqrt{ } & \sqrt{ }\end{array}$
structures

$\begin{array}{llllllllllll}\text { Time spent (minutes) } & 20 & 18 & 20 & 18 & 18.3 & 23 & 30.4 & 28 & 20 & 18.2 & 17\end{array}$

\section{Practice}

g. Drill practice of target

structural patterns

h. Pair work practice and

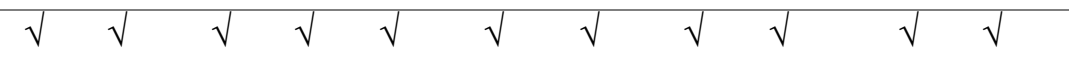
performance.

Time spent (minutes)

$\begin{array}{lllllllllll}9 & 10.5 & 10 & 9.5 & 10.8 & 9 & 7 & 9 & 9 & 7.3 & 10\end{array}$

\section{Production}

i1. Use freer practice activities

specified in the textbook.

i2. Replace the production

activities in the textbook with

interactive games

i3. Replace the production activities with communicative

tasks

\begin{tabular}{llllllllllll}
\hline Time spent (minutes) & 10 & 9 & 10 & 9 & 4.2 & 9 & 4 & 4 & 2.5 & 6 & 6 \\
\hline Consolidation (minutes) & 2 & 3 & -- & 2.5 & 4 & 2 & 1 & 1 & 3 & 3 & 2 \\
\hline Total time (minutes) & 41 & 40.5 & 40 & 39 & 37.3 & 43 & 42.4 & 42 & 34.5 & 34.5 & 35
\end{tabular}

Note. $\mathrm{L} 1=$ Lesson 1; L2 = Lesson 2 
Table 9 presents the procedures used by both Grades 3 and 4 teachers to implement the speaking lessons. It also indicates whether each action was present or absent in the observed lessons. The table shows that common practice was for all teachers to follow the PPP sequence to teach the two speaking lessons. Analysis of the observed lessons indicated the following common procedures. First, the teachers organised vocabulary-based activities before they implemented the presentation phase in Section 1, namely "Look, listen and repeat". When they carried out this phase, they all led the dialogue practice activity from which they elicited the target structural patterns and then explicitly presented them. Second, the teachers all implemented the practice phase in Section 2, namely "Point and say". They all went through the words/phrases provided before organizing the pupils in pairs/groups to practice asking and answering using the target structures. However, when it came to the production phase in Section 3, namely "Let's talk" (the production activity for Lesson 1 in the Grade 4 textbook is the pair/group work activity added to Section 2), the teachers carried out this phase in three different ways: (1) using the production activity specified in the textbook; (2) replacing the activities with interactive games $^{6}$; (3) replacing the production activity with a communicative task.

The following sub-sections detail how the teachers implemented each of the phases in the PPP speaking lessons and how they explained their implementation decisions.

\subsubsection{Presentation phase}

Analysis of the procedures the teachers used to implement the presentation phase as shown in Table 1 reveals two common themes. One is that all teachers supplemented this phase with vocabulary-based activities (see a, b and c in Table 9), many of which reflected features of communicative and task-like activities. The other reveals a tendency for the teachers to closely follow the three steps of Section 1 "Look, listen and repeat" and then to follow this with explicit explanation of grammatical structures.

\footnotetext{
${ }^{6}$ The games were different from tasks in that they were simple language practice activities. It is actually designed for language practice set up in the form of the interactive games. These activities did not meet all criteria of tasks, but nevertheless were interactive. Their primary function was to practice set phrases and forms with game-like element such as team competition.
} 


\subsubsection{Vocabulary-based activities}

The teachers conducted vocabulary-based activities to prepare the pupils for the speaking lessons throughout the presentation phase, including warm-up vocabulary activities designed to achieve a dual goal of reviewing vocabulary related to the topic of the lesson and creating an initial, enjoyable classroom atmosphere; vocabulary pre-teach activities designed to explicitly teach the new vocabulary in the lesson, and vocabulary practice activities designed to help pupils memorise the vocabulary that have been taught.

\section{(a) Warm-up vocabulary activity}

Six out of seven teachers used a warm up in their observed lessons to review the target words relating to the topic of the lessons that they were about to teach. Many of these activities were found in speaking lesson 2 to review the vocabulary in Lesson 1. Some frequently used activities identified among 11 speaking lessons included "Slap the board", "Bingo", "Memory challenge", "Passing the puppet", "Mining" and "What is Missing?". For example, the "Slap the board" and guessing activities involved pupils processing listening input from the teacher in order to be able to "slap" on the correct words or guessing the right name after being spelt, respectively. These game-like activities resulted in both a linguistic and non-linguistic outcome. However, they were merely task-like (rather than actual tasks) because they were purposefully designed for language practice and were not primarily concerned with exchanging meaning. Although the activities do not qualify as what may be considered authentic tasks, they provided an effective opportunity for real use and processing of language.

In the interviews, the teachers explained that these vocabulary-based warm up activities were included to review the content of the previous lesson and increase engagement. They commented that not only the fun element of the activities, but also their cognitively challenging features offered their pupils useful opportunities for memorizing the vocabulary items as well as improving overall language skills. For example, Hoa was satisfied with the Pelmanism game where her pupils had to find a match between words and pictures when they uncovered them under the numbers. She indicated that:

This activity encourages pupils to think. When they are cognitively involved, they would remember the vocabulary better. (Hoạt động này khuyến khích học sinh suy nghĩ. Khi học sinh tư duy, chúng có thể nhớ tù̀ tốt hơn.) (Hoa, speaking lesson 2) 
Ly stated that the Guessing game which involved the pupils guessing the right name after being spelt "could enhance pupils' listening skills and listening reaction ability" (có thể nâng cao kĩ năng nghe và khả năng phản ưng) (Ly, speaking lesson 2). The comments suggest that the teachers not only appreciated the motivational power of games, they also highlighted the cognitive challenge of such games and their value for language learning.

\section{(b) Vocabulary pre-teach activity}

In this activity the teachers taught the vocabulary that they thought was unfamiliar to their pupils. Analysis of observation data showed that the teachers used a range of traditional vocabulary teaching techniques such as visual aids, miming, translation, or examples to elicit target vocabulary items. One interesting observation was that neither Nam nor Hoa taught the new vocabulary in a traditional way. In one of their two observed speaking lessons, these teachers engaged their pupils in a "listing task" which served as a vocabulary pre-teaching activity. For example, to pre-teach the target vocabulary of "Play activities", Nam writes the topic words "Play Activities" inside two circles in the centre of the board. The class is divided into two teams (the Tigers and Lions). Each team is asked to discuss the topic of play activities in their small groups for about two minutes. When the teacher says 'start', individuals from each team took turns racing to the board to write down any words they know about Play activities around the circles. The teacher then checks with the whole class the spelling of the words, asks the pupils to practice the pronunciation of difficult words and uses a miming technique to elicit any target words that have not been written down. It is the observed, successful use of the listing task by the teachers and the pupils' enjoyment of the task that motivated my decision to include this task type in the design of the lessons for Phase 2 of this study.

In Nam and Hoa's thinking, this student-led brainstorming activity provided their pupils an opportunity to recall from their own vocabulary repertoire. As Nam explained:

I want to enhance learner-centreness rather than teacher centreness. Pupils were given opportunity to show what words they already know by writing them down. (Em muốn tăng cuờng việc lấy người học làm trung tâm hơn là giáo viên là trung tâm. Học sinh có cơ hội viết ra nhũng tù chúng đã biết.) (Nam, speaking lesson 1).

Similarly, Hoa added: 
This activity was fun and it also helped pupils recall their learned vocabulary very effectively and prepared them well for the new lesson. (Hoạt động này vui và nó cũng giúp học sinh nhớ lại tù̀ vựng mà nó đã học rất hiệu quả và chuẩn bị tốt cho bài mới.) (Hoa, speaking lesson 1).

These comments, together with the comments on the impact of the cognitively challenging activities on language learning presented above suggest that the teachers were, to some extent, oriented to principles of communicative and meaningful language teaching.

\section{(c) Vocabulary practice activity}

Only three teachers (Nhu, Mai and Ly) conducted this activity to help pupils practice and memorise the target vocabulary items which had just been presented. Some commonly used activities which had also been used in the warm-up activity were employed for the vocabulary practice activity. Such activities were Matching, Bingo, Pelmanism and Slap the board. These game-like activities made the class a fun environment for learning. For example, to help pupils memorise the vocabulary about dates of the week, Nhu engaged her pupils in a task of matching the letter forms of the words with their number versions. Nhu organised pupils into two groups of six pupils each. When the game started, pupils in each group took turns to run to the board to do the matching. Like the above-mentioned activities, this activity helped pupils memorize the new vocabulary words in a fun way. The teachers who carried out this activity emphasised the importance of having the pupils memorise the vocabulary items in the presentation phase before involving them in the practice activity.

In brief, the findings suggest that the participant teachers carefully prepared the pupils for their lessons by organizing several useful, vocabulary-based, child-friendly activities. Many of these activities were language games which were cognitively engaging and displayed some features of tasks. In addition, the findings from the interviews with the teachers reveal that the teachers believed that making the lessons more enjoyable was important, as was promoting learner-centeredness and working towards a communicative goal. From the teachers' observed practices and stated beliefs, it was clear that the teachers possessed capable pedagogical skills for teaching English to YLs and, to some extent, show an orientation towards communicative language teaching principles. 


\subsubsection{Teacher-led dialogue practice and explicit target structure explanations}

After the teachers prepared the pupils for the lesson through vocabulary-based activities, they all involved the pupils in the first textbook activity under Section 1, "Look, listen and repeat". In the "look" step, the teachers had pupils look at the pictures illustrating the dialogues and then elicited information about the pictures to guide pupils to the context in which the target structural patterns are used. In the "listen" step, the teachers played the recording of the dialogues while the pupils read the dialogues in the book and/or repeat the dialogues after the recording. Finally, in the "repeat" step, the teachers involved the pupils in repetitive practice of the dialogues before they explicitly presented the target structural patterns of the lesson. Along with the vocabulary-based activities described above, the practice of the dialogues and the explanation of the target structural patterns (in Vietnamese) marked the implementation of the presentation phase. These two activities were observed as follows.

The dialogue practice activity follows three main steps: (1) getting the pupils to repeat the dialogues after the teacher, (2) dividing the role between the pupils and the teacher, and/or (3) getting pairs/groups of pupils to play the role of the people in the dialogues. All of the participating teachers followed these three consecutive steps. Each spent between five to seven minutes drilling the dialogues. The implementation of this activity is typically illustrated in Nga's practice as follows:

Extract 1: (Teacher-led dialogue practice - Speaking lesson 2 - Teacher Nga)

01 T: Okay, now. How many pictures?

02 Ps: Hai (two), two

03 T: [T points at picture a] one, [T points at picture b] two. Now look at picture a, who are they? [T points at pictures of Linda, Mai and Mary]

04 Ps: Linda, Mai, Mary

05 T: And this one [T points at picture $b$ and then pictures of Linda, Mai and Mary in picture b.]

06 Ps: Linda, Mai, Mary

07 T: Now we will listen to their talk.

[T plays the recording. Ps listen to the recording twice and then $\mathrm{T}$ has Ps repeat the conversations in pictures $\mathrm{a}$ and $\mathrm{b}$ ]

08 T: Now class, repeat after me. This is Mai

09 Ps: This is Mai

10 T: Hello, Mai.

11 Ps: Hello, Mai.

12 T: Mai. This is my friend, Mary.

13 Ps: Mai. This is my friend, Mary.

14 T: Hello, Mary. Nice to meet you.

15 Ps: Hello, Mary. Nice to meet you. 
T: Okay. Now, now you are Mai [T points at Ps in the left-hand row]. Now you are Linda [T points at Ps in the middle row]. You are Mary [T points at Ps in the right-hand row]. Okay. Now Mai, Mai, raise your hand. Bạn nào là Mai đâu [Who are Mai?]. Okay, raise your hand. Okay. Mai, Mai.

17 T: Now class, now. [T points at Ps in the middle row]. This is Mai.

18 Ps: This is Mai

19. T: [T points to the Ps in the right-hand row and then point to the sentence "Hello, Mai"] Hello, Mai.

20 Ps: Hello, Mai.

21 T: [T points to pupils in the middle row]. Mai, this is my friend Mary.

22 Ps: Mai, this is my friend Mary.

23 T: Okay [T points at the Ps in the left-hand row]. Hello, Mary. Nice to meet you.

24 Ps: Hello, Mary. Nice to meet you.

25 T: Okay, Good! Now I need three people: one is Mai; one is Linda; and one is Mary. [T invites three Ps to stand up to play the roles of Mai, Linda and Mary]

In this interaction, before having the pupils listen to the recording, Nga elicited the two dialogues with pictures of the textbook characters in order to familiarize the pupils with the context of the dialogue (lines 1-6). Then, Nga led the pupils in repeating the dialogue (lines 8-15) after her before she then involved the pupils in practicing the dialogue in groups under her control (lines 16-25). Finally, Nga had the pupils practice the dialogue more freely in groups.

In the interviews, the teachers revealed both perceived benefits and drawbacks of following the procedures as laid out in the textbook. In terms of the benefits, all teachers acknowledged that the steps gave pupils practice in pronunciation and speaking English. They stated that repetitive practice helped their children remember the patterns better. As such, it prepared them well for the next activities. As one of the Grade 3 teachers, Mai, explains:

Repetitive practice helps the pupils remember the structures. The more they repeat the dialogues, the better they are able to say the structures. They cannot speak English if they do not remember the structural patterns. (Việc thực hành lặp đi lặp lại giúp học sinh nhớ cấu trúc. Các em thực hành càng nhiều, chúng càng có thể nhớ cách nói cấu trúc tốt hơn. Học sinh không thể nói được nếu các em không nhớ mẫu câu.) (Mai, speaking lesson 2)

However, some Grade 4 teachers, while acknowledging the benefits of following the steps, cited drawbacks. One drawback mentioned by three of the Grade 4 teachers concerns the mechanical nature of the activity. As Nam said, 
The steps are very mechanical. Pupils listen and repeat the dialogues, but they do not understand much from such repetition. The repetition just helps them practice the vocabulary. (Các bước máy móc quá. Các em nghe và lặp lại đoạn hội thoại nhưng chúng không hiểu nhiều tù việc lặp lại đó. Việc lạ̣p lại đó chỉ giúp các em thực hành tù̀ vưng.) (Nam, speaking lesson 2)

Hoa shared Nam's view on the benefit of practicing words by repetition. However, like Nam, she did not think that such repetitive practice would enhance real language use. As she said:

The steps are too mechanical and time-consuming, but I have to follow them one by one as required. Dialogue practice encourages learning from imitation. This fails to help real language use. In addition, some dialogues provided in the textbook are irrelevant. (Các bước này nguyên tắc quá vì mình phải làm bước này rồi mới tới bước kia. Điều này mất thời gian. Co hội học tập là bắt chước. Vận dụng là chura đạt và có nhiều bài họi thoại không có liên quan gì.) (Hoa, speaking lesson 1)

After the practice of the dialogue, the target structural patterns embedded in the dialogue were explicitly presented. The explanations focused on the form, meaning and use of the patterns. Some teachers explained these features more explicitly than the others. For example, Lan is one of the teachers who attempted to explain the target structural patterns most explicitly. The extract below demonstrates the way she presented the new patterns in one of her observed speaking lessons:

Extract 2: (Target structure explanations - Speaking lesson 1 - Teacher Lan)

01 T: Now you have read about this presentation, how to ask about the location of your school, the location of your school. How to ask, what question?

02 P1: [T calls one volunteer] Where is your school?

03 T: Where's your school? Very good! Okay. This is the grammar to learn today [T shows the question "Where is your school?" on the PPT slide] "Where's your school?" and you will answer by saying [T shows the answer form "It's in...." on the PPT slide)] ... it's in ..., it's in.... Okay? For example, our school, where is your school?

04 Ps: It's in Vo Thi Sau street.

05 T: Yeah. Very good. It's in Vo Thi Sau street. And so... what is the meaning of "Where is your school?" What is the meaning? 
07 T: Very good. [T shows the meaning of the question in Vietnamese]. And the usage [T shows the explanation of the usage in English], we use this question to ask and answer about the location of school ...location. [T writes on the board]. Write down in your notebook. Two minutes please. Two minutes.

\begin{tabular}{|l|}
\hline Where is your school? \\
It is in Vo Thi Sau street. \\
(Trường bạn ở đâu?)
\end{tabular}

As shown in the interaction, after explicitly presenting the target pattern, Lan carefully explains the meaning, form and use of the target patterns, as seen in lines 3,5 and 7 respectively. Finally, Lan asks the pupils to copy down the target patterns on the notebook for home study. In the interview, Lan reasoned as follows:

It was important for the pupils to know the target structures because it would be difficult for the teacher to carry out the next speaking activities without showing the pupils the structural patterns that they should use. (Việc học sinh biết cấu trúc để nói rất quan trọng vì sẽ khó có thể tiến hành các hoạt động nói tiếp theo nếu học sinh không biết trước mẫu câu các em nên dùng để nói.) (Lan, speaking lesson 1)

Lan's view on the value of explicit grammar explanations was not, however, shared by all the teachers. For example, unlike Lan, Hoa's explanations were much less explicit, even though she also presented the target structures in the presentation phase. To focus her pupils' attention on the target patterns, Hoa just had them repeat the target patterns she wrote on the board and then moved to the practice activity. She did not provide any further explicit explanation. Regarding this, Hoa had this to say:

Pupils cannot remember much from what the teacher said. They are not able to understand grammatical rules and explanations about language. Getting them to note down the language items on the notebook for home study will not help. They can only learn through using the language in real-life communication. (Học sinh không thể nhơ nhiều tùu những gì giáo viên nói. Chúng không thể hiểu qui tắt ngũ pháp và nhũng lời giải thích. Cho học sinh viết bài về nhà học sẽ không giúp ích được gì. Học sinh chỉ có thể học qua việc sử dụng ngôn ngũ trong giao tiếp thực tế) (Hoa, speaking lesson 2) 
By choosing not to explain the structural patterns explicitly, Hoa showed her orientation to meaning-focused instructions. Observation data revealed that Hoa saved the last few minutes in the lesson for her pupils to copy the target patterns down to their notebook for home study, even though she said that this was not useful for learning. She explained that having pupils record the content of the learned lesson in their notebook was a required practice at her school. Finally, it is important to note that more than half of the time allocated for a teaching period was spent for the presentation phase in all lessons.

\subsubsection{Practice phase}

The practice phase involved carrying out Section 2, namely "Point and Say" in a speaking lesson from the textbook. As specified in the teacher's book, the activities for this phase were primarily designed for pupils to carry out question and answer practice in pairs using the target question and answer patterns extracted from the dialogues. As Table 9 shows, in the 11 speaking lessons, the teachers spent between seven to ten minutes each conducting this practice activity. During this duration of time, the teachers conducted two principle activities: teacher-led drill practice and pair-work practice.

\subsubsection{Teacher-led drill practice}

Observation data showed that all teachers followed similar procedures to carry out these practice activities. For example, to conduct the ask-and-answer practice activity for the target pattern "What is the date today? It is ..." Nhu first ran through the four pictures and word prompts provided. Then she conducted the teacher-led drill practice activity by having pupils do the choral and then the individual ask-and-answer activity as follows:

Extract 3: (Dialogue practice - Speaking lesson 1 - Teacher Nhu)

01 T: Okay. Look at the board, please. [T points at picture 1] Can you tell me? What? ...The first-of-October. Again, the first of October.

02 Ps: The first of October

03 T: [T points at picture 2] The second of October.

04 Ps: The second of October

05 T: [T points at picture 3] The third of October.

06 Ps: The third of October.

07 T: [T points at picture 4] The fourteen of October.

08 Ps: The fourteen of October

09 T: [T points at picture 5] The twenty-second of October.

10 Ps: The twenty-second of October.

11 T: [T points at picture 6] The thirty-first of October.

12 Ps: The thirty-first of October 
13 T: Okay. I will ask and all of you answer. Now what is the date today? (T points at picture 1)

14 Ps: It's the first of October

15 T: What is the date today?

16 Ps: It's the second of October

17 T: What is the date today?

18 Ps: It is the third of October

19 T: Now change. All of you ask and I answer [Teachers point at the model question]

20 Ps: What is the date today?

21 T: [Point at picture 4] It's the fourteen of October.

22 Ps: What is the date today?

23 T: [Point at picture 6] It's the twenty-second of October.

24 Ps: What is the date today?

25 T: It is the thirty-first of October.

26 Ps: Okay. I need one pair. You ask and you answer. [T invites two Ps and points at picture 1]

27 P1: What is the date today?

28 P2: It's the first of October.

29 T: Very good! Thank you. Picture b, you ask and you answer, please.

30 P3: What is the date today?

31 P4: The second of October

32 T: Okay. Now listen. You answer [Teacher points at the pattern "It is..." and then picture $b)$. It ...

33 P4: It is the second of October

34 T: Very good. Sit down, please. Picture c, picture c. [T invites another pair]

35 P5: What is the date today?

36 P6: It is the fourteen...October

37 T: of ... of October

38 P6: of October

39 T: very good. Sit down, please. Picture e [T invites two Ps]

40 P7: What is the date today?

41 P8: It is the twenty-second of uhm uhm October

42 T: Okay. Very good. Sit down, please. [T invites another pair]

43 P9: What is the date today?

44 P10: It is the first uhm twenty-first of October.

In this interaction, Nhu first runs through the six pictures with word prompts with the whole class (lines 1-12). Then Nhu divides the role of asking and answering using the target patterns with the pupils (lines 14-25). After practicing with the whole class, Nhu asks pairs of pupils to practice the ask-and-answer patterns (lines 26-43). During this phase, in line 31, pupil 4 answers the question without using the pattern "It is...". That is why Nhu stops pupil 4 in line 31 to recast "It is..." so that this pupil can answer in a complete sentence. Similarly, in line 36, pupil 6 skips the word "of" in the answer. Nhu also stops this pupil and provides a recast for the word "of". Overall, Nhu spent a total of 4.5 minutes conducting this intensely teacher-led practice activity. By so doing, Nhu not only helped her pupils repeat the target 
patterns through her controlled practice, but she was also able to correct the pupils' mistakes to ensure the accurate production of the target language.

\subsubsection{Pair work practice}

The practice became less controlled when Nhu organised a pair work activity for further practice of the dialogue. Four minutes were spent on this activity, making a total 8.5 minutes for the practice phase. Below is how Nhu continued the practice:

\section{Extract 4: (Pair work practice - Speaking lesson 1 - Teacher Nhu)}

1 T: Now look we have one, two, three, four, five, six. We have six pictures. You are going to work in pairs. Chúng ta làm việc theo nhóm. (We will work in pairs.)

2 Ps: two

3 T: Mỗi bạn hỏi cho cô three pictures. (Each of you asks about three pictures.) Mỗi bạn hỏi cho cô bao nhiêu bức tranh vậy? (How many pictures does each of you ask?)

4 Ps: three

5 T: three pictures and then. Và sau đó chúng ta làm gì vậy? (What are we doing next?)

6 Ps: Đổi vai (change role)

7 T: Đổi vai (change role). Và chúng ta có two minutes (We have "two minutes”). Chúng ta có ... hai phút (We have ... two minutes). Are you ready?

8 Ps: Yes

9 T: Let's go

This interaction shows Nhu code-switching between English and Vietnamese to instruct her pupils about how to carry out the less controlled pair work practice activity. It seems that what Nhu expected was more like a substitution drill than a meaningful activity. Field notes reveal that this dialogue practice activity required little meaningful and communicative language use. Following the teacher's instructions, pairs of pupils simply looked at the pictures. In pairs, one student asked using the question prompt in the bubble, the other gave the answer using the answer prompt and the picture cues. From a task-based learning perspective, Willis (1996) argued that although this form of role-playing may carry meaning, pupils are not primarily concerned with meaningful and communicative exchange.

In the interviews, most teachers, notably Mai, Ly and Lan highlighted the important role the practice phase played in preparing the pupils for the production phase. They agreed that these mechanical drill exercises, which involved choral and individual drilling, give their pupils a sense of security and confidence to move to the production phase. In other words, they believed that before getting pupils to talk more freely about themselves, their world and 
to begin to interact with their friends in class, it was important for them to master the structural patterns through repetitive practice. Mai, a Grade 3 teacher provides a typical comment:

Pupils need a lot of repetitive practice to master the new structural patterns. If this step is skipped, it would be difficult for them to proceed to the production phase. (Hoc sinh cần luyện tập lạ̣p đi lạ̣p lại nhiều lần để thành thạo cấu trúc mới. Nếu bỏ qua buớc này, sẽ khó cho học sinh vào giai đoạn luyện nói cuối.) (Mai, speaking lesson 2)

However, while acknowledging this important role of the practice phase, some teachers also expressed doubt on the communicative value of this phase. For example, in talking about the practice phase in the interview, Nga provided an example from her lesson which asked her pupils to practice the pattern "Are they your friends? Yes, they are/No, they aren ' $t$ '. In the textbook, there are four pictures of textbook characters. Pairs of pupils are required to answer "Yes" to the first two pictures and then "No" to the second two pictures, although none of the characters in the four pictures are their real friends. Nga, a Grade 3 teacher, had this to say on this activity:

I feel that my pupils cannot learn much from this pair work practice. They have to keep in mind what they had to say "Yes" when they are asked about the first two pictures and then say "No" when they are asked about the next two pictures. The questions initiate meaningless answers. This practice is mechanical and unreal. (Em nghĩ học sinh không học được nhiều tù̀ việc thực hành này. Các em phải nhớ là phải trả lời "Yes" khi được hỏi về hai búc tranh đầu và trả lời "No" khi được hỏi về hai bức tranh tiếp theo. Câu hỏi chỉ dân đến câu trả lời không có ý nghĩa. Việc thực hành này là máy móc và không thục tế.) (Nga, speaking lesson 2)

Similarly, the three Grade 4 teachers Hoa, Nhu and Nam, while following the procedures required for this practice phase, expressed their concern about the communicativeness of this controlled practice activity. For example, Nhu pointed out the unrealistic features of the practice activity she carried out in Extracts 3 and 4 above. She stated that this just helped the pupils practice saying the vocabulary items of dates. As Nhu said, 
The pictures provided in the books are unrealistic. You see, it is now September not October. But pupils had to say it is October when they answered the question "What's the date today?" This is just meaningless practice, just for mastering saying the dates. (Các bức tranh trong sách không thực tế. Chị thấy đó bây giờ là tháng chín chứ không phải tháng 10. Nhung học sinh phải nói là tháng 10 khi chúng trả lời câu hỏi 'What is the date today?' Cái này là thục hành máy móc, chỉ giúp luyện nói ngày tháng cho thành thạo.) (Nhu, speaking lesson 2)

Overall, the results show that all teachers followed similar procedures in carrying out the practice phase. They all taught the controlled drill practice activity provided in the textbook. This activity, based on its design and implementation, was primarily aimed to help pupils memorise the target structural patterns. While most teachers recognized that as a practice activity it prepared their pupils for the production phase, many expressed concern about the communicative value of the activity.

\subsubsection{Production phase}

Results from the analysis of the classroom observation data indicate that the production activities in the textbook were carried out in three different ways. Table 9 shows that only two of the 11 production activities in the textbooks (2/11) were conducted as freer practice activities in which pupils exchanged personal or real information in pairs or groups before they demonstrated their work in front of the class. Four activities (4/11) were replaced with interactive games which stimulated meaningful exchange in a joyful way. Five (5/11) were replaced with communicative tasks. Table 9 shows that the time allocated for each production activity ranged from 2.5-10 minutes. In the following section, I provide three classroom examples to illustrate the three types of adapted production activities. The examples were selected purposely from the seven teacher's observed classroom practices, to represent, respectively, activities that are freer practice activities, interactive games and communicative tasks.

First, the two freer practice activities were conducted as instructed in the teacher's book. Pupils were organized in pairs or groups and asked to reproduce the language they had just learnt using information about themselves. The two identified activities were conducted by Lan in both of her observed lessons. In her speaking lesson 1, for example, after having pupils practice asking and answering about the location of the schools in the four pictures provided in the practice phase using the patterns "Where is your school? It is in..." Lan 
asked pupils to get into pairs again to ask about their own school. Then she invited two pairs of pupils to come to the front of the class to demonstrate their work. Although this activity involves "a series of mini task-planning-report cycles" (Willis, 1996, p. 145), it nevertheless falls short of an actual task. It does not have an authentic outcome or involve a real meaning focus. All the pupils really do is ask and answer questions with the same information (they are in the same school). When asked to comment on this production activity, Lan explained:

This is my initial plan [...]. I want to know whether the pupils are able to ask about their own school after the lesson. Furthermore, if the pupils practice asking and answering about their own school, they will be able to answer this question when someone asks them. The aim is to help pupils apply what they have learned in real situations. They can ask and answer about their own school. (Tại vì đây là dụ định ban đầu của em [...]. Sau khi học xong thì em cho các em tụ trả lời xem có được không. Hơn nữa, nếu thực hành về trừ̀ng của mình thì sau này ra ngoài có ai hỏi về truò̀ng của mình thì các em cũng biết cách trả lời. Mục tiêu là muốn các em ứng dụng thực tế cái đã học. Các em có thể hỏi và trả lời được về trường của mình." (Lan, speaking lesson 1)

This comment suggests that Lan was committed to creating opportunities for her pupils to use the target language in a meaningful way. She believed that this particular activity enabled her pupils to use English for real-life communication. She was satisfied when her pupils were able to ask and answer confidently about their school in their performance in front of the class. However, Lan also expressed concerns about the limited time for this production activity. Table 9 shows that Lan allocated four minutes for this activity (two minutes for pair work practice and two minutes for performance). In essence, this activity was similar to the pair work practice activity except for the fact that it provided opportunity for more meaningful communication exchange. The pupils talked about their own school not the school provided in the pictures. However, though most performed the activity successfully, they showed little excitement. The fact that the activity lacks an engaging outcome and game-like elements may have made it less interesting to the pupils.

Second, while Lan carried out the freer practice activity provided for the production phase in the textbook, some other teachers (Hoa, Nhu, Nam and Mai) replaced the textbook production activity with interactive games in one of their observed lessons. These interactive games were observed to create a more engaging opportunity for interactive language practice. 
Table 9 shows that four teachers carried out this type of activity in four different lessons. A typical example of such an activity can be seen from Hoa's observed speaking lesson 2. Hoa carried out a game, namely "Passing the puppet" for her pupils to practice asking and answering about ability, using "What can you do? I can ..." and "Can you...? Yes, I can/No, I can' 't'. When the music was on, the pupils passed a puppet around the class. When the music stopped, the pupil who kept the puppet was allowed to ask any peer a question. The pupils enjoyed the game a great deal. They seemed to be excited at the music and at the fact that they could invite their friends to answer their questions. Hoa had this to say about this game:

This activity aims to create a relaxing classroom atmosphere and to enable a freer and more meaningful practice. Pupils could ask who they want to instead of asking and answering from the pictures provided. (Hoạt động này nhằm tạo bầu không khí thoải mái trong lớp học và để tạo điều kiện cho học sinh thục hành nói tụ do hơn và có ý nghĩa hơn. Học sinh có thể hỏi bạn nào nó muốn thay vì hỏi và trả lời dựa trên các búc tranh.) (Hoa, speaking lesson 2)

Finally, five communicative task-like activities (two language games and three interviews) were designed to replace the textbook production activity by Nhu, Hoa, Nam, Ly and Nga. A typical example of a language game can be seen from the observed speaking lesson conducted by the Grade 3 teacher, Nga. Nga replaced the production activity in the textbook in Lesson 2 in Unit 5 which asks pupils to ask and answer whether the textbook characters Mai, Nam, Phong and Quan are their friends with a guessing game. The target sentence structures are "Are they your friends? Yes, they are/No, they aren' $t$ ". Pictures of four textbook characters were provided. However, Nga did not use those textbook pictures. She brought to the class pictures of her own pupils and those in other classes in the same school. Before she showed the whole pictures on the screen, she asked the pupils to turn to each other to discuss whether the pupils partly hidden in the pictures were their friends or not. After that she showed the whole photos for pupils to check the results. The purpose of this game was thus meaningful to them. It involved a non-linguistic outcome because the pupils have to decide whether their guesses are right or wrong.

Observation notes reveal that the pupils were stimulated by the authentic photos. When Nga showed the photos on the screen, many pupils shouted excitedly "Yes" and "No" in response to the photos. Given their less target-like responses, Nga slowly recast a target 
answer "Yes, they are or No, they aren ' $t$ " and asked the whole class to repeat the correct responses.

Nga expressed her satisfaction with her pupils' performance. She said that she was happy because her pupils participated actively in working out whether the pupils in the pictures are their friends or not using English. She attributed this engagement to the meaningfulness of the activity which, as Nga believed, encouraged more effective communication:

This activity engaged pupils effectively because it was meaningful to them. The engagement enabled them to communicate better with their peers. (Hoạt động này thu hút học sinh hiệu quả vì nó có ý nghĩa. Việc tập trung này giúp các em giao tiếp với bạn tốt hơn.) (Nga, speaking lesson 2)

In the interview, Nga also further explained the reason why she replaced the production activity in the textbook with this guessing game. As she said,

The production activity in the textbook wasn't used because it is not communicative. Pupils can't give a meaningful answer by looking at the pictures of the characters in the book and ask whether they are their friends. (Hoạt động nói tụ do trong sách không thể sử dụng vì nó không có tính giao tiếp. Học sinh không thể cho câu trả lời ý nghĩa bà̀ng cách nhìn vào các bức tranh về các nhân vật trong sách và trả lời xem có phải bạn các em không.) (Nga, speaking lesson 2)

Such a commitment to meaningful communication drove Nga to invest her effort in designing the guessing game. Also driven by this commitment, like Nga, the three Grade 4 teachers (Hoa, Nhu and Nam) replaced the production activities in the textbook with interview tasks in one of their observed lessons (the speaking lesson 2). The tasks were organised in the way that involved pupils in both rehearsal and performance phases. In the rehearsal, the pupils exchanged real information in pairs, groups or with the whole class before they were invited to give a performance in front of the class. For example, Nhu organized an interview task. Each pupil was given a handout with a table to complete with information about the names and the dates of birth of at least three pupils in the class. The pupils circulated around the class to interview their friends for information to fill out the interview form. When the form was completed, Nhu invited two volunteers to go to the front 
to report the findings to the whole class. Below is what Nhu said about the interview task she carried out:

When I organised the interview activity, my pupils had more opportunities to communicate with their peers and they did not have to focus their attention on the textbook. (Khi em tổ chức hoạt động phỏng vấn, học sinh có nhiều co hội hơn để giao tiếp với bạn và các em cũng không phải tập trung sụ chú ý vào trong sách.) (Nhu, speaking lesson 2)

Nam also used similar procedures to carry out the interview task in his speaking lesson 2. The pupils were also given an interview sheet on which they had to fill in with the names and hobbies of three pupils in the class and then report the results to the class. Nam comments on this task:

In this activity, I want my pupils to decide who they want to ask. They can interact with more peers, not just the one next to them. Pupils can ask what they really want to know in English and their peers can give a true answer. This activity also excited my pupils a lot. (Ở hoạt động này, em muốn học sinh quyết định hỏi bạn nào các em muốn. Các em có thể nói với nhiều bạn hơn, không chỉ bạn ngồi kế bên. Học sinh có thể hỏi nhũng gì chúng thật sụ muốn biết bằng tiếng Anh và bạn các em có thể đưa ra câu trả lời thực tế. Học sinh rất hứng thú với hoạt động này.) (Nam, speaking lesson 2)

From Nhu and Nam's comments it appeared that they shared the same belief about the benefits of using the interview task. The main benefit, as they said, was related to the way the tasks provided opportunity for free, meaningful communication.

To sum up, data from the observation and stimulated-recall interviews showed that the teachers were committed to adapting the production textbook activities and demonstrated their effective pedagogical skills to implement them. In the hands of the teachers, the adapted production activities, despite differing in their design, shared the common goal of increasing opportunities for purposeful and meaningful practice and, at the same time, of realizing the objectives stated in the textbook. Many of the activities possessed features of tasks, even though none of the teachers were aware of tasks or TBLT. The interview findings regarding the teachers' perceptions of their implementation decisions revealed that there were mixed 
views on the implementation of the PPP approach in their speaking lessons. To explore these issues further, follow-up in-depth interviews were conducted with each of the teachers. Results from the interviews are reported in the following section.

\subsection{Teachers' views of the PPP speaking lessons}

This section presents data from follow-up, in-depth interviews with each of the seven teachers. The purpose of these interviews was to explore in greater depth how the teachers perceived using the PPP sequence for teaching the textbook speaking lessons. The interviews were conducted as a discussion between the teachers and the researcher in order to invite the teachers to elaborate on their teaching practice and specifically about the PPP sequence they had closely followed to teach the speaking lessons.

First, the teachers were asked why they chose to follow the PPP sequence set out in the textbook. Six of the seven teachers commented that they used PPP because the local educational authority expected them to follow this sequence. For example, as Nam commented:

I have to use the traditional teaching method when I teach in my school because it will be a disadvantage if I do not follow the established rules. (Em phải sư dụng phưong pháp truyền thống để dạy ở trường vì nếu không em sẽ gặp bất lợi nếu không dạy theo qui định.)

One of the disadvantages that Nam further elaborated was shared by Nga:

I have to teach the steps in the textbook. If not, my pupils will not be well-prepared when their class is observed. (Em phải dạy theo các buớc qui định trong sách giáo khoa. Vì nếu không làm vậy thì học sinh sẽ không được chuẩn bi tốt khi có người dụ giờ)

Hoa who shared with Nam and Nga the above-mentioned disadvantage shared a story of being criticized by a district education officer for not closely following all of the steps required for teaching a speaking lesson when she joined a teaching competition.

The teachers were then asked about their general perceptions of the PPP approach. Their responses reveal their varying views of this approach. Except Ly who tended to be somewhat 
neutral about this approach, the other six teachers were divided in their views of the PPP approach. Three of the teachers (Lan, Mai, Nhu) expressed positive views about this approach. They noted that the PPP sequence was suitable for lower level classes because it provided a predictable lesson structure. Furthermore, because they had learned to use this approach in their pre-service teacher education, they were familiar with it. A typical comment is provided by Nhu:

I have followed the PPP approach because I learned this approach in my pre-service education and from my colleagues. I find it effective for teaching speaking skills in that following this sequence, new target language items are drawn from contexts. Pupils learn how to communicate from the contexts. Repetitive practice is needed for the learning of new language items $[\ldots]$ only after a lot of repetition can pupils develop their fluency in the production phase. (Em sủ dụng phưong pháp PPP vì em hoc phương pháp này ở đại học và hoc tù đồng nghiệp. Em thấy phưong pháp này hiệu quả khi dạy kĩ năng nói vì khi dạy theo phương pháp này mình có thể rút ra cấu trúc mới tù̀ ngũ cảnh. Học sinh học cách giao tiếp tù̀ ngũ cảnh được cho. Sau đó học sinh cần thực hành tới lui nhiều lần. Chỉ có thực hành nhiều lần học sinh mới nói lưu loát ở giai đoạn nói tụ do.)

Familiarity with the PPP approach made it easy for not only the teachers, but also their pupils. This is the only advantage that Hoa could say about the PPP approach. As she said,

The advantage when I follow the steps is pupils are familiar with the steps, so the teaching is smoother. Pupils could approach the lessons more easily. However, I still feel that pupils' speaking and listening skills are not fully developed. (Thuận lợi của phương pháp này vì là học sinh đã quen với các buớc nên lúc dạy nhẹ nhàng hơn và hoc sinh có thể theo bài dễ dàng hơn. Tuy nhiên, em vẫn thấy kĩ năng nghe nói của học sinh không được phát triển đầy đủ.)

While noting this advantage, Hoa and the other two teachers Nam and Nga spoke extensively about its limitations. Their comments reveal two main themes regarding the limitations of the PPP approach. The first common theme is that the PPP approach is boring, mechanical and time-consuming. As Nam comments, 
I have noticed that some structural patterns in the presentation phase are quite long and if I follow all the required steps, I will have to spend a lot of time and my pupils will also get bored. As a result, they will refuse to repeat the dialogue. The steps are "I ask them, they ask me"; then Group A asks group B; then closed pairs and open pairs. I feel this procedure is quite boring. (Em thấy là một vài mẫu câu trong giai đoạn trình bày khá dài. Nếu em làm theo tất cả các bước thì sẽ mất rất nhiều thời gian và học sinh sẽ chán. Lúc đó nó sẽ không chiu thục hành đoạn nói lặp lại đoạn hội thoại. Các bước trong thục hành đoạn hội thoại là em hỏi, học sinh trả lời. Sau đó, nhóm A hỏi nhóm $B$ và cuối cùng là cặp đóng và cặp mở. Em thấy các buớc này khá nhàm chán.)

According to Nga, this issue was particularly problematic for her high proficiency pupils who could get bored easily because of the lack of challenge of the lesson. As Nga comments,

I have based my teaching on the three steps for a year and found it ineffective [...]. Some lessons were too easy, which bored the pupils. They even ignored my first step of presenting the language. They did not look at all. (Em đã dạy theo các bước này đurợc một năm và thấy nó không hiệu quả. [...] Một số bài hoc quá dễ nên học sinh chán. Các em thậm chí không chịu chú ý trong giai đoạn giới thiệu ngũ liệu. Các em không chịu nhìn luôn.)

A second common theme concerns the extent to which the PPP approach can enhance language learning. According to these teachers, the PPP approach is less effective in its impact on learning because of its overemphasis on form practice rather than communicative use. As Hoa comments:

I think the steps are so fixed. It's like we arrange and assign things for pupils. We show them this is what they should say. Then pupils just have to follow the structural patterns we have taught them. This fails to enhance pupils' ability to use the language. I also think that here teachers play a more central role and just lead pupils to what they want them to do. [...] It is like the learning process is very theoretical. It means we have to provide pupils something in advance and then they have to follow. We provide the theory for pupils before we get them to practice. I think this can't enhance pupils' ability to use English language. It is like we force them to do what we want them to 
do, speak what we want them to speak. (Em nghĩ các buớc quá cúng ngắc. Giống nhu mình sắp xếp và đura việc cho học sinh làm. Mình chỉ các em là các em nên nói cái gì. Sau đó, các em chỉ cần bám theo cấu trúc đã học. Cái này không giúp tăng cuờng khả năng sử dụng ngôn ngũu. Em cũng nghĩ là ở đây giáo viên đóng vai trò trung tâm để hướng dẫn các em nên làm gì [...] Giống nhu là việc học rất lí thuyết. Nghĩa là mình phải cung cấp cái gì đó cho học sinh trước và chúng chỉ cần làm theo. Mình cho nó biết lí thuyết truớc khi cho nó thục hành. Em nghĩ cái này không giúp tăng cuờng khả năng sủ dụng tiếng Anh. Giống nhu là mình ép học sinh làm điều mình muốn, nói cái mình muốn.)

Moreover, as shown in the observational data, the presentation and practice phases took a considerable amount of time, leaving a very limited amount of time for the production phase (2.5-10 minutes). This suggests that too much focus on practicing reproduction of the target vocabulary and structural patterns in the first two phases limited time for communicative language use. This concerned Hoa who was dissatisfied with the time allocated for communicative practice even though she was one of the three teachers who spent the most amount of time on the production phase in her observed lessons. Below is Hoa's comment,

The time allotted is not enough to maximize the communication ability in pupils. It is because the production phase just lasts around 10 to 15 minutes. I think it is quite short while this phase is very important. This is when pupils apply what they have learned in practice and expand their conversation beyond the structures they have just learned in the presentation and practice phases. (Thời gian không đủ để phát huy tối đa khả năng giao tiếp cho học sinh. Cái này là vì giai đoạn nói tụ do chỉ có tùi 10 đến 15 phút. Em nghĩ thời gian nhu vậy là khá ngắn mà giai đoạn này rất quan trọng, Đây là lúc học sinh áp dụng nhũng gì các em đã học vào thực tế và mở rộng giao tiếp sủ dụng nhiều hơn cấu trúc đã học trong giai đoạn trình bày và thục hành.)

Finally, I asked the teachers to comment on an approach that prioritises meaning over form. Specifically, I asked the teachers for their opinions on an approach that engaged pupils in communicative activities before the teacher elicited the performance of the activities to draw out the target structures. Nhu, Lan and Mai who were in favour of PPP avoided commenting on the meaning-focused approach being introduced. However, they expressed a wish to see how the approach might work in practice. The teachers who were negative about 
PPP were all receptive to the approach. Nam, for example, was quite positive although his pupils' proficiency was lower. As Nam comments,

I think it is better when pupils learned by doing or through activities. I think the pupils themselves can also learn better in this way than from what we have prepared for them. (Em nghĩ cho học sinh học qua làm hay qua các hoạt động sẽ tốt hơn. Em nghĩ bản thân học sinh sẽ hoc tốt bằng cách này hơn là học tì̀ nhũung gì mình đã chuẩn bị sã̃n cho các em.)

When asked about this, Nga talked about her effort to reverse the sequence of activities so that the production activity came first before any attention was given to forms. It is important to note that Nga's pupils were stronger than those of other Grade 4 teachers. As Nga explains it,

Yes, I have learned a lesson from this, so I decided to reverse the steps if the lessons were easy. I had them to do the difficult part first [the production phase], and moved quickly through the other two parts. Then I provided them with the rules or something they need in the end. [...]. For example, as you can see in activity 3 , I asked them to look at the pictures and encouraged them to talk about the pictures. The aim was to see what was known to them. Their performance helped me decide whether they were able to cover the lesson of the day. If it was enough, I got them to practice right after that. (Vâng, em đã học được một bài học tù việc này nên em quyết định hoán đổi các bước nếu bài học dễ. Em cho học sinh làm phần khó trước (the production phase) và dạy nhanh các bước khác. Sau đó em cung cấp qui tắc và nhũng cái cái em cần biết ở cuối giò̀ học. [...] Ví du nhur, nhu chị thấy ở hoạt động 3, em kêu các em nhìn vào tranh và khuyến khích các em nói về các bức tranh. Mục đích là để xem các em đã biết gì về bài hoc mới. Khi quan sát các em thục hành, em sẽ biết là các em có thể nắm được bài học hôm nay không. Nếu thấy vậy là đủ, em cho các em thực hành ngay sau đó.)

This comment suggests that Nga actually experimented with a TBLT approach in her practice without explicit awareness of doing so. 


\subsection{Discussion of teachers' implementation of the speaking lessons}

This Phase 1 of the study investigates how the Vietnamese EFL primary teachers implemented the PPP textbook speaking lessons and how they viewed the lessons. The overall results reveal that although the teachers closely followed the PPP approach as prescribed in the teacher's book, they were divided in their perceptions of the approach they employed to teach the lessons.

The findings from the classroom observations show that most teachers carried out all three phases of the PPP speaking lessons. In the presentation phase, the teachers actively involved pupils into the lesson through interactive game-like activities and prepared necessary input (i.e., key vocabulary and target structural patterns for them to carry out the practice and production activities). In the practice phase, the teachers involved pupils in intensive repetitive practice for them to master the target patterns before they moved to the production phase. All teachers carried out the production phase. Of note is that many teachers attempted to replace the textbook production activities with communicative activities and tasks in order to provide opportunities for freer and more meaningful language use. By including communicative activities and tasks in the production phase, the teachers showed a strong tendency to develop pupils' oral communication ability. The reasons these teachers gave for their activity choices reflect an awareness of underlying principles of communicative language teaching: the notion of context (real-life situations) indicated in the curriculum guidelines; the concept of "learning by doing"; and, the idea that pupils should be putting language into use rather than just drill practice (Willis \& Willis, 2007). Overall, the teachers understood the role that they play in motivating pupils and the importance of meaningful and communicative language use.

This finding that the teachers carried out the final P (Production) in the PPP lesson contrasts with results of a previous study in a similar context by V. G. Nguyen et al., (2015) These researchers" exploration of high school teachers in Vietnam showed that teachers "had little time, or apparently expertise to implement the third phase where pupils should use the target structures in freer production activities" (p.80). In addition, the findings that the teachers tried to engage pupils in meaningful and communicative tasks in the production phase was inconsistent with the results of the study by Nguyen (2011) who found that the Vietnamese EFL primary teachers at a public school "emphasise [d] mastery of sentence patterns and words rather than simulating creative or real-world communicative use of language" (p.240) and lacked the awareness, skills and resources to develop a more 
communicative pedagogy. This discrepancy may be explained by the fact that Nguyen's (2011) research was carried out at a time when the new curriculum had just been introduced and the new textbooks had not been used. Thus, teachers had little experience with the new curriculum and particularly with teaching English communicatively. More recent English teachers in Vietnam may be developing better capacity for teaching English as the curriculum progresses. Over time, they may be becoming more accustomed and comfortable with communicative language teaching.

Although the findings showed positive signs for teachers using communicative activities in their practices of the PPP lessons, they reveal several concerns regarding the implementation of the PPP speaking lessons. First, there appears to be a situation among the teacher practices that the teachers were under pressure to cover the textbook content and to carry out all the steps required for the presentation and practice phases such as the dialogue practice activity and the drill practice activity, respectively. This practice impacted on the time available to carry out the communicative activities as well as the tasks designed for the production phase. In fact, the results suggest that much of the time (more than $70 \%$ for Grade 4 and $80 \%$ for Grade 3 ) in the observed lessons was devoted to what could be described as teacher explanation or form-focused practice rather than activities for communicative use. As a result, although the teachers expressed commitment to incorporating stimulating interactive games and communicative, task-like activities in the production phase, such commitment treated the games and task-like activities as "cherries on the cake" (Vale \& Feunteun, 1995, p. 69), which means that limited remaining time consequently prevented the pupils from actually tasting the cherries. In other words, these activities were viewed more as "nice to haves" rather than "essentials".

Another concern is that although the teachers had expertise and skills in designing and organising child-friendly communicative activities and tasks in order to engage pupils in meaningful language use in the production phase, they treated the activities and tasks simply as a means of practicing the target form and thus continued to focus primarily on form rather than on meaning. From a task-based language teaching perspective, Willis (1996) claimed that such an upfront focus on form might result in the pupils still being "in practice mode" (p.134) or "still in the mind-set that is concerned with producing specified forms" (Willis \& Willis, 2007, p.209), even though the pupils used the target forms in a freer and more meaningful production. These claims applied to the context of this study. Although there was no data that captured the pupils' interaction in pair and group work during the production phase, findings from the observation notes and audio recording of whole class interaction 
showed that most pupils showed control of the structures rather than expressing their own meaning in the production phase. Since the target structural patterns had been explicitly presented and extensively practiced before the freer production practice activities, the pupils seemed to have little difficulty communicating in this phase. As a result, there was little evidence of these pupils engaging in important goal-oriented interaction during which they exchange information, negotiate to achieve its comprehensibility or engaged in "push output" opportunities (Swain, 2005). Overall, the results suggested that the teachers' implementation of the speaking lessons reflects a version of PPP or TSLT, so an absence of the kind of interactive processes argued to generate the psycholinguistic affordances for language learning.

However, as noted above, what is surprising is that although all seven teachers followed the PPP approach, three of them were negative towards this approach. For example, Nga's views reflected certain principles of communicative and task-based language teaching when she reported she sometimes reversed the PPP sequence by carrying out the production activities first or skipping the presentation phase. Nam and Hoa were dissatisfied with the repetitive nature of the PPP lessons and expressed a desire for ways to enhance the communicativeness of the lessons. What is common among the teachers is their commitment to enhancing their pupils' communicative ability. However, despite their negative views of the PPP speaking lessons, none of the teachers was aware of TBLT or any other effective ways to enhance communicative language use in their classrooms.

Looking back at the findings, there are signs that these teachers appeared to be ready to adopt a more communicative way of teaching English or specifically a more task-based approach to language teaching. It is, however, important to note that research has shown that adopting a more task-based approach to TBLT in the Asian context have met with numerous constraints (e.g., Adams \& Newton, 2009; Carless, 2004; Zhang, 2015). Among the many constraints, teachers' misunderstanding of TBLT, their inability to carry out communicative tasks in authentic classrooms and their negative attitudes towards communicative and taskbased language teaching have been widely reported. Given the constraints, researchers such as Carless (2009) have called for the task-based approach to be adapted so that the communicativeness of the PPP speaking lessons can be enhanced. Other researchers such as V. G. Nguyen et al., (2015) suggest incorporating the principles and procedures of tasks into the production phase given that teachers are unable to implement this phase, thus encouraging TSLT as a preparatory step for adopting a task-based approach. 
However, for the teachers in this study, it seems unnecessary to adopt this initial step of adopting TSLT. The results showed that teachers tended to take a stronger task-supported teaching approach. They were not only able to implement the production phase, they were also able to develop and innovated on the textbook production activities changing them into tasks and implementing them successfully. As such, what should be taken into consideration is the teacher factor. Researchers (e.g., Carless, 2003; Deng \& Carless, 2009; Nguyen \& Nguyen, 2017) have reported that failure to implement TBLT may be due to the fact that teachers lack the ability to implement tasks and have insufficient training in the use of TBLT. In considering this issue, at the conclusion of Phase1, I was confident that with sufficient and quality training, the teachers in this study would have confidence and necessary skills to implement TBLT in Phase 2 given their strong pedagogical skills and their positive attitude towards CLT. However, while the teacher factor can be resolved, the remaining concern was how to introduce TBLT in authentic classrooms while teachers are obliged to cover the textbook content. My solution to this problem was to find ways to design task-based lessons based on the existing PPP textbook lessons. The next chapter will present the process of redesigning the PPP speaking lessons to be implemented in Phase 2 of the study.

\subsection{Summary of Phase 1 findings}

This chapter consists of two main sections which have alternatively reported findings regarding the teachers' implementation of the PPP textbook speaking lessons and their views of the lessons. The findings showed that the teachers closely followed the PPP sequence in the textbook. However, they were also found to add tasks and task-like activities to the presentation and production phases to increase opportunities for meaningful and communicative practice. In particular, although the teachers followed the PPP sequence, their perceptions regarding their implementation of the PPP lessons varied. The teachers who expressed positive views of the lessons agreed that the PPP approach was suitable for low level YLs. The ones who hold negative views of the lessons expressed the view that the PPP approach was mechanical, time-consuming and boring. It thus fails to enhance learners' communicative competence. These concerns of the PPP speaking lessons motivated Phase 2 of the study which investigated the implementation of the task-based versions of the PPP speaking lessons. The results of this implementation are reported in Chapter 6 after a discussion of the redesign of the PPP speaking lessons in Chapter 5 below. 
This page is intentionally left blank 


\section{CHAPTER 5 LESSON DESIGN}

\subsection{Introduction}

This chapter provides an account of why and how I redesigned the two PPP speaking lessons to reflect more closely the principles of task-based language teaching for use in the classroom as part of Phase 2 of the research. As such this chapter acts as a bridge between the evaluation and description of how teachers taught the current PPP speaking lessons and how they taught the redesigned task-based versions of the lessons. This process of redesigning the PPP lessons included input from the three teacher participants in the study. I begin by reflecting on the implications of findings in Phase 1 for the redesign of the textbook speaking lessons and proceed to document the process that I went through to redesign the lessons. The final section involves my reflection on some key elements of the redesign.

\subsection{Reflecting on Phase 1 results}

As both a teacher and teacher trainer, I have had first-hand experience with the shortcomings of the PPP approach currently being used in the teaching of speaking lessons for primary school pupils in Vietnam. In particular, the shortcomings concerned challenges centred around a teacher-centred approach and a lack of focus on meaningful communication. For years, I wondered whether other teachers had experienced similar issues with this all too common practice. Therefore, interviewing the participant teachers offered me a valuable opportunity to investigate formally what other professionals, like myself, thought of the PPP approach.

As discussed in Chapter 4, three of the seven interviewed teachers shared my concerns about the ineffectiveness of the PPP approach. These teachers commented that it was difficult to keep pupils engaged and communicated concern about the mechanical nature of the PPP speaking lessons. This was especially, true for one of the teachers, Hoa, who spoke extensively about the PPP speaking lessons and went as far as to express a wish that my research could help bring about ways to enhance the communicativeness of the PPP speaking lessons.

Through my observation of the teachers' implementation of the PPP textbook speaking lessons, I noted two particular issues that would inform the redesign. First, I appreciated the teachers' commitment to enhancing pupils' communicative ability by providing additional (i.e., outside of the prescribed textbook activities) opportunities for 
meaningful communication. Despite this, however, I found that teachers' practice primarily focused on helping their pupils master the prescribed structures and display their mastery of these specific structures. Second, I observed that the teachers tended to teach to their textbooks, and felt strongly obliged to do so. Thus, I was aware that any adaptations I planned to make to the PPP speaking lessons needed to incorporate the available textbook content.

My exploration of research literature on TBLT (e.g., Edwards \& Willis, 2005; Shintani, 2012, 2014, 2016) found that teachers worldwide shared similar concerns about the limitations of the PPP approach and had also successfully used the task-based approach to address these concerns. A teacher in Japan, for example, successfully used a task-based approach with her young and beginner learners in her private language centre (Shintani, 2012, 2014, 2016). Shintani found that by introducing task-based activities her pupils improved their vocabulary and grammar more effectively than the PPP approach. In thinking of how to approach this process of activity revision, I had to consider the fact that the teachers in my study did not have as much freedom as others have had to introduce TBLT into their classrooms. I concluded that the best possibility for introducing TBLT was to adapt the existing PPP speaking lessons to reflect TBLT principles rather than completely replacing the PPP speaking lessons.

With these parameters in mind, in the middle of October, 2015 as I was about to finish collecting data for Phase 1, I took my plan of redesigning the PPP lessons to the three Grade 4 teachers. All three teachers supported my plan and agreed to assist. After discussing time and availability, we chose to redesign the two PPP speaking lessons in Unit 8 in the Grade 4 textbook (see Appendix 7 for the textbook lessons). These lessons were chosen because the observation of the Grade 4 teachers' implementation of the textbook lessons ended at Unit 7 and the teachers were available to implement Unit 8.

With committed support from the teachers, I started preparing the redesign. Although the teachers were not directly involved in redesigning the lessons due to their busy schedule, they were able to provide valuable comments on the lesson plans.

\subsection{Preparing for the redesign}

To prepare for the redesign process, I followed Ellis's (2003) suggestion of first deciding on the basic format of a lesson and then worked on developing the idea for the main task. The lesson was centred around this task. Willis's (1996) seminal work on TBLT proposes a flexible TBLT framework for beginners and YLs and suggests ways to adapt it to 
suit other learners. The inherent flexibility of this framework was a key consideration in my decision to adopt it for my redesign.

According to the framework, a task-based lesson includes three main phases: pre-task (introduction to topic and task), task cycle (task-planning-report), and post-task (language analysis and practice) (see Section 2.4.1). For beginner and YLs, Willis suggests lengthening the pre-task phase to give more weight to exposure to language input. To reflect this advice and to match the amount of input in the existing textbook presentation phase, I decided to include two preparatory activities in the pre-task phase: a vocabulary priming activity and an input-based listening task. The vocabulary priming activity was already a regularly used activity in the teachers' implementation of the textbook speaking lessons. The input-based listening task was also not completely new, but was a modification of the presentation phase in the textbook. This modification turned the "Look, listen and repeat" textbook activity into a listening task designed to capture pupils' interest and provide meaningful exposure to the target forms. The modification also helped ensure that the textbook content was covered. Overall, these preparatory activities helped achieve three objectives: (1) to help teachers cover the textbook content, (2) to prepare pupils for the main tasks, and (3) to address teachers' concerns regarding their pupils' ability to do the main tasks.

For the task cycle, Willis suggests including a set of short tasks for beginners and YLs. However, given that the pupils in my study already had some background English knowledge, I felt that they could just do one main task in the task cycle rather than a set of short tasks. The main task was the two-way information gap task developed from the "Point and say" practice activity from the speaking textbook lesson. This activity involves pair work exchange, which could be turned into a task by adding an outcome and splitting the information to create a gap. These revisions were incorporated to ensure that the activity would meet Ellis's (2003) four criteria for tasks: (1) a primary focus on meaning, (2) some kind of gap, (3) a non-linguistic outcome, and (4) learners drawing on their own resources to achieve task outcomes. In considering the focus for the main task, a focused task which helps pupils to implicitly learn the target structural patterns (Ellis, 2003) would meet the objectives of mastering the target structural patterns required in the textbook speaking lesson. Moreover, the two-way information gap tasks where there has to be information transfer between the two speakers reflected the nature of the textbook practice activity.

In addition, as Willis suggests, the main task should be followed by the planning and report activities and, for young and beginner learners, these activities should take less time or be conducted with teacher assistance. The planning activity where pupils compare the 
completed worksheets to identify similarities and differences between the two timetables remained in the task cycle. However, given time limitations and challenges for YLs to report task outcomes in public (Muller, 2005), I moved the report activity to the post-task phase where teacher assistance could be more appropriately provided. This activity was then simplified as a teacher-led discussion of the task outcomes. By making this small revision, the report activity became less challenging and also left more time for the post-task activities. Finally, the post-task phase was designed to provide opportunities for public performance of the main task (Newton \& Nguyen, forthcoming). In this redesign, the public performances preceded the report activity. The report activity was then followed by language analysis and language practice activities.

Next I needed to consider the demands of the tasks and related these to pupils' skills and needs (Cameron, 2001; Ellis, 2003; Skehan, 1996, 1998, 2018). Skehan (1998) points out factors related to task difficulty such as linguistic complexity, cognitive complexity, and communicative stress. Skehan suggests that a task should be made cognitively less demanding so that pupils can maximise their focus on linguistic factors rather than cognitive factors. Similarly, Cameron (2001) also notes two main types of demand of tasks for YLs: cognitive and language. She also points out other possible demands such as the type of interaction required (e.g., pair work or group work) or participants in talk (e.g., adults or peers), and involvement in task performance. She suggests that teachers maintain "the dynamic relationship between demands and support" (p. 26, original italics) because this relationship decides the extent to which a task can be completed and learning can occur. She further states that, for YLs, high demands on task performance may discourage them from completing the task while too much support may prevent them from stretching their interlanguage. These insights were all considered in my redesign of the two PPP lessons.

With a clear framework selected and clear awareness of task demands in mind, I proceeded with redesigning the two PPP speaking lessons.

\subsection{Redesigning the PPP speaking lessons}

Two task-based lessons were developed from the two PPP speaking lessons in Unit 8 in the Grade 4 textbook. An overview of the redesign is provided in Table 10 below. In the following sections, I document in detail how I altered each of the two PPP speaking lessons to reflect principles of task-based language teaching. 
Table 10. The two task-based versions of the PPP speaking lessons

\begin{tabular}{|c|c|c|}
\hline Original PPP lesson & $\begin{array}{l}\text { Revised TBLT version of the } \\
\text { lesson } 1\end{array}$ & $\begin{array}{l}\text { Revised TBLT version of the } \\
\text { lesson } 2\end{array}$ \\
\hline $\begin{array}{l}\text { Presentation } \\
\text { (i) Listen and repeat activity } \\
\text { using a picture-based } \\
\text { dialogue provided in a } \\
\text { recording and written form. } \\
\text { (ii) After this teacher-led } \\
\text { practice, the teacher explains } \\
\text { the target structural patterns. }\end{array}$ & $\begin{array}{l}\text { Pre-task } \\
\text { (i) Brainstorming school } \\
\text { subjects in a spider gram for } \\
\text { vocabulary priming. } \\
\text { (ii) An input-based listening } \\
\text { task in which learners listen to } \\
\text { a conversation between two } \\
\text { pupils about their timetables } \\
\text { and choose three picture cards } \\
\text { representing the three subjects } \\
\text { one of the pupils has in the } \\
\text { day. }\end{array}$ & $\begin{array}{l}\text { Pre-task } \\
\text { (i) Review school subjects } \\
\text { through a song. } \\
\text { (ii) An input-based listening } \\
\text { task in which learners listen to } \\
\text { a conversation between two } \\
\text { pupils about their timetables } \\
\text { and complete a handout } \\
\text { containing missing information } \\
\text { about the timetables. }\end{array}$ \\
\hline $\begin{array}{l}\text { Practice } \\
\text { Q\&A drill based on the target } \\
\text { structural pattern. Teacher-led } \\
\text { practice first and then pair- } \\
\text { work. }\end{array}$ & $\begin{array}{l}\text { Main Task } \\
\text { An information gap task for } \\
\text { pair work in which partners } \\
\text { share information about two } \\
\text { timetables in order to produce } \\
\text { final versions and then to find } \\
\text { three differences and two } \\
\text { similarities between the } \\
\text { timetables. }\end{array}$ & $\begin{array}{l}\text { Main Task } \\
\text { An information gap task for } \\
\text { pair work in which partners } \\
\text { share information about two } \\
\text { timetables in order to complete } \\
\text { the worksheets and then } \\
\text { compare the worksheets to find } \\
\text { two differences and three } \\
\text { similarities between the } \\
\text { timetables. }\end{array}$ \\
\hline Performance & Post-task & Post-task \\
\hline $\begin{array}{l}\text { Pair communication activity- } \\
\text { ask and answer questions } \\
\text { about your partners' timetable } \\
\text { using the target patterns } \\
\text { provided. }\end{array}$ & $\begin{array}{l}\text { Public performances of the } \\
\text { main task by three pairs of } \\
\text { learners followed by teacher- } \\
\text { led focus-on-form discussion } \\
\text { and a language practice game. }\end{array}$ & $\begin{array}{l}\text { Public performances of the } \\
\text { main task by three pairs of } \\
\text { learners followed by teacher- } \\
\text { led focus-on-form discussion } \\
\text { and a language practice game. }\end{array}$ \\
\hline
\end{tabular}




\subsubsection{Task-based lesson 1}

This task-based lesson was the redesigned version of the first speaking lesson in Unit 8. As stated in the teacher's book, the lesson aims to enable pupils to ask and answer questions about the subjects they have in their timetable. Pupils are expected to master the target structural patterns: "What subject do you have on ...? I have..." by the end the lesson. The redesigned lesson was built around a focused task which facilitates the learning of the specified target patterns. The following sections detail how each of the phases in the PPP speaking lesson was redesigned. It starts from the presentation phase, moves to the practice phase and finishes at the production phase.

\section{(a) Pre-task (Presentation $\rightarrow$ Pre-task)}

In the PPP speaking lesson, the teachers typically talked about the vocabulary before they engaged pupils in the "Look, listen and repeat" activity (Figure 5). Therefore, in the pretask phase of the revised version of the lesson (Figure 6), I added a vocabulary priming activity before turning the "Look, listen and repeat" activity into an input-based listening task. The vocabulary priming activity was designed as a listing task which involves pupils brainstorming the school subjects in groups before racing to the board to write down the subjects in a spider gram. The outcome is a draft mind map. The activity is designed to introduce the lesson topic and relevant vocabulary (Willis, 1996). From a cognitive perspective, this listing task activates pupils' language resources about school subjects they already know. It also contains elements of competitiveness as teachers need to decide on a winning team (i.e., the team with the most correct words written on the board). This competitive dimension is intended to engage pupils' interests in the early stages of the lesson. 
Figure 5. Textbook presentation phase

This image has been removed by the author of this thesis for copyright reasons.
Figure 6. Pre-task phase

This image has been removed by the author of this thesis for copyright reasons.

Following the listing task is an input-based listening task developed from the "Look, listen and repeat" activity. This original textbook activity exposed pupils to a context in which the target patterns are used. However, results from observations and interviews in Phase 1 showed that the three steps of looking, listening and repeating the dialogues failed to capture pupils' interest. Many of the teachers commented that the activity was particularly "mechanical" and "boring".

Motivated by the teachers' comments and my own observations and experience, I turned the "Look, listen and repeat" activity into a more engaging input-based listening task in the form of a guessing game. This input-based listening task is preceded by a pre-listening activity. From a set of eight picture cards provided, pupils in groups guess which three subjects the textbook character Nam has in a day and select the three cards. To check whether their guesses are right or wrong, pupils listen to the recording of the dialogue provided in the textbook. This purpose-driven listening activity aims to engage pupils in the listening task. Also, the pictures in the cards used for the guessing game are reused in the worksheets for the main tasks in both lessons. This provides a useful visual support which eases the processing load required for the main tasks (Skehan, 1996).

\section{(b) Main task (Practice $\rightarrow$ Main task)}

The textbook practice activity (Figure 7 below) involves pupils practicing the target patterns "What subjects do you have today? I have...". To do this activity, pairs of pupils simply rely on the question and answer patterns in the speech bubbles and word prompts 
underneath the pictures. This controlled practice activity involves repetition of the target patterns. Therefore, the primary focus is to encourage pupils to memorize the correct question and answer patterns while meaning is of secondary importance. To enhance the meaningfulness of this activity, I turned it into a focused information gap task.

\section{Figure 7. Textbook practice phase}

This image has been removed by the author of this thesis for copyright reasons.

The purpose of the information gap task is for pupils to compare their given timetable with their partner's timetable in order to identify three differences and two similarities across the timetables. To perform this task, each pupil in a pair is assigned to a class (Class 4A or Class 4B). Each class 4A pupil is given a complete Class 4A timetable (Figure 8.1) and an incomplete Class 4B timetable (Figure 8.2). Similarly, each Class 4B pupil is given a complete Class 4B timetable (Figure 9.1) and an incomplete Class 4A timetable (Figure 9.2). Each pupil is given their complete timetable first and told to keep it hidden from his or her partner. To achieve the task goals, pupils work in pairs, exchanging information to complete the incomplete timetables. When doing this, pupils are instructed to read the timetable consistently from left to right so that the listeners can catch the needed subjects to fill the gaps. This activity results in each pupil having two completed timetables to compare. The expected outcomes are three differences and two similarities between a Class 4A and a Class 4B timetable. 
This image has been removed by the author of this thesis for copyright reasons.
This image has been removed by the author of this thesis for copyright reasons.
Figure 9.1 Class 4B timetable

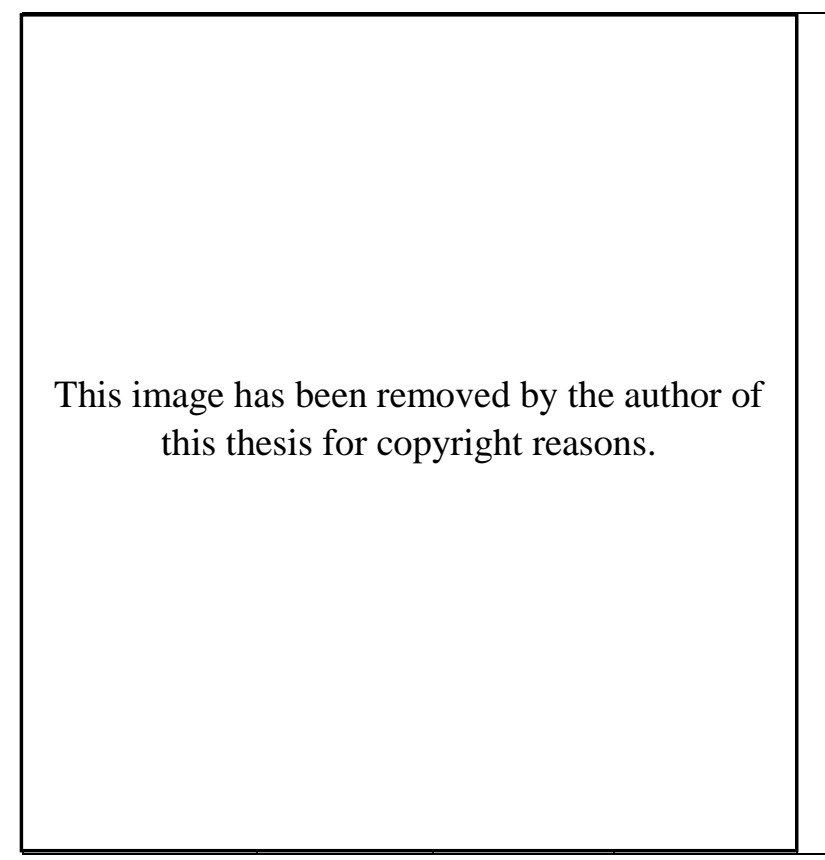

Figure 9.2 Class 4A incomplete timetable

This image has been removed by the author of this thesis for copyright reasons.

\section{(c) Post task (Production $\rightarrow$ Post task)}

This section describes the production and post-task phases of the redesign process. Figure 10 shows how a textbook production activity is designed. As seen, this activity requires pupils to work in pairs to exchange real information regarding the school subjects they have in the day. 
Figure 10. Textbook production activity

This image has been removed by the author of this thesis for copyright reasons.
Figure 11. Post-task activity

This image has been removed by the author of this thesis for copyright reasons.

I replaced this production activity with post-task activities which involve the language analysis and language practice (Figure 11). These activities follow the public performance of the main task and the teacher-led discussion of the task outcomes. Depending on time availability, the teachers decide the number of pairs that should perform the task in front of the class for class-wide evaluation on task completion and analysis of language use. The aim is to draw out the target structural patterns from the performances. Finally, the teachers involve their pupils in the practice activity.

\subsubsection{Task-based lesson 2}

This second task-based lesson was developed from the second PPP textbook speaking lesson in Unit 8. As stated in the teacher's book, this lesson aims to help pupils ask about when a particular subject is taught. Pupils are expected to master the target patterns "When do you have English? I have..." by the end of the lesson. This textbook speaking lesson was redesigned as follows.

\section{(a) Pre-task (Presentation $\rightarrow$ Pre-task)}

The second speaking lesson involves vocabulary for school subjects and days of the week which were introduced in the first speaking lesson. The vocabulary priming activity in the textbook lesson involves pupils listening to a song called "What day is it today?" to review the target vocabulary and stimulate pupils' interest. Like Lesson 1, the "Look, listen and repeat" presentation activity in this lesson (Figure 12) exposes the pupils to the context in which the target structural pattern "When do you have English? I have ..." are embedded. 
This image has been removed by the author of this thesis for copyright reasons.

Figure 13. Input-based listening task for the pre-task phase

This image has been removed by the author of this thesis for copyright reasons.

In the revised lesson, this activity was turned into an input-based listening task. Instead of having pupils look, listen and repeat the dialogue, this task requires them to listen to the recording of the dialogue provided in the textbook to obtain information about the days when the two textbook characters Nam and Tom have English in order to fill gaps in the table (Figure 13). After ticking off the days when Tom and Nam have English, pupils examine the completed table to identify the three days on which both Tom and Nam have English. 
Additionally, pupils are required to listen for the name of Nam's English teacher and circle the correct letter $(\mathrm{a}, \mathrm{b}$ or $\mathrm{c})$.

\section{(b) Main task (Practice $\rightarrow$ main task)}

Like Lesson 1, the "Point and say" textbook activity is designed as a controlled pair work practice activity (Figure 14). Each pupil in a pair takes turns to ask and answer about one school subject, Science. The question and answer forms "When do you have Science? I have it on..." are provided in the speech bubbles. The pupil who answers the question plays the role of each of the four pupils (Sam, Fred, Mimi and Winnie), referring to the ticks to provide the answers. The principle focus of this activity is not on pupils expressing and exchanging their own meaningful ideas, but rather on practising the target patterns and displaying their ability to produce the target patterns. This activity is primarily form-focused because the structural patterns are already provided and so, does not require pupils to make efforts in producing language.

\section{Figure 14. Textbook practice activity}

This image has been removed by the author of this thesis for copyright reasons.

I turned this practice activity into a focused information gap task which focuses on the target structural patterns mentioned above. 


\section{Figure 15.1 Class 4A timetable}

This image has been removed by the author of this thesis for copyright reasons.

\section{Figure 15.2 Class 4B worksheet}

This image has been removed by the author of this thesis for copyright reasons. 
Figure 16.1 Class 4B timetable

This image has been removed by the author of this thesis for copyright reasons.

Figure 16.2 Class 4A worksheet

This image has been removed by the author of this thesis for copyright reasons. 
I turned this textbook practice activity into an information gap task by splitting the information and adding a clear outcome. Each pupil in a pair is assigned as a Class 4A pupil or Class 4B pupil. A Class 4A pupil receives a Class 4A timetable (Figure 15.1) and a Class 4B worksheet (Figure 15.2). A Class 4B pupil receives a Class 4B timetable (Figure 16.1) and a Class 4A worksheet (Figure 16.2). Pupils are instructed to not let their partners see their timetable. In pairs, pupils exchange information from their timetable to help each other complete the worksheet. To do this, the pupils take turns asking about the days when each has Vietnamese, Maths, English, Science, IT and Music as well as the teachers who teaches English, Science, IT and Music. When receiving the answers, pupils place a tick on the right days and write the names of the teachers in the blank provided. When pairs of pupils have completed their worksheets, they work together to identify the similarities and differences between the two timetables based on the completed worksheets.

\section{(c) Post task (Production $\rightarrow$ Post-task)}

The production textbook activity (see Figure 17) is a pair work activity involving pupils in dialogue exchange. Pupils exchange real information about the school subjects they have, the days they have the subjects and the teachers who teach the subjects. I replaced this production activity with language-focused activities (Figure 18). The activities include a language analysis of public performance of two or three pairs of pupils followed by a language practice game.

\section{Figure 17. Textbook production activity}

This image has been removed by the author of this thesis for copyright reasons.

\section{Figure 18. Post-task activity}

This image has been removed by the author of this thesis for copyright reasons.

\subsection{Reflecting on the redesign}

The two PPP speaking lessons were redesigned to achieve an initial focus on meaning where pupils discovered and negotiated meaning through task fulfillment and where there was no intention to explicitly pre-teach the target language. The two-way information gap task in each lesson where a Class 4A pupil and a Class 4B pupil had to exchange information and ask questions to complete their timetable in Lesson 1 and a worksheet in Lesson 2 involved a 
clear gap and an outcome that they must navigate to complete and achieve. Although pupils were distanced from the target structures in their task performance, they should be able to draw on the input provided in the pre-task phase. According to Ellis (2003), the pre-task activities, together with the post-task activities are essential for lower proficiency and YLs to work towards task completion.

More specifically, the redesigned PPP speaking lessons aimed to address the teachers' concerns about the mechanical, time-consuming nature of the presentation and practice phases. First, in each lesson, the input-based listening task in the pre-task phase turned the "Look, listen and repeat" activity into a more engaging activity which switched pupils' focus from passive listening to active, purpose-driven listening. Similarly, the main task developed from the controlled practice activity in the textbook switched pupils' focus from practicing the specified grammar structures to expressing their own meaning by drawing on their own linguistic resources. Therefore, it helped address the teachers' concerns about the communicative value of the textbook practice activity. Finally, the language analysis and practice activities in the post-task phase which replaced the textbook production activity addressed the need to achieve the target language objectives required for the textbook lesson. These activities ensured that the redesigned lessons addressed both fluency and accuracy and engaged pupils in more "meaningful" interaction.

While such changes in focus were made to engage pupils more deeply in their tasks, they posed additional demands on task performance. Therefore, in the redesign, measures were taken to keep the demands at an appropriate level to promote language use (Cameron, 2001; Ellis, 2003; Skehan, 1996, 1998). First, linguistic demands were managed by means of the preparatory activities in the pre-task phase. These activities exposed pupils to target vocabulary items necessary for performing the tasks. Pupils were, therefore, assisted with the lexical demands of the task. Second, the interactional demand of task performance was minimised because pupils were paired with their peers in the same class.

Third, cognitive demands were managed by the activities and tasks in the two taskbased lessons being sequenced in a logical and coherent order. In other words, the order of the tasks and activities moved from more guided input-based tasks to more demanding production tasks with the input-based task in the pre-task phase acting as a facilitating task (Willis \& Willis, 2007). This enabled task complexity to be gradually increased to expose learners to manageable challenges (Van den Branden, 2016). In fact, the vocabulary priming activity and the input-based listening task in both lessons were used specifically to help reduce the cognitive and linguistic demands on the eventual performance of the main tasks. For example, 
the input-based listening task in Lesson 1 actually prepared pupils for the task of asking their friends for the school subjects to complete the timetable in the main task. Similarly, the inputbased listening task in Lesson 2 prepared pupils for the task of finding differences and similarities regarding the days when they have particular subjects in their timetables. As such, the input-based tasks provided ready-made schemata that pupils could draw on to help them organize their production when they performed the main tasks (Skehan, 1996).

Cognitive demands were also minimized by way of the pupils' familiarity with the topics of the tasks. Both tasks were designed to share the same topic of the timetable which is meaningful and communicative. While not entirely authentic in terms of its language (the pupils are in the same class) or class schedule (pupils may have more than three subjects a day), the two main tasks employed a more plausible situation, created a genuine information gap, and required real-world language use to complete (asking about each other's timetable is also something they usually do with their friends in other classes). Thus we can see a connection between the two main tasks and a real-world activity.

In sum, the two PPP speaking lessons were redesigned in accordance with an adapted TBLT framework. Issues of task demands that might impede the task performance were also addressed to maximise task performance. Support for task performance was provided at a level that does not prevent learners from stretching their interlanguage.

The task-based versions of the two PPP speaking lessons were implemented in real classrooms by each of the three Grade 4 teachers who participated in Phase 1 of the study. The results of the implementations are presented and discussed in the following chapter. 
This page is intentionally left blank 


\section{CHAPTER 6 PHASE 2: THE IMPLEMENTATION OF TWO TASK-BASED LESSONS}

\subsection{Introduction}

The second phase of the current study investigated the implementation of the two revised textbook speaking lessons designed specifically to reflect a stronger version of taskbased teaching. This chapter reports on and discusses the results from this implementation. It addresses three research questions (RQs):

RQ1. (a) How did the teachers implement the task-based lessons?

(b) How did they evaluate their implementation of the lessons?

RQ2. How did the pupils perceive their experience of carrying out the two task-based lessons?

RQ3. (a) How did the pupils perform the main tasks in the task-based lessons?

(b) What verbal interactional strategies did they adopt to perform the tasks?

Three types of data were collected to investigate the research questions: Lesson transcripts, classroom observations and interviews with teachers and their pupils. Research question 1 is addressed through analyses of lesson transcripts and field notes, interview data with the teachers and transcripts of peer-peer interaction. Research question 2 is addressed through analyses of pupils' interview data and classroom notes. Finally, research question 3 is addressed through analyses of transcripts of peer-peer interaction and from classroom notes. To offer more nuanced insight into the implementation process of the three participating teachers, I created an individual profile for each teacher. These teacher profiles provide relevant contextual information which is key in understanding more fully the rationale for their decision-making process.

\subsection{Teacher profiles}

As described in the methodology chapter (Section 3.4.3), the three teachers Nam, Nhu and Lan shared similarities in their teaching qualifications. All teachers were graduates of a local college and possessed a BA certificate in English language teaching. All were trained in the theory and practice of communicative approaches. In addition, they all obtained a B2 level of CEFR or above. This meant that they could act as appropriate language models. Two of 
them (Nam and Nhu) were "teacher leaders" who had had several opportunities to attend teacher training workshops provided by the local education and training department in the province. Their pupils were all in Grade 4 and the same age (nine years old).

Despite these similarities, there are important differences that are worth outlining. For example, the teachers differed in their types of teaching experiences, the number of pupils in their classes, their pupils' proficiency level, and their school location. These differences are further explained below.

Nam was a male teacher in a rural school, which was 15 kilometres from the city. This school was ranked as an 'A' school, indicating that the school was one of the best in the district. Nam had five years of experience teaching English to primary school pupils. He was also the vice-head of the primary English teacher committee in the district. Nam had a relatively small class of 27 pupils. His classroom, which was reserved for teaching English, contained a computer and a television screen. The walls in the room were decorated with pictures about days, months, numbers, fruit and animals. Most pupils in Nam's class were from poor families and had little access to private English classes. Their overall proficiency was quite low, but their motivation for learning English was high as evidenced from Phase 1 observations. Phase 1 results showed that Nam's pupils participated in his lessons with joy and a genuine desire to learn English. As an experienced primary school teacher, Nam was tolerant of noise and skilful at controlling his pupils. He was also successful at involving his pupils actively and cheerfully in lessons. In the briefing prior to the implementation of the two task-based lessons, Nam expressed his interest in trying out the revised lessons. However, he also expressed concern about his pupils' low level of proficiency.

Nhu was an experienced female teacher in a semi-rural school, which was situated in the outskirts of the city. She had eight years of teaching experience. Her school was also ranked ' $\mathrm{A}$ ', identifying it as one of the best schools in the district. At the time of the research project, Nhu was in charge of four Grade 4 classes at her school. She was considered a master teacher in the district, well-known and recognised for her innovative teaching skills and her strong classroom management. Her class for the current study consisted of 43 pupils, which was large compared to that of Nam and Nhu. Her classroom was well-equipped with an overhead projector, a computer and two white boards, and was a room reserved for English classes only. In the interview in Phase 1, Nhu expressed positive views on the PPP approach. She emphasised the importance of providing repetitive practice before engaging pupils in free production. Although Nhu was an experienced teacher and a proponent of PPP, she was open to learning new things and showed a willingness to develop her pedagogy. She said that she 
regularly searched for new teaching techniques on YouTube or Google to integrate them into her established ways of teaching. My analysis of her teaching practice and interview data from Phase 1 revealed that Nhu was keen on using communicative activities to enhance her pupils' English ability. However, she was not familiar with TBLT. When I talked her through the principles of TBLT during the briefing, she grasped them quickly. Regarding her pupils' proficiency, my classroom observations and discussion with her reveal that proficiency levels were mixed, with half of the class being quite low. From here, we came up with the idea of pairing a weaker pupil with a stronger one in hope of addressing the concern about the weaker pupils' ability to perform the main tasks. The classroom observations in Phase 1 also revealed that as an experienced teacher, Nhu was tolerant of noise, and like Nam, she could manage it well. Believing in learner-centred and communication-oriented teaching, she concentrated on stimulating pupils' interests and boosting their confidence in learning English.

Lan, the youngest female teacher of the three, had three years' experience teaching Grade 4 pupils English. Unlike Nam's pupils, the majority of Lan's pupils were from rich and educated families in the city and had access to private classes. Lan had graduated with a BA in TEFL. Her BA program is slightly different from that of Nhu and Nam's in that she undertook a four-year program, while Nam and Nhu's program was for 3 years. By the time of the research project, she was in charge of four Grade 4 classes. The pupils in her school were of above-average ability. Her participating class consisted of 35 pupils. My observations in Phase 1 showed that the majority of Lan's pupils were confident in their spoken English and participated actively. The classroom was large and well-equipped with comfortable chairs and desks for individual pupils, a television screen and two blackboards. Lan regularly used the television screen to show her e-lessons. Unlike Nhu and Nam, Lan more tightly managed her pupil's behaviour and noise levels.

To sum up, the classroom layout, the backgrounds of the pupils, including their proficiency and socio-economic situation, teachers' qualifications and experience are important factors affecting the implementation of the two task-based lessons.

The findings regarding the implementation of the lessons in the three participating classes are presented in the following sections. 


\subsection{Teachers' implementation of the task-based lessons}

In this section, I present the results of how the three teachers implemented the two task-based lessons in their everyday classrooms and how they evaluated their implementation of the lessons. The findings are presented through the analysis of classroom field notes, lesson transcriptions, pair task interaction and interviews with the three teachers.

As outlined in the Methodology chapter, prior to the implementation of the two taskbased lessons, I discussed the principles of task-based teaching with the three teachers and then instructed them on how to carry out the two task-based lessons in their classrooms. Given the differences in their pupils' proficiency levels, the teachers were encouraged to adjust the demand of the tasks to suit their own pupils provided their decisions aligned with TBLT principles. The time allotted for each lesson was 45 minutes. All lessons except one were completed within the time allotted. The exception was Nhu's implementation of Lesson 1 (eight minutes extra) and Lesson 2 (five minutes extra) due to issues related to the management of her large class. The question of how each teacher implemented the two taskbased lessons in their classes is presented below.

\subsubsection{Teacher Nam}

Based on the assigned schedule for each of the three teachers, Nam was the first to implement the two task-based lessons. These lessons were implemented in two consecutive weeks in Nam's normally scheduled class of 27 Grade 4 pupils. Table 11 summarizes the three phases in each of the observed lessons and indicates how long each lesson and associated activities lasted.

Table 11. Nam's lessons

\begin{tabular}{|c|c|c|c|c|}
\hline Phase & Lesson 1 & $\begin{array}{c}\text { Time } \\
(44 \text { mins })\end{array}$ & Lesson 2 & $\begin{array}{c}\text { Time } \\
(42 \text { mins })\end{array}$ \\
\hline \multirow{2}{*}{ Pre-task } & $\begin{array}{l}\text { Listing task: "Board race" } \\
\text { game. }\end{array}$ & 7 & $\begin{array}{l}\text { Vocabulary review: Sing } \\
\text { a song }\end{array}$ & 5 \\
\hline & $\begin{array}{l}\text { Input-based listening task: } \\
\text { Guessing game. }\end{array}$ & 10 & Input-based listening task & 11 \\
\hline Main task & Information-gap task & 17 & Information-gap task & 16 \\
\hline \multirow{2}{*}{ Post task } & $\begin{array}{l}\text { Language performance } \\
\text { and analysis }\end{array}$ & 6 & $\begin{array}{l}\text { Language performance } \\
\text { and analysis. }\end{array}$ & 5 \\
\hline & $\begin{array}{l}\text { Language practice: } \\
\text { "Passing the ball" game }\end{array}$ & 4 & $\begin{array}{l}\text { Language practice: } \\
\text { "Passing the ball" game }\end{array}$ & 5 \\
\hline
\end{tabular}




\section{Pre-task}

Both lessons started with vocabulary priming activities. In Lesson 1, the vocabulary priming activity was designed as a listing task to which Nam added with competitive elements. As I observed in Phase 1, although the proficiency level of Nam's pupils in these lessons was low compared to that of Nhu's and Lan' pupils, they worked well when they were put in groups or engaged in game-like activities. These factors may have motivated Nam to add features of enjoyment and competitiveness to the listing task in order to meet his pupils' needs and interests. In fact, Nam turned the listing task in Lesson 1 which primes the vocabulary items for the main task into a "Board race" game. First, Nam organized pupils in two groups (the Lions and the Tigers) to brainstorm among themselves on the subjects listed in their normal timetable. After two minutes, the pupils in groups raced to the board to organize the subjects in a mind map. Given their low-proficiency level, Nam encouraged them to write the subjects in either English or Vietnamese. As a result, the pupils wrote down all of their daily timetable subjects in Vietnamese except Music, English and IT. Nam then used picture cards to elicit the English equivalents of the words and wrote them on the board before getting the class to repeat the words several times.

In Lesson 2, a vocabulary review activity was conducted through a song "What day is it today?". The song featured days of the week, which is intended to help pupils consolidate days-of-the-week vocabulary. After having pupils listen and sing after the song three times, Nam wrote the vocabulary items on the board and led some choral pronunciation practice. The song effectively achieved the dual goal of stimulating a joyful classroom atmosphere and reviewing the vocabulary necessary for the performance of the main task.

The pre-task phase in both lessons then continued with the input-based listening tasks. For Lesson 1, Nam again organised pupils in groups to choose three subject cards from a set of eight. Nam explained to his pupils that the three subjects they were going to choose represented the three subjects the textbook character Phong had in the day. I noticed that they quickly turned to each other to decide which of the three cards they should choose. The pupils seemed excited at the sight of the colourful picture cards. It may have been partly because of this excitement that a lot of the pupils used Vietnamese to discuss their choices. After the pupils had decided on the three picture cards, they listened to the audio-recording to check their guesses. This goal-oriented listening task seemed to arouse a moment of high concentration among the pupils who seemed to be trying very hard to find the answers to confirm or disconfirm their guesses. 
The same scenario was also identified in the input-based listening task in Lesson 2 which requires the pupils to identify the three days when both of the two textbook characters Tom and Nam had English. Nam quickly drew a table on the board with the names "Nam" and "Tom" on the side and the days of the week on the top before he explained the instructions. From the table and through Nam's instructions, the pupils knew that they needed to listen carefully to identify the four days on which each of the two textbook characters had English. While the recording was playing, I noticed that most pupils listened very attentively. That might explain why they were able to provide the correct answers when Nam asked them. After the third listening, Nam invited answers from the pupils to get information corresponding to the four days each of the characters Nam and Tom had English. When the table was filled by putting a tick $(\sqrt{ })$ against the weekdays, Nam asked the whole class to observe the table carefully and to identify the three days when both textbook characters had English. This activity meant that the goal of the task had been fully achieved.

Nam valued the input-based listening tasks for both lessons. He remarked that these tasks could engage his pupils more effectively than the original versions which involved the mechanical dialogue practice, namely "Look, listen and repeat". As Nam said:

When the listening activity was delivered in the traditional way [Look, listen and repeat], there was no guarantee that all pupils would listen. Many pupils just listened to the recording with little interest. However, the input-based listening task could attract pupils' attention more effectively [...]. Pupils listened with their book closed, so they concentrated better. I noticed that pupils got more curious and excited. (Lúc dạy bài nghe theo phuoong pháp cũ (nhìn, nghe và lặp lại) thì không bảo đảm là đứa nào nó cũng lắng nghe. Đứa nào nó hưng thú nó sẽ nghe nhung nhiều đứa không hứng thú nó sẽ không muốn nghe mà chỉ đọc sơ so: Em thấy khi dạy bài nghe theo phuơng pháp mới, học sinh tập trung hiệu quả hơn. [....] Lúc này nó không mở sách ra nên nó tập trung hơn phương pháp trước. Em thấy nó tò mò và hứng thú hơn phưong pháp trước.) (Interview 1)

\section{Main task}

The instructions for the main tasks in both lessons were carefully delivered. Since the class was small, Nam was able to approach his pupils to provide clarifications when necessary. This ensured that all pupils understood the task's instructions. Before the pupils 
carried out the main task in Lesson 1, Nam modeled the task with one strong pupil in the class using a similar set of handouts. In his modeling, Nam emphasized the importance of reporting the timetable systematically (from left to right), which is a way to reduce the cognitive load of the task, essentially allowing pupils to concentrate more strongly on language features (Skehan, 1996). No task modeling was conducted for the main task in Lesson 2 because, as Nam explained, he realized that his pupils were able to work out how to do the main task after they had completed the input-based listening task. This suggests that this task had in fact familiarized the pupils with how to tick off the days and how to work out the similarities between the timetables, which were the two activities required for completing the main task.

Many pupils started the main tasks in both lessons with some initial reluctance, although most appeared more confident in Lesson 2. The reluctance indicated how the pupils reacted when they were suddenly left to manage their talk without any pre-teaching and practicing of the structural patterns as they normally had. During the pupils' performance of the main tasks, I noticed that many of them were working hard to get their meaning across though sometimes all they could do was utter single words or simple phrases. Some switched to Vietnamese in order to proceed towards the task outcomes. Others tried to seek help from the teacher by asking questions such as "Teacher, what should I say?" or "Teacher, I do not know the sentence structure. How can I say?" (Translated from Vietnamese). This was when Nam decided to provide assistance to move the task performance forwards. Extract 5 shows that Nam steps in as soon as he finds that P2 fails to answer P1's question. In line 3, Nam first draws P2's attention to the timetable and then instructs her on how to give the answer. He elicits the responses from $\mathrm{P} 2$ as a way to provide co-construction assistance. From lines 4 to 8, Nam also uses elicitation as a way to provide co-construction assistance to P2.

Extract 5: (Teacher co-construction assistance - Lesson 2)

1 P1: When do you have ... When do you have ... BE?

$2 \quad \mathrm{P} 2: \ldots$

3 T: PE. Okay. Quyền con. Okay. Look at your timetable. PE, PE là môn gì con? (What does PE mean?). PE là môn...là môn gì? ... thể, thể dục ( $P E$ means... thể $d u c$ ). Right? Okay. Look at your timetable. Coi con học giờ nào đây (Let's see when you have this subject). Tuesday, right? You can say I have PE ...I have $\mathrm{PE}$ on ... on gì con? (on what day?). I have...

4 P2: I have.

5 T: $\mathrm{P}$

6 P2: PE

7 T: on

8 P2: on...Tuesday. 
While some pupils did not know what to say or how to respond, others started the task by simply uttering single words. This was when the teacher's assistance was provided. This time the assistance was not intended to move the task performance forward, but it was aimed to scaffold a target form. Extract 6 below shows that Nam follows up from line 2 when he realizes that P1 fails to ask P2 in English and P2 fails to answer in a complete sentence. Here he intervenes to help these two pupils by responding to what has arisen. From the input provided, P1 can grasp the question quickly and uses it to ask P2 in line 5. With this teacher's co-construction assistance and his timely withdrawal, the two pupils are able to move on with their task performance and eventually complete the task.

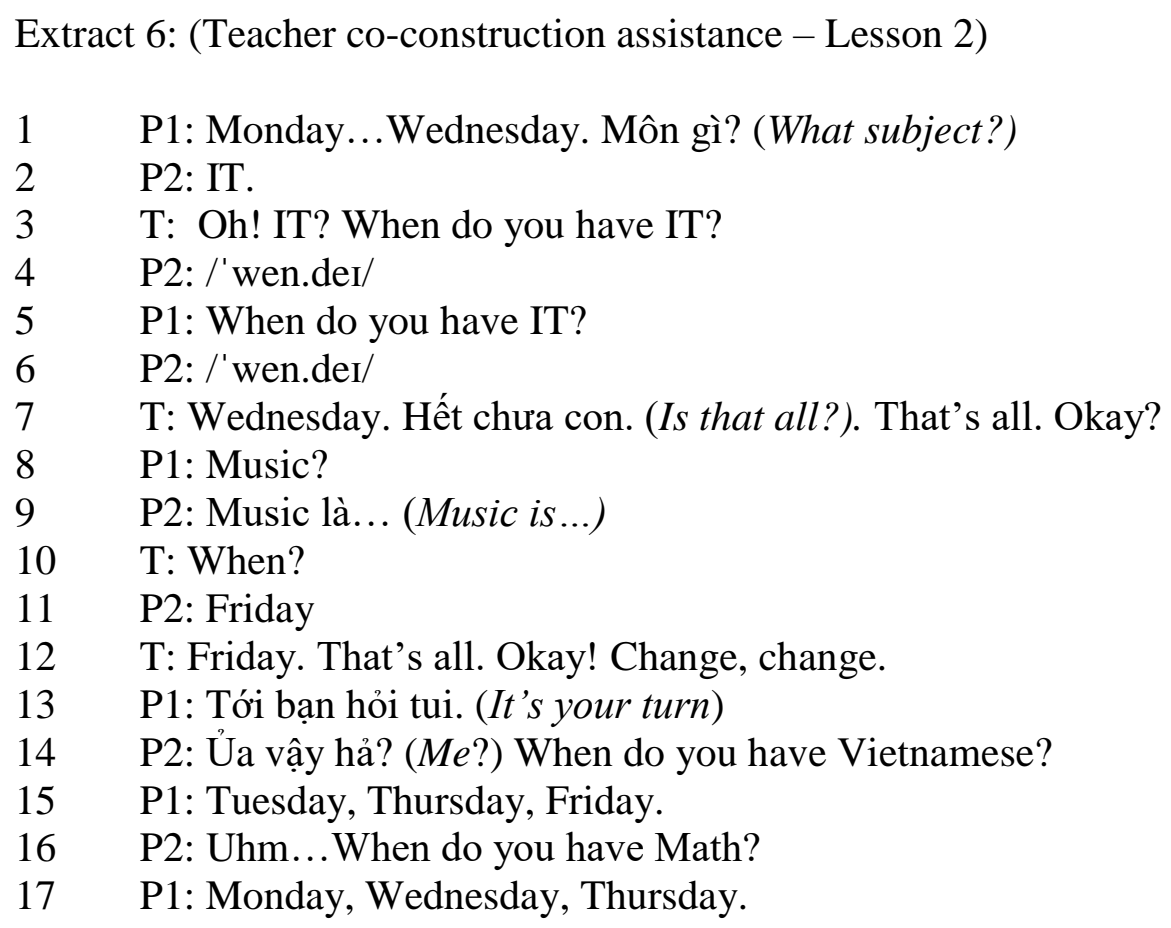

Extracts 5 and 6 illustrate some typical ways of providing co-construction assistance by Nam to his pupils at the beginning stage of their performance. The characteristics of interaction at this stage, prior to the teacher assistance, often reflect language use at the word level rather than the sentence level, meaning that pupils tend to use words or short phrases to express themselves without much attention to using grammatical sentences. This limitation of classroom interaction has been pointed out by Seedhouse (1999) and Swan (2005) in relation to lower proficiency pupils such as those in Nam's class. While acknowledging this limitation, Ellis $(2003,2018)$ has further argued that because learners seek to achieve the task 
outcomes, their attention is focused more on what they want to say rather than on producing full sentences in English. For the beginner learners in the current study, such interaction may still be beneficial because, according to Ellis (2018), it enables them to "make use of their limited resources and thus helping to develop their strategic competence” (p.162). Another benefit of this interaction is that it enabled the learners to realise that there was a gap between what they want to say and how to say it, which in turns provided a strong motivating force for wanting to learn the target structure.

Teacher assistance was essential in enabling the pupils to move forwards and for focusing their attention on the target forms because, as Nam explained, without it, they would be demotivated or discouraged to continue with the tasks or would switch to Vietnamese to complete the tasks. Furthermore, the data showed that in subsequent turns, most pupils were able to work on their own as soon as the teacher withdrew. In fact, results from the analysis of classroom interaction revealed that all six performances needed either one occasion of peer and/or teacher co-construction assistance primarily at the start of the task performance. Only one performance required an additional occasion of assistance (see Table 15 in Section 6.5.2.1).

Nam said that he was satisfied with his pupils' performance of the main tasks after the co-construction assistance had been provided. He noted a high level of engagement in his class. The evidence he provided for this was related to the type of task itself. He commented that the two-way information gap tasks which require information exchange enhanced his pupils' participation, as task completion demanded everyone's contribution. As Nam said:

To achieve the task outcome, the pupils had to provide the answers when asked or ask to get information. This engaged them and stimulated them to speak English. (Để đạt được mục tiêu, học sinh phải cung cấp câu trả lời khi được hỏi hoạc hỏi để lấy thông tin. Điều này thu hút các em và kích thích các em nói tiếng Anh.) (Interview 2)

\section{Post-task}

For the post-task, in each lesson, Nam asked his pupils to notice the public performance of two dyads and then compare these performances with their own. Then, he asked them to tell him the question and answer they used to ask for information to complete the main task. He wrote all possibilities on the board and asked his pupils to suggest the correct question and answer forms. Finally, he elicited the Vietnamese meaning of the 
question and answer. One important decision Nam made at this stage is that he did not involve his pupils in identifying the differences and similarities between the timetables in both lessons as planned. Instead, in both lessons, after the language analysis activity described above, the pupils participated in a language practice activity in a form of a game called "Passing the ball”. This game involved the pupils passing around a ball and, when the music stopped, the pupil holding the ball answered a question from Nam. The classroom notes revealed that most pupils responded to Nam's questions confidently, using the target structures. They also maintained a high level of engagement throughout the lesson.

However, Nam's decision resulted in the outcomes of the main tasks in both lessons (i.e., identifying the differences and similarities between the two timetables), being only partially achieved. Nam explained that he needed to adjust the task this way for two reasons: (1) because he wanted to save time for the language practice activity (necessary to ensure that the objectives of the lessons were achieved) and (2) because he wanted to ensure that the task outcomes were simple enough to suit his low-level learners. My interpretation is that Nam was driven by the need to achieve the lesson objectives. His decision reflects his awareness of his pupils' proficiency level.

Finally, both lessons ended within the time allocated. Nam said that he was happy because the objectives of the lessons were achieved as a result of the completion of the two main tasks. When invited to comment further on the learning outcomes resulting from teaching the two speaking lessons using the task-based approach compared to the PPP approach, Nam said:

The pupils could learn better when the two speaking lessons were taught this way. It may be because they were cognitively engaged during the lesson. They had to think to work out the language to speak. They had to manage their talk by themselves.

Previously the pupils did not have such experiences. Their learning was controlled. They just followed the teacher. (Học sinh có thể đã học tốt hơn khi hai bài nói được dạy theo phưong pháp mới. Có thể là vì học sinh nó tập trung suy nghĩ trong suốt bài học. Nó phải nghĩ để tìm ra ngôn ngũ để nói. Bản thân nó phải tụ tìm cách nói. Trước đây học sinh không có nhũng trải nghiệm này. Việc học của nó có sụ điều khiển. Nó chi làm theo giáo viên.) (Interview 1) 


\subsubsection{Teacher Nhu}

Table 12 below summarizes the phases in the two observed lessons and indicates how long each lasted.

Table 12. Nhu's lessons

\begin{tabular}{|c|c|c|c|c|}
\hline Phase & Lesson 1 & $\begin{array}{c}\text { Time } \\
(53 \text { mins })\end{array}$ & Lesson 2 & $\begin{array}{c}\text { Time } \\
(50 \mathrm{mins})\end{array}$ \\
\hline \multirow{2}{*}{ Pre-task } & Teacher-led listing task & 6 & Classifying game & 7 \\
\hline & Input-based listening task & 14 & Input-based listening task & 12 \\
\hline Main task & Information-gap task & 21 & Information-gap task & 20 \\
\hline \multirow[b]{2}{*}{ Post task } & $\begin{array}{l}\text { Language performance and } \\
\text { analysis }\end{array}$ & 9 & $\begin{array}{l}\text { Language performance and } \\
\text { analysis }\end{array}$ & 9 \\
\hline & $\begin{array}{l}\text { Ask-and-answer activity: } \\
\text { Teacher asks, pupils answer. }\end{array}$ & 3 & $\begin{array}{l}\text { Ask-and-answer activity: } \\
\text { Teacher asks, pupils } \\
\text { answer. }\end{array}$ & 2 \\
\hline
\end{tabular}

\section{Pre-task}

The table shows that the task-based lessons required Nhu to spend an extra eight minutes in Lesson 1 and 5 minutes in Lesson 2. Observation data show that the extra time was required because certain implementation activities such as organizing group work, delivering task handouts, and giving and checking task instructions took more time than planned. Two factors in particular (a large class size and mix-ability pupils) were found to demand a considerable amount of organization. Nevertheless, as an experienced teacher, Nhu was able to involve her pupils in the task sequence successfully. As for pre-task actions, instead of involving her pupils in a game-based listing task as Nam did in Lesson 1, Nhu led the listing task by asking the whole class to tell her the subjects in their daily timetables. When a pupil could describe a subject in English, she asked that pupil to go to the whiteboard and write it down in the form of a mind map. She then used picture cards to elicit some other subjects that her pupils could not talk about in English before involving them in a pronunciation practice activity (Figure 19). She commented that this teacher-led activity helped her control her large class and enable her to better control the class time. 


\section{Figure 19. Mindmap of the school subjects}

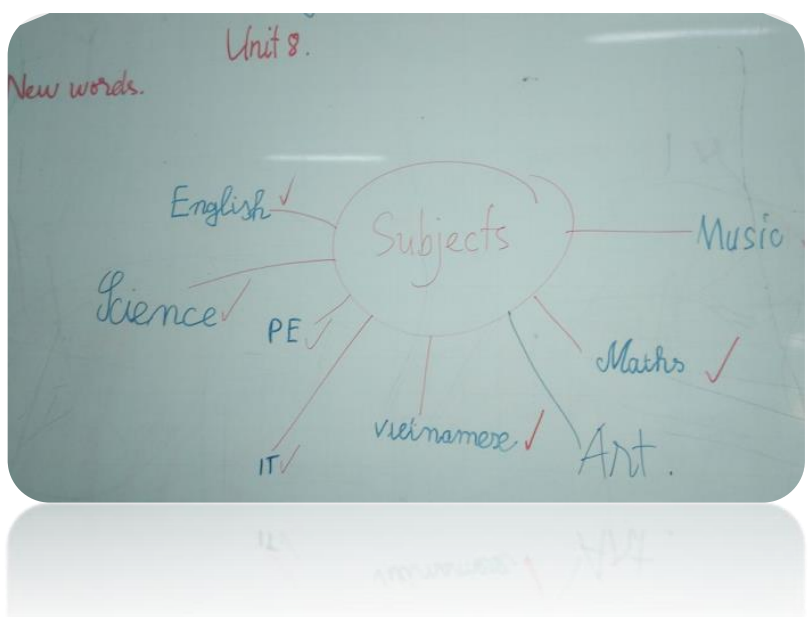

For the same reason, in Lesson 2, Nhu did not have the pupils listen to the song "What day is it today?" as specified in the lesson plan. Instead, she involved the pupils in a classifying game. Two groups of pupils were provided with a set of word cards mixed between the school subjects and days of the week. They then classified the cards in two groups of school subjects and days of the weeks in two separate columns (Figure 20).

\section{Figure 20. Classifying task}

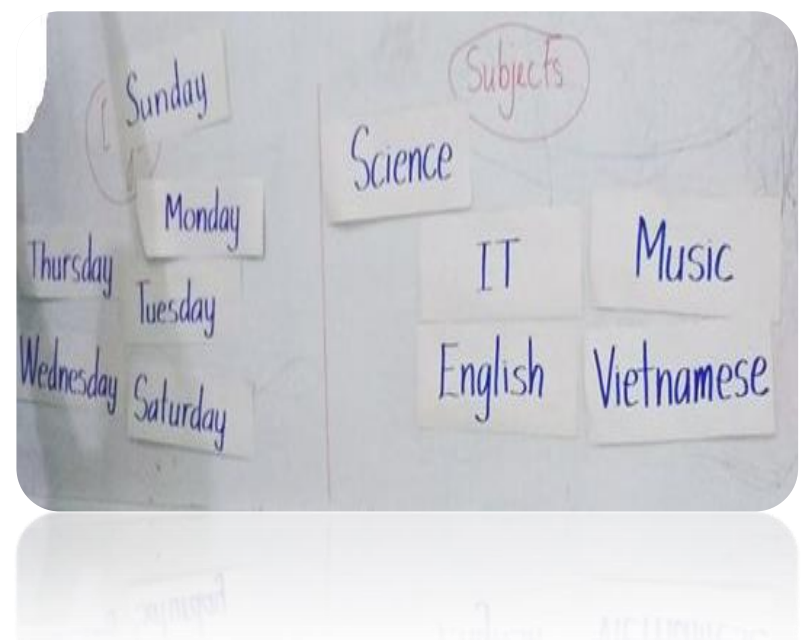

After the classifying task, Nhu quickly directed her pupils' attention to the input-based listening task in each lesson. Like Nam, in Lesson 1, Nhu involved her pupils in a guessing game which served as a pre-listening activity for the listening task. After she had delivered the picture cards to the groups, she asked them to discuss and choose three cards. When the cards had been selected, the pupils listened to the recording to check their guesses. During this 
stage, I noted that the pupils were highly focused on finding out whether they had made a correct guess. In Lesson 2, unlike Nam, Nhu presented the task handouts on PowerPoint slides. She attracted the pupils' attention to the table on the slides where there were pictures of Nam and Tom next to the weekdays. After asking the pupils to listen to the recording three times, she asked them to tell her the days when each of the textbook characters Tom and Nam had English. My observation notes showed that most pupils were able to tell the target days. Some pupils shouted out the days loudly. Nhu then invited two volunteers to report the results. Finally, she guided the class as they filled out the table in the handout before asking the pupils to indicate the three days when English was taught to both Nam and Tom. Like Nam, Nhu also highly valued the input-based tasks for both lessons. She commented that these tasks prepared her pupils well for the main tasks because they served as a schema that provide her pupils with important preliminary ideas about how to perform the main tasks.

\section{Main task}

Nhu also used PowerPoint slides to present instructions for the main tasks in both lessons. This digital teaching aid helped ease the complexity of task instructions. For example, the slides displaying the task handouts allowed Nhu to explain the instructions for the main tasks more easily. All instructions were in Vietnamese. In Lesson 1, Nhu modeled the performance of the main task with a strong pupil using slightly different task handouts. Like Nam, Nhu demonstrated clearly how to report the timetable systematically from left to right. In Lesson 2, Nhu explained the instructions without providing task modeling because, as she explained, her pupils were able to grasp the task instructions after familiarizing themselves with the input-based listening task.

Before the pupils performed the main tasks in both lessons, Nhu, unlike Nam, decided not to leave any elicited vocabulary items on the blackboard for her pupils' reference to do the main tasks in both lessons. She explained her decision as follows:

I did not want to leave the target vocabulary items on the board because I expected the pupils to try to recall the vocabulary items they had learned. [...]. They will remember the words better if they attempt to do so. (Em không muốn giũu lại tù vựng trên bảng vì em muốn các bé tập trung nhớ lại, cố gắng nhớ lại.[...]. Tụi nó cố gắng nhớ được thì nó sẽ nhớ nhũng tù̀ mói đó sâu hơn.) (Interview 1) 
However, this does not mean that no support was needed or that Nhu had little concern about her pupils' performance. When asked about this, Nhu said that she was quite worried that her pupils might say nothing or very little without such vocabulary support. Therefore, as a way to help her pupils cope with this challenge, Nhu encouraged them to draw pictures to illustrate the meaning of the words if they failed to write them down in English. Likewise, the givers of the information were encouraged to use gestures or hints to express their meaning if they were unable to tell their peers the target vocabulary items. During the task performance, Nhu moved around to encourage talk and remind her pupils to speak English. She stopped at some dyads to clarify task instructions, but she tried to minimise giving assistance in terms of language. In the interview, Nhu mentioned explicitly that she was particularly happy with the results of her pupils' taking up her guidance. As she said:

The tasks could help my pupils speak English with confidence. They were able use different communication strategies to get their meaning across. I also noticed that they tried to mobilise their language resources to do the tasks. I am very satisfied with this. (Phần "task" của mình thì em thấy giưp cho học sinh có thể tự tin nói tiếng Anh. Nó có thể dùng nhiều cách khác nhau để diễn đạt ý muốn nói. Em cũng thấy là học sinh cố gắng huy động kiến thức mà nó đã biết để làm. Em rất hài lòng với việc này.) (Interview 1)

An issue that arose during the performance of the main tasks in both lessons is that, like Nam's pupils, some of Lan's pupils failed to use the desired target structural patterns when they were undertaking the main tasks. In addition, their utterances contained grammatical or phonological errors. Extract 7 below taken from Lesson 2 illustrates this point.

\section{Extract 7}

1 P2: What what /'sar.kən/ do you have /'t $\int \mathrm{u}: \mathrm{de} /$ ?

2 P1: Cái gì? (What?)

3 P2: What /'sar.kən/ ... what /'sai.ən/ do you have today?

4 P1: It's Monday, Wednesday and Friday.

\footnotetext{
7 The word "task" is Nhu's actual word.
} 
Extract 7 shows that the question $\mathrm{P} 2$ produces is not the desired target question (the target question is "When do you have Science?). Additionally, P2 mispronounces the word Science which triggers $\mathrm{P} 1$ to ask for clarification in line 2 . In response, in line $3, \mathrm{P} 2$ is able to produce a more target-like pronunciation of the word Science, which then makes sense to P1. This enables P1 to provide the desired information, though the answer form is not target-like. The interaction suggests that both pupils are focusing their attention on their intended meaning, focusing on the key word Science rather than the target language forms. Regarding this issue, Nhu had this to say:

Since the pupils did not have to focus on grammar, they were not afraid of making mistakes. They were thus more willing to speak English. I think this is important for the development of their ability to communicate in English. (Vì học sinh không phải tập trung vào ngũ pháp, nó không sợ bị mắc lỗi. Vậy nên nó sã̃n sàng nói tiếng Anh hơn. Em nghĩ điều này là quan trọng cho học sinh phát triển kĩ năng giao tiếp bằng tiếng Anh.) (Interview 2)

The above comments suggest that Nhu seemed to have recognized one of the most important values of TBLT is to "promote learners' confidence by providing them with plenty of opportunities to use language in the classroom without being constantly afraid of making mistakes" (Willis \& Willis, 2007, p.2). Evidence from the classroom observation and interaction data provided further support for this. The data show that many pupils managed to make themselves understood by employing such strategies as hints or gestures. For example, the interaction data show that there was an occasion when one pupil used the word "computer" to refer to the target word $I T$ when she was providing information about her timetable to her peer in the main task in Lesson 1. This pupil might have noticed this word from the teacher who referred to it to explain the meaning of the word IT in the priming in the pre-task phase. Some simple drawings were found in the task handouts as the pupils were not able to always write the target words (see Appendix 8.1 for a sample of one pupil's work). This shows that Lan's decision of erasing the vocabulary items on the board had encouraged the use of communication strategies which characterize task-based interaction (Willis, 1996; Willis and Willis, 2007). 


\section{Post task}

There remains a concern that pupils may focus on fluency at the expense of accuracy when they engage in task-based interaction (Skehan, 2018). However, what Nhu did in the post-task phase and her perceptions of this phase suggest that this is not necessarily the case. The post-task phase went smoothly. For both lessons, Nhu asked her pupils to carefully notice the performance of two dyads of pupils so that they could report back the language the performers used to exchange information about the timetables. Nhu then focused the pupils' attention on the target pattern while she was writing them on the board. She then asked the whole class to tell the meaning and use of the patterns. Such a decision might have enabled a focus on form to take place, as Nhu commented:

When it came to the post-task stage, by analysing their output, the pupils would be able to notice the appropriate ways to express their meanings. I like this idea. (Khi vào phần cuối mình cho học sinh phân tích nhũ̃ng gì nó nói. Như vậy học sinh sẽ có thể chú ý được những cách thích hợp để diễn đạt cái muốn nói. Em thấy thích điều này.) (Interview 1)

Also at this stage, Nhu made another notable decision, asking the pupils to notice some of the question and answer forms that she picked up from their interactions. One example is that she asked the pupils to comment on the acceptability of the alternative question "English teacher's name, please?" for the target question “Who is your English teacher? Nhu expressed that she was satisfied as she found that in their efforts to find the language to express themselves, her pupils were able to construct different possibilities of expressing meaning. This result provides evidence to support previous claims that through peer interaction, learners are able to comprehend and use language in different ways (Philp et al., 2014).

Because of the limited availability of time, Nhu was not able to involve her pupils in the language practice activity after the analysis activity. However, she took the last few minutes to call on some weaker pupils to ask about their real timetable of the day. Her purpose was to check whether the goals of the lessons had been achieved. She said that she was happy as those pupils were able to respond confidently to her questions.

Like Nam, in both lessons, due to time constraints, Nhu did not set the task of identifying the differences and similarities between the timetables as a desired task outcome. 
However, she did not consider this a limitation. She argued that for her pupils, being able to complete the timetables was already a success outcome. Given her pupils' lower level of proficiency and the availability of time, she commented:

The outcomes could be varied depending on the proficiency level of the pupils. If the pupils had been stronger and more familiar with learning with tasks, and if time allowed, I would have set the task outcomes as planned. However, I think completing the timetables also means that the outcome has been achieved. (Các mục tiêu có thể thay đổi tùy vào khả năng của học sinh. Nếu học sinh giỏi hơn và đã quen với việc làm tasks và nếu có thời gian em chắc sẽ đã cho các em làm theo giáo án. Nhung em nghĩ, việc các em hoàn thành thòi khóa biểu cũng có nghĩa là mục tiêu đã đạt.) (Interview 1)

When asked to reflect on the learning outcomes that occurred during the task-based lessons compared with the PPP version of the lesson, Nhu had this to say:

PPP focuses on accuracy. In a PPP lesson, a teacher first introduces the new structural patterns accurately. Pupils then practice them repeatedly so that they can imitate and use them in the last stage. TBLT puts a greater focus on fluency with accuracy being promoted in the last stage. I think each has its own strengths. TBLT helps pupils speak English more confidently. If they cannot say a correct sentence, they can say a few words or use gestures to express themselves. By so doing, I see that pupils are stimulated to recall the knowledge that they have learned so that they can communicate their ideas to their friends. I like this. ("PPP" tập trung vào “accuracy”. PPP thì đầu tiên vô thì chị phải "input" cái dũ liệu nó chính xác, cái ngôn ngũ và câu hỏi phải chính xác để cho các bé tù đó bắt chước và làm theo cái phần fluency ở phần cuối. PPP thì nó tập trung vào "accuracy" nhiều hơn. Còn em thấy phần "tasks" mình sủ dụng thì nó tập trung vào "fluency" nhiều hơn, rồi sau đó phần cuối mới có “accuracy”. Thì em thấy cái nào cũng có cái hay của nó. Phần tasks của minh thì em thấy giúp cho hoc sinh có thể tụ tin nói tiếng Anh. Nó không thể nói hết nguyên câu được thì nó có thể nói 1, 2 tù cho bạn nó hiểu. Nó có thể làm động tác hoặc mô tả gì đó cho bạn nó hiểu. Tù đó em thấy các bé nhớ lại kiến thức mà các bé đã học đượ. Nó kích thích lại được nhũng tù của nó, tiềm ẩn của nó học được tù bấy lâu rồi. Các bé nhớ lại và cố gắng nói cho bạn nó nghe. Em thấy thích.) (Interview 2) 
This comment seems to suggest that Nhu recognized one of the basic differences between PPP and TBLT. That is, she recognized a greater focus on fluency while acknowledging that accuracy is not overlooked in the task-based lessons. It could be that through her experience with TBLT, Nhu realised a stronger communicative value in TBLT compared to PPP.

\subsubsection{Teacher Lan}

Table 13 below summarizes the stages in the two observed lessons and indicates how each lasted.

Table 13. Lan's lessons

\begin{tabular}{clclc}
\hline Phase & \multicolumn{1}{c}{ Lesson 1 } & $\begin{array}{c}\text { Time } \\
\mathbf{( 4 0} \\
\text { mins) }\end{array}$ & \multicolumn{1}{c}{ Lesson 2 } & $\begin{array}{c}\text { Time } \\
\text { (41mins) }\end{array}$ \\
\hline Pre-task & $\begin{array}{l}\text { Listing task: Board race } \\
\text { game } \\
\text { Input-based listening task: }\end{array}$ & 8 & Slap the board game & 7 \\
Guessing game & Input-based listening task & 8 \\
\hline Main task & Information-gap task & 16 & Information-gap task & 17 \\
\hline Post task & $\begin{array}{l}\text { Language performance } \\
\text { and analysis }\end{array}$ & 8 & $\begin{array}{l}\text { Language performance } \\
\text { Ask and answer activity: } \\
\text { Teacher asks, pupils answer. }\end{array}$ & 5 \\
\hline
\end{tabular}

\section{Pre-task}

Like Nam, Lan used the same procedures to carry out the listing task in Lesson 1. However, unlike Nam's pupils, Lan's pupils were able to write up all of the subjects in the timetable in English on the board when they played the Board Race game. Lan ended this task by putting the flashcards next to the words so that the pupils could relate the meaning to the pictures (Figure 21). In Lesson 2, Lan did not have her pupils listen to the song "What day is it today?" as planned. She started by having her pupils play the game "Slap the board" to review the vocabulary items taught in the previous lessons. These vocabulary items were needed for the performance of the main task in this lesson. Each activity was followed by a quick, teacher-led, choral repetition of the target vocabulary items before Lan moved to the input-based listening tasks. 


\section{Figure 21. Mindmaping the school subjects}

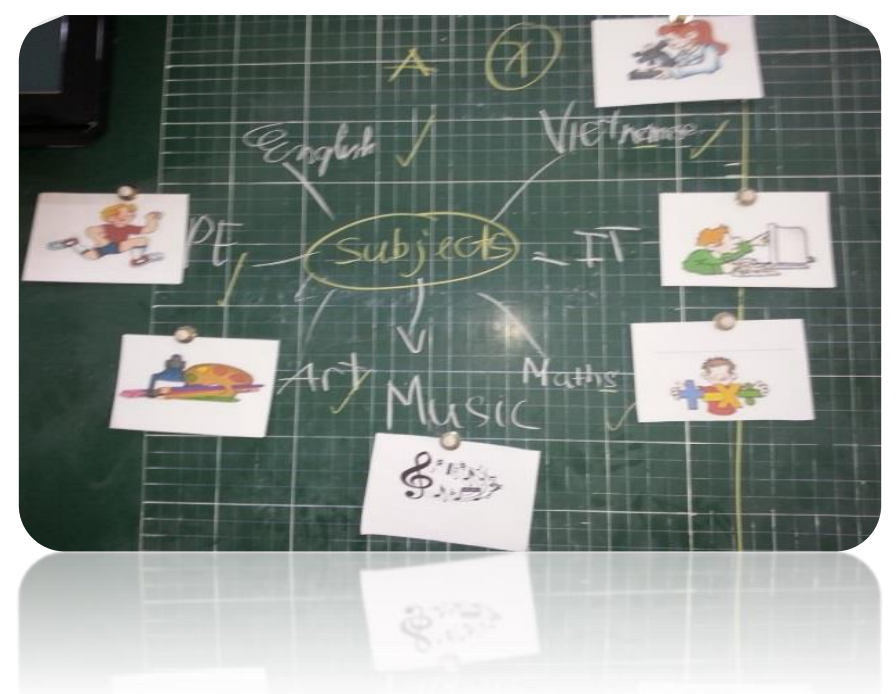

The input-based listening tasks in both lessons were also carried out as planned. In Lesson 1, each group of four received a set of eight picture cards and discussed which three cards they would choose to represent the three school subjects the textbook character Phong had on the day. The task handout for Lesson 2 was shown on the television screen, which made it easier for the teachers to present the task handouts and for the pupils to understand the instructions. Like Nam and Nhu, the way Lan directed the input-based listening tasks drew the pupils' attention to what was to be done, thus activating relevant schemata for the performance of the main task. Similar to what happened in Nam and Nhu's classes, most pupils in Lan's class completed the listening tasks with enthusiasm.

\section{Main task}

For the main tasks in both lessons, like Nhu, Lan used the TV screen to present the task handouts. Without such support, as Lan said, giving instructions would be highly timeconsuming. She also added that the instructions for both tasks, though quite complicated, made good sense to her pupils. Compared with Nhu's and Nam's classes, Lan encountered the least difficulty since she had the advantage of having more proficient pupils. Most pupils understood her instructions quite quickly even though some parts of the instructions were given in English. Given this advantage, Lan chose not to provide task modeling to support the performance of the main tasks in both lessons.

Like Nhu, Lan's involvement during the task performance was minimal. While the pupils were performing the tasks, Lan moved around to monitor the class and provided 
clarification on task instructions when needed. She chose to give the most support to those who needed it the most and to allow the pupils who were coping well with the tasks to work on their own. Also, like Nhu, to stimulate their talk, Lan kept encouraging her pupils to get their meaning across in English without worrying about making mistakes. Analysis of the classroom observation and peer interaction data (Section 6.5) reveals that Lan provided coconstruction support to only one pair. In this situation, she attempted to help the weaker pupil construct a complete sentence. Extract 8 shows that P2 is able to respond to P1's question but he does not use the target answer pattern "I have...". Seeing this Lan steps in to provide the pattern "I have..." in line 3. Thanks to this assistance, P2 is able to use the target-like pattern in his utterance in line 6 and then due to the prompts provided, $\mathrm{P} 2$ is able to list all the subjects in subsequent turns.

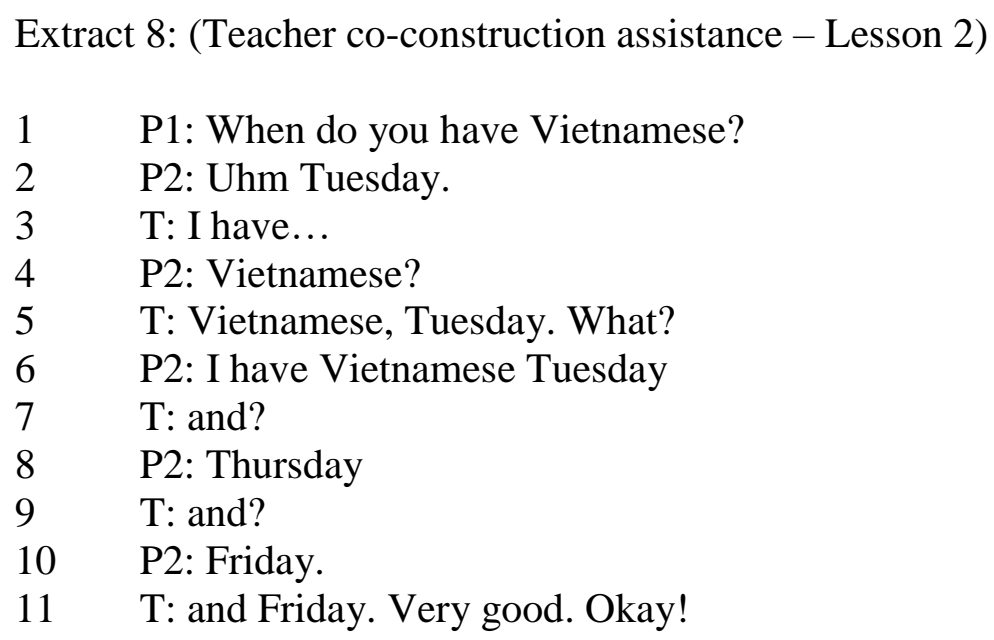

Evidence from the analysis of the peer-peer interaction revealed that unlike Nhu's and Nam's pupils, these higher proficiency pupils were able to use more varied language through clarifying and negotiating meaning. For example, in addition to the target language, the pupils frequently used words and phrases such as "How do you spell X?", "How about you?", "Do you understand?", "Thank you” and "Okay". Some of these words and phrases are exemplified in Extract 9 below.

\section{Extract 9:}

$1 \quad$ P2: When do you have Vietnamese?

2 P1: I have on Tuesday, Thursday and Friday too. When do you have Maths?

3 P2: Maths?

$4 \quad$ P1: When do you have Maths?

$5 \quad$ P2: I have Maths at Monday, Tuesday and Thursday. 
$6 \quad$ P1: Okay!

$7 \quad$ P2: What about you?

8 P1: I have it on Monday, /'wen.deI/ and Thursday.

Extract 9 shows a typical example of the interaction among these higher proficiency pupils. In line 2, P1 is able to use the word "too" to show that she has the same answer. Also, P1 uses the word "Okay" in line 6 to acknowledge that the message has been understood. In line 7, P2 uses the phase "What about you?" instead of repeating the target question form to ask for the information in return. This example shows that Lan's pupils were able to use more varied language while the language used by Nam's and Nhu's pupils was generally limited to the target question and answer forms. This is most likely a consequence of their exposure to English in private classes and Lan's frequent use of English as a medium of instruction in the classrooms.

Although most of pupils' discourse was on task, there was also evidence of pupils going off task. However, exploration of this off-task discourse revealed a high level of "engagement". Engagement here refers to the extent to which pupils are "attracted to their work, persist in it despite challenges and obstacles and take visible delight in accomplishing work" (Schlechty, 1994, p.5). The third characteristic of engagement is exemplified in Extract 10 below. In line 2, S1 expresses her satisfaction in completing the task and then, without prompting from the teacher the two learners autonomously appropriate English expressions from the task to engage in a small piece of genuine communication in English (lines 4-5) before reverting to Vietnamese again to tell the teacher they have finished the task.

\section{Extract 10: (Off-task talk)}

$1 \quad$ P2: Crazy

2 P1: Cô ơi xong rồi, cô ơi. (Teacher, we've finished.)

3 P2: Crazy.

$4 \quad$ P1: ...What subject do you like best?

$5 \quad$ P2: Uhm...I like Math. What about you?

6 P1: I like Vietnamese. Xong rồi cô ơi (We've finished, teacher).

The performance of the main tasks in both lessons ended within 11-12 minutes. In Lesson 1, the main task ended when the pupils had completed their timetables. This was immediately followed by the post-task phase. This means that the task outcomes (three similarities and two differences between the two timetables) were not fully achieved. Lan explained that there was not enough time for her pupils to compare the two timetables. However, this did not happen in Lesson 2. Immediately after the pupils finished completing 
the two timetables, Lan asked them to find the three differences and two similarities, and to do this in Vietnamese. Pupil's unfamiliarity with reporting task outcomes may have influenced Lan's decision to ask them to do this in Vietnamese. As I observed, the pupils quickly showed each other their completed timetable so that they could make the comparison.

\section{Post task}

The post-task activities were conducted as planned. In both lessons, Lan asked two dyads to come to the front of the class to demonstrate their performance of the main task while the rest of the class were asked to focus their attention on these. Just as in Lesson 2, after the performances, Lan asked the performers to report on the results of comparing the two completed worksheets. Both dyads were able to provide the correct results which were then confirmed by the rest of the class. Simultaneous responses were heard from the rest of the class, indicating that many of the dyads had completed the tasks and achieved the required outcomes.

Like Nhu and Nam, the way Lan conducted the language analysis activity encouraged pupils to attend to the target language forms and to figure out the appropriate forms by themselves. The value of this activity is reflected in Lan's comment as follows:

This analysis activity offers the pupils an effective way to learn the target structural patterns. When the pupils have to analyse the language, they can learn a lesson for themselves and thus remember the target language items better. (Phần phân tích là một cách hiệu quả để giúp học sinh học các mẫu câu. Khi mà kêu tự nó phân tích sau khi xem bạn nói thì nó sẽ rút ra bài học cho bản thân và do đó sẽ nhớ các điểm ngôn ngũ cần hoc tốt hơn.) (Interview 2)

The language analysis activity concluded Lesson 1. Lan said that the remaining time did not allow her to carry out the language practice activity. In Lesson 2, the language practice activity was replaced by a brief question-and-answer session between Lan and her pupils. Lan randomly asked some of the pupils about the subjects they had in the day, the time when they had a particular subject and the names of the teachers of some subjects. Observational notes showed that most of the pupils were able to respond to Lan's questions confidently using the target structural patterns. Like Nam, in the interview, Lan said that she 
was happy because the objectives required for the current lesson and the previous lesson were achieved.

Furthermore, in the interview, Lan obviously valued the strategy of pairing a weaker pupil with a stronger one. She believed this was an effective technique to encourage task completion. She commented that some of her weak pupils needed assistance, but since they were in pairs, the stronger peer could help. Accordingly, this removed some of the burden from the teacher. As Lan commented:

The stronger pupils could effectively help me in providing assistance. I noticed that the weak pupils tried to seek help from their stronger peers before they turned to me for help. (Mấy đứa giỏi có thể giúp em hỗ trợ mấy đưa yếu hơn rất hiệu quả. Em thấy mấy đưa yếu hơn cố nhờ nhũng bạn khá hơn giúp trước khi tìm đến cô.) (Interview 1)

When invited to compare the task-based lessons with the PPP lessons, Lan raised two issues. First, she commented that the task-based lessons better helped her pupils mobilise relevant vocabulary from their existing linguistic resources in order to serve their communication needs. As she said:

When I used the traditional method, I taught pupils structural patterns first and then got them to practice the patterns repeatedly using the pictures. This repetitive practice also helped them learn the structures. However, sometimes, the learning was mechanical and did not help pupils use more vocabulary. When involving themselves in the lessons [task-based lessons], besides using the structures, pupils had to mobilise their vocabulary resources to help them express their ideas. Because they were not fully provided with the target structural patterns necessary for their communication, they had to make every effort to help their friends understand what they want to say. This could enable a lot of vocabulary words to be mobilised. (Khi day theo phuong pháp cũ, em dạy học sinh mẫu câu truớc, sau đó cho các em thục hành mâu câu tới lui sử dụng tranh ảnh. Việc thục hành này giúp các em học cấu trúc. Nhung đôi khi việc học nhu thế này rất máy móc và học sinh không học được nhiều tù vựng. Khi học sinh được học theo phuơng pháp mới, ngoài việc đọc được cấu trúc, học sinh còn phải huy động vấn tù vựng để giúp các em diễn đạt ý mình muốn nói. Vì các em không được dạy truớc cấu trúc cần để nói, các em phải tụ nỗ lục làm sao cho bạn hiểu. Điều này giúp các em huy động được nhiều tù̀ vụng.) (Interview 2) 
Second, as a result of their self-mobilization efforts of the existing knowledge, as Lan remarked, they could develop their communication skills.

This approach [TBLT] helps the pupils handle their communication more effectively in real-life situations. Whereas, the PPP approach could merely help them learn the target structural patterns taught to them. (Phương pháp này sẽ giúp học sinh linh hoạt hơn trong giao tiếp trong nhũng tình huống thưc tế. Trong khi đó phương pháp cũ chỉ giúp các em học được nhũng cấu trúc mà giáo viên dạy cho.) (Interview 2)

Lan's comment suggests that the task-based lessons required greater efforts from the pupils compared to the PPP lessons. This suggests that Lan seemed to have realised that through the process of attempting to accomplish the tasks using their own language repertoire, the pupils might have gained the confidence and willingness to communicate in the target language, which, as Willis and Willis (2007) and Ellis (2003) stated, is an opportunity for the development of communicative competence. However, Lan's comments about her pupils' ability to mobilise their linguistic resources could also be partly explained through their greater access to English compared to the limited access that Nhu's and Nam's pupils had.

\subsubsection{Discussion of the implementation of the task-based lessons}

The first research question in Phase 2 investigated how the teachers implemented the two task-based lessons and how they evaluated their implementation of the lessons. The following section discusses key implementation issues and the teachers' evaluation of their lessons. It also includes findings and discussions of concerns the teachers had about implementing the lessons.

\subsubsection{Implementation of the task-based lessons}

Two notable implementation issues related to the pre-and-post phases and the main tasks are discussed here. First, the findings indicated that the teachers successfully carried out most of the activities in these two phases. In the hands of the teachers, the input-based listening task in the pre-task phase, which was adapted from the "Look, listen and repeat" activity in the textbook presentation phase, acted as a type of scaffolding to reduce the cognitive and linguistic demands placed on the performance of the main task. All three teachers valued this task, agreeing that it addressed their concern about the mechanical nature 
of the textbook's presentation activity. In a similar vein, it was found that the teachers were able to promote a kind of focus on form discussion (Ellis 2003; Willis \& Willis, 2007) when they carried out the language analysis activity.

Additionally, all teachers expressed positive views about the effectiveness of the language analysis activity. They commented that with this activity promoted not only fluency, but also accuracy. Their views appeared to support Willis and Willis' (2007) claim that having learners reflect on the language they have experimented with may be more effective than providing them with the language beforehand. The language analysis activity followed by the language practice activity addressed the teachers' concern about their pupils' ability to grasp the target language structures. More specifically, it addressed the teachers' concern about the requirement for achieving the lesson objectives.

Second, with regard to the main tasks, there were variations in the way the teachers implemented these tasks. One variation concerns the extent to which they provided coconstruction assistance. For example, unlike Nam and Lan, Nhu decided to not provide her pupils with co-construction assistance during their task performance. As she explained, her decision was driven by her intention to challenge her pupils' ability to recall what they had learned through interacting with peers. Another variation concerns the extent to which the teachers simplified the task outcomes. Lan was able to carry out the task of identifying the differences and similarities across the two timetables in one of the task-based lessons, but the other teachers were not able to do so. The finding that the teachers simplified the task outcomes reveals that the outcomes of the two main tasks were not fully achieved. However, researchers (e.g., Ellis, 2003; Skehan, 1998, 2018) suggest that task completion has priority over performance outcomes. Therefore, success or failure of task performances should not only be judged in terms of performance outcomes. Ellis (2003) argues that the genuine purpose of the task is not that learners should achieve outcomes, but "it is the cognitive and linguistic processes involving in reaching the outcome that matter" (p.8). Task completion as expected by the teachers in the current study involved the completion of the two timetables in Lesson 1 and the two worksheets in Lesson 2, regardless of whether the similarities and differences between the two timetables were identified or not.

Results from the interviews with the teachers revealed their motives to minimise the task outcomes: to reduce task demands to match with their pupils' competences and to avoid tensions with regard to time management. These teachers' implementation decisions were aligned with those made by the teachers in Berben, Van Den Branden, and Van Gorp (2007), suggesting that the teachers deviated from the intentions of the task designers and transformed 
the tasks in a way that suited their own situations. Regarding this adaptation, Van den Branden (2016) has further pointed out that "Tasks on paper are merely workplans. Once they enter into the hands of actual teachers, they become reinterpreted and reshaped to fit the latter predispositions, capabilities, educational beliefs and established classroom practices" (p.247).

Despite the variations, the three teachers successfully carried out the two task-based lessons in their normally scheduled classes. They were able to manage their classes, give clear instructions and handle all phases of the lessons. These findings were a surprise, considering the large class sizes and mixed proficiency classes in Nhu's class and the low level of proficiency of the pupils in Nam's class. For example, large class sizes are identified in studies such as Carless $(2002,2004)$ and Zhang (2015) as a major factor that hinders the implementation of TBLT in the primary classroom, but this did not hinder Nhu's implementation of the two task-based lessons. Results show that despite having a large class of 46 pupils, Nhu skilfully regulated her discipline and gained control over the learning process during both lessons. Similarly, the factor relating to the low proficiency of pupils identified in the literature as a barrier to the implementation of the communicative and taskbased approach (Bao, 2012; Carless, 2003; Li, 1998) did not inhibit the implementation of TBLT in Nam's class, even though it impacted on language production. One of the reasons for this is that Nam had an advantage of having a small class of 27 pupils who were able to work well in groups and pairs. Being a skilful teacher, Nam was able to engage and motivate his pupils throughout the lessons. However, as a least experienced teacher, Lan was less skilful in maintaining a high level of engagement in her class compared to Nam. Thus her success was attributed to her pupils' higher proficiency level. The pupils were able to obtain rich input from the input-based listening tasks, together with their access to language resources, and this may have enabled them to complete the tasks. Put simply, it can be concluded that the teacher factors generally play a decisive role in the success of the two taskbased lessons.

\subsubsection{Teachers' evaluation of their implementation of the task-based lessons}

The findings reveal that despite acknowledging that the pupils struggled at some stages and needed teacher assistance, the teachers were pleased with the overall engagement the pupils showed and with the efforts with which they attempted to complete the tasks. They showed appreciation for the student-centred and meaning-focused values of the task-based lessons compared to the PPP versions of the lessons. Of note is that, Nhu, a proponent of PPP, developed a view that reflects the idea that "learning a language does not necessitate always 
treating it as an 'object"' (Ellis, 2015, p.383). Her view on this fundamental difference in terms of learning between PPP and TBLT suggests that as a result of experimenting with TBLT, Nhu's belief about language learning seemed to have shifted and the change is more congruent with communicative and task-based language teaching principles.

However, the teachers raised three major concerns associated with implementing the lessons. The first concern is related to preparation time. As Nhu, noted:

Preparing such tasks would take me a lot of time while it is quite easy to just follow the textbooks. (Chuẩn bị cho các tasks đó sẽ mất nhiều thời gian. Trong khi đó, bám theo sách thì khá là dê̂.) (Nhu, in-depth interview)

This practical concern is often shared by teachers especially when faced with the choice between ready-made textbook lessons or preparing original lesson materials from scratch. Thus, if teachers are to be encouraged to take a more task-based approach to teaching, readymade materials may need to be available to combat this concern (Carless, 2002; Zhang \& Hu, 2010).

Another concern is related to difficulty of explaining tasks. Nam, for example, noted that giving clear instructions was difficult if pupils were not familiar with tasks. As Nam further explained:

The tasks are difficult or not depending on the instructions. Clear instructions make it easier for pupils to perform the tasks. (Các hoạt động mình đưa ra khó hay không là do cách mình huoóng dẫn. Lời hướng dẫn rõ ràng sẽ giúp học sinh thục hành các hoạt động dêe hon.) (Nam, in-depth interview)

Nhu and Lan shared the same view, but they also noted that giving instructions was not challenging if both teachers and pupils were familiar with tasks. This was also noted as a challenge in the classroom notes and shared this view with the teachers. It is important to note that without training and rehearsal of giving task-related instructions, teachers can face numerous difficulties. In other words, teachers will need to practice and get used to giving task-related instructions, as they are often different from the types of instructions they are used to giving. To investigate this assumption, however, more longitudinal research is needed on how teacher task-based teaching can evolve over a longer period of time. 
The third and final concern is related to limited practice opportunities, which is a more substantive one for task-based teaching. Following Willis and Willis (2007), the task-based lessons included opportunities for controlled practice and focus on form in the post-task phase. However, because this phase always occurs towards the end of a lesson, it is the one most likely to be dropped when the main task runs over time, as tasks often do. One of the teachers, Lan, confirmed this point:

The target structural patterns were not provided until it came to the post-task phase. However, the time left for practicing the target patterns was not enough. More time was needed for explaining the target patterns and for pupils, especially the weaker ones to practice the patterns. (Cấu trúc câu chỉ được cung cấp khi học sinh đã làm xong hoạt động. Tuy nhiên, thời gian còn lại để thực hành cấu trúc không đủ. Cần thêm nhiều thời gian để học giải thích và thục hành cấu trúc cho học sinh.) (Lan, in-depth interview)

Given this, the issue may not be one of limited practice opportunities per se, but of insufficient time at the end of the task-based lessons to fully realize controlled practice opportunities. Again, for the teachers in the current study, this is an issue that may be resolved as the teachers develop expertise in balancing the different phases of a task-based lesson, and perhaps by readjusting their expectations about how much controlled practice is required.

Finally, additional issues of noise and discipline were raised by Carless $(2002,2004)$ as factors constraining task implementation in primary school classrooms in Hong Kong. However, in the current study, only one teacher (Lan) expressed her concern about these issues. As experienced teachers, Nhu and Nam were able to maintain discipline whilst also involving pupils in the tasks, and neither of them expressed concern about "noise" or "discipline". This suggested that these teachers were more tolerant of noise than Lan who stressed good behavior. This is seen in one of her comments related to this stage "the tasks engaged the pupils but cause a lot of noise" (Các hoạt động thu hút học sinh nhung cũng gây nhiều tiếng ồn). As the least experienced teacher, Lan's ability to tolerate noise may have been more limited than the other more experienced teacher. It is important to note that Nhu's and Nam's success in managing the class appears to be a result of their experience and the consequent well-developed classroom management. Thus, they could establish with more facility, the required learning behaviors such as setting up effective group work in Nam's class and settling noise by Nhu. 


\subsection{Pupils' perceptions of the two task-based lessons}

This section presents the results of pupils' perceptions of their experiences carrying out the two task-based lessons. Six participating pupils in each of Nhu's and Lan's class were interviewed twice in groups after each of the two task-based lessons. Pupils from Nam's class were interviewed once only after the second lesson due to pupil availability and time constraints. Each group comprised three pairs with each pair consisting of a lower and a higher proficiency pupil. The interviews were in the form of an informal discussion about their general impressions of the lessons, the activities they liked best, the difficulties they encountered and the strategies they used to overcome them, and finally their use of L1.

There were some unavoidable challenges in conducting the interviews associated with time and characteristics of the pupils. First, based on the availability of the pupils, the interviews were conducted during the break time or after school. This severely limited the time for each interview (15-17 mins). Second, many of the weaker pupils, including particularly the weaker ones from each dyad across the higher proficiency group (HPG Lan's class) and the moderate proficiency group (MPG - Nhu's class), and many of the six pupils in the lower proficiency group (LPG - Nam's class) were quite shy or reluctant to speak, even though the interviews were in Vietnamese. Therefore, except for their responses about their most favourite activity, many of the weaker pupils tended to rely on their more confident and proficient peers for explanations. Finally, since both lessons shared many similar features in terms of the design and implementation, many of the pupils' responses to the questions in the second interview were similar to their responses to those in the first interview (both interviews were semi-structured and used the same set of interview questions (see Appendix 6 for the interview questions). Thus, most of the quotes provided here are representative of both lessons and were, therefore, confirmed across the two interviews. Despite these constraints, the analysis of the collected interview data revealed several important findings that support the teachers' implementation decisions and perceptions presented in the previous section. A summary of the pupil interview data is presented group by group.

\subsubsection{Nam's pupils (LPG)}

The six participating pupils in Nam's class appeared quite shy in the interview which was conducted after the second lesson had been completed. Therefore, except the responses to the questions concerning their favourite activity, in many cases, responses to other questions 
were limited to two stronger pupils and one weaker one. The others either expressed their agreement with the responses from these three pupils by nodding their head or chose to keep silent. Unfortunately, responses from this group did not carry enough detail to be quoted and so, they have been paraphrased.

In the interview, most of the pupils stated clearly that they enjoyed the lessons. When asked to indicate the activities they liked best, most pupils were able to respond to this question. The activities that interested them included the guessing game that served as a prelistening activity for the input-based task in Lesson 1, the language games that were organised to practice the target language items in the post-task stage in both lessons, and the main task in both lessons.

The guessing game which involved the pupils working in groups to select the three subject cards from a set of eight cards before listening to the recording to check their guesses interested most of the pupils interviewed. The pupils who selected this activity agreed with each other that the game was "fun". The same reason was also given for the preference for the "Passing the ball" game which was conducted in the post-task phase for the practice of the elicited target patterns in both lessons. This suggests that Nam's decisions to add elements of fun to the input-based listening task in the pre-task phase and to the language practice activities in the post-task phase were effective in capturing the pupils' interest in the lessons.

While many pupils appreciated the fun elements of the activities included in the preand-post task phases, only two stronger pupils stated their interest in the main tasks in both lessons. An explanation was provided and supported by two of the stronger pupils. One pupil simply explained that he liked to exchange the information about the timetables with his friend. Although this answer was not particularly detailed, it seemed to suggest that the information-gap tasks which demanded information exchange motivated these pupils to participate in task performance. These pupils' view on the main tasks further support Nam's observation of a high level of pupil involvement when they performed the main tasks.

When asked about the difficulties they encountered, the three pupils commented on the difficulty of speaking English without the pre-teaching and repetitive practice of the structural patterns. These comments were also supported by the others. The two stronger pupils revealed that the teacher assisted them. The weaker one said that she received help from her stronger peer and the teacher. These findings revealed that teacher and peer assistance played an important role in enabling the pupils in Nam's class to complete the two tasks. The assistance was primarily required to facilitate the initial phase of task performance 
when pupils were finding language to talk. Finally, the reason for the use of L1 to ask for help was given by a weaker pupil and confirmed by the others.

In brief, despite the limited data, the findings supported the observational findings and Nam's perceptions of his pupils' enjoyment during the task-based lessons. Moreover, the findings suggest that teacher and peer assistance were instrumental in enabling these pupils to complete the tasks.

\subsubsection{Nhu's pupils (MPG)}

The six participating pupils in Nhu's class were from a semi-rural school on the outskirts of the city. Compared to Nam's pupils, their overall proficiency level was higher and they were also more confident in using English. During both interviews, all pupils were able to respond to most of the interview questions. However, the most clear and detailed explanations were provided by the three stronger pupils and one of the weaker ones. The quotes presented below are from these four pupils.

In both of the interviews, the six participating pupils all reported that they enjoyed both lessons. When asked to indicate their favourite activities, the pupils expressed interest in a variety of activities. Like Nam's pupils, the weaker pupils in this group appreciated the enjoyment of the guessing game which served as a pre-listening activity for the input-based listening task in Lesson 1. The stronger ones, further, indicated that they liked the input-based listening tasks in lessons 1 and 2 because they challenged them. As one of the more proficient pupils said:

I like the listening activity because I could understand what I listened to. When I was involved in the listening, I concentrated hard. I could not understand much after the first listening, but then I concentrated harder and could do the task easily. (Con thich hoạt động nghe vì con hiểu nhũng gì con nghe. Lúc con làm bài nghe, con tập trung nhiều. Con không hiểu nhiều sau lần nghe đầu nhung sau đó con đã tập trung nhiều hơn và có thể làm bài nghe dê dàng.) (Interview 1)

This comment evidenced a high level of concentration while the pupils were completing the input-based listening tasks in both lessons. This echoed the teachers' perceptions, suggesting that these tasks seemed to engage the pupils more effectively than the original "Look, listen and repeat" textbook presentation activity. 
Following the input-based tasks, the main tasks in both lessons were chosen by many pupils as their other favourite activities. Similar to Nam's pupils, two of the three stronger pupils, who were able to explain the reasons behind their preferences for these tasks, shared a similar view that the tasks created an opportunity for speaking English:

I could speak English with my friend. (Con có thể nói tiếng Anh với bạn.) (Interview 1)

and for collaborative learning:

I liked to work with my friend to complete the timetable. (Con thich làm chung vớ bạn hoàn thành thời khóa biểu.) (Interview 1)

These pupils' comments suggest that these pupils were motivated by opportunities to use English for communication and to collaborate with each other.

When asked about the difficulties of performing the main tasks, these four pupils spoke up. Like Nam's pupils, they commented that they were not familiar with speaking English when the target structural patterns had not been explicitly taught. However, when asked why they could perform the main tasks successfully given such unfamiliarity, two of the three stronger pupils shared similar thoughts that it was the input-based listening task that helped them. A comment from one of these pupils clearly illustrates this point:

As I understood what was talked in the listening task, I learnt some words and structures. Then I used these words [and structures] together with some of the words I knew to make sentences to ask my friend. (Vi con hiểu nhũng gì nói trong bài nghe nên con đã biết một vài tù̀ và cấu trúc, sau đó con đã sủ dụng nhũng tù̀ này cùng với nhũng tù con đã biết để để đặt câu để hỏi bạn con.) (Interview 2)

The comment suggests that the two input-based listening tasks not only captivated the pupils' interest and attention in the lessons, but they also served as a valuable scaffold for the performance of the main tasks. While doing the listening tasks, the pupils' attention was focused on the target structural patterns and vocabulary items which were necessary for their performance of the main tasks. It was possible that, since many pupils were able to make use 
of the input from these tasks, they were able to do the main tasks even though the teacher assistance was not available.

Another scaffold revealed by two of the three weaker pupils concerns the communication strategies recommended by the teacher. These pupils shared a similar view that when they did not know how to write a word, they drew a picture to illustrate the meaning (see Appendix 8.1) or when they did not know how to say a word, they used gestures or hints to express their ideas. In particular, one of them said that she was able to do the main task because she followed the teacher's instruction which encouraged her to focus on expressing herself regardless of mistakes. This girl was able to articulate her idea well as follows:

I could freely express myself as long as I could get myself understood so that my friend could provide me with information [to complete the timetable]. In the end, the teacher helped me correct my mistakes. (Con có thể tụ do diễn đạt ý của con miễn sau bạn con hiểu để cung cấp con thông tin để hoàn thành thời khóa biểu. Cuối cùng, cô sẽ giúp con sủa lồi.) (Interview 1)

These findings support Nhu's positive comments on her decision of not providing the target vocabulary on the board for the pupils to refer to when they were performing the main tasks in both lessons. Instead, she advised her pupils to use particular communication strategies to make themselves understood. Taken together, the effective employment of the communication strategies and the input-based listening tasks could be regarded as one of the important factors that enabled Nhu's pupils to successfully complete the tasks.

Regarding the use of L1, the three stronger pupils agreed that they needed to use L1 to explain how to do the tasks and to encourage each other to talk as the main reasons. Due to limited time, data regarding the use of L1 was limited to the responses from the three stronger pupils.

Overall, the findings revealed insights into how the pupils managed to complete the tasks. It was apparent that the pupils were able to make use of the language from the inputbased listening task and the communication strategies for their performance of the main tasks. In addition, they were also able to use L1 effectively to manage their task performances. 


\subsubsection{Lan's pupils (HPG)}

The pupils from Lan's class who were from an urban school expressed their views with the most confidence. Again, like Nhu's pupils, the stronger pupils in this group were able to provide the clearest and most detailed explanations. However, for many questions, the responses were limited to the three strongest pupils.

Like Nam's and Nhu's pupils, in both interviews, all pupils said that they found the lessons fun. The activities that particularly interested them include the listing task in Lesson 1, the input-based listening task, and main task in each of the two lessons. First, the listing task in Lesson 1 was selected by two of the three stronger pupils and one weaker pupil as their favourite activity. These pupils shared the same view that the task helped them learn the vocabulary effectively. As one of the two stronger pupils explained:

I like it because through the game I can recall the vocabulary words I have learned. I do not need the teacher to teach me. (Con thích nó [bài liệt kê] vì qua trò chơi này con có thể nhớ lại tù̀ vựng mà con đã học. Con không cần Cô dạy con.) (Interview 1)

This comment suggests that the listing task served as an effective way to activate the pupils' existing linguistic resources related to the topic. It might be that getting the pupils to work in groups to brainstorm helped them activate and mobilise the necessary vocabulary items for the performance of the main tasks.

I further asked the whole group why some of them could write down the subject words in English in a mind map without any pre-teaching. Their answers revealed that they had learned the words from their private classes, from their parents teaching them some English at home, and/or from reading books. These answers suggest that in some contexts explicit vocabulary teaching could be unnecessary for pupils who may have the opportunity to learn English outside the classrooms. It is also worth noting that, with their strong language background, the stronger pupils might have played an important role in assisting their weaker peers with the performance of the main tasks.

Following the listing task in Lesson 1, the input-based listening tasks in both lessons were widely regarded as a "favourite". Like Nhu's pupils, the four pupils who chose these tasks were able to explain clearly why they preferred them. In particular, they shared the same thoughts with some of Nhu's pupils about the importance of the input-based listening tasks in enabling their performance of the main tasks. Their views suggested that their active engagement in the input-based tasks enabled them to understand the input from the listening 
and consequently created a schemata that enable them to complete the main tasks. Here are two such comments:

I like the listening tasks. When I listened, I understood what I listened to. So I learned the question and answer forms. (Con thich bài nghe. Khi con nghe, con hiểu nên con học được cách hỏi và trả lời.) (Interview 1)

The listening task helped me know how to ask my friend. (Bài nghe giúp con biết cách hỏi bạn con.) (Interview 2)

The responses for the preference of the main tasks seem to be related to the benefits of peer task interaction. According to the two stronger pupils who referenced these tasks, peer task interaction provided a context for using their English knowledge in a communicative way. As one of these pupils said,

I like to exchange information about the timetables. I had an opportunity to communicate with my friend. I was able to write down and speak out what I have learnt. (Con thích trao đổi thông tin về thời khóa biểu với bạn. Con có cơ hội nói với bạn con. Con có thể viết ra và nói ra nhũ̃ng gì con đã học.) (Interview 1)

Interestingly, one of these two stronger pupils further pinpointed one of the most important benefits of task interaction when she recognised an improvement in the naturalness of her spoken English. As she said:

I like to exchange information about the timetable with my friend. I tried to help my friend understand using the language I knew. This helps me speak English more naturally. (Con thích trao đổi thông tin về thời khóa biểu với bạn. Con cố gắng giúp bạn hiểu qua nhũng gì con biết. Điều này giúp con nói tiếng Anh tụ nhiên hơn.) (Interview 1)

The comments on the main tasks showed that these pupils whose experiences of communication in English had been limited to well-rehearsed dialogue and drills were now able to point out an improvement gained from their new way of learning English where communicative and meaningful language use is prioritised. As Ellis (2015) suggested, such 
experimentation with the language is needed if the "pupils are to develop the interactional competence needed for communication in the real world" (p.383).

Finally, when asked about any difficulties that they encountered, none of the pupils mentioned anything in particular. However, when asked about the reasons why they resorted to Vietnamese when they were performing the main tasks, two of the weaker pupils explained that they switched to L1 when they were not sure how to continue.

I spoke Vietnamese when I did not know what to say next. (Con nói tiếng Việt khi con không biết nói gì tiếp theo.) (Interview 1).

However, the stronger pupils from this group shared the view that they resorted to Vietnamese when they needed to give support or explanations to their less capable peers,

I used Vietnamese when I needed to tell my partner what to do. (Con sủ dụng tiếng Việt khi con cần nói với bạn nên làm gì.) (Interview 1)

One pupil added that:

My friend could not understand. I had to use Vietnamese to explain. (Bạn con không hiểu. Con phải sủ dụng tiếng Việt để giải thích.) (Interview 2)

In brief, the participating pupils in Lan's class expressed positive attitudes towards the two task-based lessons. Though limited, the responses from the three stronger pupils in this class highlighted certain communicative values of the main tasks in both lessons. One interesting finding is that none of the pupils mentioned any difficulties regarding their performance of the two lessons. Regarding their views of L1 use, the finding confirmed the importance of using L1 in facilitating the completion of the two task-based lessons.

\subsubsection{Discussion of pupil perception data}

The second research question investigated pupils' perceptions of their experiences of the two task-based lessons. The findings revealed that all participating pupils across the three classes enjoyed the lessons and were able to identify activities they particularly liked. However, not all pupils were able to articulate why they liked certain activities. The following discussion synthesized the findings from the three classes and identified some key themes. 
One key theme is that the pupils had a shared interest in the input-based listening task in both lessons. They valued the input-based listening task in terms of its enjoyment and its function as a scaffold for the performance of the main tasks. This finding supported the teachers' views, indicating that the input-based listening tasks engaged the pupils effectively. This may have attracted pupils' attention to the input necessary for the performance of the main tasks and therefore facilitated their performance of these tasks. Of note is that many of Nam's pupils expressed interests in activities that were enjoyable such as the listing task, the guessing games for the input-based listening tasks and the language games for language practice in the post-task phase. This suggests that the way in which these activities were presented, through interactive game-like activities, was seen by the pupils as motivating and making learning fun for them. Therefore, the competitive and fun features added to the tasks appeared to be one of the important elements facilitating the implementation of the task-based lessons.

Another common theme concerns the main tasks. The finding that the pupils across the three classes expressed their interest in the main tasks in both lessons highlighted the effectiveness of these tasks in enhancing pupils' communicative ability. This provides evidence to support the teachers' positive views on these tasks and the positive changes that they observed regarding their pupils' performances during the task-based lessons compared to the PPP version of the lessons. However, it is important to note that interest in the main tasks were mostly indicated by the more proficient pupils while the other activities were preferred by the weaker ones. It can thus be suggested that the stronger pupils were more able to appreciate the benefits from performing the tasks than the weaker ones. One possible explanation for this may be that the stronger pupils encountered fewer challenges in performing the main tasks than the weaker ones.

The findings regarding difficulties of performing the two task-based lessons were shared among Nam's and Nhu's pupils. According to them, performing the main tasks was difficult because the target structural patterns had not been pre-taught as they were normally done. Surprisingly, Lan's pupils did not mention any difficulties. This seemed to suggest that Lan's pupils appeared more confident and more capable of performing the main tasks than Nam's and Nhu's pupils. Despite the difficulties raised by Nam's and Nhu's pupils, data from classroom notes and peer-peer interaction showed that most pupils across the three classes were able to complete the main tasks although the outcomes achieved varied. Regarding this, the pupils indicated support from the teachers and their stronger peers as factors that helped them overcome the challenges of performing the main tasks. This finding supported Nam's 
decision to provide co-construction to his pupils and Lan's view on the benefits of pairing a weaker pupil with the stronger one. Finally, regarding the L1 use, despite the limited data collected from the three groups, the findings indicated that L1 was necessary for both the higher and lower proficiency pupils. While the higher proficiency pupils were found to use L1 regularly to give assistance or manage task performance, the lower proficiency ones used L1 mainly to seek assistance. L1 was thus important for managing task performance and seeking/asking for assistance. It did not seem to impede on learning, but rather facilitated it.

Overall, the findings show a match in the perceptions of the effectiveness of different activities in the task-based lessons between the teachers and their pupils. In particular, the pupils' positive attitudes towards the lessons supported the teachers' views and their implementation decisions. However, given the quantity and quality differences of the responses from the pupils across the three groups, it is important to note that the proficiency level of the pupils in itself, to some extent, affected their perception and performance of the lessons and that pairing learners with different proficiencies may have been a key to the tasks' success.

\subsection{Pupils' performance of the main tasks in the task-based lessons}

This section presents findings regarding the amount and characteristics of the interaction displayed by dyads across the three groups to provide insights into the performance of the main tasks in the task-based lessons. A discussion of the verbal interactional strategies the pupils adopted to perform the tasks follows. Data were obtained through field notes and transcribed recordings of 18 performances (9-12 minutes each) of two tasks by nine dyads across the three groups representing three different schools.

\subsubsection{Amount and characteristics of pupils' main-task interaction}

The amount of talk in each of the groups was determined by means of c-units. This includes the interaction with the teachers. 
Table 14. Frequency of c-units

\begin{tabular}{|c|c|c|c|c|c|c|c|}
\hline \multirow{2}{*}{$\begin{array}{l}\text { Proficiency group / } \\
\text { school type }\end{array}$} & \multirow[b]{2}{*}{ Task } & \multicolumn{3}{|c|}{ Dyad } & \multirow{2}{*}{$\begin{array}{l}\text { Sub } \\
\text { Total }\end{array}$} & \multirow[b]{2}{*}{ Total } & \multirow[b]{2}{*}{$M(S D)$} \\
\hline & & D1 & D2 & D3 & & & \\
\hline \multirow{2}{*}{$\begin{array}{c}\text { LPG (Rural) } \\
\text { (n=3dyads) }\end{array}$} & $\mathrm{T} 1$ & 53 & 54 & 46 & 153 & \multirow{2}{*}{322} & 53.7 \\
\hline & $\mathrm{T} 2$ & 69 & 60 & 40 & 169 & & (10.2) \\
\hline \multirow{2}{*}{$\begin{array}{l}\text { MPG (Semi-rural) } \\
\quad(\mathrm{n}=3 \text { dyads })\end{array}$} & $\mathrm{T} 1$ & 37 & 54 & 48 & 139 & \multirow{2}{*}{342} & 57 \\
\hline & $\mathrm{T} 2$ & 56 & 73 & 74 & 203 & & (14.4) \\
\hline \multirow{2}{*}{$\begin{array}{c}\text { HPG (Urban) } \\
\text { (n=3dyads) }\end{array}$} & $\mathrm{T} 1$ & 92 & 82 & 76 & 250 & \multirow{2}{*}{469} & 78.2 \\
\hline & $\mathrm{T} 2$ & 53 & 93 & 73 & 219 & & (14.8) \\
\hline Total & & & & & & 1133 & \\
\hline
\end{tabular}

Note $. \mathrm{T}=$ Task $; \mathrm{D}=$ Dyad LPG = Lower proficiency group (rural school); MPG = Moderate proficiency group (semi-rural school); HPG = Higher proficiency group (urban school).

Table 14 above shows the amount of talk measured by c-units across tasks, dyads and groups. The table shows that in all 18 performances across the three groups, the pupils produced $1133 \mathrm{c}$-units including interaction in the L1. The higher proficiency group (HPG) produced 469 c-units $(M: 78.2 ; S D: 14.8)$ while the moderate proficiency group (MPG) and lower proficiency groups (LPG) produced quite a similar number of c-units at $342 \mathrm{c}$-units $(M$ : 57; $S D: 14.4)$ and 322 c-units ( $M: 53.7 ; S D: 10.2)$, respectively. This shows that pupils in the HPG spoke more on average than those in the other two groups. Another notable finding is that there was a steady increase in the number of c-units from task 1 to task 2 across the LPG and the MPG.

A qualitative analysis of the interaction data shows that most dyads across the three groups exhibited an expert-novice interaction pattern which Storch (2002) operationalises as a situation in which one of the participants has primary control over the task and acts as an expert, encouraging and/or helping their partner. Additionally, a common turn-taking interaction pattern was identified in the interactions across many dyads, particularly among those from the LPG and the MPG. This suggests that pupils tended to rely on a pattern of question and answer which is familiar to them for their task performance

\subsubsection{Verbal interactional strategies the pupils used to complete the main tasks}

Although the amount of talk (measured by c-units) varied across the three groups, there were notable commonalities in the performance of the two main tasks. All nine dyads (three in each group) were able to complete the tasks, even though the achieved outcomes varied slightly. Moreover, results from the analysis of teachers' and pupils' perceptions presented above indicated similar levels of engagement throughout the performances. In 
addition, my observations notes confirm that the pupils were engaged in sustained taskfocused interaction. For these reasons, all performances of the main tasks by each and all of the groups were synthesised into a whole data set for larger-scale analysis. Analysis of the interactional strategies below comes from this combined data set.

The presence of five interactional strategies proposed in sociocultural and cognitive accounts of language development was found across the three data sets. They include coconstruction, other-correction, self-correction, negotiation for meaning and L1 use. The strategies occurred both in combination and in isolation. This means that in some cases, an occasion of co-construction included a correction and/or an NfM strategy. Similarly, L1 use was found to assist the identified strategies, occurring throughout the performances. Therefore, although I treated each strategy separately for convenience of exposition, there is a certain amount of interplay across the strategies within the interaction.

In sum, the five primary strategies depicted how pair task performances across the three groups progressed. My observation of these lessons confirmed that the five identified strategies were representative of what happened across all the task performances. The following sections discussed each of the strategies qualitatively, with their frequency across the three data sets tallied.

\subsubsection{Co-construction}

The co-construction strategy employed by dyads in the current study shows how the stronger pupil who assumed the expert role assisted his/her weaker peer who needed language assistance to participate successfully in producing utterances. The following quantitative analysis presents instances of co-construction, including those involving the teachers, although these were a minority. 
Table 15. Occurrence of co-construction provided by peers and teachers

\begin{tabular}{|c|c|c|c|c|c|c|c|}
\hline \multirow{2}{*}{$\begin{array}{l}\text { Co-construction } \\
\text { assistance }\end{array}$} & \multirow{2}{*}{$\begin{array}{c}\text { Proficiency } \\
\text { group / school } \\
\text { type }\end{array}$} & \multirow[t]{2}{*}{ Task } & \multicolumn{3}{|c|}{ Dyad } & \multirow[t]{2}{*}{ Subtotal } & \multirow[t]{2}{*}{ Total } \\
\hline & & & D1 & D2 & D3 & & \\
\hline \multirow{6}{*}{ Peer } & \multirow{2}{*}{$\begin{array}{c}\text { LPG } \\
\text { (Rural) } \\
(\mathrm{n}=3 \text { dyads })_{-}\end{array}$} & $\mathrm{T} 1$ & 1 & 1 & 0 & 2 & \multirow[t]{2}{*}{4} \\
\hline & & $\mathrm{T} 2$ & 0 & 2 & 0 & 2 & \\
\hline & \multirow{2}{*}{$\begin{array}{c}\text { MPG (Semi- } \\
\text { rural) } \\
\text { (n=3dyads) }\end{array}$} & $\mathrm{T} 1$ & 0 & 1 & 1 & 2 & \multirow[t]{2}{*}{5} \\
\hline & & $\mathrm{T} 2$ & 0 & 2 & 1 & 3 & \\
\hline & \multirow{2}{*}{$\begin{array}{c}\text { HPG } \\
\text { (Urban) } \\
\text { (n=3dyads) }\end{array}$} & $\mathrm{T} 1$ & 1 & 2 & 2 & 5 & \multirow[t]{2}{*}{6} \\
\hline & & $\mathrm{T} 2$ & 0 & 0 & 1 & 1 & \\
\hline \multirow{6}{*}{ Teacher } & \multirow{2}{*}{$\begin{array}{c}\text { LPG } \\
\text { (Rural) } \\
(\mathrm{n}=3 \text { dyads })\end{array}$} & $\mathrm{T} 1$ & 0 & 0 & 1 & 1 & \multirow[t]{2}{*}{3} \\
\hline & & $\mathrm{T} 2$ & 1 & 0 & 1 & 2 & \\
\hline & \multirow{2}{*}{$\begin{array}{l}\text { MPG (Semi- } \\
\text { rural) } \\
\text { (n=3dyads)_ }\end{array}$} & $\mathrm{T} 1$ & 0 & 0 & 0 & 0 & \multirow[t]{2}{*}{0} \\
\hline & & $\mathrm{T} 2$ & 0 & 0 & 0 & 0 & \\
\hline & \multirow{2}{*}{$\begin{array}{c}\text { HPG } \\
\text { (Urban) } \\
\text { (n=3dyads) }\end{array}$} & $\mathrm{T} 1$ & 0 & 0 & 0 & 0 & \multirow[t]{2}{*}{1} \\
\hline & & $\mathrm{T} 2$ & 1 & 0 & 0 & 1 & \\
\hline
\end{tabular}

Note. $\mathrm{T}=$ Task $\mathrm{D}=$ Dyad LPG $=$ Lower proficiency group; $\mathrm{MPG}=$ Moderate proficiency group; $\mathrm{HPG}=$ Higher proficiency group.

Table 15 above presents a summary of the peer and teacher co-construction data across groups. The table shows that co-construction occurred in most of the performances $(15 / 18)$. There were a total of 19 co-construction occasions identified across the 18 performances. The majority of these occasions were provided by peers (15/19) with only four being provided by teachers (4/19). The analysis showed that both teacher and peer coconstruction assistance was particularly noticeable at the beginning of the tasks when the pupils were still working out what to do. In some instances $(n=4)$, an occasion of coconstruction was shown to include both a correction and/or a NfM strategy such as a confirmation check. These instances were counted for the subsequent strategies.

The results show that teacher co-construction assistance was mainly needed by the LPG. Of the four occasions of teacher co-construction assistance, three were found in the LPG. The other occurred in the HPG and none was found in the MPG. These findings suggest that the provision of teacher co-construction assistance was influenced by not only the proficiency but also, to some extent, by the teacher's beliefs. This was evidenced in the case of the MPG whose teacher $(\mathrm{Nhu})$ provided little co-construction assistance to her pupils. The teacher's rationale, as mentioned in Section 6.3.2 above, was to encourage her pupils to express themselves authentically and seek assistance from each other. 
While most performances required either teacher or peer assistance or both, there were two performances in the MPG and one in the HPG where neither teacher nor peer assistance was needed. In contrast, there were four performances (one in the LPG, one in the MPG and two in the HPG) where two occasions of peer assistance were provided. Data show that peer co-construction assistance was sometimes repeated due to the pupils' uncertainty in using the target language. The finding that peer co-construction assistance was more frequently repeated in the HPG may be due to the fact that the stronger pupils in the HPG were more sensitive to errors than those in the LPG. It is likely that pupils with higher levels of proficiency are not only more aware of errors, but also more able to provide language assistance.

Furthermore, while there was little variation in the provision of peer co-construction assistance between the performance of the HPG and MPG, there was a sharp decline of this assistance from the performance of the main task in Lesson 1 (five occasions) to that of Lesson 2 (one occasion) in the HPG. This seemed to suggest that the pupils in this group were maybe more willing to communicate after they had finished the main task in Lesson 1.

The descriptive statistics presented above show that co-construction assistance from peers and teachers occurred sporadically across the performances. Since teacher coconstruction assistance has been discussed previously in Section 6.3, the following qualitative micro-analysis, using representative extracts drawn from the transcripts, centres on how and why peer co-construction assistance occurred and how it was used.

Table 15 above shows that at least one occasion of peer co-construction assistance occurred in 11 of the 18 performances. In these occasions, the most common scenario was that a weaker pupil stopped his/her utterance in order to look for a word or a phrase so as to construct a question to ask his/her stronger peer for information. This was when the stronger pupil stepped in to assist him/her with or without request. The extract below taken from the LPG illustrates this point.

Extract 11: (Co-construction without request)

$1 \quad$ P2: When...uhm?

2 P1: When you

3 P2: When you...? When do you have?

$4 \quad$ P1: Môn gì? (What subject?)

5 P2: When you? Nữa quên mất tiêu rồi. (Again I forgot.)

$6 \quad$ P1: do you?

7 P2: When do you have...Math?

8 P1: Math? ... Monday, Wednesday and Thursday. Hỏi! (Ask!)

(LPG, task 2, dyad 2) 
Here, P2, a weaker pupil, stops for a while to look for words to produce a question to ask P1, a stronger peer. Without request, P1 prompts P2 with the word "when" and chimes in with the word "you" in line 2. In line 3, P2 catches this assistance and successfully selfcorrects the error in his subsequent utterance. However, $\mathrm{P} 1$ also realises that $\mathrm{P} 2$ 's question is incomplete, so she asks him for the subject he wants to ask about. While P2 is trying to modify his utterance, he suddenly forgets what he has just said. P1 immediately steps in and assists by prompting "do you”. This prompt finally helps P2 finish his utterance.

As detailed above, in most cases, co-construction assistance was provided without requests. It could be that the stronger pupils were aware of their weaker peers' need for assistance and provided it without waiting for a request. However, in some cases, it was explicitly requested as in Extract 12 below taken from the MPG in their performance of the main task in Lesson 2:

\begin{tabular}{|c|c|}
\hline 1 & P2: When gì? ("When" what?) \\
\hline 2 & P1: When do you have? \\
\hline 3 & P2: When do you have? \\
\hline 4 & P1: on? \\
\hline 5 & P2: on ...English? \\
\hline 6 & P1: It's /' $\theta_{3}:$ deI/ ... Thursday. \\
\hline
\end{tabular}

(MPG, task 2, dyad 2)

We see here that the weaker peer (P2) actively requests assistance to construct the target question. Since P2 has difficulty in formulating the question to ask P1, a stronger pupil, he makes an explicit request for assistance in L1. P1 then provides him with part of the question. He repeats P1's question as a way to appropriate it. P1 then prompts P2 with the word "on". Although this prompt is incorrect, it reminds $\mathrm{P} 2$ of mentioning the specific school subject needed. It thus encourages a focus on meaning and keeps the conversation moving forward.

As Extract 12 has shown, although the prompt provided by the stronger pupil constituted a grammatically incorrect utterance, it successfully met the inquiry for a desired answer. A further example is provided below:

Extract 13: (Co-construction with a correction)

$1 \quad$ P2: What about...?

2 P1: What subject, what subject? Subject là môn học được chưa. ("Subject" means school subject.) 
Here, $\mathrm{P} 2$ has difficulty formulating a question to ask $\mathrm{P} 1$. P1 prompts $\mathrm{P} 2$ with the key word "subject" and tries to explain it in Vietnamese. In line 3, P2 uses the word provided and adds a specific day to make a meaningful question. In line 4, P1 realizes that the question P2 produces is grammatically incorrect, so she recasts P2 with a more target-like question. Although the recast provided by $\mathrm{P} 1$ in line 4 requires a preposition before the day of the week, it is up taken by $\mathrm{P} 2$ in line 5. This helps P2 successfully request an answer from P1 in line 6 . This occasion also illustrates a case where co-construction occurs in combination with correction. It is also coded as a case of inaccurate occasion of other-correction which resulted in incorrect uptake. Four such occasions were found across the 15 occasions of peer coconstruction assistance and included in the other- and self-correction strategy presented below.

Similar to corrections, in some cases across the proficiency groups, NfM strategies occurred within an occasion of co-construction assistance to facilitate communication. Extract 14 below taken from the HPG in task 1 exemplifies this case. It illustrates how the stronger pupil provides co-construction assistance to the weaker peer in lines 2 and 4 and how the weaker peer negotiates to confirm that the information he has obtained is correct in line 7.

Extract 14: (Co-construction with a negotiation move)

$1 \quad$ P2: What...?

2 P1: Ông hỏi là what subject do you have today á. Hiểu không? (You ask me, "What subject do you have today? "Do you understand?)

$3 \quad$ P2: What subject do you have today?

4 P1: on?

$5 \quad$ P2: Tuesday

6 P1: Uhm. On Tuesday.... I have Music, IT, Vietnamese.

$7 \quad$ P2: Music hả? (Music?)

8 P1: Uhm. Rồi hỏi tiếp đi (Keep asking!). Ông hỏi (You ask).

(HPG, task 1, dyad 2)

Moreover, analysis of classroom observation confirmed that the use of co-construction assistance contributed to a supportive classroom atmosphere and facilitated the performance of the main tasks in both lessons. Often the weaker pupil in each pair first relied on the assistance of the teacher or strong peer or both to construct their utterances and consequently 
had less difficulty in accurately producing their own subsequent utterances. Along with teacher assistance, peer co-construction assistance facilitated the initial stage of task performance. Once a performance was underway, it was mainly facilitated by the selfand other-correction strategies, which will be described and discussed in the following section.

\subsubsection{Self- and other-corrections}

The results presented above show that when weaker pupils struggled with the formulation of an utterance, stronger pupils or a teacher could help them continue by providing co-construction assistance. As the tasks continued after being facilitated by coconstruction, correction, and NfM, the pupils started to encounter various language difficulties which triggered corrections. From this stage, self- and other-corrections occurred more frequently and served as subsequent strategies the pupils employed to transact the main tasks. As with the co-construction strategy, these strategies were first quantified to describe their frequency followed by their linguistic focus before they were explored qualitatively to understand how the process of correcting was proceeded and how this process fostered task completion.

Table 16. Occurrence of self- and other-corrections in response to non-target-like utterances

\begin{tabular}{lcccc}
\hline & \multicolumn{3}{c}{ Proficiency group / school type } & Total \\
\cline { 2 - 5 } & $\begin{array}{c}\text { LPG (Rural) } \\
\text { (n=3dyads) }\end{array}$ & $\begin{array}{c}\text { MPG (Semi-rural) } \\
\text { (n=3dyads) }\end{array}$ & $\begin{array}{c}\text { HPG (Urban) } \\
\text { (n=3dyads) }\end{array}$ & \\
\hline Self-correction & $\mathbf{1 4}$ & $\mathbf{1 6}$ & $\mathbf{1 4}$ & $\mathbf{4 4}$ \\
\hline a. Successful & 10 & 13 & 11 & 34 \\
\hline b. Unsuccessful & 4 & 3 & 3 & 10 \\
\hline Other-correction & $\mathbf{3}$ & 6 & 15 & $\mathbf{2 5}$ \\
\hline a. Recast & 2 & 1 & 0 & 23 \\
\hline b. Explicit correction & 1 & 23 & 29 & 69 \\
\hline Total & 17 & $\mathbf{7}$ & 2 \\
\hline Note.
\end{tabular}

Note . LPG = Lower proficiency group (rural school); MPG = Moderate proficiency group (semi-rural school); HPG = Higher proficiency group (urban school).

As detailed in Chapter 3, talk across dyads all contained errors which were either treated or ignored. When the errors were treated, they were coded and counted. Table 16 presents the frequency of the self- and other-correction strategies and their distribution across the three groups representing the three different schools (see Appendix 10.2 for dyad 
information). The table shows that pupils engaged in 69 occasions of both self- and othercorrections. The number of occasions of correction in each of the 18 task performances ranged from zero to four. Within these 69 occasions, the pupils self-corrected their own errors in 44 times $(44 / 69 ; 63.7 \%)$ and helped correct each other's errors in 25 times $(25 / 69 ; 36.2 \%)$, using mostly recasts. As such, the number of self-corrections was almost double that of othercorrection. The data show that often pupils' initial attempts to construct their own utterances produced errors. The errors were subsequently corrected by themselves or peers with or without success.

One notable finding is that while the amount of other- and self-correction in the HPG was relatively equal, the amount of other-correction in the MPG and the LPG was much lower than that of self-correction. This suggests that the pupils in these two groups were less sensitive to errors than those in the HPG. It is also possible that they were less aware of errors or less confident in correcting. Specifically, they tended to provide fewer corrections to each other than those in the HPG. The finding that the MPG corrected each other less frequently might have been because these pupils followed the teacher's advice of focusing on expressing their meaning rather than correcting errors.

Table 16 above also shows that all three groups engaged in a relatively equal amount of self-correction (HPG 14; MPG 16; LPG 14). In the majority of cases, the correction was successful $(34 / 44 ; 77.3 \%)$. However, there was notable variation in the frequency of othercorrection across the three groups. The HPG corrected each other most frequently (15/25; $60 \%)$ followed by the MPG $(7 / 25 ; 28 \%)$ and the LPG $(3 / 25 ; 12 \%)$. Again, a possible explanation for this might be that the higher proficiency pupils were more sensitive to errors and were more willing and able to help each other correct the errors.

\section{Table 17. Uptake from other-correction}

\begin{tabular}{ccccc}
\hline & \multicolumn{3}{c}{ Uptake } & \\
\hline & Correct & Incorrect & No uptake \\
\hline $\begin{array}{c}\text { Correction } \\
(\mathbf{n = 2 5})\end{array}$ & Accurate $(\mathrm{n}=19)$ & 16 & 0 & 3 \\
\cline { 2 - 5 } & Inaccurate $(\mathrm{n}=6)$ & 0 & 6 & 0 \\
\hline
\end{tabular}

In addition, as Table 17 shows, more than two-third of other-correction were accurate $(19 / 25 ; 76 \%)$, which resulted in 16 occasions of correct uptake and 3 occasions of no uptake. The other six occasions of other-correction $(6 / 25 ; 24 \%)$ were inaccurate and all led to incorrect uptake. Two of these occurred in the LPG, one in the MPG and the other three in the 
HPG. An account of how and why these occasions occurred is described and discussed later in the microgenetic analysis of task interaction.

\section{Linguistic focus of correction}

After identifying the occurrence of the other- and self-correction strategies, the data were further analysed for the linguistic features that received the most attention for correction, regardless of whether the correction was successful or not. Results show that the pupils paid particular attention to two three types of linguistic errors: phonological, syntactical and lexical errors.

Table 18. Correction type and linguistic focus

\begin{tabular}{|c|c|c|c|c|c|}
\hline & & \multicolumn{4}{|c|}{ Proficiency group / school type } \\
\hline & & $\begin{array}{c}\text { LPG } \\
\text { (Rural) } \\
\text { (n=3dyads) }\end{array}$ & $\begin{array}{c}\text { MPG } \\
\text { (Semi-rural) } \\
(\mathrm{n}=3 \text { dyads })\end{array}$ & $\begin{array}{c}\text { HPG } \\
\text { (Urban) } \\
(\mathrm{n}=3 \text { dyads })\end{array}$ & Total \\
\hline \multirow{4}{*}{ Self-correction } & Phonological & 10 & 9 & 8 & 27 \\
\hline & Syntactical & 2 & 7 & 6 & 15 \\
\hline & Lexical & 2 & 0 & 0 & 2 \\
\hline & Total & 14 & 16 & 14 & 44 \\
\hline \multirow{4}{*}{$\begin{array}{c}\text { Other- } \\
\text { correction }\end{array}$} & Phonological & 1 & 4 & 10 & 15 \\
\hline & Syntactical & 2 & 3 & 5 & 10 \\
\hline & Lexical & 0 & 0 & 0 & 0 \\
\hline & Total & 3 & 7 & 15 & 25 \\
\hline Total & & 17 & 23 & 29 & 69 \\
\hline
\end{tabular}

Note. $\mathrm{LPG}=$ Lower proficiency group (rural school); MPG = Moderate proficiency group (semi-rural school); HPG = Higher proficiency group (urban school). 


\section{Figure 22. Linguistic focus of correction}

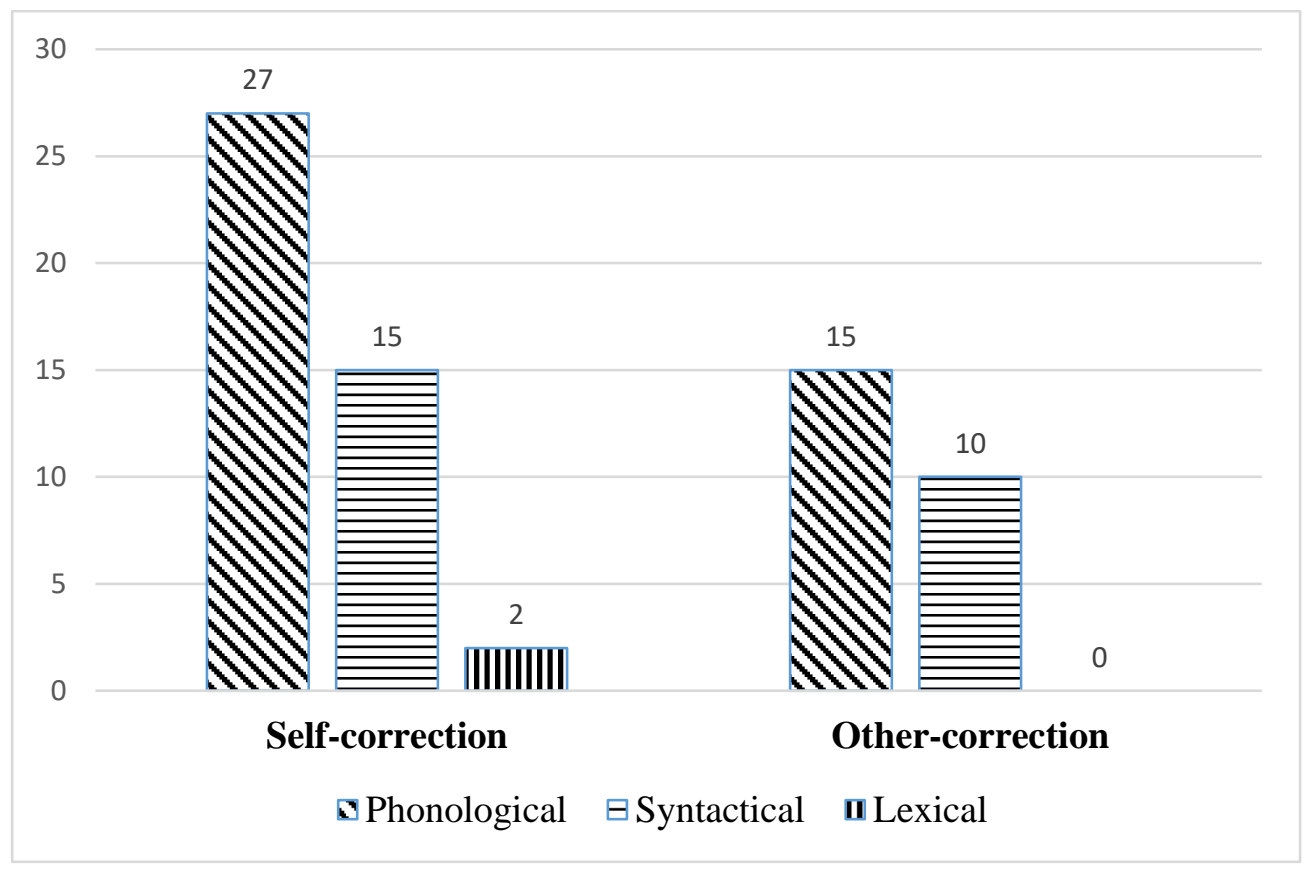

As Table 18 and Figure 22 above show, phonological errors receive the most attention for both other- and self-corrections compared to syntactical and lexical errors. Occasions of phonological correction occurs most frequently $(42 / 69 ; 60.86 \%)$ followed by syntactical correction $(25 / 69 ; 36.2 \%)$ and lexical correction $(2 / 69 ; 2.9 \%)$. The high frequency of phonological correction might have resulted from the lack of repeated practice of the vocabulary items which the pupils normally had.

Despite variations, the results provide evidence of the pupils across the three groups engaging in self-correction and the correction of others. Their active engagement with corrections seems to support Philp et al.' s (2014) claim that task interaction provides an opportunity for experimenting with language, which can promote eventual learning. Such opportunities are described and discussed below.

As mentioned above, the descriptive statistic results show that self-correction was used more frequently than other-correction and the majority of self-correction involved the correction of pronunciation errors. In most cases, the correction involved the substitution of a correct item for an incorrect one. In general, occasions of correction were brief with minimal impact on conversational flow. Below is a typical example of self-correction of pronunciation errors. The extract shows that P1 independently modifies her pronunciation of the word IT, changing the non-target like /i: ti/ to /.../ar 'ti:/. 
Extract 15: (Self-correction - phonological focus)

1 P1: When do you have...When do you have /i: ti/.../ar 'ti:/.../aI 'ti:/?

2 P2: Wednesday

(LPG, task 2, dyad 2)

In particular, many corrections in the data concerned the correction of /s/ sound which is a typical pronunciation error made by many Vietnamese learners of English (Lane \& Brown, 2010). Interestingly, the pupils in the current study were able to notice and correct this type of error by themselves. As shown in Extract 16 below, P2 initially skips the /s/ sound in the word "Tuesday". After the second correction attempt, he is able to pronounce this word correctly and does not make this error again in the next word Thursday.

Extract 16: (Self-correction - phonological focus)

$1 \quad$ P1: When do you have Vietnamese?

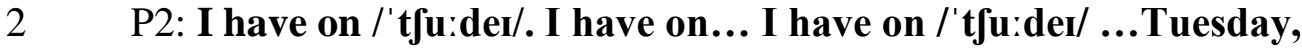
Thursday and Friday.

(HPG, task 1, dyad 1)

Following phonological errors, syntactical errors were another focus for correction. Extract 17 below taken from the MPG shows a pupil, P1, formulating a target sentence through a series of exploratory modifications to her output. She finally produces the more target-like utterance "Who is Science teacher?" after starting with "Who... who...teach" to "Who is Science teacher name" and to "who is Science teacher?". Although the final version is not completely target-like, it is the act of trying to produce the question correctly that pushes pupils to reflect on language form, identify knowledge gaps, and find solutions (Swain, 2000).

\section{Extract 17: (Self-correction - syntactical focus)}

$1 \quad$ P1: Okay. English teacher name.

2 P2: Who is ...

3 P1: English teacher name.

4 P2: Who is English teacher name?

5 P1: It's Ms Nhung too. Who...who...teach ...who Science teacher name? Who is Science teacher, who is Science teacher? Who is Science teacher?

(MPG, task 2, dyad 3)

The results presented above show that the pupils not only attempted to correct their own errors, but they were also able to help correct each others' errors. When they corrected 
each other, they used mostly recasts. Extract 18 below illustrates an occasion of othercorrection using recasts taken from the HPG. In line 2, P2 uses "It" as a subject for his answer. P1 however does not accept this. P1 thus recasts "It" as " $P$ " as an attempt to foster a target-like utterance. In response, in line 4, P2 uses “ $I$ " to formulate his answer. However, P2's utterance is not grammatically correct, which requires another recast from P1 in line 6. In line 7, P1 continues assisting P2 by prompting. She repeats the phrase “Music and...” just uttered by $\mathrm{P} 2$. This prompt enables $\mathrm{P} 2$ to continue and finally complete his utterance.

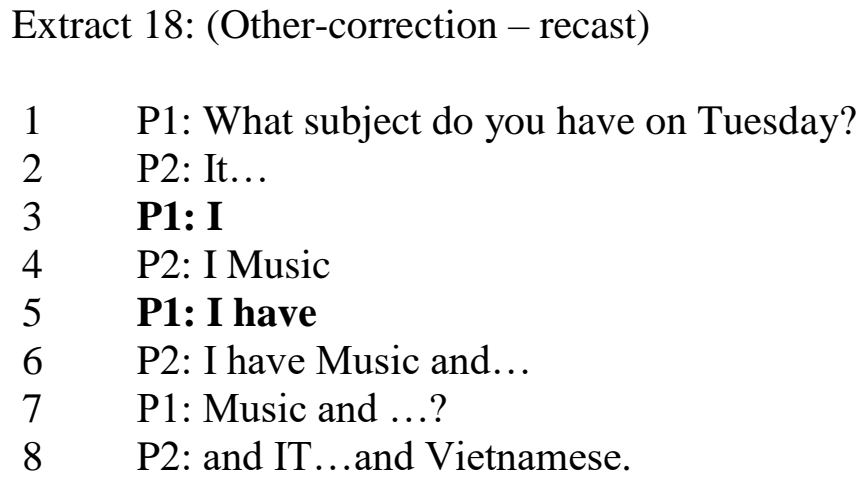

(HPG, task 1, dyad 3)

The other form of corrective feedback identified in the data was via explicit correction. However, this form of correction was rarely used. Only two occasions of explicit correction were identified in the data. Below is one of them:

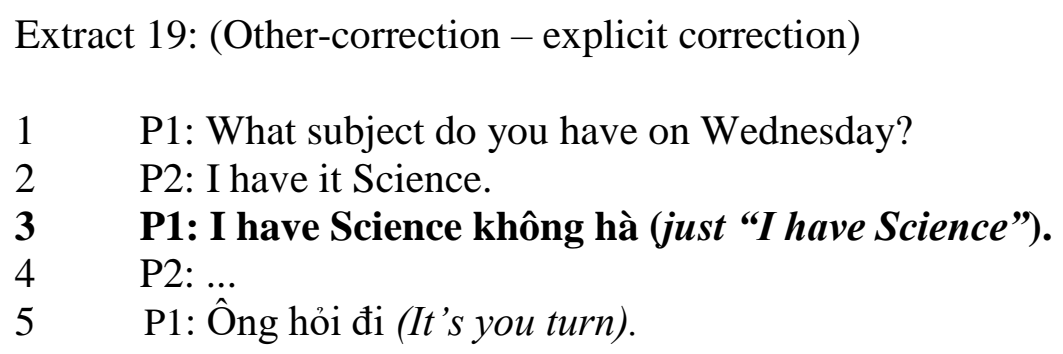

(MPG, task 1, dyad 2)

In this extract, P2 added the unnecessary word " $i t$ " to the answer to P1's question in line 2. P1 then tell P2 to just say "I have Science", which means without adding the word 'it'. This correction looks like a recast, but the fact that P1 further adds the word "just" implied an explicit meaning. However, this explicit correction does not result in uptake because P2 does not incorporate it in her subsequent turn.

Regarding the linguistic focus of other-correction, like self-correction, when the pupils corrected each other, they focused on correcting phonological errors most frequently. The 
extract below shows a typical example of phonological correction initiated by a peer. Here, P2 mispronounces the letter P in the word PE. He then has an opportunity to modify his nontarget-like " $B$ " in the word " $P E$ " in response to $\mathrm{P} 1$ 's recast.

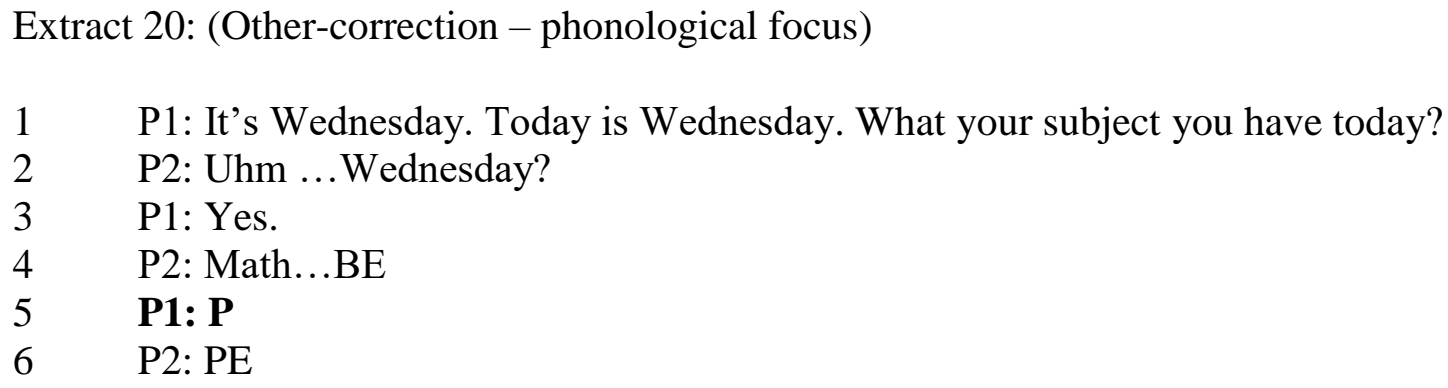

$$
\text { (HPG, task 2, dyad 1) }
$$

With regard to uptake from feedback provided, as shown above, in the majority of cases, the pupils were able to provide accurate correction which helped their peers correctly modify their output. However, in some cases, the corrections were inaccurate, which resulted in incorrect uptake. There were also a few occasions where the corrections were accurate, but they did not lead to uptake. The two extracts below illustrate each of the cases.

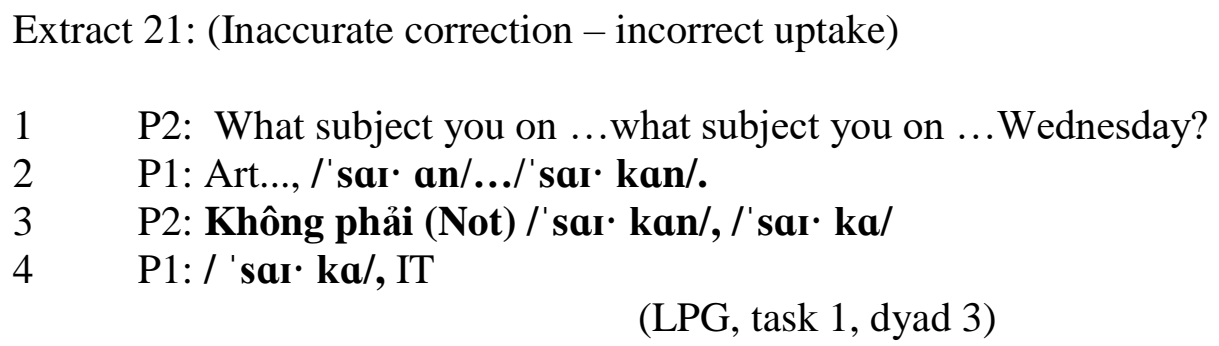

Extract 21 shows that in line 2, the stronger pupil P1 mispronounces the word "Science". In line 3, the weaker pupil P2 helps P1 say the word by explicitly telling P1 his pronunciation is wrong and then providing P2 with a correction. However, P2's correction is incorrect. In line 4, P1 immediately uptakes the correction provided without realizing that it is incorrect. Similarly, in Extract 22 below, in line 3, P1 tries to remind P2 to give a complete answer using the target sentence structure. P2 however ignores this reminder and continues with answer without a subject and a verb in line 4 .

Extract 22: (Accurate correction - no uptake)

$1 \quad$ P1: When do you have Science?

2 P2: Science? Uhm...Monday, Friday, Wednesday.

3 P1: Okay. I have Science on...

4 P2: Monday, Wednesday, Friday. 
$5 \quad$ P1: Monday, Wednesday and Friday. What's your teacher name?

(HPG, task 2, dyad 2)

It is interesting to note that the stronger pupil (P1) in this extract is trying to foster a target-like answer from the weaker pupil (P2) although the answer carries sufficient meaning. The fact that P2 did not incorporate the target form provided could suggest that this pupil puts a greater focus on meaning than on form. It could be concluded that although uptake was not achieved in some cases, it did not impede the communication flows or prevent the pupils from achieving the task outcomes. Regardless of whether the correction was successful or not, its occurrence highlighted the pupils' effort in fostering the use of the target language.

Overall, the analysis so far has shown the process from the beginning stage when teacher and peer co-construction assistance was provided to help overcome initial difficulties to the stage when the pupils were able to proceed with the task performance. During this stage, linguistic errors occurred, which initiated the use of self- and other-correction strategies. At the same time, the pupils encountered numerous communication breakdowns which motivated them to negotiate for meaning to solve the problems. The following section describes and discusses how the NfM strategies were used to solve the communication problems.

\subsubsection{Negotiation for meaning (NfM)}

The analysis shows that NfM strategies did occur in the data and were primarily used to solve comprehension difficulties emerging during the interactions. Regarding the frequency of NfM, results showed that the number was quite low. Negotiation occasions occurred in 15 of the 18 performances. The three performances that did not contain any of these were from the LPG. For the MPG and HPG, NfM occasions occurred in all of the 12 performances with a score ranging from one to six. 
Table 19. Occurrence of NfM strategies

\begin{tabular}{ccccc}
\hline \multicolumn{5}{c}{ Proficiency group / school type } \\
NfM strategies & $\begin{array}{c}\text { LPG } \\
\text { (Rural) } \\
(\mathrm{n}=3 \text { dyads })\end{array}$ & $\begin{array}{c}\text { MPG } \\
(\text { Semi-rural }) \\
(\mathrm{n}=3 \text { dyads })\end{array}$ & $\begin{array}{c}\text { HPG } \\
\text { (Urban) } \\
(\mathrm{n}=3 \text { dyads })\end{array}$ & Total \\
\hline Confirmation check & $5(9.3 \%)$ & $12(22.2 \%)$ & $20(37 \%)$ & $37(68.5 \%)$ \\
\hline Clarification request & $4(7.4 \%)$ & $4(7.4 \%)$ & $5(9.3 \%)$ & $13(24.1 \%)$ \\
\hline Self-repetition & $1(1.9 \%)$ & $2(3.7 \%)$ & $1(1.9 \%)$ & $4(7.4 \%)$ \\
\hline Total & $10(18.5 \%)$ & $18(33.3 \%)$ & $26(48.2 \%)$ & $54(100 \%)$ \\
\hline
\end{tabular}

Note. $\mathrm{NfM}=$ Negotiation for meaning; $\mathrm{LPG}=$ Lower proficiency group; $\mathrm{MPG}=$ Moderate proficiency group HPG $=$ Higher proficiency group

Table 19 above presents the frequency of NfM strategies used to solve the communication breakdowns by the three groups (see Appendix 10.3 for dyad information). It showed that pupils employed three NfM strategies: confirmation checks, clarification requests, and self-repetition. There were a total of $54(54 / 1133 ; 4.8 \%)$ occasions where these strategies were employed. Among them, confirmation checks accounted for more than twothird of all NfM occasions $(37 / 54 ; 68.5 \%)$. The rest concerned clarification requests (13/54; $24 \%$ ) and self-repetition (4/54; 7.4\%). Comprehension checks were not used. Analysis showed that in most cases, the pupils clarified or confirmed meaning for themselves when they were unsure about a word or failed to get the information they needed. Across the three groups, the HPG engaged in the highest number of NfM occasions $(26 / 54 ; 48.1 \%)$ followed by the MPG $(18 / 54 ; 33.3 \%)$, and the LPG $(10 / 54 ; 18.5 \%)$. The number of NfM occasions found in the HPG more than doubled that of the LPG. A possible explanation for this may be that the HPG were more fluent and willing to communicate.

As presented above, the pupils used confirmation checks most frequently. Extract 23 below taken from the MPG illustrates one of the negotiation moves involving a confirmation check. Here, in line 2, P2 has a chance to modify his non target-like word "draw" in response to P1's confirmation check move. However, P2 is not able to notice his error until he has another opportunity to modify his output in response to P2's second confirmation check move which brings P1's full attention to his lexical error.

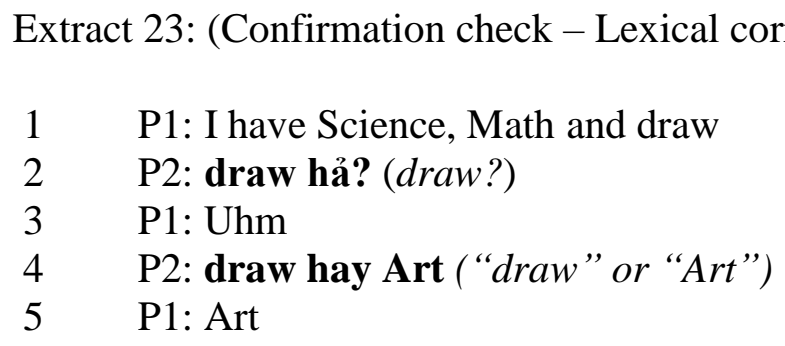

(MPG, task 1, dyad 1) 
This extract shows one of the less frequent occasions when a weaker pupil took the lead to negotiate clarification. This same lexical item was also corrected in the LPG, but in this case the error was self-corrected.

The extract presented above also illustrates one of a few occasions of confirmation check involving a communication breakdown due to lack of clarity in language use. This example of pupils' engaging in the NfM also shows a dual focus on form and meaning when pupils engaged in meaning negotiation. Classroom observation data revealed that in the majority of cases, confirmation checks were used to solve comprehension difficulties associated with the nature of these information-gap tasks in the current study. To cope with this, in most occasions, pupils raised their voice after uttering a subject word or attached to it the exclamation word "hả?" (what?) (as in Extract 23 above) or "phải không?" ("is it?") to construct a confirmation check. For example, the main task in Lesson 1 requires pupils to fill in a gap in a row of three subjects where one of them is missing. This requires careful listening in order to correctly catch that missing subject. For this reason, confirmation checks were needed to make sure that the target subject was correctly heard.

In Extract 24 below, for example, P1 needs to know one of the three subjects that P2 has on Friday in order to fill in a gap in her/his incomplete timetable. The missing subject is "Vietnamese". Thus, to have the correct information to fill in the gap, in line 3, P1 asks P2 to confirm that he has heard it correctly by asking "Is it Vietnamese?". Following this, P1 asks P2 in Vietnamese to tell her again the three subjects. In line 5, P1 continues asking to make sure that the day that P2 has the three subjects Art, Vietnamese and Science is "Friday".

\section{Extract 24: (Confirmation check)}

$1 \quad$ P1: What subject do you have on Friday?

$2 \quad$ P2: It...I have Art and Vietnamese and Science...Vietnamese and Science

3 P1: Vietnamese hả? (Is it Vietnamese?) Đọc lại cho tui nghe coi. (Say it again)

$4 \quad$ P2: I have Art and Vietnamese and Science

5 P1: Friday phải không? (Is it Friday?)

$6 \quad$ P2: Friday

$$
\text { (MPG, task 1, dyad 3) }
$$

Another possible challenge, creating difficulties in these interactions, may be related to these young pupils' ability to concentrate especially with the level of noise inherent in naturalistic classrooms. In other words, these factors may have motivated many of the clarification requests in the current study. As the task interaction data shows, to overcome this 
difficulty, on many occasions, the listeners frequently used the Vietnamese word "gi ??" which means "what?" to ask for clarifications. Below is a typical example of a pupil asking for clarification within the data. Extract 25 shows that for some reasons, P1 cannot hear clearly what P2 has said. Therefore, to get the correct information, in line 2, P1 shows his confusion by saying "What?" which also means a request for P2 to repeat or clarify what he has just said. Then in line 4, after P2 has repeated the question, P1 continues to confirm that he has heard the subject word "English" correctly. However, P1's confirmation in this case seems to show that he wants to confirm to himself that he has grasped the question. That is why he provides the answer to $\mathrm{P} 2$ right after his confirmation.

\section{Extract 25: (Clarification request)}

$1 \quad$ P2: When do you have on English?

2 P1: Gì? (What?)

3 P2: When do you have on English?

$4 \quad$ P1: English hả? (Is it English?) ... Thursday.

(HPG, task 2, dyad 2)

This interaction may also be interpreted in another way. It could be that driven by the need to complete the tasks, the pupils made more clarifications because they needed to obtain specific information quickly.

Finally, some occasions of self-repetition were also employed although the number was low (only four). Repetition occurred mostly when pupils performed the main task in Lesson 2. In this task, the goal is to fill out the timetable with a check $(\checkmark)$ on the days when a particular subject is scheduled. This took pupils some time to locate the days in the timetable. Thus, in most repetition occasions, pupils needed to repeat the target word as a way of holding a conversational floor and helping their peers record the answers. These occasions appear similar to confirmation checks. However, the difference lies in the lack of rising intonation at the end of the word. A typical example can be observed in the following interaction taken from the MPG in task 2.

\section{Extract 26: (Self-repetition)}

1 P1: When do you have Vietnamese? When do you have Vietnamese?

$2 \quad$ P2: I have on Thursday uhm Tuesday... Friday.

$3 \quad \mathrm{P} 1: \ldots$

4 P2: Tuesday and Friday

(MPG, task 2, dyad 3) 
The above extract shows that in line 2, P2 repeats the word "Tuesday" while searching for it in the timetable. In line 4, P2 voluntarily repeats the words "Tuesday and Friday" as a way to help P1 while she was looking for the correct boxes in the worksheet to put a tick on.

Overall, the analysis has shown that when NfM was employed, it helped resolve comprehension difficulties which emerged during the task interactions. Together with the coconstruction strategy and self- and other-correction strategies, the pupils across the three groups were all able to complete the main tasks in the two task-based lessons. However, the two main tasks could not have been completed without the use of the pupils' first language (L1), which is discussed in the following section.

\subsubsection{L1 use as a scaffold}

This section presents and discusses the use of L1 as a scaffolding strategy. It first considers the extent to which the pupils employed their L1 and then the functions of L1 use. Before reporting this strategy in more depth, I will present findings regarding the amount of talk in L2 and L1.

Table 20. Amount of L1 and L2 use by c-units

\begin{tabular}{ccccc}
\hline $\begin{array}{c}\text { Proficiency group / } \\
\text { school type }\end{array}$ & L2 & L1 & L2 \& L1 & Total \\
\hline LPG (Rural) $(\mathrm{n}=3$ dyads $)$ & $215(66.8 \%)$ & $55(17.1 \%)$ & $52(16.1 \%)$ & $322(100 \%)$ \\
$M(S D)$ & $35.8(5.3)$ & $9.2(6.5)$ & $8.7(6.9)$ & \\
\hline MPG $($ Semi-rural $)$ & $246(71.9 \%)$ & $47(13.7 \%)$ & $49(14.4 \%)$ & $342(100 \%)$ \\
$(\mathrm{n}=3$ dyads $)$ & & & & \\
$(M(S D)$ & $41(16.5)$ & $7.8(5.3)$ & $8.2(2.3)$ & \\
\hline HPG (Urban) $(\mathrm{n}=3$ dyads $)$ & $324(69.1 \%)$ & $60(12.8 \%)$ & $85(18.1 \%)$ & $469(100 \%)$ \\
$M(S D)$ & $54(8.6)$ & $10(5.1)$ & $14.2(7.3)$ & \\
\hline Total & $785(69.3 \%)$ & $162(14.3 \%)$ & $186(16.4 \%)$ & $1133(100 \%)$ \\
\hline
\end{tabular}

Note . L1 = Vietnamese; $\mathrm{L} 2=$ English; $\mathrm{LPG}=$ Lower proficiency group; $\mathrm{MPG}=$ Moderate proficiency group; HPG = Higher proficiency group.

Table 20 shows that the pupils produced 1133 c-units with 785 c-units $(785 / 1133$; $69.3 \%)$ containing only L2, 162 c-units $(162 / 1133 ; 14.3 \%)$ with only L1 and 186 (186/1133; 16.4\%) c-units with both L1 and L2 (see Appendix 10.1 for dyad information). In total, the pupils produced $348 \mathrm{~L} 1 \mathrm{c}$-units $(348 / 1133 ; 30.7 \%)$. Overall, L2 was used more than twice as much as L1 in both categories of L1 use only and L1 plus L2, indicating that pupils did not make excessive use of their shared L1. The results lend support to a recent study by Azkarai and García Mayo (2017) who found that the EFL young learners in their studies used quite a 
similar amount of L1 (below 36\%). In addition, the proportion of L1 use (including both categories of L1 use only and L1 plus L2) compared to the proportion of L2 use only slightly differed across the three groups, being slightly higher in the LPG (107/322; $33.2 \%)$ compared to the MPG and HPG $(96 / 342 ; 28 \%$ and $145 / 469 ; 30.9 \%$, respectively).

As detailed in the methodology chapter, to codify the functions of L1 use, each c-unit containing any instance of L1 was identified as a L1 c-unit, including c-units that contain only L1 and those with both L1 and L2. These L1 c-units occurred throughout each task performance. A common pattern was that L1 was employed at the start of the task performance when pupils were still working out what to do. This required them to switch to L1 (mainly in the form of L1 plus L2) to seek or provide co-construction assistance. As the tasks moved on, pupils continued using L1 when they helped each other correct their errors and when they negotiated for meaning to overcome communication breakdowns. During this process, L1 use also occurred to serve a task management purpose. Apart from the two prominent functions mentioned above, L1 was also used to serve other functions. Data show that pupils also used L1 for their off-task talk at the beginning and end of the task performance. They also used L1 as phatics (e.g., "yeah", "okay", "well” or "uhm") which are words employed to express sociability rather than specific meaning (Azkarai \& García Mayo, 2015 ) in some cases. Despite their occurrence, these functions were not chosen for the analysis because they were rare and did not seem to serve as a prominent form of support for task completion. 
Table 21. Functions that the first language $\mathrm{L} 1$ served

\begin{tabular}{ccccc}
\hline \multicolumn{5}{c}{ Functions of L1 use } \\
\hline $\begin{array}{c}\text { Proficiency group / } \\
\text { school type }\end{array}$ & $\begin{array}{c}\text { Task management } \\
(M / S D)\end{array}$ & $\begin{array}{c}\text { Seeking/giving } \\
\text { assistance } \\
(M / S D)\end{array}$ & Total & L1 c-units \\
\hline $\begin{array}{c}\text { LPG (Rural) } \\
(\mathrm{n}=3 \text { dyads })\end{array}$ & $\begin{array}{c}33 \\
(5.5 / 1.6)\end{array}$ & $\begin{array}{c}22 \\
(3.7 / 2.3)\end{array}$ & 55 & 107 \\
\hline $\begin{array}{c}\text { MPG } \\
\text { (Semi-rural) } \\
(\mathrm{n}=3 \text { dyads })\end{array}$ & $\begin{array}{c}39 \\
(6.5 / 2.0)\end{array}$ & $\begin{array}{c}16 \\
(2.7 / 2.0)\end{array}$ & 55 & 96 \\
\hline $\begin{array}{c}\text { HPG (Urban) } \\
(\mathrm{n}=3 \text { dyads })\end{array}$ & $\begin{array}{c}44 \\
(7.3 / 2.8)\end{array}$ & $\begin{array}{c}12 \\
(2 / 1.3)\end{array}$ & 56 & 145 \\
\hline Total & $116(69.9 \%)$ & $50(30.1 \%)$ & $166(100 \%)$ & 348 \\
\hline
\end{tabular}

$\overline{\text { Note } .}$ L1 = Vietnamese L2 = English LPG $=$ Lower proficiency group; MPG = Moderate proficiency group; $\mathrm{HPG}=$ Higher proficiency group.

To further explore the role L1 played in task performance, all L1 c-units that served the functions of seeking/giving assistance and task management were tallied. Table 21 above shows that the number of c-units that served the two functions of task management and giving/seeking assistance accounted for almost half of the total number of L1 c-units (166/348; 47.7\%) (see Appendix 10.4 for dyad information). This helps confirm the role of L1 in assisting the performance of the tasks. Furthermore, between the two functions, the number of L1 c-units that served the function of task management was more than twice that of seeking/giving assistance $(116 / 166 ; 69.9 \%)$. Across the three groups, L1 was used for task management most frequently by the HPG while it was used for seeking/giving assistance most frequently by the LPG. It may be that the LPG experienced more difficulties understanding task procedures and finding the language to speak, thus requiring more assistance compared to the HPG.

The descriptive statistics provide evidence testifying to the key functions of L1 use. The following in-depth qualitative analysis details a description of how L1 use assisted task performance. Table 21 above shows that the pupils across the three groups made use of L1 most frequently for task management purposes. In most cases, it was the stronger pupils who took control of the tasks by using their L1 to direct the task process. An example of this function can be seen in Extract 14 in Section 6.5.2.1 above which illustrates an occasion of co-construction assistance where the stronger pupil used L1 to clarify task procedure to assist her weaker peer at the initial stage of task performance. The following Extract 27 taken from the HPG further illustrates this key function: 
Extract 27: (L1 use - Task management)

$1 \quad$ P2: When do you have English?

2 P1: I have it on Thursday.

3 P2: Rồi (Done). Gì nữa không? (Anything else?)

4 P1: Rồi (Done). Giờ tui hỏi nè (It's my turn). Uhm... when do you have IT?

5 P2: I have Tuesday...Tuesday. Rồi hết (That's all).

6 P1: Rồi hỏi tiếp (Keep asking!).

(HPG, task 2, dyad 3)

The extract shows that P1 and P2 took turns to organise their talk. In line 3, P2 uses L1 to let P1 know that he has got the information and asked P1 to confirm if there are any other subjects. In line 4, P1 used L1 to tell P2 that it is now his turn. Similarly, in line 6, P1 told P2 that it is his turn, so he needs to continue asking. Such utterances of taking/assigning roles and encouraging talk as "It's my turn" or "Keep asking" as seen in lines 4 and 6 respectively were deployed frequently by the pupils throughout all of their performances as an effective way to manage turn-taking, encourage each other to talk and drive the interaction forward.

The other most frequent function of L1 use that fostered task completion was seeking/giving assistance. As mentioned above, on some occasions, L1 was used for seeking co-construction assistance when a pupil failed to start the task performance. In other occasions, L1 was used to seek or give assistance regarding grammatical features or meaning, spelling or pronunciation of a particular vocabulary item. These functions were also identified in previous studies of EFL beginners, YLs (Pinter, 2007; Shintani, 2014, 2016). This function is illustrated in the extract below taken from the LPG.

Extract 28: (L1 use - Seeking/giving assistance)

$1 \quad$ P1: What subject do you have on Wednesday?

2 P2: I have I...I have ....Science.

3 P1: Science?

4 P2: Science

$5 \quad$ P1: Science viết sao? (How is Science spelt?)

6 P2: Sờ-cờ-i-nờ-sờ-cờ-i [Spelling out in Vietnamese].

(LPG, task 1, dyad 2)

The extract presents a typical example of using L1 to request for assistance for a lexical item in order to achieve task goals. This was frequently found in the LPG and the MPG. It might be that the LPG used L1 frequently for seeking/giving assistance regarding vocabulary items due to their limited vocabulary resources. The pupils in the MPG also used 
L1 for this function because their teacher decided not to leave any vocabulary items on the board for the pupils to refer to while they were performing the tasks. Of note is that this function was found least frequently in the HPG. It may be because many pupils were able to use L2 to seek and provide lexical help regarding the spelling or meaning of a vocabulary item.

One striking finding is that requests for assistance regarding vocabulary using L1 were most frequently identified in the LPG and were carried out explicitly or in the form of selftalk which acted as a useful tool to direct one's own thinking (Antón \& DiCamilla, 1998). This is illustrated in the extract below:

Extract 29: (L1 use - self-talk)

1 P1: Monday hả? (Monday?) ... /'sai.ən/ and Maths and rồi (done)

$2 \quad$ P2: Tuesday?

3 P1: and Music and...cái gì quên (what is it?). Chữ đầu là chữ gì nè? (The first letter is?)

$4 \quad$ P2: Chữ đầu là... (The first letter is...)

5 P1: Cái gì nè (What is it?) .../i: ti/ ... /aI 'ti:/.

(LPG, task 1, dyad 1)

Here, in line 3, P1 has difficulty recalling the first letter of the word IT. She then switches to L1 in her self-talk which signals a request for help. While waiting for P2 to search for the word in his memory, P1 produces more self-talk which then facilitates her cognitive processing. As a result, she can successfully retrieve the word IT from memory in line 5. In this case, the switch to L1 in a form of a meta talk was effective in scaffolding the cognitive process of searching for vocabulary items (Antón \& DiCamilla, 1998; Storch \& Aldosari, 2010) and, as Ellis \& Shintani (2014) claim, self-talk is "a primary means by which the learners can mediate learning" (p.242).

Overall, the analysis of the task interaction data has shown that the pupils did not make an excessive use of their shared L1, Vietnamese. They used L1, mainly to manage organizational aspects of the tasks so that they could move the tasks along. They also relied on L1 when they needed to seek or give assistance on linguistic aspects of the tasks and when they needed to clarify or confirm their understanding. Those strategies are closely connected and as discussed above, they assisted effective task completion. 


\subsubsection{Discussion of the task performance data}

The third and final question in Phase 2 of the current study investigated pupils' performance of the main tasks in the task-based lessons and the verbal interactional strategies the pupils adopted to carry out the tasks. The following section discusses the findings regarding these issues.

\subsubsection{Characteristics of the task-interaction}

The findings indicated that all dyads across the three groups completed the two main tasks in the task-based lessons within the allotted timeframe. They were able to negotiate and support each other to work towards task completion. However, there were some interesting variations that were observed in the data set. One variation concerns the amount of talk across groups and across performances. The HPG produced more c-units than the other two. Another variation is not between groups or performances but between task 1 and task 2 . When it came to task 2, LPG and MPG produced more c-units while the HPG produced fewer. A number of factors may have accounted for these variations: (1) time on task performances (varying between 9-12 minutes); (2) pairing by the teachers (teachers decided the pairing of a lower and a higher proficiency pupils based on their own rating); (3) learner characteristics (some learners appeared more active or fluent than the others); (4) proficiency (more proficiency learners spoke faster and took more frequent turns in some cases); (5) performance outcomes (the additional task of asking about the teachers' names in task 2 was not fully achieved in some performances by the MPG and HPG and not at all by the LPG); and (6) teachers' implementation decisions (teacher assistance was provided for some performances in HPG and LPG while none was provided in MPG). These variations partly reflect the complex nature of task interaction in real classrooms. It is not appropriate or feasible in the classroom study of this kind to strictly control every variable. For this reason, comparisons across groups and dyads within each group must be treated with caution.

Another aspect of task interaction concerns the interaction patterns identified across the three groups. The general pattern of interaction identified in the current study reflects an expert-novice pattern of interaction (Storch, 2002). This interaction pattern has instructional advantages as reported in SLA studies such as Kim and McDonough (2008) and Watanabe and Swain (2007) and occurs in a primary classroom where learners were paired with native English speaking children (Ives, 2004). Reflecting this pattern, the stronger pupils in the current study took an active role in supporting their weaker peers through interactional strategies such as scaffolding, recasting and NfM. These strategies together with L1 use were 
employed consistently across the three groups and consequently fostered task completion. The pairing of a higher proficiency pupil with a lower proficiency one may be attributed to the occurrence of this pattern. Following the teachers' advice and driven by a need to complete the tasks, the stronger pupils seemed to assume greater responsibility for actively assisting their weaker peers and consequently monitoring the task performance towards completion.

The final aspect of interaction characteristics, linking with the above points concerns the use of fixed turn-taking patterns. The findings show that many dyads, particularly those from the LPG and the MPG frequently used fixed turn-taking (i.e., asking and answering each other using the target structural patterns) while many dyads in the HPG used a wider variety of language. Varying proficiency levels and familiarity with the PPP approach may have been responsible for the occurrence of fixed turn-taking patterns. This finding was also reported by Butler and Zeng $(2014,2015)$ who investigated the interactional characteristics of the fourth graders through a EFL pair task assessment context. As the authors explained, the dominant classroom discourse of asking and answering inherent in the PPP approach that the pupils are used to may have influenced the way they approached the tasks. Moreover, the fixed turntaking pattern identified in the current study was likely also influenced by task type. The twoway information gap tasks used in the current study demanded constant information exchange. This may have encouraged the pupils to rely on turn-taking during communication because as Butler and Zeng (2014) explained using fixed turn-taking patterns may be "a strategy among young foreign language learners given the limited cognitive and linguistic resources available to them" (p. 68).

Finally, it is important to note that many of the interactions in the LPG and MPG were limited to words or phrases. Seedhouse (1999) and Swan (2005) have argued that this limited language production carries limited language learning value. This limitation may be attributed to the fact that the pupils in the current study had been exposed to PPP before experimenting with TBLT. They had difficulties communicating in English when the target vocabulary and structures were not explicitly pre-taught and repetitively practiced. However, this study provides evidence to suggest that although the pupils used limited vocabulary and grammatical structures, they had an opportunity to exchange meaningful messages in an attempt to reach a communicative solution.

\subsubsection{Verbal interactional strategies in the task performances}

Although the amount of talk varied slightly across the three groups, the results indicate a high degree of focus on task performance displayed by the pupils across the groups. The 
consistent focus on task performance became more pronounced as the tasks progressed towards completion. This represents a noteworthy finding consistent with results reported in other studies involving child task-based interaction (e.g., Azkarai \& Imaz Agirre, 2016; Gagné \& Parks, 2013; García Mayo \& Imaz Agirre, 2019; García Mayo \& Lázaro-Ibarrola, 2015; Oliver, Philp \& Duchenes, 2017; Pinter, 2006, 2007). In-depth qualitative analysis of the task interaction data shows that task performance was facilitated by five verbal interactional strategies proposed in social and cognitive accounts of language development. The strategies identified in the data were co-construction, self-correction, other-correction, NfM and L1 use. The overall findings suggest that these strategies in concert supported task performance and foster task completion.

First, co-construction assistance was effectively used to facilitate task performance. As noted previously, this strategy was utilised when pupils engaged in the joint co-construction of an utterance with their stronger peer and/or the teacher. The results show that peer coconstruction assistance was employed across the three groups in order to overcome struggles which primarily occurred at the initial stage of task performance. In this situation, the stronger peers took an active role of providing assistance regardless of it being requested or not. As a result, pairs were able to move the task forwards. This finding draws attention to the collaborative nature of the interaction and the consideration the stronger pupils show towards their weaker peers. It provides further support for previous findings of empirical research on co-construction and peer-peer assistance in classroom interaction (e.g., Foster \& Ohta, 2005; Ohta, 2001; Pinter, 2007). For example, Ohta (2001) and Pinter (2007) found that the more proficient learners effectively assisted the less proficient learners in coping with the linguistic demands of the task. Finally, in considering peer co-construction across the three groups, the results showed that the pupils in the LPG required more teacher and peer co-construction assistance than those in the other two groups. This suggests that the lower proficiency pupils may not be as capable of working with tasks as the higher proficiency pupils. Therefore, proficiency level might have been a major factor affecting the amount of co-construction required across groups and dyads in each group.

Further strategies identified in the data were self-correction and other-correction. These strategies were adopted in instances where pupils produced an error which was subsequently corrected by their peers or themselves. One notable finding is that the pupils engaged in more self-correction than other-correction. This result lends support to studies by Buckwalter (2001), Foster and Ohta (2005), and McDonough (2004) who found that their adult learners engaged in more self-correction than other-correction during their peer 
interaction. As Ohta (2001) suggests, "this experience not only builds confidence as learners successfully produce and self-correct their own utterances, but also promote the ability to selfcorrect" (p.90). Through self-corrections, the pupils experimented with new structures and forms, and in this way, test out new hypothesis (Swain, 1995, 2005). In addition, it was found that when the pupils helped each other correct their errors, they employed predominantly recasts. Notably, most recasts resulted in successful uptake. This finding that the pupils predominantly used recasts as a means of providing NF (92\%) lends support to studies on child interaction by Oliver $(1998,2002)$ which found that the young ESL learners in her studies preferred using recasts to provide feedback.

Another notable finding is that the HPG appeared to correct each other more frequently compared with the other two while the three groups were found to engage in a relatively equal amount of self-correction. One explanation for this may be that the higher proficiency learners were more sensitive to errors and more able and confident to offer correction. Moreover, when the pupils engaged in error correction, they focused on a variety of linguistic problems. Among them, pronunciation errors were the main triggers for correction with about half of the self-correction having to do with pronunciation. The greater use of correction regarding pronunciation errors may be explained by the fact that the pupils were not involved in extensive vocabulary practice before the main tasks. Moreover, the finding that less attention was focused on the correction of lexical errors can be partially explained by the fact that child interlocutors with low levels of proficiency have limited target language resources.

Another verbal interactional strategy concerns NfM. The findings indicate that the pupils employed a variety of NfM strategies to overcome communication difficulties. These findings provide evidence to support earlier studies that have focused on child populations in ESL contexts (e.g., Oliver, 1998, 2000, 2002) and EFL contexts (e.g., Azkarai \& Imaz Agirre, 2016; Butler \& Zeng, 2014, 2015; García Mayo \& Lázaro-Ibarrola, 2015; Pinter, 2006), suggesting that the Vietnamese EFL children were able to negotiate for meaning to overcome communication breakdowns and employed a variety of strategies to do so. Pupils in the current study employed mainly confirmation checks, clarification requests and selfrepetitions. None of them used comprehension checks, which differentiates one way YLs negotiate for meaning from that of adults (Oliver, 1998). Oliver justifies that YLs focus on clarifying or confirming meaning for themselves than checking comprehension from their peers as a result of their developmental stage and their "purported egocentric nature" (Oliver, 1998, p. 379). 
Across the three groups, the pupils in the HPG tended to negotiate more frequently than those in the other two groups. Notably, three of the performances in the LPG contained no occasions of NfM. This finding is inconsistent with studies conducted by Oliver's (2002) with ESL children and by Azkarai and Imaz Agirre (2016) and García Mayo and LázaroIbarrola (2015) with EFL children. Oliver (2002) found that the lower proficiency ESL learners negotiated more frequently than the higher proficiency ones. Azkarai and Imaz Agirre (2016) found that mainstream and fourth-grade CLIL learners fell back on clarification requests and other- and self-repetitions more frequently during a guessing game task than mainstream, sixth-grade CLIL learners. One possible reason, as these authors explained, is that the fourth-grade learners whose English skills could have been less developed than those of the sixth-grade learners may have had more difficulties carrying out the task and hence, needed to employ more NfM strategies to overcome difficulties. However, the pupils in the LPG in the current study received frequent teacher co-construction assistance, which could be an explanation for their less frequent use of NfM strategies compared to their counterparts in the HPG.

The primary focus of NfM in the current study is message communication, though there were a few occasions when pupils' attention was drawn to both message and forms. Pica (1994) identified message communication as one of the three functions of NfM in L2 learning among the other two which are modification of output and feedback focused on form. To overcome difficulties in understanding messages, pupils used confirmation checks most frequently which assisted them to obtain the desired information during the task completion process. The characteristics of the tasks could be the main factor contributing to the frequent use of confirmation checks. The main task in Lesson 1 required pupils to search for correct subjects among others to fill the gaps while the main task in Lesson 2 required pupils to look for right places to tick off. These demands required the listeners to ask for clarifications to make sure that they had understood or heard correctly the subjects reported. Moreover, lack of pronunciation clarity also initiated confirmation checks to make sure that the subjects were heard correctly. This may also include noise inherent in the classrooms which may have caused hearing difficulties. Put together, the use of NfM strategies, particularly confirmation checks assisted learners when they encountered message comprehension difficulties during the task completion process.

Finally, L1 was used throughout the performances. It seemed to act as an essential support to deal effectively with task demands and to make the tasks more manageable. In line with several studies on L1 use by adult EFL learners (e.g., Azkarai \& García Mayo, 2015; 
Storch \& Aldosari, 2010; Swain \& Lapkin, 2000) and 9-10 year-old EFL learners (e.g., Azkarai \& García Mayo, 2017), the pupils in the current study did not use L1 excessively. In terms of the functions, L1 was used most frequently for task management and seeking/giving assistance with the former being used more frequently across the three groups. The finding that L1 was used frequently for task management was in line with that found by many studies on L1 functions (e.g., Azkarai \& García Mayo, 2017; Storch \& Aldosari, 2010; Tognini \& Oliver, 2012). Task management was also one of the most frequent functions L1 served in directing the writing activity in a study of EFL adults by Storch and Aldosari (2010). It was also used in child EFL task-based interaction as a way to scaffold language production, manage and expedite the completion of the task in studies by Azkarai and García Mayo, (2017) and Tognini and Oliver (2012). This might be due to the demand of the two-way information gap tasks which requires the management of turn-taking or the control of task procedures in order to achieve task goals. Furthermore, the finding that seeking/giving assistance was used most frequently by the LPG may be explained by the lower proficiency level of the pupils in this group compared to those in the other two groups.

Overall, we may conclude that the combined utilization of the verbal interactional strategies discussed above facilitated the task performance. The frequency of the attempts to provide co-construction, modify their own utterances, offer correction, negotiate for meaning and use L1 to move task performance forward are signs that the learners are indeed focusing on completing the tasks. Consequently, this process, from both cognitive and social theoretical perspectives is assumed to provide a prime context for L2 learning and development in classrooms. 


\subsection{Summary of Phase 2 findings}

Phase 2 of the study investigated the implementation of the task-based versions of the two PPP speaking lessons. The overall results show that the task-based versions of the PPP lessons worked well in Vietnamese primary classrooms. Findings from the teachers' practices show that all three teachers successfully implemented the two task-based lessons in their normally scheduled classes. They acknowledged that the task-based lessons resulted in better communicative development and higher levels of learner engagement compared with their PPP versions. Findings from pupils' perceptions of their experiences of carrying out the two task-based lessons provided evidence to support the teachers' claims. All pupils reported positive experiences of working with the task-based lessons. However, pupils' reported preferences for activities in the lessons varied across the three groups. While many pupils in the LPG reported preferences for activities other than the main tasks such as the language games in the pre-and post-task phases, many pupils across the MPG and HPG reported preferences for the input-based tasks in the pre-task phases and the main tasks. They were able to point out the scaffolding value of the input-based tasks and the communicative value of the main tasks. At the same time, many weaker pupils across the three groups revealed challenges in carrying out the main tasks due most likely to a lack of pre-teaching and repetitive practice of the target structures. They admitted their reliance on peer and teacher assistance for their performance of the main tasks.

The results from analysis of the performance of the main tasks show that pupils across the three groups were able to work towards task completion. The characteristics of interaction across the groups reflected an expert-novice pattern, which showed that the stronger pupils were able to assist the weaker peers to achieve the task goals. During the performance process, the pupils adopted five verbal interactional strategies including co-construction, selfcorrection, other correction, NfM and L1 use. These strategies altogether not only contributed to task completion but also provided a useful context for pupils to manage their own interactions and experiment with ways to get their meaning across. All of these factors are claimed to be conducive to more effective language learning. However, it is important to note that tasks and proficiency levels affected not only the amount, but also the characteristics of the talk across the three groups. The HPG produced more talk and used a wider variety of language while those in the other two groups tended to use fixed turn-taking patterns more regularly. Lack of access to English and confidence may be responsible for this issue from the LPG and MPG. 
The next chapter brings together the findings of the two phases of the research and addresses implications for pedagogy, methodology, and theory as well limitations of the study and future research areas. 


\section{CHAPTER 7 CONCLUSION: SUMMARY OF FINDINGS AND IMPLICATIONS, LIMITATIONS, AND FUTURE RESEARCH DIRECTIONS}

\subsection{Introduction}

In this chapter, I present a summary of the key findings, and the pedagogical, theoretical and methodological implications of these findings. I also assess the limitations of the study and discuss suggestions for future research. The chapter ends with a concluding remark.

\subsection{Summary of findings}

Below, the main findings are summarised for each of the two research phases that make up the thesis.

\subsubsection{Phase 1}

The current study set out to explore the viability of implementing task-based language teaching in Vietnamese EFL primary schools. The exploration process was conducted through two interconnected phases. Phase 1 investigated first how seven EFL teachers in six Vietnamese primary schools implemented the PPP speaking lessons from their English textbooks for Grades 3 and 4, and second how they perceived these PPP speaking lessons. Observation and interview data were collected from the primary school teachers who were based at six different schools across An Giang province.

The results of this investigation showed that the teachers closely followed the PPP sequence specified in the textbooks. Not only did they carry out all three phases of the PPP speaking lesson, but they also frequently added language games to the presentation phase and replaced the textbook production activities with communicative or task-based activities. The primary reason the teachers gave for their decisions to alter the activities was their commitment to enhancing meaningful and communicative language use.

However, despite the teacher's professed desire to promote meaningful communication, analysis of the lesson transcripts showed that all seven teachers spent the majority of class time in the presentation and practice phases where they involved pupils in dialogue and drill practice of the target vocabulary and structures. As a result, the time 
remaining for the production phase where pupils engaged in communicative and task-based activities was minimal. Moreover, since the target structures had been explicitly pre-taught in the presentation phase and repetitively practiced in the practice phase, when it came to the production phase, pupils tended to focus on reproducing the pre-taught target structures rather than engaging in authentic and meaningful communication. Importantly, although the seven teachers were similar in the ways they implemented the PPP speaking lessons, they differed in how they perceived the lessons. Three teachers clearly reported positive views, one remained neutral and the other three expressed negative views. The three teachers who held negative views of the PPP speaking lessons explicitly commented that the PPP lessons were overly prescriptive, which made it difficult to enhance pupils' ability to communicate in real-life

situations. The teachers' concern about the mechanical nature of the PPP speaking lessons and the affordances latent in the textbook content for more communicative task-based lessons motivated Phase 2 of the study.

\subsubsection{Phase 2}

Phase 2 investigated the implementation of the task-based versions of the speaking lessons. Two speaking lessons in a Grade 4 textbook unit were redesigned by the researcher and implemented in real classrooms by the three Grade 4 teachers who had participated in Phase 1 of the study. The teachers represented three different school contexts: rural, semirural and urban. Observation results showed that all three teachers successfully implemented the two task-based lessons across the three classroom contexts. They were able to carry out all three phases of each lesson and engaged pupils throughout the lesson. However, it is important to note that Nam and Nhu, who taught at the rural and semi-rural schools respectively, decided to simplify the task outcomes due to certain contextual constraints such as time and their pupils' low linguistic competence. Although the expected task outcomes were not fully achieved, analysis of task interaction data revealed the pupils had an opportunity to experience the task of exchanging information to complete the two timetables in Lesson 1 and the two worksheets in Lesson 2. According to Ellis (2003), task completion has some priority over task outcomes, suggesting that learning can take place during the process of completing the tasks.

Interview results revealed that both teachers and pupils held positive attitudes toward the introduction of the task-based lessons. In evaluating the task-based lessons against their PPP versions, the teachers stated that the task-based lessons resulted in greater learner involvement and enhanced opportunities for communicative language use. Analysis of pupils' 
performance of the main tasks in the task-based lessons revealed further evidence to support the teachers' views. Pupils across the three classroom contexts were able to complete the tasks although the achieved task outcomes varied slightly. They typically adopted an expert/novice interaction pattern in which the stronger pupils actively assisted the weaker peers during their task performance. This interaction pattern enabled the task performance to proceed successfully.

Moreover, in all performances of the main tasks in both lessons, pupils were found to employ five verbal-interactional strategies as they were attempting to complete the tasks: (1) they helped each other co-construct their utterances; (2) they corrected their own errors; (3) they corrected each other's errors; (4) they negotiated for meaning to resolve comprehension difficulties; and (5) they used their L1 as a valuable resource to scaffold their task performance. In most cases, peer co-construction of utterances was provided by the stronger peer who helped the weaker peer construct his or her utterances regardless of whether it was explicitly requested or not, primarily at the initial stage of task performance. All of the teachers except Nhu also provided a similar form of assistance, although less frequently.

Teacher and peer assistance with constructing utterances was found to move task performance forward. However, as the task performance continued, pupils made phonological, syntactical and lexical errors and, at the same time, attempted to correct those errors. Results showed that pupils tended to correct their own language-related errors more regularly than receiving correction from their peers. Transcription analysis and observation showed that pronunciation errors occurred most frequently and received the most attention for correction. During the task performance, pupils also negotiated for meaning to help overcome comprehension difficulties arising from unclear pronunciation and the complex nature of the two-way information gap tasks which pupils were largely unfamiliar with. When negotiating for meaning, pupils employed three main types of negotiation strategies including confirmation checks, clarification requests, and self-repetition. Throughout the task performances, pupils also employed their L1 to facilitate performance, but they did not use L1 excessively. Primarily, the L1 was employed to manage the task performance and seek/provide assistance. Overall, this process of task performance, through the employment of the five identified verbal and interactional strategies, supports sociocultural and cognitive accounts of language learning and development.

The findings further indicated that pupils' linguistic competence influenced task performance. The higher proficiency pupils reported more benefits and fewer challenges when carrying out the task-based lessons than the lower proficiency ones. The linguistic 
competence also influenced the amount of talk and the verbal interactional strategies the pupils adopted to perform the main tasks. The higher proficiency pupils (Lan's pupils) tended to use a greater amount and a wider variety of language, engaged in more correction, and negotiated for meaning more frequently than their counterparts. Proficiency slightly affected the amount of L1 use, but it did not change the functions of L1 use across the three groups. All groups used L1 mainly for task management and giving/seeking assistance.

In conclusion, the current study has provided empirical evidence to show that TBLT can be implemented in the Vietnamese EFL primary school context. The evidence comes from the positive perspectives of this approach from both teachers and their pupils, and the successful peer-peer interaction observed during the task performance. The study suggests that a task-based approach might be suitable and practicable at EFL primary school levels, provided that a number of conditions at the level of task design and task implementation are fulfilled. The results, therefore, support Pinter's (2007) claim that it is "possible to introduce fluency tasks in primary English classrooms early on to let children experience communication that is more 'real' than drilling and pattern practice" (p.202).

\subsection{Implications}

The findings from the research have implications for task-based language teaching and learning. Pedagogical, methodological and theoretical implications for teachers, education managers, researchers and teacher trainers are discussed below.

\subsubsection{Pedagogical implications}

Several pedagogical contributions and implications may be drawn from the findings of the current study. The first implication, targeting teachers, concerns task design and implementation. Regarding the task design, the findings that teachers and pupils expressed a high level of interest in the input-based listening task indicated that this adapted task has more potential to engage pupils than the more commonly used its look, listen and repeat textbook version. In other words, the input-based listening task which involves more clearly defined communicative guidelines engaged pupils more effectively than the look, listen and repeat textbook presentation activity. Therefore, teachers should consider adapting this textbook activity into input-based listening tasks as a means of increasing pupils' engagement and facilitating the subsequent performance of the main task. Moreover, the input-based listening task helped address teachers' concerns about their pupils lack of familiarity with task 
performance and the requirement to cover the textbook content. Finally, the findings suggested that the two-way information gap tasks motivated pupils to more actively participate, as they have have information of value to share. Therefore, in a primary school context where pupils are used to doing more "mechanical" pair work activities such as the Point and say activity in the practice phase of the PPP lesson, the two-way information-gap task, which encourages more authentic communication and was perceived as more enjoyable by both teachers and pupils in the current study, should be considered as a primary textbook practice activity.

Regarding implementation, the findings highlight the importance of pairing learners of different proficiency levels, indicating that pairing a stronger pupil with a weaker one addresses the problems of mixed-ability classes and of weaker pupils' ability to work with tasks. In the current study, the pupils themselves resolved many of their linguistic problems through peer support and assistance. However, the findings suggest that successful task performance requires a degree of mutuality from the stronger pupil who needs to be willing to provide language support and give encouragement. However, the stronger pupil may not automatically assume the active role of assisting their less competent peer. Teachers may need to, at least initially, train learners to become efficient interlocutors who understand the value of assisting each other and of being sensitive and responsive in peer interaction (Choi \& Iwashita, 2016; Kim \& McDonough, 2011)

Moreover, according to Van den Branden (2016), YLs may need interactional support to bridge the gaps between task demands and their language proficiency. Therefore, as the research findings suggest, teacher co-construction assistance is essential, especially at the start of the performance provided that it is provided in a way that can indirectly scaffold task performance. Moreover, as the results of the current study indicated, TBLT is still challenging for the lower proficiency pupils, partly due to pupils' lack of familiarity with tasks. Therefore, teachers need to carefully consider all of the possible linguistic and cognitive limitations faced by their pupils. Provision of language input such as target vocabulary necessary for the performance of the main tasks for example is essential for low proficiency learners. If teachers find that their pupils may have difficulty doing certain tasks, it is recommended that teachers pre-teach key vocabulary and provide exposure to sufficient input through inputbased tasks such as those adopted in the current study. These tasks should be engaging and motivating so that they can capture and maintain pupils' attention to the target forms necessary for the performance of the main tasks. 
The second implication, targeting education managers, is concerned with the support required for teachers. The results suggest that successful implementation of TBLT into language classrooms depends on teachers' English proficiency, pedagogic competence, and attitudes toward communicative and task-based language teaching. A key policy priority, therefore, should be to plan for the on-going enhancement of teachers' language proficiency and their pedagogical skills. Moreover, adopting TBLT would require teachers not only to change their teaching practices, but also to shift their perceptions of the teaching-learning process. It is also important to note that the textbooks play a role in the successful design and implementation of the task-based lessons. The textbooks contain communicative pair/group activities and child-friendly activities such as interactive games, songs and chants. These activities not only motivate pupils to learn English but they also familiarise them with pair/group work. This familiarity could have facilitated the implementation of the pair/group activities in the task-based lessons (see Sections 4.2 and 4.3 for an overview of the textbooks and a full analysis of a textbook unit).

In terms of the required support, the lessons learned from the current study suggest that primary school teachers will require "focused professional development" (East, 2012, p.207) in the form of training and other opportunities for practice when transitioning from traditional L2 teaching methods to TBLT. Providing on-going training concerning both theoretical and pedagogical aspects of TBLT is essential. As Van den Branden (2009a) argues, teachers need to be "supported throughout all the following phases of the innovationdecision process, especially when they introduce the innovation into the classroom" (p. 665). It is, therefore, important for school administration to offer assistance to teachers in designing and implementing tasks. Support regarding ready-made tasks or task materials may be essential given teachers' busy schedules and lack of access to task materials.

The third implication targets researchers and teacher trainers. The current study suggests that successful adoption of TBLT can take place when there is the presence of supportive partners such as researchers and teacher trainers throughout the different levels of implementation. Teachers may, for example, need guidance and support regarding how the textbook lessons can be redesigned to reflect principles of TBLT, how the redesigned lessons can be effectively implemented, and what roles the teacher should play during the implementation process. Therefore, as Pica (2012) suggests, "as long as teachers and researchers find ways to work together in the classroom, and remain committed to long-term relationships with language learners and with each other, tasks provide principled and informed direction and guidance" ( $p$. xviii). This type of collaborative effort may be 
approached in terms of exploratory practice (Allwright, 2003), teacher-researcher collaboration (Steward, 2006), and action research (Burns, 2005). It is, however, important that such active engagement and collaboration between teachers and researchers in developing and implementing tasks cannot be left to individual initiatives, but would require additional institutional effort from colleagues, schools, parents and the broader educational community.

Finally, as the current study has indicated, the introduction of TBLT in EFL primary schools is feasible if factors concerning task design and implementation, teachers' linguistic and pedagogic skills, support for teachers, and collaboration between teachers and researchers are all taken into consideration. However, as Ellis (2015) argues, "in teaching contexts where teachers and students are used to traditional approaches it would be unwise to make a sudden and total switch to TBLT. Rather, teachers would do better to introduce TBLT in some lessons while continuing with familiar traditional approaches in others" (p.383). This suggestion may be relevant to this Vietnamese EFL primary school context. Following this, teachers can consider redesigning and implementing some of the PPP speaking lessons in the textbooks. With the passage of time, after pupils have become familiar with TBLT, teachers can increase the number of the task-based lessons to be introduced.

\subsubsection{Methodological implications}

The principal methodological implication of the study concerns the research design. The study was designed to include two consecutive phases. Phase 1 of the current study investigated the implementation of the PPP speaking lessons from a range of contexts and a variety of teachers' perspectives. The results provided not only a motive but also insights into the redesign of the PPP speaking lessons to be implemented in the classrooms in Phase 2 of the study. The implementation of the task-based versions of the PPP speaking lessons was evaluated from different sources of data including those from teacher and pupil observations and interviews, and from pupils' performance of the main tasks in the task-based lessons. The data were analysed both qualitatively and quantitatively, from both etic and emic perspectives, and under the lens of both teachers and pupils. These multiple approaches to data analysis provide an enriched view on teaching and learning through tasks and add explanatory power to the findings. Consequently, the investigation of TBLT in the current study lays the ground for understanding the implementation of TBLT in authentic primary classrooms.

This research design involves certain theoretical and methodological characteristics of action research. To a certain extent, the current study can serve as a partial collaborative 
action research project where one cycle has been completed. In this first cycle, teachers and researchers identified a problem, reflected on it, took actions and evaluated the actions empirically. Although more cycles are required to more fully reflect on the actions taken, the study highlights the importance of using action research as a means by which teachers can address problems that arise in their own teaching context. It calls for teachers and researchers to collaborate on action research projects and suggests that action research be incorporated into teacher language education and the professional development of in-service teacher.

\subsubsection{Theoretical implications}

The findings of the current study suggest that it is important to interpret task interaction through the lens of both cognitive and sociocultural perspectives. While the sociocultural perspectives provided insights into the way in which L2 learners support each other's learning and how social dynamics foster task performance, the cognitive perspectives enabled an understanding of how learners negotiated for meaning during interaction to solve comprehension difficulties. The adoption of these two perspectives helped uncover more fully the process of primary school pupils performing tasks in the classroom and how this process facilitated language learning. The findings highlight the importance of viewing TBLT through the lens of "theoretical pluralism" (Ellis, 2008) and support those of earlier studies such as Foster and Ohta (2005), suggesting that L2 classroom interaction is better understood by exploring it from different perspectives.

The results have confirmed the value of viewing primary English education as a sociocognitive phenomenon where learners collaborate with peers to transact communicative tasks. Collaboration also provides the kind of experiential learning which has been claimed to be valuable for YLs (Enever, 2016; Nunan, 2011). Specifically, the results showed how collaborative dialogue provides space for pupils to make conscious effort to resolve language problems in their meaning-making during task performance. Moreover, it provides opportunities for peer assistance, negotiation for meaning, NF and "push output" (Swain, 2005).

\subsection{Limitations and future research directions}

The current study has certain limitations which warrant acknowledgment and provide areas for future research. First, the study involved a small group of EFL primary school teachers at six primary schools in Phase 1 with three of these teachers participating in Phase 2. 
This small sample is not necessarily representative of a wider population of Vietnamese primary EFL teachers implementing the textbook speaking lessons. Moreover, the teachers in the current study were strong in both pedagogical skills and language skills given the fact that they were qualified implementers of the new curriculum. The findings, therefore, should not be generalised for teachers who may not meet particular proficiency requirements or whose pedagogical competence may be under-developed.

Second, the intervention in Phase 2 is brief, involving three teachers and using two redesigned PPP speaking lessons in a textbook unit, which again limits the generalization of the findings of the current study. Moreover, the investigation of the performance of the main tasks in the task-based lessons used a small sample of only nine dyads, three for each proficiency group or school context. Future research incorporating a similar design and a larger sample size or in a wider range of schools, would be of value. Moreover, a longitudinal intervention which involves a more substantial coverage of the textbook speaking lessons and a greater number of dyads would be helpful to provide additional insights into the implementation of the task-based versions of the PPP speaking lessons and to establish specific learning gains resulted from task-based learning.

Third, due to constraints associated with data collection, there is no equivalent peer interaction data from the PPP speaking lessons to be compared with the peer interaction data collected from the performance of the main tasks in the task-based lessons. A further study could also be conducted to collect peer interaction data from the PPP lessons to establish differences in terms of language learning between the task-based lessons and the PPP versions of the lessons. It should be, however, noted that the current study does not directly address the question of second language development of the task-based lessons compared to the PPP versions of the lessons. Rather, it aims to explore the implementation of the task-based lessons in authentic EFL primary school classrooms.

Fourth, in the analysis of the pupils' performance of the main tasks in the task-based lessons in Phase 2, I classified the proficiency groups (LPG, MPG and HPG) according to their school contexts (rural school, semi-rural school and urban school), respectively. My classification was based on my knowledge of the school contexts and my observation of the abilities of the pupils from each school in Phase 1 (see Sections 3.4.1 and 3.7.5 in the methodology chapter). Additionally, the teachers selected dyads of a lower and a higher proficiency pupil based on their perceptions of their pupils' abilities. This aimed to address the teachers' concern about the lower proficiency pupils' ability to perform the main tasks. Future research could employ more objective proficiency measures such as pre-tests to 
determine the proficiency levels of pupils across different school contexts and within dyads if one aim of the research is to compare differences in their task performances.

Fifth, in my study, I focused exclusively on verbal interaction data. However, face-toface interaction is invariably multimodal, involving not just verbal communication but also non-verbal means of communication such as gestures, facial expressions and other forms of physical movements. Future research could usefully look more closely at the multimodal resources that YLs draw on to transact communication tasks (Seedhouse \& Almutairi, 2009).

Sixth, as discussed in the methodology chapter, my position as a teacher trainer may offer me both advantages and disadvantages, at the same time this may cause bias. The teachers may have seen me as an expert and this might have resulted in a Hawthorne effect where they may have performed better and tried to tell their ideal perspectives, rather than what they actually thought. Similarly, the pupils might have been excited by the newness of the lesson activities and this may have influenced their responses during the interviews. Since they were chosen for the recording, they may have made greater efforts in doing the tasks than the rest of the class. Further research is needed to repeat the tasks in different school contexts over a longer period of time to more fully evaluate the effectiveness of the redesigned lessons.

Finally, the current study suggests that continued efforts are needed to involve schoolbased teachers in action research projects. The projects should encourage them to reflect on their current practices, find ways to redesign textbook speaking lessons, implement them in their own classrooms and finally reflect on their implementation process. Teachers' reflections on their research projects will offer valuable insights into the implementation of TBLT in classrooms, which can in turn benefit education managers and policy-makers.

\subsection{Concluding remarks}

This research contributes to the TBLT research literature in three areas. The first contribution is that because this research focused on real classrooms, real teachers and real learners using their textbooks, it provided insights into the actual practice of task-based language teaching in primary school classrooms. The second contribution is that this research focused on tasks in EFL primary school classrooms, an under-researched educational sector. The findings showed how tasks could be used effectively in such classrooms. The third related contribution is in relation to the Vietnamese context. Research on TBLT in Vietnam to date has mostly focused on high school and tertiary contexts. Thus, the current study corrects this imbalance by showing how tasks can be used in primary school EFL classrooms in 
Vietnam. Overall, therefore, the findings of this research can be used to inform the development of pre-service and in-service teacher education and training in Vietnam in order to support the more effective implementation of the 2010 primary English curriculum in particular and the 2008-2020 and 2017-2025 two-phase national foreign language project in general.

On a personal level, I started my $\mathrm{PhD}$ with a desire to be the best teacher and teacher trainer I can be. This research will be of great value to me when I resume my job as an EFL teacher and a teacher trainer. Through this research, I have gained a better understanding of both the benefits and challenges of implementing TBLT in authentic classrooms as well as the possibilities for incorporating tasks into primary school classrooms in Vietnam. From my experience of carrying out this research and engaging deeply with the classroom data, I am convinced that if teachers have an opportunity to explore TBLT they will agree with Ellis's (2015, p.383) claim that "if students are to develop the interactional competence needed for communication in the real world, they also need to experience language used as a tool (i.e., TBLT)". The experience of the teachers and pupils reported in the current study provide ample evidence to support this claim. Through tasks, primary school EFL learners in Vietnam were indeed able to put English language to use for real communicative purposes and, in so doing, to develop their interactional competence. 
This page is intentionally left blank 


\section{REFERENCES}

Adams, R., \& Newton, J. (2009). TBLT in Asia: Opportunities and constraints. Asian Journal of English Language Teaching, 19, 1-17.

Aljaafreh, A., \& Lantolf, J. P. (1994). Negative feedback as regulation and second language learning in the Zone of Proximal Development. The Modern Language Journal, 78(4), 465-483.

Allwright, R. (2003). Exploratory practice: Rethinking practitioners' research in language teaching. Language Teaching Research, 7(2), 113-141.

Anderson, J. (2017). The potted history of PPP with the help of ELT journal. ELT Journal, $71(2), 218-227$.

Andon, N., \& Eckerth, J. (2009). Chacun à son gout? Task-based L2 pedagogy from the teacher's point of view. International Journal of Applied Linguistics, 19(3), 286-310.

Antón, M., \& DiCamilla, F. J. (1998). Socio-cognitive functions of L1 collaborative interaction in the L2 classroom. Canadian Modern Language Review, 54, 314-342.

Azkarai, A., \& García Mayo, M. P. (2015). Task-modality and L1 use in EFL oral interaction. Language Teaching Research, 19, 550-571.

Azkarai, A., \& García Mayo, M. P. (2017). Task repetition effects on L1 use in EFL child task-based interaction. Language Teaching Research, 21(4), 480-495.

Azkarai, A., \& Imaz Agirre, A. I. (2016). Negotiation of meaning strategies in child EFL mainstream and CLIL. TESOL Quarterly, 50(4), 844-870. https://doi.org/10.1002/tesq.249

Azkarai, A., \& Oliver, R. (2016). Negative feedback on task repetition: ESL vs. EFL child settings. The Language Learning Journal. 1-12.

Bao, R. (2012). Does task-based teaching work unconditionally? In X. Y. Yu \& M. J.

Kirkebæk (Eds.), Exploring task-based PBL in Chinese teaching and learning (pp. 99111). Newcastle: Cambridge Scholars Press.

Bao, R., \& Du, X. (2015). Implementation of task-based language teaching in Chinese as a foreign language: Benefits and challenges. Language, Culture and Curriculum, 28(3), 291-310. https://doi.org/10.1080/07908318.2015.1058392

Berben, M., Van Den Branden, K., \& Van Gorp, K. (2007). "We'll see what happens": Tasks on paper and tasks in a multilingual classroom. In K. Van Den Branden, K. Van Gorp, \& M. Verhelst (Eds.), Tasks in action: Task-based language education from a classroom-based perspective. (pp. 32-63). London: Cambridge Scholars Publishing.

Borg, S. (2003). Teacher cognition in language teaching: A review of research on what language teachers think, know, believe, and do. Language Teaching, 36(2), 81-109.

Borg, S. (2006). Teacher cognition and language education. London: Continuum. 
Brooks, F. B., Donato, R., \& McGlone, C. V. (1997). When are they going to say "it" right? Understanding learner talk during pairwork activity. Foreign Language Annals, 30, 524-541.

Brooks, L., Swain, M., \& Polio, C. (2009). Languaging in collaborative writing: Creation of and response to expertise. In A. Mackey (Ed.), Multiple perspectives on interaction: Second language research in honour of Susan M. Gass (pp. 58-89). New York: Routledge.

Bryman, A. (2016). Social research methods (5th ed.). Oxford: Oxford University Press.

Buckwalter, P. (2001). Repair sequences in Spanish L2 dyadic discourse: A descriptive study. The Modern Language Journal, 85(3), 380-397.

Burns, A. (2005). Action research: An evolving paradigm? Language Teaching, 32(2), 57-74.

Burns, R. B. (2000). Introduction to research methods. Melbourne: Longman.

Butler, Y. G. (2011). The implementation of communicative and task-based language teaching in the Asia-pacific region. Annual Review of Applied Linguistics, 31, 36-57.

Butler, Y. G. (2015). English language education among young learners in East Asian: A review of current research (2004-2014). Language Teaching, 48(3), 303-342.

Butler, Y. G., \& Zeng, W. (2014). Young foreign language learners' interactions during taskbased paired assessments. Language Assessment Quarterly, 11, 45-75.

Butler, Y. G., \& Zeng, W. (2015). Young learners' interactional development in task-based paired-assessment in their first and foreign languages: A case of English learners in China. Education 3-13, 43(3), 292-321.

Bygate, M. (2016). Sources, developments and directions of task-based teaching. The Language Learning Journal, 44(4), 381-400.

Bygate, M., Skehan, P., \& Swain, M. (2001). Introduction. In M. Bygate, P. Skehan, \& M. Swain, Researching pedagogic tasks: Second language learning, teaching and testing (pp. 1-20). Harlow: Longman.

Cameron, L. (2001). Teaching languages to young learners. Cambridge: Cambridge University Press.

Cameron, L. (2003). Challenges for ELT from the expansion in teaching children. ELT Journal, 57(2), 105-112.

Carless, D. (2002). Implementing task-based learning with young learners. ELT Journal, 56(4), 389-396.

Carless, D. (2003). Factors in the implementation of task-based teaching in primary schools. System, 31(4), 485-500.

Carless, D. (2004). Issues in teachers' interpretation of a task-based innovation in primary schools. TESOL Quarterly, 38(4), 639-662. 
Carless, D. (2008). Student use of the mother-tongue in the task-based classroom. ELT Journal, 62(4), 331-338.

Carless, D. (2009). Revisiting the TBLT versus P-P-P debate: Voices from Hong Kong. Asian Journal of English Language Teaching, 19, 49-66.

Carless, D. (2012). TBLT in EFL settings: Looking back and moving forward. In A. Shehadeh \& C. Coombe (Eds.), Task-based language teaching in foreign language contexts (pp. 345-358). Amsterdam: John Benjamins.

Carter, R., \& Nunan, D. (2001). The Cambridge guide to teaching English to speakers of other languages. Cambridge: Cambridge University Press.

Chan, S. P. (2012). Qualitative differences in novice teachers' enactment of task-based language teaching in Hong Kong primary classrooms. In A. Shehadeh \& C. A. Coombe (Eds.), Task-based language teaching in foreign language contexts: Research and implementation (pp. 187-213). Amsterdam: John Benjamins Publishing Company.

Choi, H., \& Iwashita, N. (2016). Interactional behaviors of low-proficiency learners in small group work. In S. G. Ballinger \& M. Sato, Peer interaction and second language learning (pp. 113-134). Amsterdam: John Benjamins Publishing Company.

Cohen, L., Manion, L., \& Morrison, K. (2017). Research methods in education (8th ed.). London: Routledge.

Council of Europe. (2001). Common European framework of reference for languages: Learning, teaching, and assessment. Cambridge: Cambridge University Press

Creswell, J. W., \& Poth, C. N. (2018). Qualitative inquiry and research design: Choosing among five approaches (4th ed.). Thousand Oaks, CA: Sage.

Dang, T. C. T., \& Seals, C. (2018). An evaluation of primary English textbooks in Vietnam: A sociolinguistic perspective. TESOL Journal, 9(1), 93-113.

DanTri. (2017, December 29). Điều chỉnh đề án dạy ngoại ngữ 2020 và kéo dài đến 2025.(Making amendments to the national foreign language project 2020 and extending the project to 2025). Retrieved from https://dantri.com.vn/giao-duc-khuyen-hoc/de-anngoai-ngu-2020-that-bai-dieu-chinh-va-keo-dai-den-2025-20171229155520734.htm

Dao, P., \& McDonough, K. (2017). The effect of task role on Vietnamese EFL learners' collaboration in mixed proficiency dyads. System, 65, 15-24.

De Guerrero, M. C. D., \& Villamil, O. S. (2000). Activating the ZPD: Mutual scaffolding in L2 peer revision. The Modern Language Journal, 84, 51-68.

Deng, C., \& Carless, D. (2009). The communicativeness of activities in a task-based innovation in Guangdong, China. Asian Journal of English Language Teaching, 19, 113-134.

Denzin, N. K., \& Lincoln, Y. S. (Eds.). (2000). The handbook of qualitative research (2nd ed.). Thousand Oaks: Sage Publications.

Dörnyei, Z. (2007). Research methods in applied linguistics. Oxford: Oxford University Press. 
East, M. (2012). Task-based language teaching from the teachers' perspective. Amsterdam: John Benjamins Publishing Company.

Ecrisson, K. A., \& Simon, H. A. (1984). Protocol analysis: Verbal reports as data. Cambridge, MA: MIT Press.

Edwards, C., \& Willis, J. (Eds.). (2005). Teachers exploring tasks in English language teaching. New York: Palgrave Macmillan.

Ellis, R. (2000). Task-based research and language pedagogy. Language Teaching Research, 4(3), 193-220.

Ellis, R. (2003). Task-based language learning and teaching. Oxford: Oxford University Press.

Ellis, R. (2008). The study of second language acquisition. Oxford: Oxford University Press.

Ellis, R. (2009). Task-based language teaching: Sorting out the misunderstandings. International Journal of Applied Linguistics, 19(3), 221-246.

Ellis, R. (2012). Language teaching research and language pedagogy. West Sussex: WileyBlackwell.

Ellis, R. (2015). Epilogue. In M. Thomas \& H. Reinders (Eds.), Contemporary task-based language teaching in Asia (pp. 381-384). London: Bloomsbury.

Ellis, R. (2018). Reflections on task-based language teaching. Bristol: Multilingual Matters.

Ellis, R., \& Heimbach, R. (1997). Bugs and birds: Children's acquisition of second language vocabulary through interaction. System, 25(2), 247-259.

Ellis, R., \& Shintani, N. (2014). Exploring language pedagogy through second language acquisition research. London and New York: Routledge.

Enever, J. (2016). Primary ELT: Issues and trends. In G. Hall (Ed.), The Routledge handbook of English language teaching (pp. 353-365). London: Routledge.

Estaire, S., \& Zanon, J. (1994). Planning class work: A task-based approach. Oxford: Heinemann.

Foster, P. (1998). A classroom perspective on the negotiation of meaning. Applied Linguistics, 19(1), 1-23.

Foster, P., \& Ohta, A. S. (2005). Negotiation for meaning and peer assistance in second language classrooms. Applied Linguistics, 26(3), 402-430.

Gagné, P., \& Parks, S. (2013). Cooperative learning tasks in a Grade 6 intensive ESL class: Role of scaffolding. Language Teaching Research, 17(2), 188-209.

García Mayo, M. P., \& Imaz Agirre, A. I. (2016). Task repetition and its impact on EFL children's negotiation of meaning strategies and pair dynamics: An exploratory study. The Language Learning Journal, 44(4), 451-466. 
García Mayo, M. P., \& Imaz Agirre, A. I. (2019). Task modality and pair formation method: Their impact on patterns of interaction and LREs among EFL primary school children. System, 80, 165-175.

García Mayo, M. P., \& Lázaro-Ibarrola, A. (2015). Do children negotiate for meaning in taskbased interaction? Evidence from CLIL and EFL settings. System, 54, 40-54.

Gass, S., Mackey, A., \& Ross-Feldman, L. (2011). Task-based interactions in classroom and laboratory settings. Language Learning, 61(1), 189-220.

González-Lloret, M. \& Nielson, K. B. (2015). Evaluating TBLT: The case of a task-based Spanish program. Language Teaching Research, 19(5), 525-549.

Guba, E. G. (1990). The alternative paradigm dialog. In E. G. Guba (Ed.), The paradigm dialog (pp. 17-30). Newbury Park, California: Sage.

Guba, E. G., \& Lincoln, Y. S. (1994). Competing paradigms in qualitative research. In N. K. Denzin \& Y. S. Lincoln (Eds.), Handbook of qualitative research (pp. 105-117). Thousand Oaks, California: Sage.

Guba, E., \& Lincoln, Y. S. (1988). Do inquiry paradigms imply inquiry methodologies? In D. M. Fetterman (Ed.), Qualitative approaches to evaluation in education: The silent scientific revolution (pp. 89-115). New York: Praeger.

Guk, L., \& Kellogg, D. (2007). The ZPD and whole class teaching: Teacher-led and studentled interactional mediation of tasks. Language Teaching Research, 11(3), 281-299.

Harmer, J. (2001). The practice of English language teaching. Harlow: Longman.

Haverkamp, B. E. (2005). Ethical perspectives on qualitative research in applied psychology. Journal of Counselling Psychology, 52(2), 146-155.

Hesse-Biber, S. N. (2017). The practice of qualitative research (3th ed.). Los Angeles: Sage.

Hoang, V. V., Nguyen, T. Q., Phan, H., Do, H. N. T., Dao, L. N., \& Truong, M. N. T. (2015a). Sach giao vien tieng Anh 3 (Teacher's book 3). Ha Noi: Education Publishing House.

Hoang, V. V., Nguyen, T. Q., Phan, H., Do, H. N. T., Dao, L. N., \& Truong, M. N. T. (2015b). Sach giao vien tieng Anh 4 (Teacher's book 4). Ha Noi: Education Publishing House.

Hoang, V. V., Nguyen, T. Q., Phan, H., Do, H. N. T., Dao, L. N., \& Truong, M. N. T. (2015c). Tieng Anh 3,4,5 (English 3, 4, 5) (3rd ed.). Ha Noi: Education Publishing House.

Hood, M., Elwood, J., \& Falout, J. (2009). Student attitudes toward task-based language teaching at Japanese universities. Asian Journal of English Language Teaching, 19, 1947.

Hu, R. (2013). Task-based language teaching: Responses from from Chinese teachers of English. TESL-EJ, 16(4), 1-21. 
Ives, D. (2004). Three NS-NNS upper primary school pairs: A case study. Australian Language and Literacy Matters, 1(4), 11-16.

Iwashita, N. (2001). The effect of learner proficiency on interactional moves and modified output in nonnative-nonnative interaction in Japanese as a foreign language. System, 29, 267-287.

Jeon, I. J., \& Hahn, J. (2006). Exploring EFL teachers' perceptions of task-based language teaching: A case study of Korean secondary school classroom practice. Asian EFL Journal, 8(3), 192-260.

Johnson, R. B., \& Christensen, L. (2014). Educational research: Quantitative, qualitative, mixed approaches. (5th ed.). Thousand Oaks, California: Sage.

Kim, Y., \& McDonough, K. (2008). The effect of interlocutor proficiency on the collaborative dialogue between Korean as a second language learners. Language Teaching Research, $12,211-234$.

Kim, Y., \& McDonough, K. (2011). Using pre-task modeling to encourage collaborative learning opportunities. Language Teaching Research, 15(2), 183-199.

Lai, C. (2015). Task-based language teaching in the Asian context: Where are we now and where are we going? In M. Thomas \& H. Reinders (Eds.), Contemporary task-based language teaching in Asia (pp. 12-29). London: Bloomsbury.

Lane, L., \& Brown, H. D. (2010). Tips for teaching pronunciation: A practical approach. New York: Pearson Longman.

Lantolf, J. P. (2000). Second language learning as a mediated process. Language Teaching, 33(2), 79-96.

Lantolf, J. P., \& Thorne, S. (2006). Sociocultural theory and the genesis of second language development. Oxford: Oxford University Press.

Le, C. V., \& Barnard, R. (2009). Curricular innovation behind closed classroom doors: A Vietnam case study. Prospect, 24(2), 20-33.

Le, C. V., \& Do, C. M. T. (2012). Teacher preparation for primary school English education: A case of Vietnam. In B. Spolsky \& Y. Moon (Eds.), Primary school English Language Education in Asia: From Policy to Practice. (pp. 106-128). New York: Routledge.

Lee, J. (2000). Tasks and communicating in language classrooms. Boston, MA: McGrawHill.

Li, D. F. (1998). 'It's always more difficult than you plan and imagine': Teachers' perceived difficulties in introducing the communicative approach in South Korea. TESOL Quarterly, 32(4), 677-703.

Lin, T.-B., \& Wu, C.-W. (2012). Teachers' perceptions of task-based language teaching in English classrooms in Taiwanese junior high schools. TESOL Journal, 3(4), 586-609.

Lincoln, Y., S., \& Guba, E., G. (1985). Naturalistic inquiry. Newbury Park, California: Sage. 
Littlewood, W. (2007). Communicative and task-based language teaching in East Asian classrooms. Language Teaching, 40(3), 243-249.

Loewen, S., \& Philp, J. (2012). Instructed second language acquisition. In A. Mackey \& S. Gass (Eds.), Research methods in second language acquisition: A practical guide (pp. 53-73). West Sussex: Wiley-Blackwell.

Long, M. H. (1983). Does second language instruction make a difference? A review of research. TESOL Quarterly, 17(3), 359-382.

Long, M. H. (1985). A role for instruction in second language acquisition: Task-based language teaching. In K. Hyltenstam \& M. Pienemann (Eds.), Modelling and assessing second language acquisition (pp. 77-99). Clevedon: Multilingual Matters.

Long, M. H. (1991). Focus on form: A design feature in language teaching methodology. In K. De Bot, R. B. Ginsberg, \& C. Kramsch (Eds.), Foreign language research in crosscultural perspective (pp. 39-52). Amsterdam: John Benjamins.

Long, M. H. (1996). The role of linguistic environment in second language acquisition. In W. C. Ritchie \& T. K. Bhatia (Eds.), Handbook of second language acquisition (pp. 413468). New York: Academic.

Long, M. H. (2015). Second language acquisition and task-based language teaching. West Sussex: John Wiley \& Sons.

Lyster, R., \& Ranta, L. (1997). Corrective feedback and learner uptake. Negotiation of form in communicative classrooms. Studies in Second Language Acquisition, 19(1), 37-66.

Mackey, A. (2012). Input, interaction and corrective feedback in L2 learning. Oxford: Oxford University Press.

Mackey, A., \& Gass, S. M. (2005). Second language research: Methodology and design. Mahwah, N.J: Routledge.

Mackey, A., \& Oliver, R. (2002). Interactional feedback and children's L2 development. System, 30(4), 459-477.

Mackey, A., Oliver, R., \& Leeman, J. (2003). Interactional input and the incorporation of feedback: An exploration of NS-NNS and NNS-NNS adult and child dyads. Language Learning, 53(1), 35-66.

Mackey, A., \& Silver, R. E. (2005). Interactional tasks and English L2 learning by immigrant children in Singapore. System, 33(2), 239-260.

Marshall, C., \& Rossman, G. B. (2006). Designing qualitative research (4th ed.). Thousand Oaks, California: Sage Publications.

McAllister, J., Narcy-Combes, M., \& Starkey-Perret, R. (2012). Language teachers'perceptions of a task-based learning program in a French University. In A. Shehadeh \& C. A. Coombe (Eds.), Task-based language teaching in foreign language contexts: Research and Implementation (pp. 313-324). Amsterdam: John Benjamins Publishing Company. 
McDonough, J., \& McDonough, S. (1997). Research methods for English language teachers. London: Arnold.

McDonough, K. (2004). Learner-learner interaction during pair and small group activities in a Thai EFL context. System, 32, 207-224.

McDonough, K. (2015). Perceived benefits and challenges with the use of collaborative tasks in EFL contexts. In M. Bygate (Ed.), Domains and directions in the development of TBLT (pp. 225-245). Amsterdam, Philadelphia: John Benjamins Publishing Company.

McDonough, K., \& Chaikitmongkol, W. (2007). Teachers' and learner's reactions to a taskbased EFL course. TESOL Quarterly, 41(1), 107-132.

McKay, S. (2006). Researching second language classrooms. Mahwah, N.J: Lawrence Erlbaum.

Merriam, S. B., \& Tisdell, E. J. (2016). Qualitative research: A guide to design and implementation (4th ed.). San Francisco: Jossey-Bass.

Miles, M. B., \& Huberman, A. H. (1994). Qualitative data analysis: A sourcebook of new methods. Newbury Park, CA: SAGE.

Moon, J. (2005, June). Investigating the teaching of English at primary level in Vietnam. A summary report presented at the Presentation at the conference on English language teaching at primary level., Ha Noi: Vietnam.

Muller, T. (2005). Adding tasks to textbooks for beginner learners. In C. Edwards \& J. Willis (Eds.), Teachers exploring tasks in English language teaching (pp. 69-77). New York: Palgrave Macmillan.

Nakatsukasa, K., \& Loewen, S. (2015). A teacher's first language use in form-focused episodes in Spanish as a foreign language classroom. Language Teaching Research, 19(2), 133-149.

Newton, J. (2013). Incidental vocabulary learning in classroom communication tasks. Language Teaching Research, 17(2), 164-187.

Newton, J., \& Nguyen, B. T. (forthcoming). Task rehearsal and public performance in taskbased language teaching at a Vietnamese high school. Language Teaching for Young Learners, 1(1).

Nguyen, H. M. T. (2011). Primary English language education policy in Vietnam: Insights from implementation. Current Issues in Language Planning, 12(2), 225-249.

Nguyen, H. M. T., \& Nguyen, T. Q. (2007). Teaching English in primary schools in Vietnam: An overview. Current Issues in Language Planning, 8(2), 162-173.

Nguyen, T. A., Jaspaert, K. \& Van den Branden, K. (2018). EFL teachers' perceptions of taskbased language teaching in a Vietnamese university. The European Journal of Applied Linguistics and TEFL, 73-90.

Nguyen, T. A., \& Nguyen, T. P. B. (2017). In-service teachers' reaction to a training program of task-based language teaching: A case study of English language teachers in Vietnam. IOSR Journal of Research and Method in Education, 7(3), 53-68. 
Nguyen, T. B. T. (2013). Tasks in action in Vietnamese EFL high school classrooms: The role of rehearsal and performance in teaching and learning through oral tasks (Unpublished doctoral thesis). Victoria University of Wellington, Wellington.

Nguyen, T. B. T., Newton, J., \& Crabbe, D. (2015). Preparing for tasks in Vietnamese EFL high school classrooms: Teachers in action. In M. Thomas \& H. Reinders (Eds.), Contemporary task-based language teaching in Asia (pp. 170-188). London: Bloomsbury.

Nguyen, T. N., Pham, B. D., Phan, H., Do, H. N. T., Dao, L. N., \& Wong, L. M. (2010). Let's learn English 1,2,3. Ha Noi: Vietnam Education Publishing House.

Nguyen, V. G. (2014). Forms or meaning? Teachers' beliefs and practices regarding taskbased language teaching: A Vietnamese case study. The Journal of Asia TEFL, 11(1), $1-36$.

Nguyen, V. G., Le, C. V., \& Barnard, R. (2015). "Old wine in new bottles": Two case studies of task-based language teaching in Vietnam. In M. Thomas \& H. Reinders (Eds.), Contemporary task-based language teaching in Asia (pp. 68-86). London: Bloomsbury.

Norris, J. M. (2009). Task-based teaching and testing. In M. H. Long \& C. J. Doughty (Eds.), Handbook of language teaching (pp. 578-594). Oxford: Blackwell.

Nunan, D. (2003). The impact of English as a global language on educational policies and practices in the Asia-Pacific region. TESOL Quarterly, 37(4), 589-613.

Nunan, D. (2004). Task-based language teaching. Cambridge: Cambridge University Press.

Nunan, D. (2011). Teaching English to young learners. Anaheim, CA: Anaheim University Press.

Nunan, D., \& Baily, K., M. (2009). Exploring second language classroom research. Boston: Heinle, Cengage Learning.

Ohta, A. S. (1995). Applying sociocultural theory to an analysis of learner discourse: Learnerlearner collaborative interaction in the Zone of Proximal Development. Issues in Applied Linguistics, 6(2), 93-121.

Ohta, A. S. (2001). Second language acquisition process in the classroom. Mahwah, N.J.: Lawrence Erlbaum Associates, Pulishers.

Oliver, R. (1998). Negotiation of meaning in child interaction. The Modern Language Journal, 82(3), 372-386.

Oliver, R. (2000). Age differences in negotiation and feedback in classroom and pairwork. Language Learning, 50(1), 119-151.

Oliver, R. (2002). The patterns of negotiation for meaning in child interactions. The Modern Language Journal, 86(1), 97-111.

Oliver, R., Philp, J., \& Duchenes, S. (2017). Children working it out together: A comparison of younger and other learners collaborating in task-based interaction. System, 69, 1-14 
Patton, M. Q. (2015). Qualitative research and evaluation methods (4th ed.). Los Angeles: Sage.

Philp, J., Adams, R., \& Iwashita, N. (2014). Peer interaction and second language learning. New York: Routledge.

Philp, J., Oliver, R., \& Mackey, A. (2006). The impact of planning time on children's taskbased interactions. System, 34, 547-565.

Philp, J., Walter, S., \& Basturkmen, H. (2010). Peer interaction in the foreign language classroom: What factors foster a focus on form? Language Awareness, 19(4), 261-279. https://doi.org/10.1080/09658416.2010.516831

Phuong, Y. H. (2016). Challenges of shifting to task-based language teaching: A story from a Vietnamese teacher. Can Tho University Journal of Science, 2, 37-45.

Pica, T. (1994). Research on negotiation: What does it reveal about second language learning conditions, processes, outcomes? Language Learning, 44(3), 493-527.

Pica, T. (2012). Foreword. In A. Shehadeh \& C. A. Coombe, Task-based language teaching in foreign language contexts: Research and Implementation (pp. xv-xix). Amsterdam, Philadelphia: John Benjamins Publishing Company.

Pica, T., \& Doughty, C. (1985). The role of group work in classroom second language acquisition. SSLA, 7, 233-248.

Pica, T., Kanagy, R., \& Falodun, J. (1993). Choosing and using communication tasks for second language instruction and research. In G. Crookes \& S. Gass (Eds.), Tasks and language learning: Integrating theory and practice (pp. 9-34). Clevedon, UK: Multilingual Matters.

Pica, T., Kang, H.-S., \& Sauro, S. (2006). Information gap tasks: Their multiple roles and contributions to interaction research methodology. Studies in Second Language Acquisition, 28, 301-338.

Pinter, A. (2005). Task repetition with 10-year-old children. In C. Edwards \& J. Willis (Eds.), Teachers exploring tasks in English language teaching. (pp. 113-126). New York: Palgrave MacMillan.

Pinter, A. (2006). Verbal evidence of task-related strategies: Child versus adult interactions. System, 34, 615-630.

Pinter, A. (2007). Some benefits of peer-peer interaction: 10-year-old children practicing with a communication task. Language Teaching Research, 11(2), 189-207.

Pinter, A. (2014). Child participant roles in applied linguistics research. Applied Linguistics, $35(2), 168-183$.

Pinter, A. (2015). Task-based learning with children. In J. Bland (Ed.), Teaching English to young learners (pp. 113-127). London: Bloomsbury.

Pinter, A., \& Zandian, S. (2014). "I don't ever want to leave this room”: Benefits of researching "with" children. ELT Journal, 68(1), 64-74. 
Prabhu, N. S. (1987). Second language pedagogy. Oxford: Oxford University Press.

Révész, A. (2012). Coding second language data validly and reliably. In A. Mackey \& S. M. Gass (Eds.), Research methods in second language acquisition: A practical guide (pp. 203-221). Oxford: Wiley-Blackwell.

Richards, J. C. (2001). Curriculum development in language teaching. New York: Cambridge University Press.

Richards, J. C., \& Rodgers, T. S. (2001). Approaches and methods in language teaching (2nd ed.). New York: Cambridge University Press.

Richards, K. (2003). Qualitative inquiry in TESOL. New York: Palgrave Macmillan.

Richardson, L. (2000). Writing: A method of inquiry. In N. Denzin \& Y. Lincoln, Handbook of qualitative research (pp. 923-948). Thousand Oaks, California: Sage.

Rulon, K. A., \& McCreary, J. (1986). Negotiation of content: Teacher-fronted and smallgroup interaction. In R. Day (Ed.), Talking to learn: Conversation in Second Language Acquisition. (pp. 182-199). Rowley, MA: Newbury House.

Samuda, V. (2015). Tasks, design, and the architecture of pedagogical spaces. In Domains and directions in the development of TBLT (pp. 271-301). Amsterdam: John Benjamins.

Samuda, V., \& Bygate, M. (2008). Tasks in second language learning. Hampshire: Palgrave Macmillan.

Sato, M. (2016). Interaction mindsets, interactional behaviors, and L2 development: An affective-social-cognitive model. Language Learning, 1-35.

Schlechty, P. C. (1994). Increasing student engagement. Jefferson City: Missouri Leadership Academy.

Schmidt, R. (1990). The role of consciousness in second language learning. Applied Linguistics, 11(2), 129-158.

Seedhouse, P. (1999). Task-based interaction. ELT Journal, 13(3), 149-156.

Seedhouse, P., \& Almutairi, S. (2009). A holistic approach to task-based interaction. International Journal of Applied Linguistics, 19(3), 311-338.

Sheen, R. (2003). Focus on form-a myth in the making? ELT Journal, 57(3), 225-233.

Shehadeh, A. (2001). Self- and other-initiated modified output during task-based interaction. TESOL Quarterly, 35(3), 433-457.

Shehadeh, A., \& Coombe, C. A. (2012). Task-based language teaching in foreign language contexts:Research and implementation. Amsterdam: John Benjamins Publishing Company.

Shintani, N. (2012). Repeating input-based tasks with young beginner learners. RELC Journal, 43(1), 39-51.

Shintani, N. (2014). Using tasks with young beginner learners: The role of the teacher. Innovation in Language Teaching and Learning, 8(3), 279-294. 
Shintani, N. (2016). Input-based tasks in foreign language instruction for young learners. Amsterdam: John Benjamins Publishing Company.

Skehan, P. (1996). A framework for the implementation of task-based instruction. Applied Linguistics, 17(1), 38-62.

Skehan, P. (1998). A cognitive approach to language learning. Oxford: Oxford University Press.

Skehan, P. (2003). Task-based instruction. Language Teaching, 36(1), 1-14.

Skehan, P. (2018). Second language task-based performance: Theory, research, assessment. New York: Routledge.

Stake, R. E. (1995). The art of case study research. Thousand Oaks, CA: SAGE.

Steward, T. (2006). Teacher-researcher collaboration or teachers' research? TESOL Quarterly, 40(2), 412-430.

Storch, N. (2002). Patterns of interaction in ESL pairwork. Language Learning, 52(1), 119 158.

Storch, N. (2007). Investigating the merits of pair work on a text editing task in ESL classes. Language Teaching Research, 11(2), 143-159.

Storch, N., \& Aldosari, A. (2010). Learners' use of first language (Abrabic) in pair work in an EFL class. Language Teaching Research, 14, 335-375.

Storch, N., \& Aldosari, A. (2013). Pairing learners in pair work activity. Language Teaching Research, 17(1), 31-48.

Storch, N., \& Wigglesworth, G. (2003). Is there a role for the use of the L1 in an L2 setting? TESOL Quarterly, 37(4), 760-770.

Storch, N., \& Wigglesworth, G. (2007). Writing tasks: The effects of collaboration. In M. P. García Mayo (Ed.), Investigating tasks in formal language learning (pp. 157-176). Clevedon: Multilingual Matters.

Swain, M. (1985). Communicative competence: Some roles of comprehensible input and comprehensible output in its development. In S. M. Gass \& C. G. Madden (Eds.), Input in second language acquisition (pp. 235-253). Rowley, MA: Newbury House.

Swain, M. (1995). Three functions of output in second language learning. In G. Cook \& B. Seidlhofer (Eds.), Principle and practice in applied linguistics (pp. 125-144). Oxford: Oxford University Press.

Swain, M. (2000). The output hypothesis and beyond: Mediating acquisition through collaborative dialogue. In J. Lantolf (Ed.), Sociocultural Theory and Second Language Learning (pp. 97-114). Oxford: Oxford University Press.

Swain, M. (2005). The output hypothesis: Theory and research. In E. Hinkel (Ed.), Handbook of research in second language teaching and learning (pp. 471-483). Mahwah, NJ: Erlbaum. 
Swain, M. (2006). Languaging, agency and collaboration in advanced second language proficiency. In H. Byrnes (Ed.), Advanced language learning: The contribution of Halliday and Vygostky (pp. 95-108). London: Continuum.

Swain, M. (2010). Talking-it-through: Language as a source of learning. In R. Batstone (Ed.), Sociocognitive perspectives on language use and language learning (pp. 112-130). Oxford, UK: Oxford University Press.

Swain, M., \& Lapkin, S. (1998). Interaction and second language learning: Two adolescent French immersion students working together. The Modern Language Journal, 83(3), 320-337.

Swain, M., \& Lapkin, S. (2000). Task-based second language learning: The uses of the first language. Language Teaching Research, 4, 251-274.

Swain, M., \& Lapkin, S. (2002). Talking it through: Two French immersion learners' response to reformulation. International Journal of Educational Research, 37, 285-304.

Swan, M. (2005). Legislation by hypothesis: The case of task-based instruction. Applied Linguistics, 26(3), 376-401.

Thornbury, S. (1999). How to teach grammar. Harlow: Longman.

Tognini, R., \& Oliver, R. (2012). L1 use in primary and secondary foreign language classrooms and its contribution to learning. In E. Alcon Soler \& M. P. Safont-Jorda (Eds.), Discourse and language learning across L2 instructional settings (pp. 53-78). Amsterdam: Rodopi.

Vale, D., \& Feunteun, A. (1995). Teaching children English: A training course for teachers of English to children. Cambridge: Cambridge University Press.

Van den Branden, K. (Ed.). (2006). Task-based language education: From theory to practice. Cambridge: Cambridge University Press.

Van den Branden, K. (2009a). Diffusion and implementation of innovations. In M. Long \& C. Doughty, The handbook of language teaching (pp. 659-672). Oxford: Wiley Blackwell.

Van den Branden, K. (2009b). Mediating between predetermined order and chaos: The role of the teacher in task-based language education. International Journal of Applied Linguistics, 19(3), 264-285.

Van den Branden, K. (2009c). Training teachers: Task-based as well? In K. Van den Branden, M. Bygate, \& J. M. Norris (Eds.), Task-based language teaching: A reader (pp. 401429). Amsterdam: John Benjamins Publishing Company.

Van den Branden, K. (2012). Task-based language education. In A. Burns \& J. C. Richards (Eds.), The Cambridge guide to pedagogy and practice in second language teaching (pp. 132-139). Cambridge: Cambridge University Press.

Van den Branden, K. (2016). Task-based language teaching. In G. Hall (Ed.), The Routledge handbook of English language teaching (pp. 238-250). London: Routledge. 
Van den Branden, K., Van Gorp, K., \& Verhelst, M. (2007). Tasks in Action: Task-Based Language Education from a Classroom-Based Perspective. Newcastle, UK: Cambridge Scholars Publishing.

Vietnamese Prime Minister. (2008). Quyết định Phê duyệt Đề án "Dạy và hoc ngoại ngũu trong hệ thống giáo dục quốc dân giai đoạn 2008 - 2020" (Decision on "The project of teaching and learning foreign languages in the national educational system 20082020”). (1400/QĐ-TTg), Ha Noi: Vietnam.

Vygotsky, L. S. (1978). Mind in society: The development of higher psychological processes. Cambridge: Harvard University Press.

Watanabe, Y., \& Swain, M. (2007). Effects of proficiency differences and patterns of pair interaction on second language learning: Collaborative dialogues between adult ESL learners. Language Teaching Research, 11, 121-142.

Widdowson, H. (2003). Defining Issues in English Language Teaching. Oxford: Oxford University Press.

Willis, D., \& Willis, J. (2007). Doing task-based language teaching. Oxford: Oxford University Press.

Willis, J. (1996). A framework for task-based learning. Harlow: Longman.

Willis, J. (2009). The TBL framework. In K. Van den Branden, M. Bygate, \& J. M. Norris (Eds.), Task-based language teaching: A reader (pp. 227-242). Amsterdam: John Benjamins Publishing Company.

Willis, J. W. (2007). Foundations of qualitative research: Interpretive and critical approaches. Thousand Oaks: Sage.

Wood, D., Bruner, J., \& Ross, G. (1976). The role of tutoring in problem-solving. Journal of Child Psychology and Psychiatry, 17(2), 89-100.

Xiongyong, C., \& Samuel, M. (2011). Perceptions and implementation of task-based language teaching among secondary school EFL teachers in China. International Journal of Business and Social Science, 2(24), 292-302.

Yin, R. (2014). Case study research: Design and method (5th ed.). Washington DC: Sage.

Zhang, Y. (2007). TBLT innovation in primary school English language teaching in Mainland China. In K. Van den Branden, K. Van Gorp, \& M. Verhelst (Eds.), Tasks in action: Task-based language education from a classroom perspective (pp. 68-91). Newcastle, UK: Cambridge Scholars Press.

Zhang, Y. (2015). Task-based language teaching in the primary schools of South China. In M. Thomas \& H. Reinders (Eds.), Contemporary task-based language teaching in Asia (pp. 87-101). London: Bloomsbury.

Zhang, Y., \& Hu, G. W. (2010). Between intended and enacted curricula: Three teachers and a mandated curricular reform in mainland China. In K. Menken \& O. García (Eds.), Negotiating language policies in schools: Educators as policy makers (pp. 123-142). New York: Routledge. 
Zheng, X., \& Borg, S. (2014). Task-based learning and teaching in China: Secondary school teachers' beliefs and practices. Language Teaching Research, 18(2), 205-221. 
This page is intentionally left blank 


\section{APPENDICES}

Appendix 1: Approval of Human Ethics Committee (Victoria University of Wellington) Appendix 2: Ethics for Phase 1

Appendix 2.1 Information sheets for teacher participants (Phase 1)

Appendix 2.2 Consent forms for teacher participants (Phase 1)

Appendix 2.3 Information sheets for school principals (Phase 1)

Appendix 2.4 Consent forms for school principals (Phase 1)

Appendix 2.5 Information and consent forms for parents (Phase 1)

Appendix 3: Interviews with teachers (Phase 1)

Appendix 3.1 Stimulated recall interview questions for teachers (Phase 1)

Appendix 3.2 In-depth interview questions for teachers (Phase 1)

Appendix 3.3 A translated in-depth interview transcript with a teacher (Phase 1)

Appendix 4: Ethics for Phase 2

Appendix 4.1 Information sheets for teacher participants (Phase 2)

Appendix 4.2 Consent forms for teacher participants (Phase 2)

Appendix 4.3 Information sheets for school principals (Phase 2)

Appendix 4.4 Consent form for school principals (Phase 2)

Appendix 4.5 Information and consent forms for parents (Phase 2)

Appendix 5: Interviews with teachers (Phase 2)

Appendix 5.1 Stimulated recall interview questions for teachers (Phase 2)

Appendix 5.2 In-depth interview questions for teachers (Phase 2)

Appendix 5.3 A translated in-depth interview transcript with a teacher (Phase 2)

Appendix 6: Interview questions for pupils (Phase 2)

Appendix 7: The PPP textbook speaking lessons for the redesign (Phase 2)

Appendix 7.1 Lesson 1

Appendix 7.2 Lesson 2

Appendix 8: Sample of pupils' work on Tasks 1 and 2

Appendix 8.1 Task 1

Appendix 8.2 Task 2

Appendix 9: Samples of pupil performance of tasks 1 and 2

Appendix 9.1 Task 1 (HPG, dyad 2)

Appendix 9.2 Task 2 (LPG, dyad 1)

Appendix 10: Dyad information (Pupils' interaction in the main tasks) 
Appendix 10.1 C-units (L2, L1, and L1 plus L2)

Appendix 10.2 Self- and other-correction

Appendix 10.3 Negotiation of meaning (NfM) strategies

Appendix 10.4 Functions of L1 use 